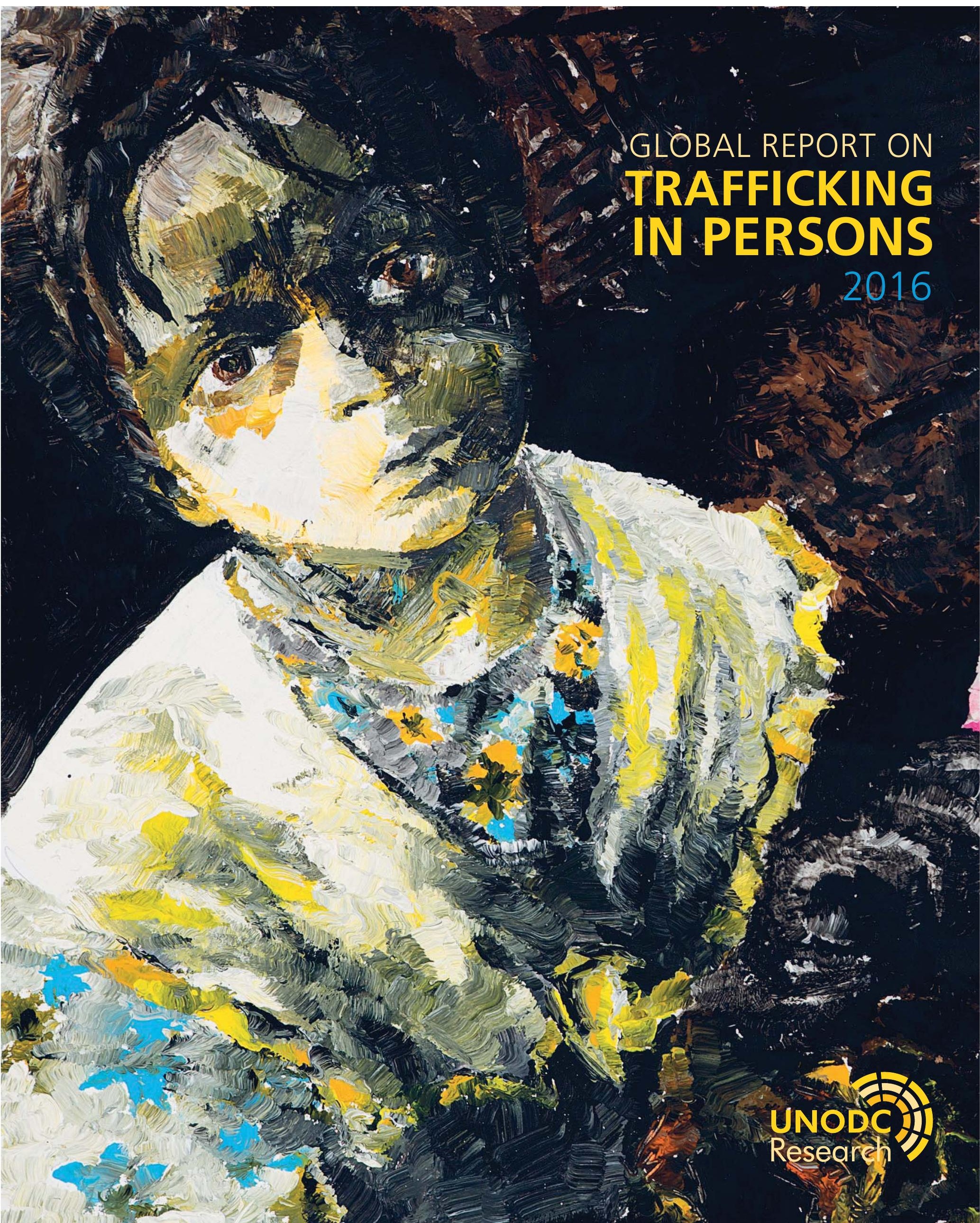



UNITED NATIONS OFFICE ON DRUGS AND CRIME Vienna

\section{Global Report on Trafficking in Persons 2016}

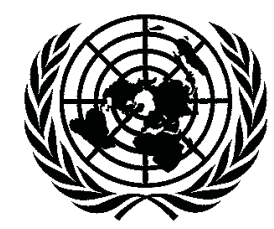

UNITED NATIONS New York, 2016 
This publication may be reproduced in whole or in part and in any form for educational or non-profit purposes without special permission from the copyright holder, provided acknowledgement of the source is made.

Suggested citation: UNODC, Global Report on Trafficking in Persons 2016 (United Nations publication, Sales No. E.16.IV.6).

Comments on the report are welcome and can be sent to:

Crime Research Section

Research and Trend Analysis Branch

Division for Policy Analysis and Public Affairs

United Nations Office on Drugs and Crime

P.O. Box 500

1400 Vienna

Austria

E-mail: globaltipreport@unodc.org

Tel.: (+43) 1260600

Fax: (+43) 12606075223

The content of this publication does not necessarily reflect the views or policies of UNODC, Member States or contributory organizations, and nor does it imply any endorsement.

This document has not been formally edited. The designations employed and the presentation of material in this publication do not imply the expression of any opinion whatsoever on the part of the Secretariat of the United Nations concerning the legal status of any country, territory, city or area, or of its authorities, or concerning the delimitation of its frontiers or boundaries.

(C) United Nations, December 2016. All rights reserved, worldwide.

Photos (C) UNODC

\section{UNITED NATIONS PUBLICATION}

Sales No. E.16.IV.6

ISBN: 978-92-1-130339-1

e-ISBN: 978-92-1-058408-1 


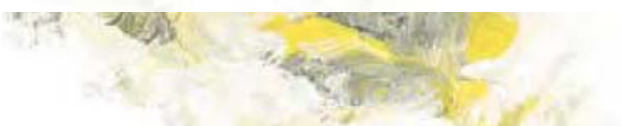

Since the last Global Report on Trafficking in Persons in 2014 there have been a number of significant developments that reinforce this report's importance, and place it at the heart of international efforts undertaken to combat human trafficking. Perhaps the most worrying development is that the movement of refugees and migrants, the largest seen since World War II, has arguably intensified since 2014. As this crisis has unfolded, and climbed up the global agenda, there has been a corresponding recognition that, within these massive migratory movements, are vulnerable children, women and men who can be easily exploited by smugglers and traffickers.

Other changes are more positive. In September 2015, the world adopted the 2030 Sustainable Development Agenda and embraced goals and targets on trafficking in persons. These goals call for an end to trafficking and violence against children; as well as the need for measures against human trafficking, and they strive for the elimination of all forms of violence against and exploitation of women and girls. Thanks to the 2030 Agenda, we now have an underpinning for the action needed under the provisions of the UN Convention against Transnational Organized Crime, and its protocols on trafficking in persons and migrant smuggling.

Another important development is the UN Summit for Refugees and Migrants, which produced the groundbreaking New York Declaration. Of the nineteen commitments adopted by countries in the Declaration, three are dedicated to concrete action against the crimes of human trafficking and migrant smuggling. UNODC's report is also the last before the world gathers in 2017 at the UN General Assembly for the essential evaluation of the Global Plan of Action to Combat Trafficking in Persons. These decisive steps forward are helping to unite the world and produce much needed international cooperation against trafficking in persons.

But, to have tangible success against the criminals, to sever the money supplies, to entertain joint operations and mutual legal assistance, we must first understand the texture and the shape of this global challenge. The Global Report on Trafficking in Persons does exactly this. It provides a detailed picture of the situation through solid analysis and research. The findings are disturbing.
Traffickers may target anyone who can be exploited in their own countries or abroad. When foreigners are trafficked, we know that human trafficking flows broadly follow the migratory patterns. We know from the report that some migrants are more vulnerable than others, such as those from countries with a high level of organized crime or from countries affected by conflicts. Just as tragically, 79 per cent of all detected trafficking victims are women and children. From 2012-2014, more than 500 different trafficking flows were detected and countries in Western and Southern Europe detected victims of 137 different citizenships. These figures recount a worrying story of human trafficking occurring almost everywhere.

In terms of the different types of trafficking, sexual exploitation and forced labour are the most prominent. But the report shows that trafficking can have numerous other forms including: victims compelled to act as beggars, forced into sham marriages, benefit fraud, pornography production, organ removal, among others. In response, many countries have criminalized most forms of trafficking as set out in the UN Trafficking in Persons Protocol. The number of countries doing this has increased from 33 in 2003 to 158 in 2016. Such an exponential increase is welcomed and it has helped to assist the victims and to prosecute the traffickers.

Unfortunately, the average number of convictions remains low. UNODC's findings show that there is a close correlation between the length of time the trafficking law has been on the statute books and the conviction rate. This is a sign that it takes time, as well as resources, and expertise to chase down the criminals. Perhaps the 2016 Report's main message is that inroads have been made into this horrendous crime. We must, however, continue to generate much needed cooperation and collaboration at the international level, and the necessary law enforcement skills at the national and regional levels to detect, investigate and successfully prosecute cases of trafficking in persons. The 2016 report has done a fine job of setting out the situation, but there is more to be done.

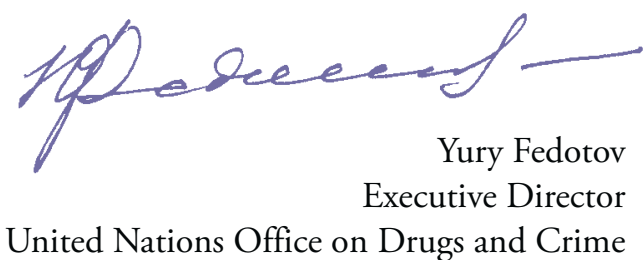

United Nations Office on Drugs and Crime 


\section{Acknowledgements}

The 2016 Global Report on Trafficking in Persons was prepared by the UNODC Crime Research Section under the supervision of Jean-Luc Lemahieu, Director of the Division for Policy Analysis and Public Affairs and Angela Me, Chief of the Research and Trend Analysis Branch.

\section{Core team}

Kristiina Kangaspunta, Fabrizio Sarrica, Tejal Jesrani, Raggie Johansen, Cecilia Manzotti.

\section{Graphic design, layout and mapping support}

Suzanne Kunnen, Kristina Kuttnig.

The Crime Research Section wishes to thank the UNODC Human Trafficking and Migrant Smuggling Section for their careful reviews and constructive comments on draft content, and the Section's interns, Tomas Horehaj, Julia Litzkow and Gamze Subasi, who have all made solid contributions to the 2016 Global Report. Moreover, valuable inputs were received from many focal points for trafficking in persons/organized crime at various UNODC Field Offices; inputs that have clearly enriched the report, and for that, we are grateful.

The report also benefited from the work and expertise of many other UNODC staff members in Vienna and around the world.

UNODC wishes to thank the artist Yasser Rezahi who generously donated the artwork used for this Report.

Photos of artwork by Johannes Kittel.

Infographs contain pictograms from Leremy/Shutterstock. 


\section{CONTENTS}

Executive summary

Introduction

\section{CHAPTER I - GLOBAL OVERVIEW}

PATTERNS OF TRAFFICKING IN PERSONS

TRAFFICKING FLOWS

THE LEGISLATIVE AND CRIMINAL JUSTICE RESPONSE TO TRAFFICKING IN PERSONS

\section{CHAPTER II}

HUMAN TRAFFICKING, MIGRATION AND CONFLICT

\section{CHAPTER III}

WESTERN AND CENTRAL EUROPE

EASTERN EUROPE AND CENTRAL ASIA

NORTH AND CENTRAL AMERICA AND THE CARIBBEAN

$\begin{array}{lr}\text { SOUTH AMERICA } & 97\end{array}$

EAST ASIA AND THE PACIFIC $\quad 102$

$\begin{array}{lr}\text { SOUTH ASIA } & 109\end{array}$

SUB-SAHARAN AFRICA 112

NORTH AFRICA AND THE MIDDLE EAST 118

\section{TEXT BOXES}

The Sustainable Development Goals and trafficking in persons 30

Trafficking in persons for marriage $\quad 32$

The use of detected cases of trafficking in persons to draw patterns and flows 39

Multiple Systems Estimate: an innovative way to help assess the real extent of trafficking in persons 47

Trafficking of migrants for extortion and organ removal on some African routes $\quad 62$

$\begin{array}{ll}\text { Trafficking for forced labour in the fishing industry } & 104\end{array}$ 



\section{EXECUTIVE SUMMARY}

\section{1) NO COUNTRY IS IMMUNE FROM TRAFFICKING IN PERSONS}

Victims are trafficked along a multitude of trafficking flows; within countries, between neighbouring countries or even across different continents. More than 500 different trafficking flows were detected between 2012 and 2014.

Countries in Western and Southern Europe detected victims of 137 different citizenships. Affluent areas - such as Western and Southern Europe, North America and the Middle East - detect victims from a large number of countries around the world.

Trafficking victims from countries in Sub-Saharan Africa and East Asia are trafficked to a wide range of destinations. A total of 69 countries reported to have detected victims from Sub-Saharan Africa between 2012 and 2014. Victims from Sub-Saharan Africa were mainly detected in Africa, the Middle East and Western and Southern Europe. There are also records of trafficking flows from Africa to South-East Asia and the Americas.

\section{Diffusion of trafficking flows: number of countries where citizens of countries in the given subregions were detected, 2012-2014}

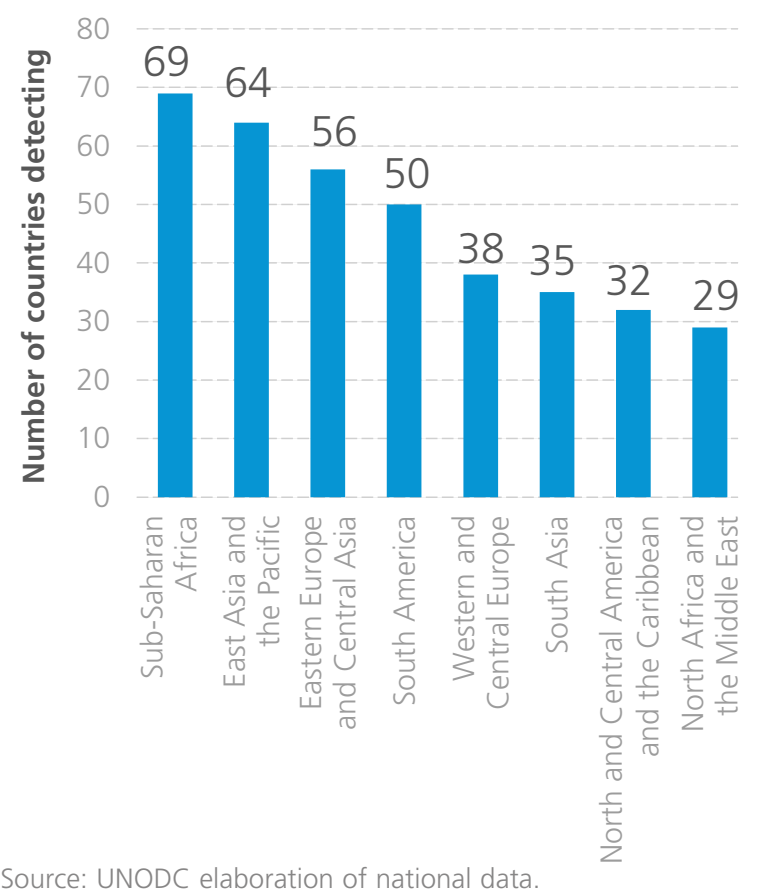

Number of citizenships among victims detected in destination countries, by region of destination, 2012-2014

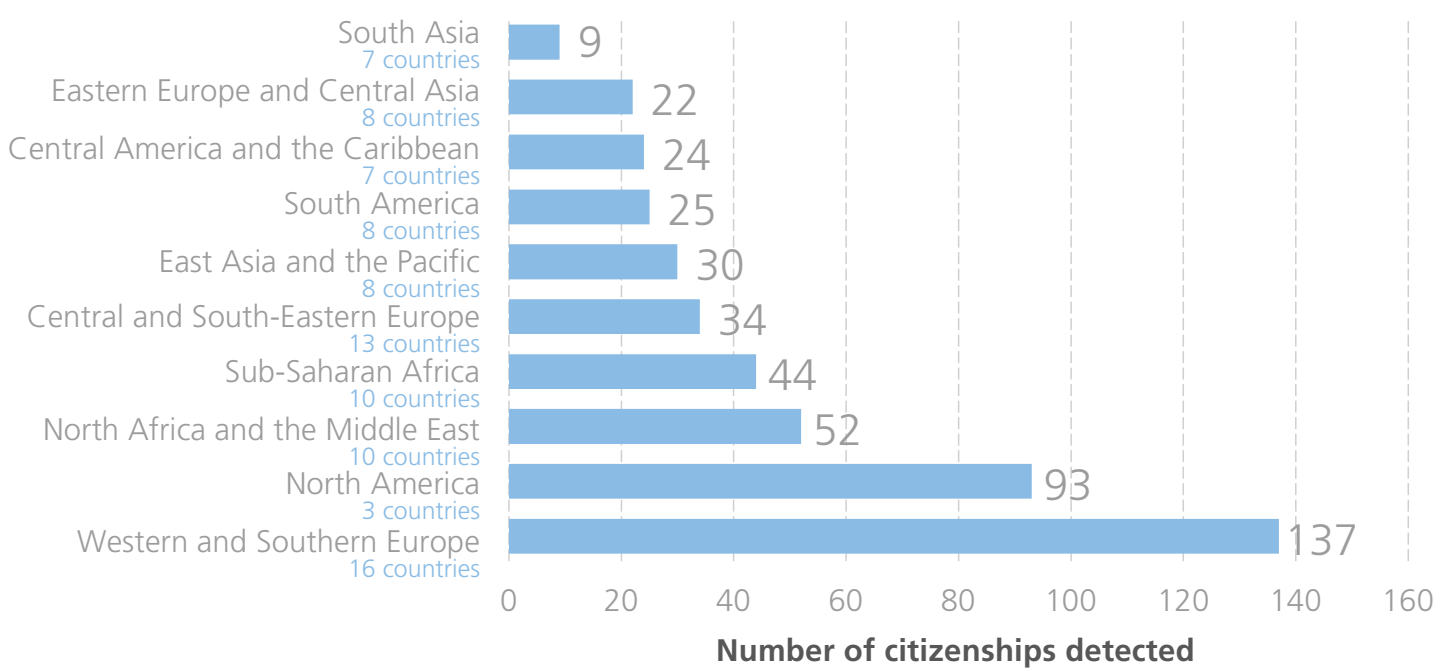




\section{2) HOW HAS TRAFFICKING IN PERSONS CHANGED IN RECENT YEARS?}

Over the last 10 years, the profile of detected trafficking victims has changed. Although most detected victims are still women, children and men now make up larger shares of the total number of victims than they did a decade ago. In 2014, children comprised 28 per cent of detected victims, and men, 21 per cent.

In parallel with the significant increases in the share of men among detected trafficking victims, the share of victims who are trafficked for forced labour has also increased. About four in 10 victims detected between 2012 and 2014 were trafficked for forced labour, and out of these victims, 63 per cent were men.

Trends in the forms of exploitation among detected trafficking victims, 2007-2014

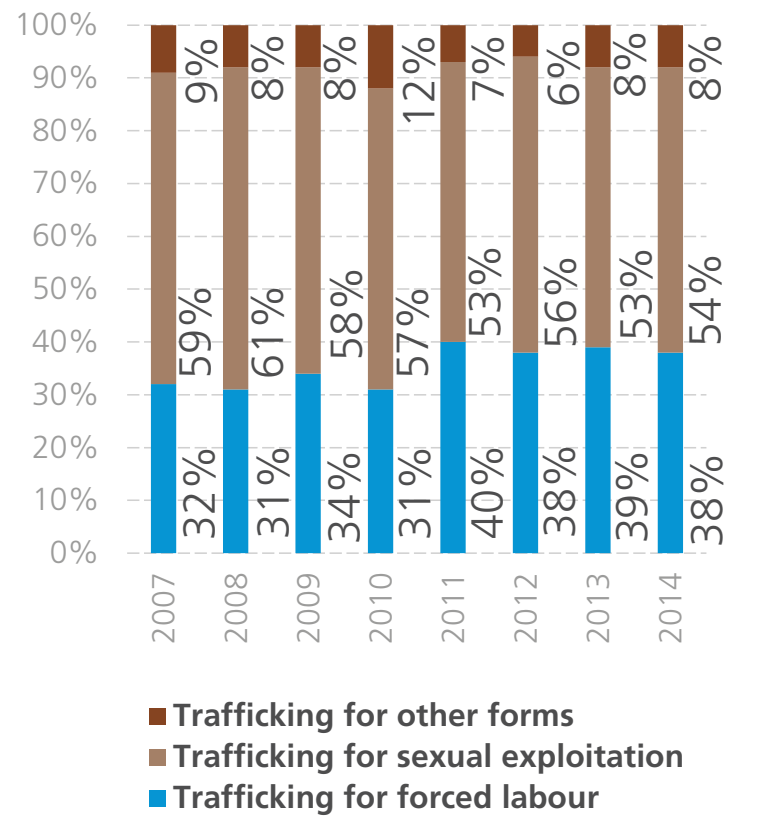

The share of detected trafficking cases that are domestic - that is, carried out within a country's borders - has also increased significantly in recent years, and some 42 per cent of detected victims between 2012 and 2014 were trafficked domestically. While some of the increase can be ascribed to differences in reporting and data coverage, countries are clearly detecting more domestic trafficking nowadays.

These shifts indicate that the common understanding of the trafficking crime has evolved. A decade ago, trafficking was thought to mainly involve women trafficked from afar into an affluent country for sexual exploitation. Today, criminal justice practitioners are more aware of the diversity among offenders, victims, forms of exploitation and flows of trafficking in persons, and the statistics may reflect this increased awareness.

\section{Trend in the share of men among the detected victims of trafficking in persons, selected years}

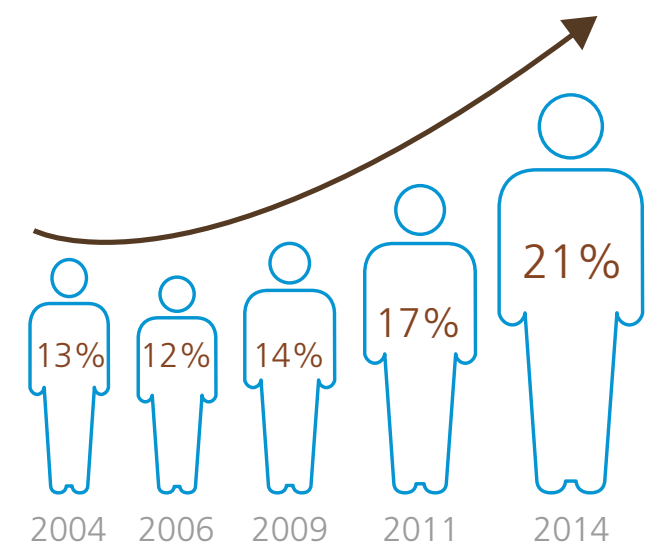

Source: UNODC elaboration of national data. 


\section{3) VICTIMS AND TRAFFICKERS OFTEN HAVE THE SAME BACK- GROUND}

Traffickers and their victims often come from the same place, speak the same language or have the same ethnic background. Such commonalities help traffickers generate trust to carry out the trafficking crime.

Traffickers rarely travel abroad in order to recruit victims, but they do travel to destination countries to exploit them. As general pattern, traffickers in origin countries are usually citizens of these countries. Traffickers in destination countries are either citizens of these countries or have the same citizenship as the victim(s) they trafficked.

Being of the same gender can also enhance trust. Data from court cases indicate that women are commonly involved in the trafficking of women and girls, in particular. Most of the detected victims of trafficking in persons are females; either women or underage girls.

While traffickers are overwhelmingly male, women comprise a relatively large share of convicted offenders, compared to most other crimes. This share is even higher among traffickers convicted in the victims' home country. Court cases and other qualitative data indicate that women are often used to recruit other women.

Family ties can also be abused to carry out trafficking crimes. For instance, this is seen in cases of relatives entrusted with the care of a family member who break their promise and profit from the family member's exploitation.

\section{Shares of national and foreign citizens (relative to the convicting country) among convicted traffickers, by countries of origin and destination, 2014 (or most recent)}

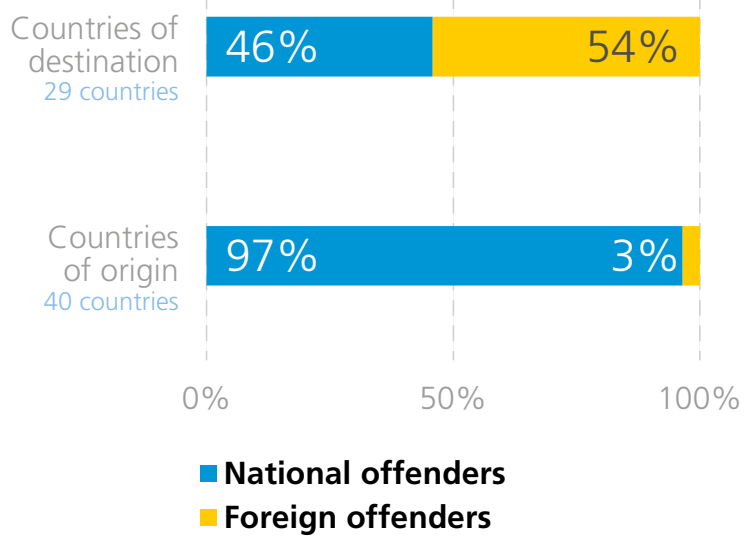

Source: UNODC elaboration of national data.

Shares of persons convicted of trafficking in persons, by sex, 2014 (or most recent)

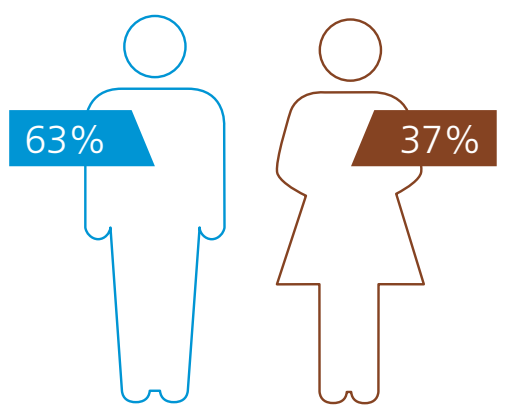

Source: UNODC elaboration of national data.

Trafficking victims can be women, men, boys and girls
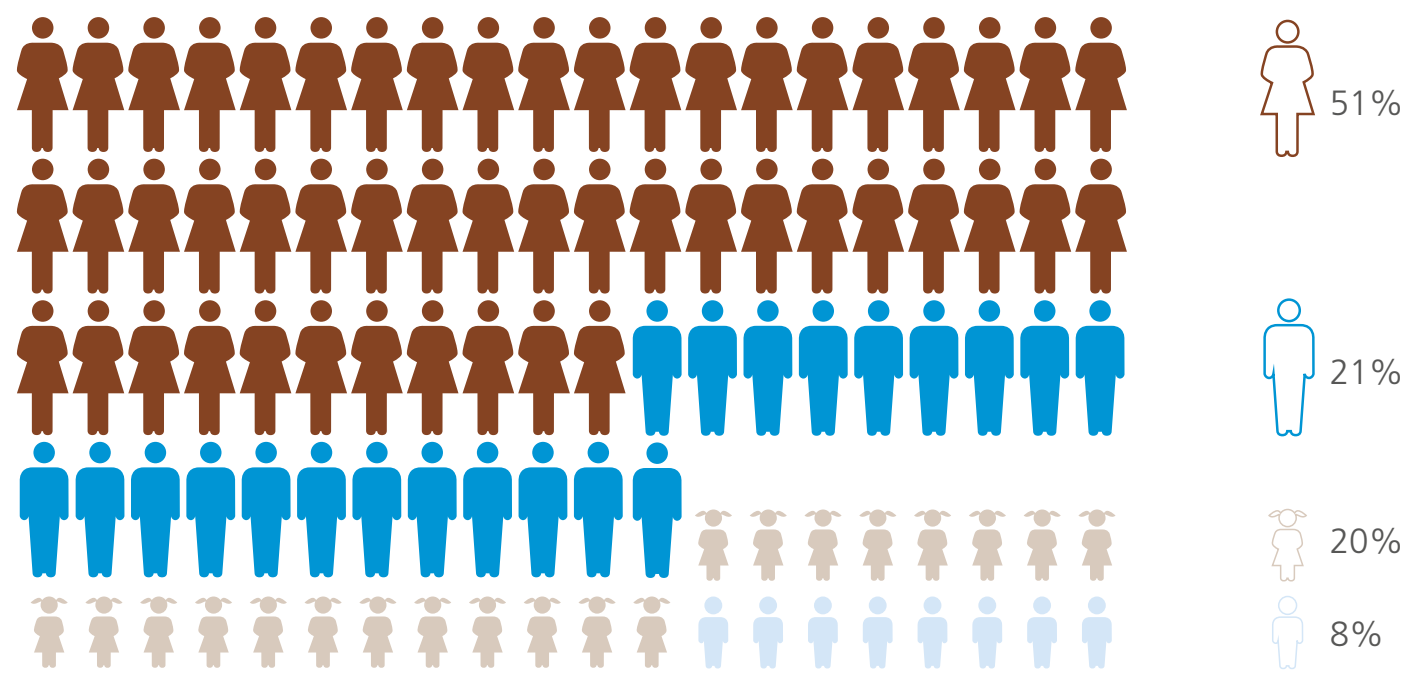


\section{4) PEOPLE ARE TRAFFICKED FOR MANY EXPLOITATIVE PURPOSES}

Trafficking for sexual exploitation and for forced labour are the most prominently detected forms, but trafficking victims can also be exploited in many other ways. Victims are trafficked to be used as beggars, for forced or sham marriages, benefit fraud, production of pornography or for organ removal, to mention some of the forms countries have reported.

Trafficking for various types of marriage has been sporadically reported in the past, but is now emerging as a more prevalent form. In South-East Asia, this often involves forced marriages, or unions without the consent of the woman (or girl). Trafficking for sham marriages mainly takes place in affluent countries.

Trafficking for forced labour in the fishing industry is commonplace in several parts of the world. This can happen, for example, on board big fishing vessels on the high seas, carried out by large companies that trade fish internationally, or in on-land processing facilities. It can also happen more locally, such as in African lake areas where the fishing tends to be small-scale and the catch is sold in street markets.
Trafficking for sexual exploitation and for forced labour in a range of economic sectors are reported nearly everywhere. At least 10 countries have reported trafficking for the removal of organs. Other forms of reported trafficking, such as the ones mentioned above, are sometimes locally acute, but less internationally widespread.

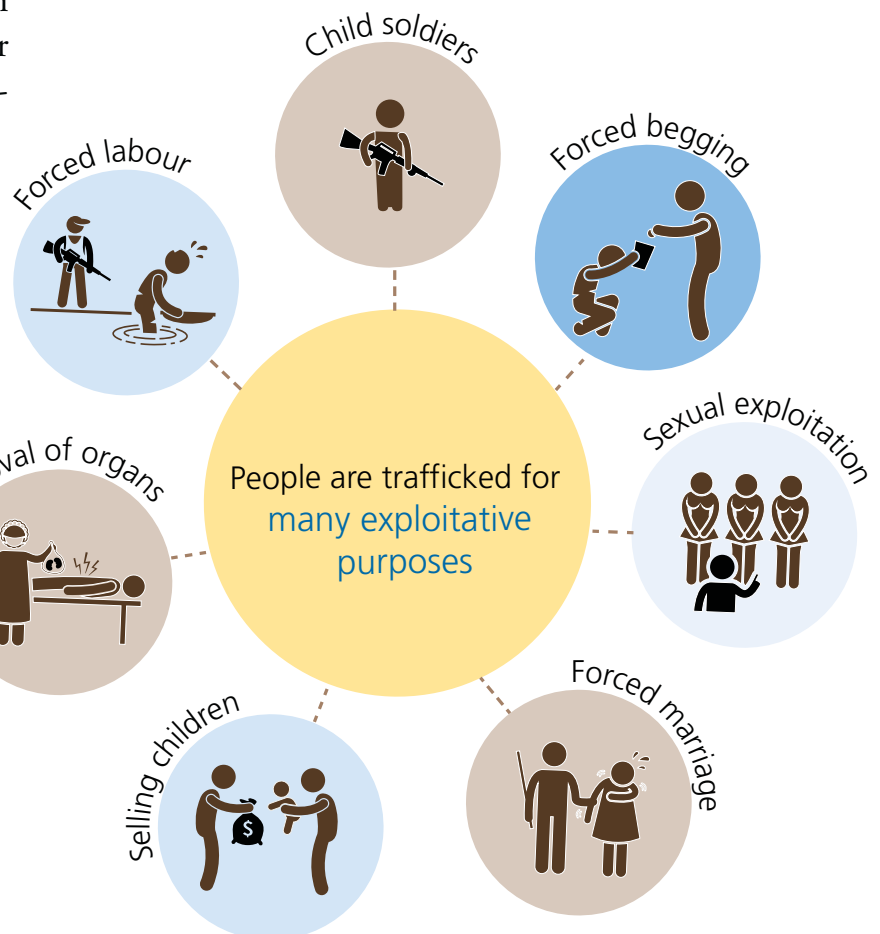

Share of forms of exploitation among detected trafficking victims, by region of detection, 2012-2014 (or most recent)

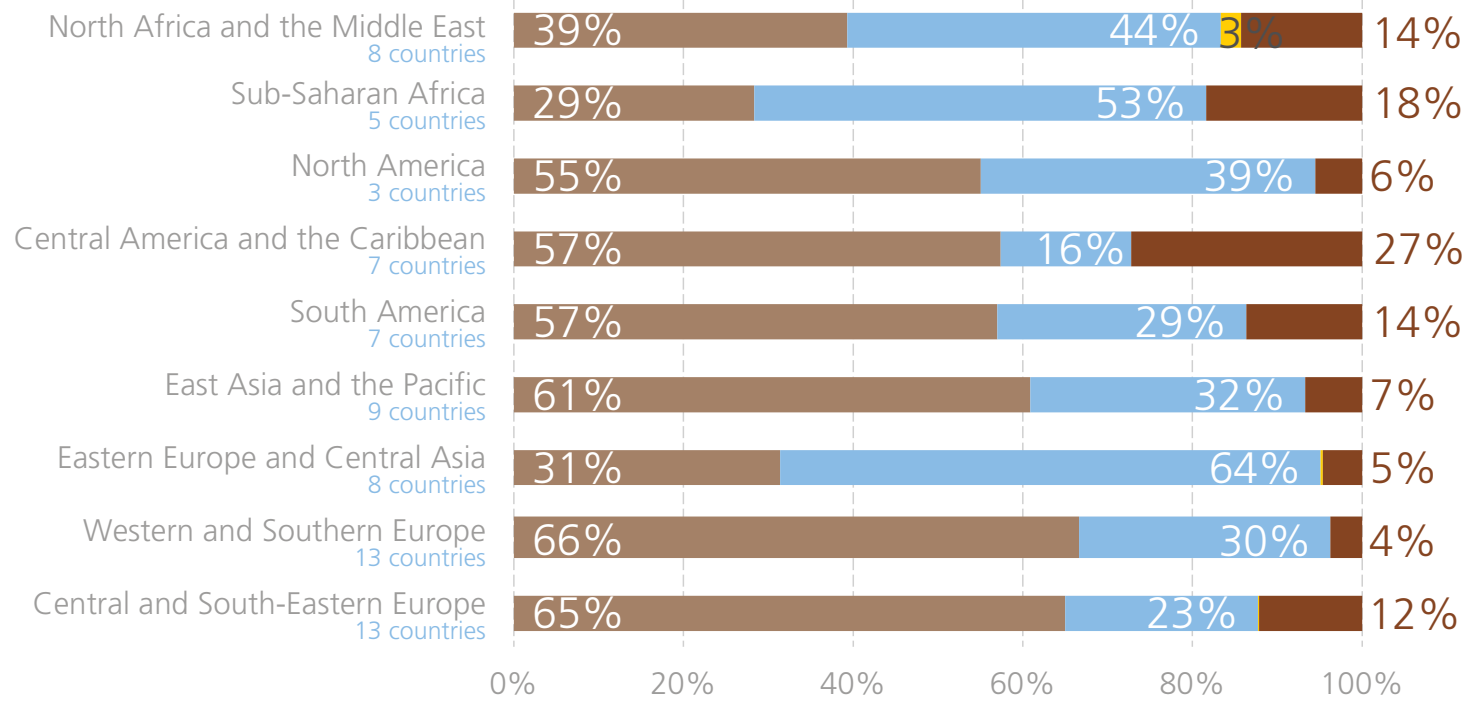




\section{5) CROSS-BORDER TRAFFICKING FLOWS OFTEN RESEMBLE REGULAR MIGRATION FLOWS}

Although many cases of trafficking in persons do not involve the crossing of international borders - some 42 per cent of the detected victims are trafficked domestically - there are some links between cross-border trafficking and regular migration flows. Certain trafficking flows resemble migration flows, and some sizable international migration flows are also reflected in cross-border trafficking flows.
The analysis of country-level data on detected trafficking victims and recently arrived regular migrants reveals that trafficking in persons and regular migration flows broadly resemble each other for some destination countries in different parts of the world.

Many factors can increase a person's vulnerability to human trafficking during the migration process, however. The presence of transnational organized crime elements in the country of origin, for instance, is significant in this regard, and a person's socio-economic profile can also have an impact.

Main destinations of transregional flows and their significant origins, 2012-2014

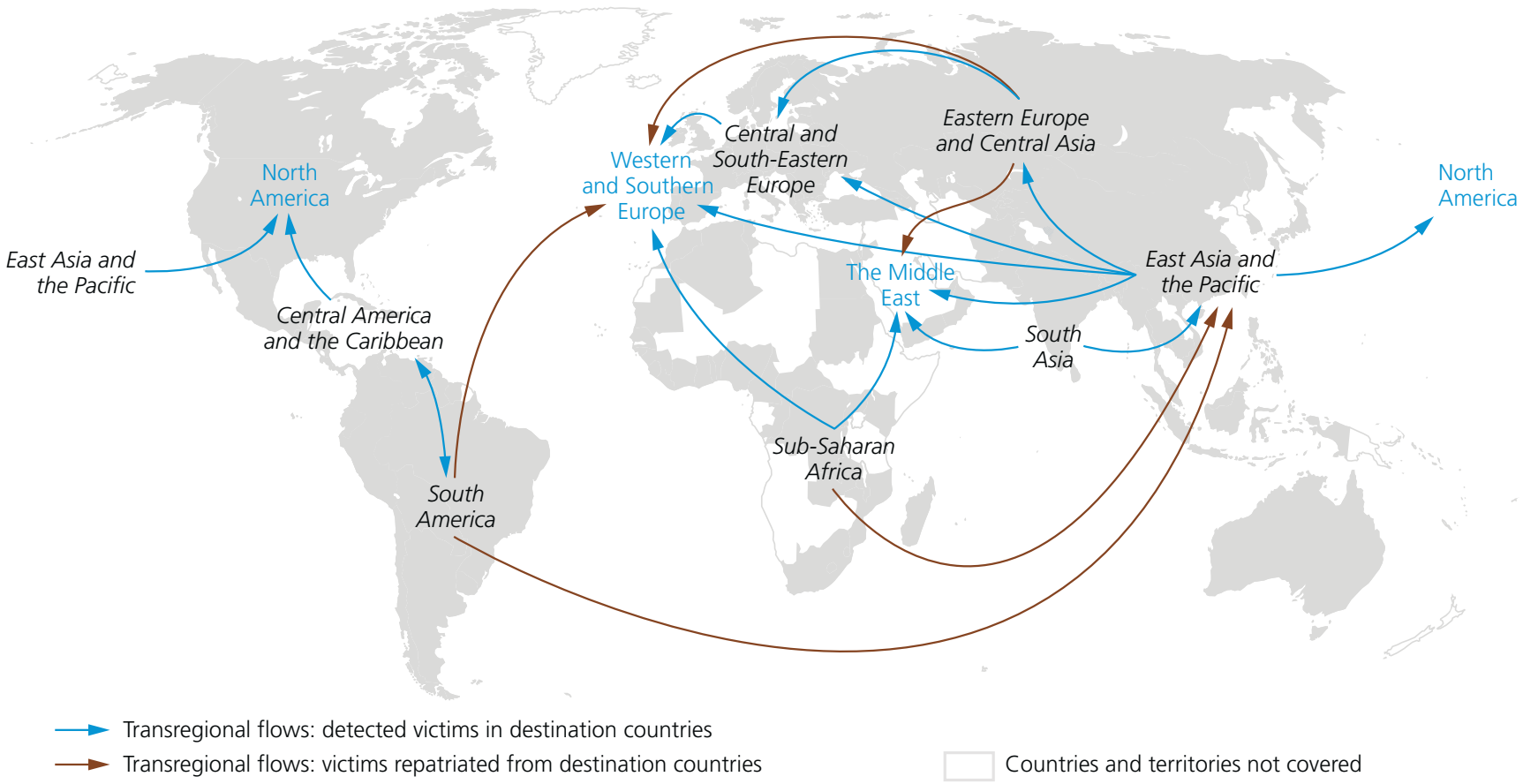




\section{6) CONFLICT CAN HELP DRIVE TRAFFICKING IN PERSONS}

People escaping from war and persecution are particularly vulnerable to becoming victims of trafficking. The urgency of their situation might lead them to make dangerous migration decisions. The rapid increase in the number of Syrian victims of trafficking in persons following the start of the conflict there, for instance, seems to be one example of how these vulnerabilities play out.

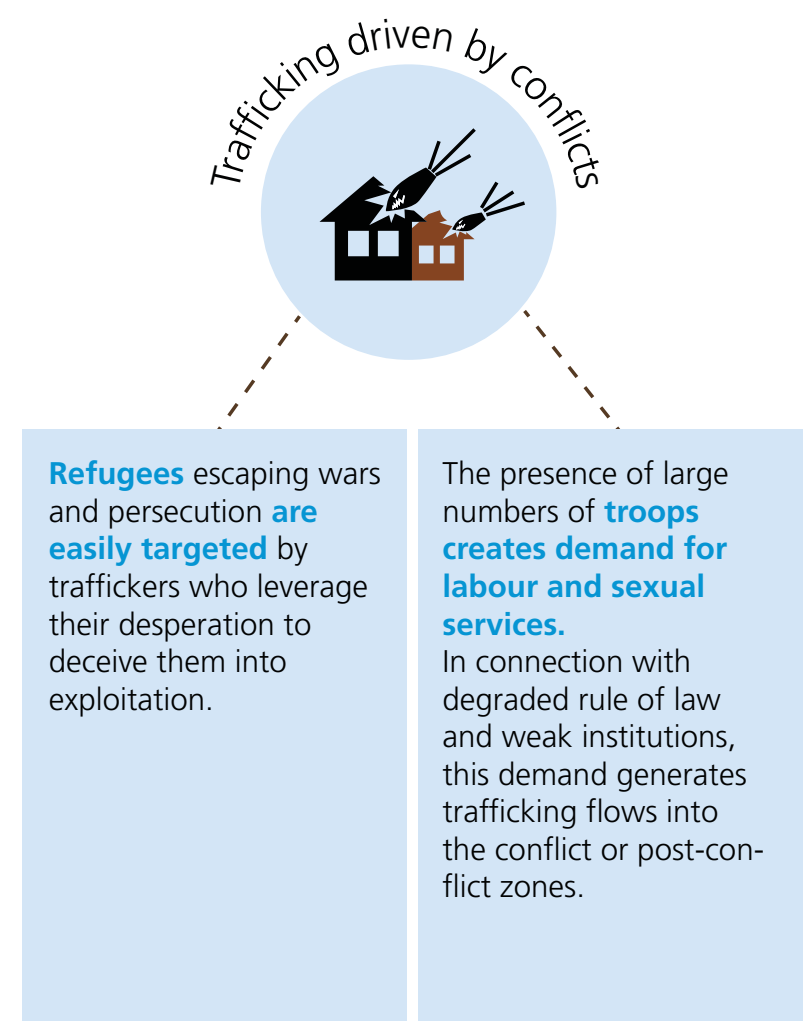

Conflicts create favourable conditions for trafficking in persons, but not only by generating a mass of vulnerable people escaping violence. Armed groups engage in trafficking in the territories in which they operate, and they have recruited thousands of children for the purpose of using them as combatants in various past and current conflicts. While women and girls tend to be trafficked for marriages and sexual slavery, men and boys are typically exploited in forced labour in the mining sector, as porters, soldiers and slaves.

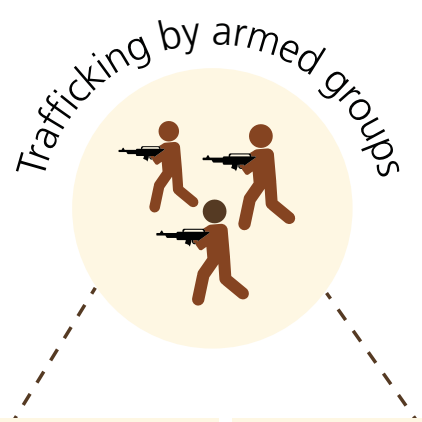

Armed groups recruit or abduct children to use them as combatants.

Children are found in villages, urban areas and in refugee camps. Thousands of victims have been documented in different conflicts, particularly in Sub-Saharan Africa and the Middle East.
In conflict zones, armed groups recruit or abduct women and girls for forced marriages, domestic work and sexual slavery.

Similarly, they recruit or abduct men and boys for forced labour, for instance, in the exploitation of natural resources, as soldiers or for slavery. 


\section{7) TRAFFICKING THE MOST VULNERABLE: CHILDREN}

The share of detected child victims has returned to levels last seen in 2009, after seven years of increases. Despite this trend, still more than a quarter of the detected trafficking victims in 2014 were children.

In Sub-Saharan Africa and Central America and the Caribbean, a majority of the detected victims are children. There are several reasons, such as demographics, socioeconomic factors, legislative differences and countries' institutional frameworks and priorities. There seems to be a relation between a country's level of development and the age of detected trafficking victims. In the least developed countries, children often comprise large shares of the detected victims.

There are clear regional differences with regard to the sex of detected child victims. Countries in Sub-Saharan Africa detect more boys than girls, which seems to be connected with the large shares of trafficking for forced labour, child soldiers (in conflict areas) and begging reported in that region. In Central America and the Caribbean and South
America, on the other hand, girls make up a large share of the detected victims, which could be related to the fact that trafficking for sexual exploitation is the most frequently detected form there.

\section{Share of children among detected victims of trafficking in persons, by gender, selected years}

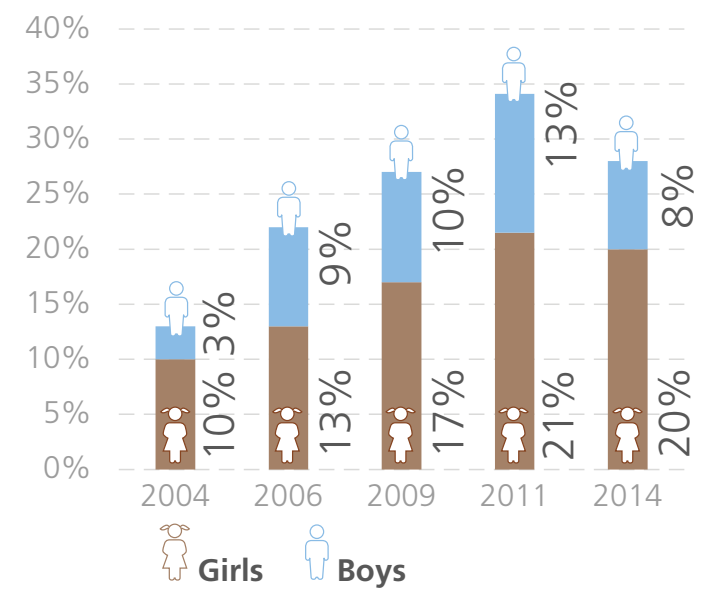

Source: UNODC elaboration of national data.

Shares of adults and children among detected trafficking victims, by region, 2014 (or most recent)

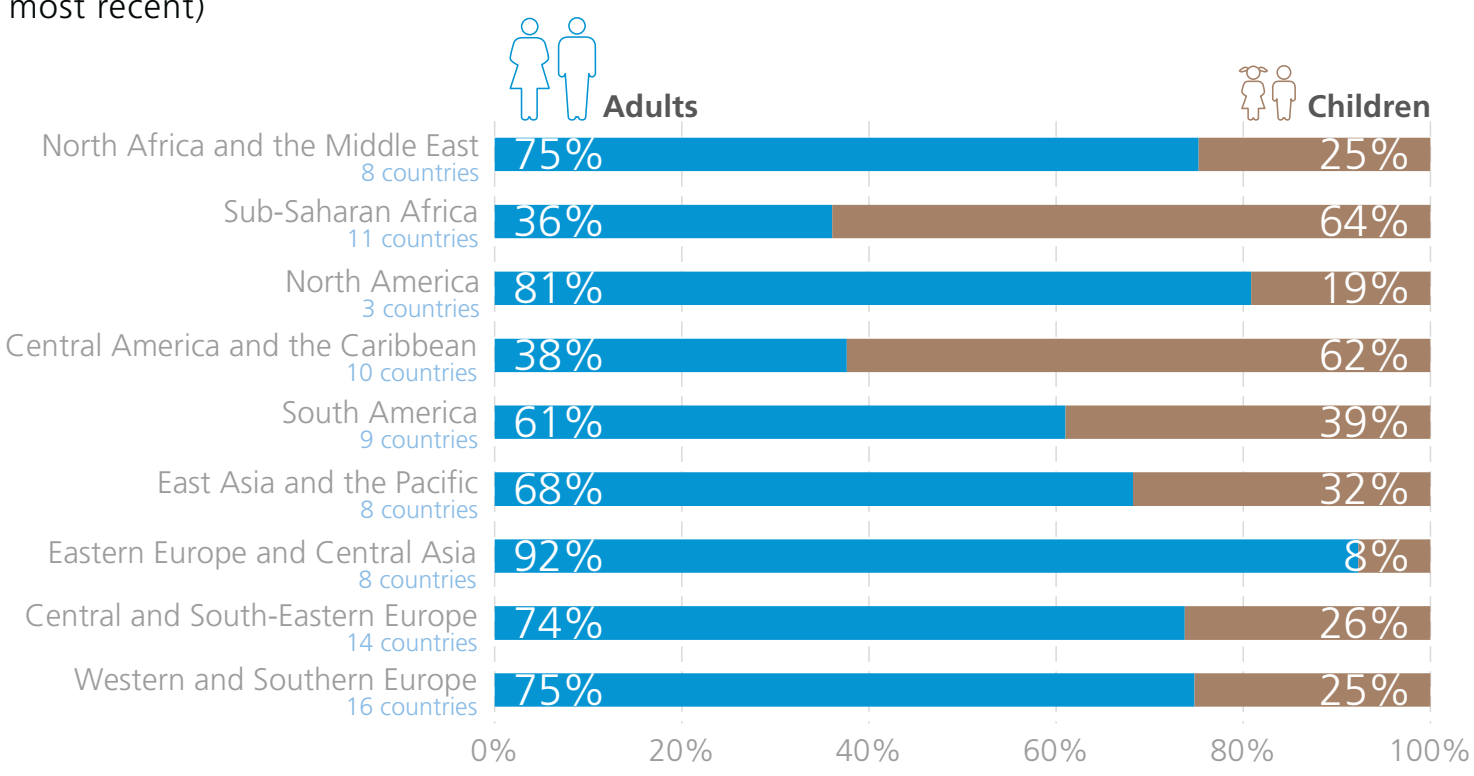




\section{8) SOLID LEGISLATIVE PROGRESS, BUT STILL VERY FEW CONVICTIONS}

The number of countries with a statute that criminalizes most forms of trafficking in persons in line with the definition used by the UN Trafficking in Persons Protocol increased from 33 in 2003 (18 per cent) to 158 in 2016 (88 per cent). This rapid progress means that more victims are assisted and protected, and more traffickers are put behind bars.

However, most national legislation is recent, having been introduced during the last eight to 10 years. As a consequence, the average number of convictions still remains

Criminalization of trafficking in persons with a specific offence covering all or some forms as defined in the UN Protocol, numbers and shares of countries, 2003-2016

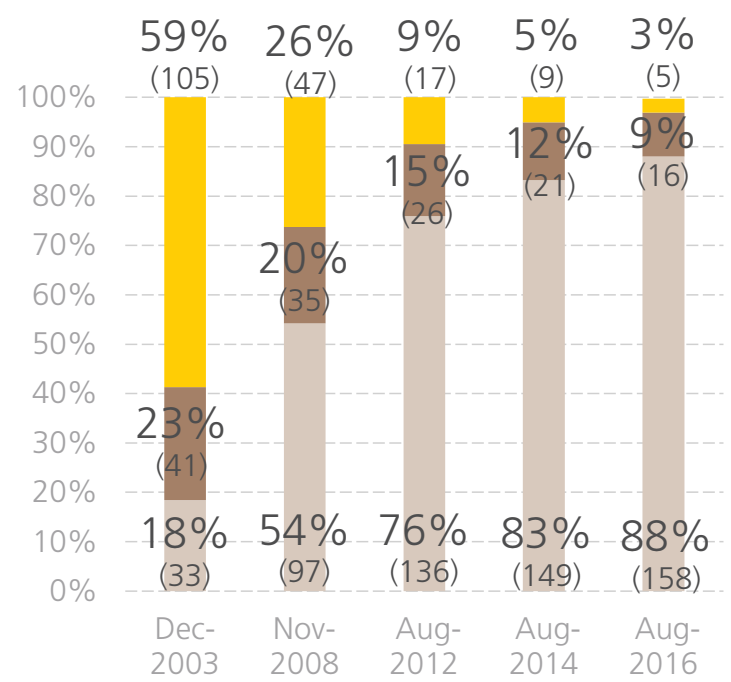

179 COUNTRIES

No specific offence

- Partial

Covers most/all forms low. The longer countries have had comprehensive legislation in place, the more convictions are recorded, indicating that it takes time and dedicated resources for a national criminal justice system to acquire sufficient expertise to detect, investigate and successfully prosecute cases of trafficking in persons.

The ratio between the number of traffickers convicted in the first court instance and the number of victims detected is about 5 victims per convicted offender. Although most countries now have the appropriate legal framework for tackling trafficking crimes, the large discrepancy between the number of detected victims and convicted offenders indicates that many trafficking crimes still go unpunished.

\section{Average number of trafficking convictions in 2014, by year of introduction of a specific trafficking in persons offence}

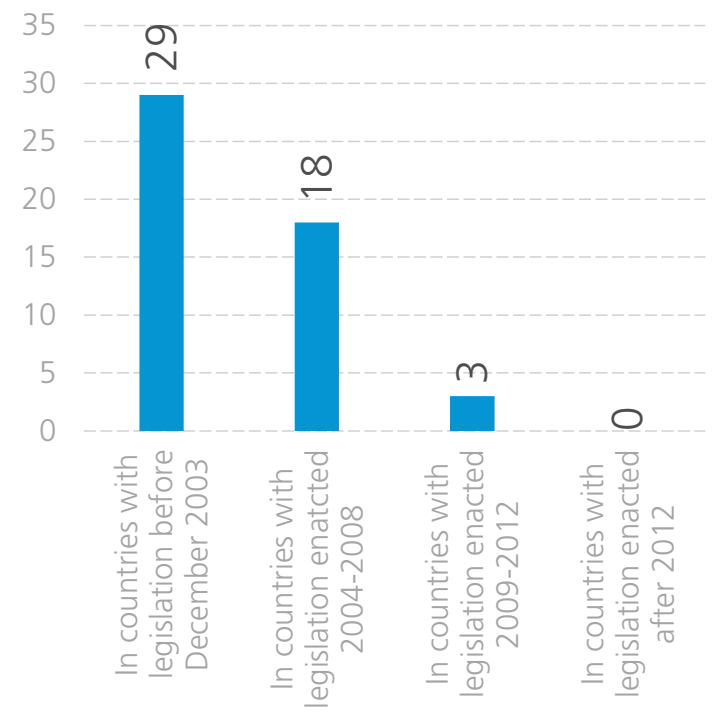

Source: UNODC elaboration of national data. 


\section{Trafficking in persons, migration and conflict}

Against a backdrop of sustained global population growth, affordable telecommunication and persistent economic inequalities, human mobility has increased. In 2015, the United Nations estimated that there were some 244 million international migrants across the world; an increase of more than 40 per cent since the year 2000 (173 million). ${ }^{1}$ Additionally, the 2009 Human Development Report by the United Nations Development Programme (UNDP) estimated that there are some 740 million internal migrants, moving within their countries. ${ }^{2}$ Many people are escaping war and persecution. In 2016, the United Nations High Commissioner for Refugees (UNHCR) reported that, at the end of 2015, more than 65 million people were forcibly displaced worldwide as a result of persecution, conflict, violence or human rights violations; an increase of 6 million compared to just 12 months earlier. $^{3}$

There is a clear link between the broader migration phenomenon and trafficking in persons. It is true that trafficking victims are not always migrants and, according to the legal definition, victims do not need to be physically moved to be considered as having been trafficked. The stories of victims of trafficking, however, often start as brave attempts to improve their life, as is also the case with many migration stories. Those who end up in the hands of traffickers often envisioned a better life in another place; across the border, across the sea, in the big city or in the richer parts of the country. Traffickers, whether they are trafficking organizations, legally registered companies, 'loners' acting on their own or family members of the victim, often take advantage of this aspiration to deceive victims into an exploitative situation.

Trafficking in persons is driven by a range of factors, many of which are not related to migration. At the same time, some people who migrate and refugees escaping from conflict and persecution are particularly vulnerable to being trafficked. The desperation of refugees can be leveraged

United Nations, Department of Economic and Social Affairs, Population Division (2016). International Migration Report 2015: Highlights (ST/ESA/SER.A/375).

2 United Nations Development Programme (2009). Human Development Report 2009 - Overcoming barriers: Human mobility and development.

3 United Nations High Commissioner for Refugees (2016). Global Trends. Forced Displacement in 2015. by traffickers to deceive and coerce them into exploitation. War and conflict can exacerbate trafficking in persons: not only may those who escape violence turn to traffickers in their hope of finding a safe haven, but armed groups also exploit victims for various purposes in conflict areas.

The thematic focus of the 2016 edition of the Global Report investigates how migrants and refugees can be vulnerable to trafficking in persons en route or at destination. This focus complements the findings of previous editions, which have looked at socio-economic factors and the role of transnational organized criminal groups in trafficking in persons. This edition also looks at the particular condition of people escaping war, conflict and persecution.

\section{Organization of the report}

This edition of the Global Report on Trafficking in Persons consists of three main analytical chapters. Chapter I provides a global overview of the patterns and flows of trafficking in persons and an overview of the status of country-level legislation and the criminal justice response to the trafficking crime. Chapter II presents an analysis of trafficking in persons in the broader perspective of migration and conflict, and chapter III contains in-depth analyses by region.

The detailed country profiles, available at the Global Report website (www.unodc.org/glotip), present the country-level information that was collected for the preparation of this edition. They are divided into three main sections: the country's legislation on trafficking in persons, suspects and investigations, and victims of trafficking.

The 136 countries covered by the data collection were categorized into eight regions: Western and Central Europe, Eastern Europe and Central Asia, North and Central America and the Caribbean, South America, East Asia and the Pacific, South Asia, Sub-Saharan Africa, and North Africa and the Middle East. The order of presentation of the regional overviews is based on the size of the sample used for the analysis in each region. As European countries reported the highest number of victims during the period considered, the two European regions are presented first. They are followed by the two regions of the Americas, then Asia and finally Africa and the Middle East.

Since many countries in Western and Central Europe provided thorough and comprehensive data, it was possible to undertake more detailed analyses for this region. There- 


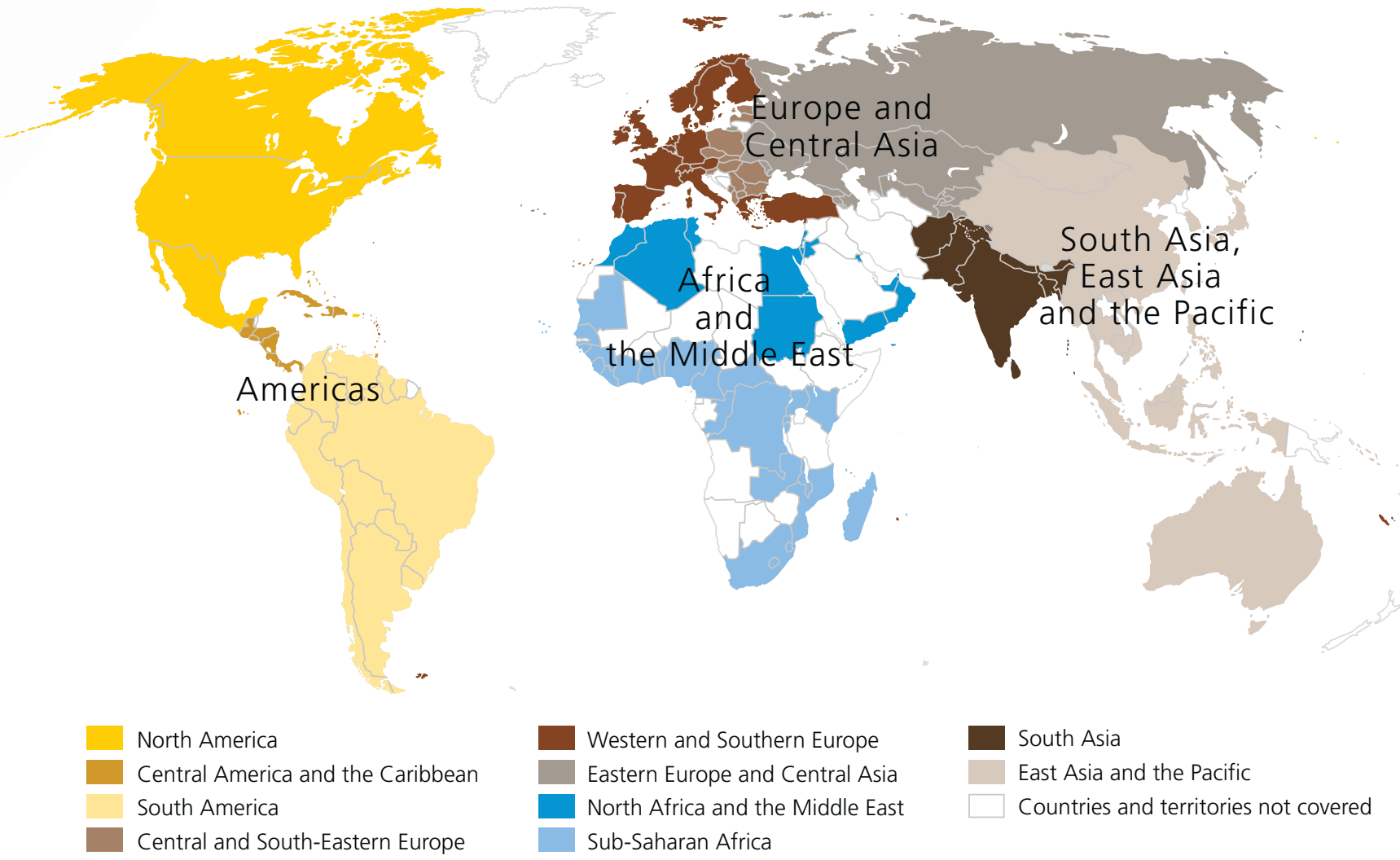

Source: UNODC elaboration of national data.

Note: The boundaries and names shown and the designations used on this map do not imply official endorsement or acceptance by the United Nations. The dotted line represents approximately the Line of Control in Jammu and Kashmir agreed upon by India and Pakistan. The final status of Jammu and Kashmir has not yet been agreed upon by the parties. The final boundary between the Republic of Sudan the Republic of South Sudan has not yet been determined. A dispute exists between the Governments of Argentina and the United Kingdom of Great Britain and Northern Ireland concerning sovereignty over the Falkland Islands (Malvinas).

fore, the region was divided into two subregions, namely Western and Southern Europe, and Central and South-Eastern Europe. The specific country breakdown for these subregions is presented within the regional overview. Similarly, the region of North and Central America and the Caribbean consists of North America, and Central America and the Caribbean. Occasionally, for analytical purposes, other country aggregations were considered. In those cases, the countries included have been listed either in the text or in a footnote.

Percentages in figures throughout the report may not always add up to $100 \%$ due to rounding.

\section{Explanation of key terms}

This section aims to explain some key terms that are frequently used in the context of trafficking in persons. At times, these definitions have been simplified in order to ease understanding, however, full legal definitions of terms have been supplied in the accompanying references.

\section{Trafficking in persons in the context of exploitation}

Trafficking in persons ${ }^{4}$ is a crime that includes three elements: 1) the ACT of recruiting, transporting, transferring, harbouring or receiving a person; 2) by MEANS of e.g. coercion, deception or abuse of vulnerability; 3) for the PURPOSE OF EXPLOITATION. Forms of

4 Legal definition: the recruitment, transportation, transfer, harbouring or receipt of persons, by means of the threat or use of force or other forms of coercion, of abduction, of fraud, of deception, of the abuse of power or of a position of vulnerability or of the giving or receiving of payments or benefits to achieve the consent of a person having control over another person, for the purpose of exploitation. Exploitation shall include, at a minimum, the exploitation of the prostitution of others or other forms of sexual exploitation, forced labour or services, slavery or practices similar to slavery, servitude or the removal of organs. The consent of a victim of trafficking in persons to the intended exploitation is irrelevant where any of the means set forth have been used. The recruitment, transportation, transfer, harbouring or receipt of a child for the purpose of exploitation shall be considered trafficking in persons even if this does not involve any of the means set forth. (Article 3 of the Protocol to Prevent, Suppress and Punish Trafficking in Persons defines Trafficking in Persons, 2000). 
Overlaps and differences between victims of trafficking, forced labour and slavery

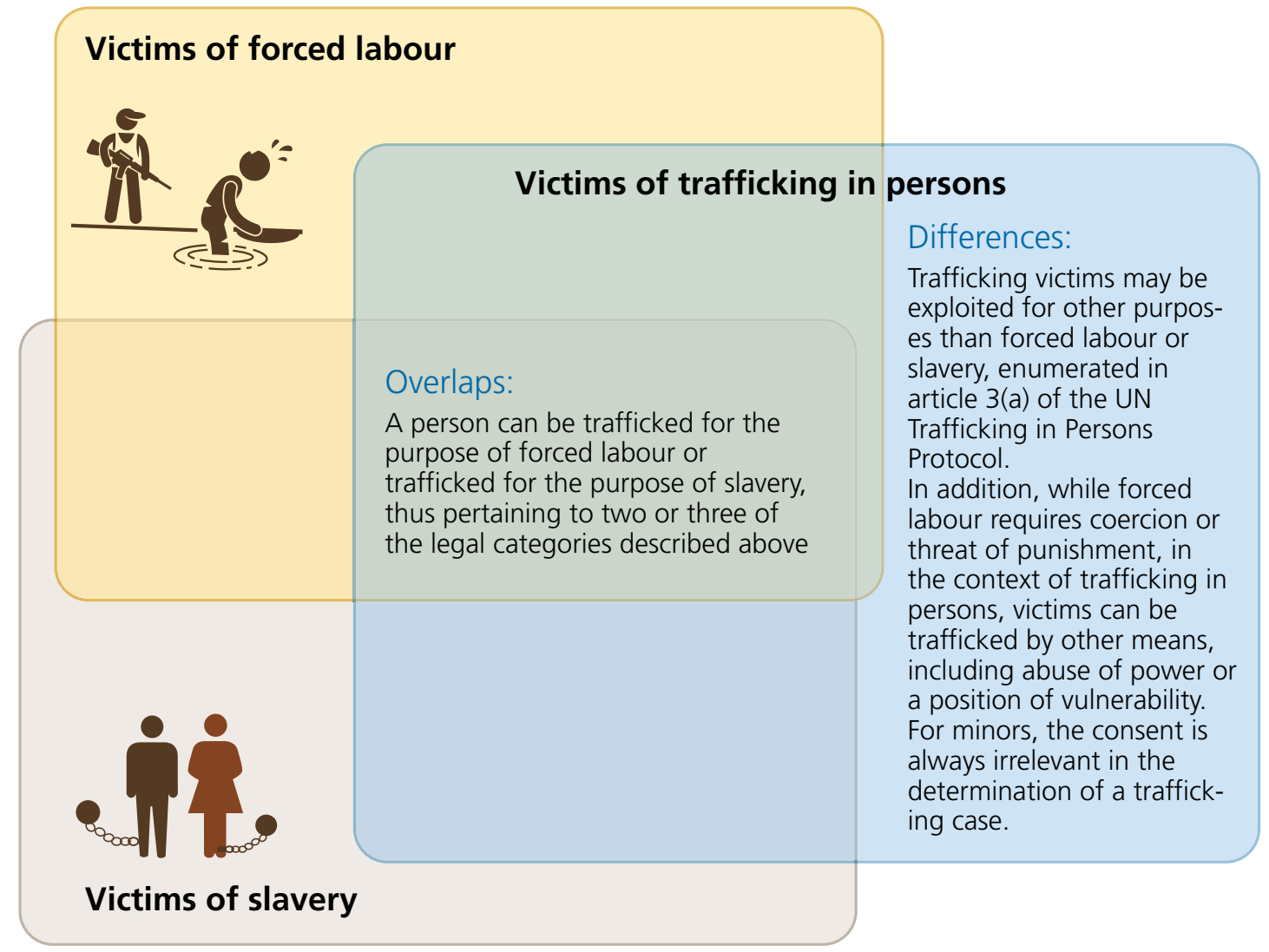

Note: The areas drawn in this figure are not intended to represent actual size population affected or covered by these different legal concepts.

exploitation specified in the definition of trafficking in persons include, sexual exploitation, slavery and forced labour, among others. Slavery and forced labour are also addressed in distinct international treaties.

A victim of forced labour ${ }^{5}$ is any person in any form of work or service which is exacted from him/her under the menace of any penalty and for which the said person has not offered himself voluntarily. ${ }^{6}$

A victim of slavery ${ }^{7}$ is a person over whom any or all of

\footnotetext{
Legal definition: all work or service which is exacted from any person under the menace of any penalty and for which the said person has not offered himself voluntarily (Article 2 Forced Labour Convention (No. 29) 1930).

6 A list of criteria to identify (in statistical surveys) penalty and threat of penalty and involuntariness can be found in ILO (2012) Hard to see Hard to see, harder to count - Survey guidelines to estimate forced labour of adults and children
}

7 Legal definition: the status or condition of a person over whom any or all of the powers attaching to the right of ownership are exercised (art 2. Slavery Convention, 1926). the powers attaching to the right of ownership are exercised.

Despite the different legal definitions that exist in the relevant international instruments, people affected by these three violations are not always distinct.

Overlaps between victims of trafficking in persons and populations affected by forced labour and/or slavery: A person can be trafficked for the purposes of slavery or forced labour, thus pertaining to two or three of the legal categories described above.

Differences between victims of trafficking in persons and populations affected by forced labour and/or slavery: trafficking victims may be exploited for other purposes than forced labour or slavery, enumerated in article 3 (a) of the UN Trafficking in Persons Protocol. ${ }^{8}$ In addi-

8 The list of forms of exploitation in the Protocol is non-exhaustive, meaning that States parties can add other specific exploitative purposes to their national legal definition. 
tion, while forced labour requires coercion or threat of punishment, in the context of trafficking in persons, victims can be trafficked by other means, including abuse of power or a position of vulnerability. For minors, the consent is always irrelevant in the determination of a trafficking case.

The term modern slavery has recently been used in the context of different practices or crimes such as trafficking in persons, forced labour, slavery, but also child labour, forced marriages and others. The common denominator of these crimes is that they are all forms of exploitation in which one person is under the control of another. The term has an important advocacy impact and has been adopted in some national legislation to cover provisions related to trafficking in persons, however the lack of an agreed definition or legal standard at the international level results in inconsistent usage.

While the legal definitions and, in certain cases the victim populations, of these different crimes may overlap to some extent, the use of one related national law over another makes great differences, especially to victims of trafficking. National legislations that comply with the UN Trafficking in Persons Protocol include a number of protection and assistance measures that are not available under other legal frameworks. ${ }^{9}$ In particular, States parties have the duty to protect the privacy and identity of victims of trafficking, to provide information on relevant court or other proceedings and assistance to enable their views to be heard in the context of such proceedings. In addition, States parties are obligated to ensure that victims of trafficking in persons can access remedies, including compensation. States parties must also consider providing for the physical safety of victims and to providing housing, counselling, medical, psychological and material assistance as well as employment, educational and training opportunities to victims of trafficking.

Adherence to the Protocol also triggers certain provisions under the UN Convention against Transnational Organized Crime (which the Protocol supplements). States parties have a broad array of mutual tools at their disposal for prosecuting trafficking in persons cases that are unavailable if there is no compliance with the convention, such as tools that address the illicit income derived from such crimes, like money-laundering, confiscation and seizure; international cooperation measures such as mutual legal assistance and extradition; and law enforcement cooperation measures such as joint investigations. Not

9 States Parties are required to implement these measures in a way that takes into account the age, gender and any special needs of the victim. fully utilizing these tools to prosecute trafficking in persons results in a piecemeal approach that organized criminals exploit to their advantage every day.

\section{Trafficking in persons in the context of migration}

The crime of trafficking in persons does not need to involve a border crossing. However, many detected victims are international migrants, in the sense that their citizenship differs from the country in which they were detected as trafficking victims.

Migrant smuggling is a crime concerning the facilitation of the illegal border crossing of a person into a State party of which a person is not a national or a resident in order to obtain a financial or other material benefit. ${ }^{10}$

Refugee is someone who has been forced to flee his/her country to preserve life or freedom. Refugees are entitled to protection under international law. ${ }^{11}$

International migrant is used in this report to refer to any person who changes his or her country of usual residence. ${ }^{12}$

10 Legal definition: the procurement, in order to obtain, directly or indirectly, a financial or other material benefit, of the illegal entry of a person into a State Party of which the person is not a national or a permanent resident. (Article 3, Protocol against the Smuggling of Migrants by Land, Sea and Air, 2000). Article 3 of the Smuggling of Migrants Protocol adopts a wide approach to the notion of "migrant" that includes both voluntary and involuntary movements. A distinction, however, must be drawn between refugees who move involuntarily and who may have no other choice but to use smugglers in order to escape persecution, and migrants who may or may not move voluntarily. Article 6 of the Smuggling of Migrants Protocol addresses the criminalization of Smuggling of Migrants when committed intentionally and in order to obtain, directly or indirectly, a financial or other material benefit, and establish as aggravated circumstances offences that endanger the lives or safety of the migrants and that entail inhuman or degrading treatment, including for exploitation, of such migrants.

11 Legal definition: a person who is outside his or her country of nationality or habitual residence; has a well-founded fear of being persecuted because of his or her race, religion, nationality, membership of a particular social group or political opinion; and is unable or unwilling to avail him or herself of the protection of that country, or to return there, for fear of persecution (Article 1A(2) Status of refugees convention 1951/1967 Protocol relating to the Status of Refugees). Several regional instruments, as well as the broader definition of refugee included in UNHCR's Statute, have extended international protection to persons fleeing indiscriminate effects of generalized violence or events seriously disrupting the public order, that do not fulfil the requirements of a refugee according to the 1951 Convention.

12 A uniform legal definition of the term 'international migrant' does not exist at the international level. For the purpose of showing differences and communalities between victims of trafficking in persons, smuggled migrants and refugees in terms of cross-border movement, UNODC refers to the United Nations Department of Economic and Social Affairs, Population Division that has defined an 'international migrant' as any person who changes his or her country of usual residence. This reference adopts a wide approach to the notion of "migrant" that includes both voluntary and involuntary movements. The International Organization for Migration (IOM) defines a 'migrant' as any person who is moving or has 
Overlaps and differences between victims of trafficking, international migrants, refugees and smuggled migrants

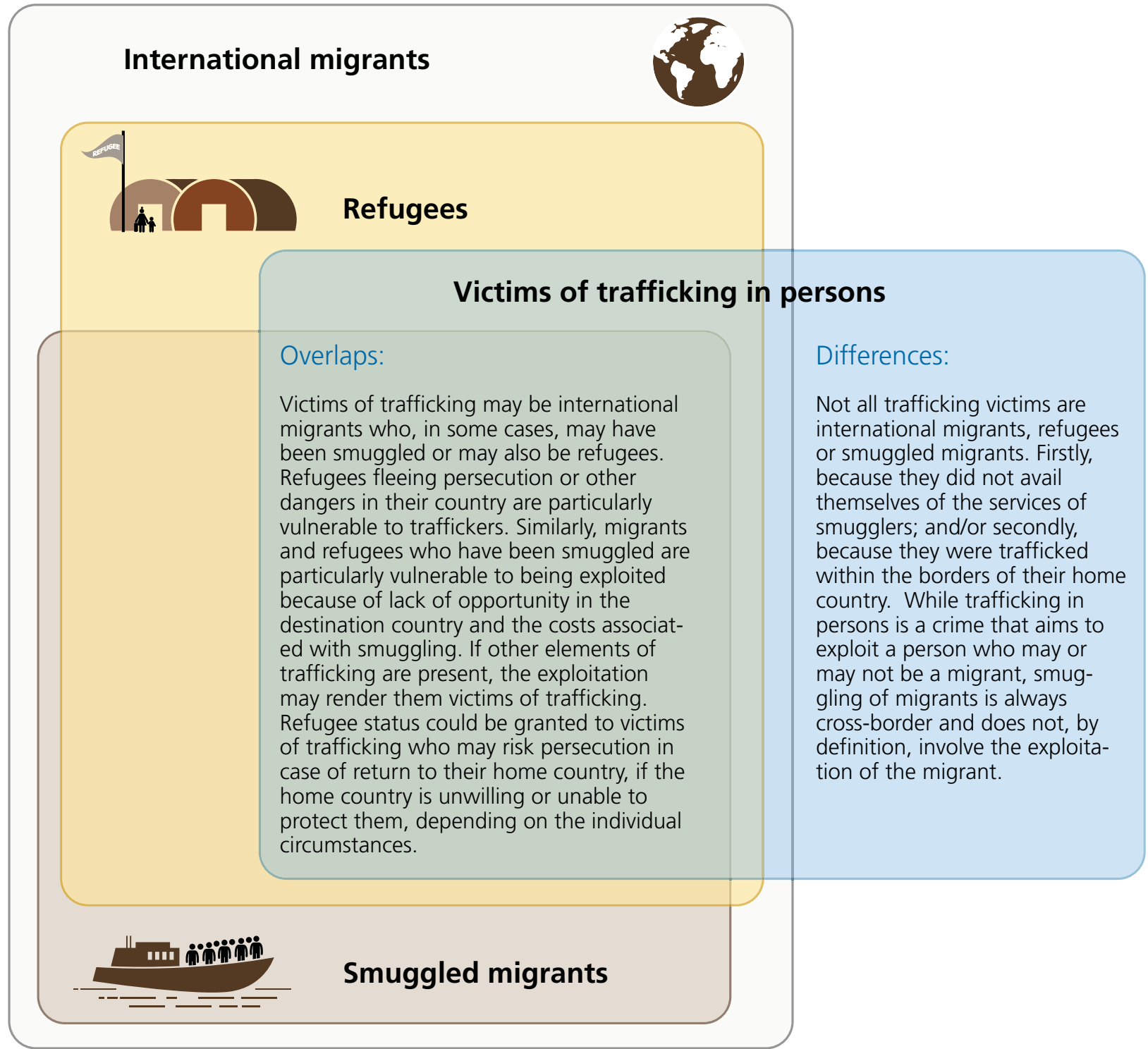

Note: The areas drawn in this figure are not intended to represent actual size population affected or covered by these different legal concepts.

Overlaps between victims of trafficking in persons, refugees and smuggled migrants:

Victims of trafficking may be migrants who have been smuggled and may also be refugees, amongst others. Refugees fleeing persecution or other dangers in their country are particularly vulnerable to traffickers. Similarly, migrants and refugees who have been smuggled are particularly vul-

moved across an international border or within a State away from his/her habitual place of residence, regardless of (1) the person's legal status; (2) whether the movement is voluntary or involuntary; (3) what the causes for the movement are; or (4) what the length of the stay is. This definition explicitly includes both voluntary and involuntary movements (http://www.iom.int/key-migration-terms\#Migration). nerable to being exploited because of lack of opportunity in the destination country and the costs associated with smuggling. If other elements of trafficking are present, the exploitation may render them victims of trafficking. Refugee status could be granted to victims of trafficking who may risk persecution in case of return to their home country, if the home country is unwilling or unable to protect them, depending on the individual circumstances.

Differences between victims of trafficking in persons, refugees and smuggled migrants:

Not all trafficking victims are smuggled migrants or refugees. Firstly, because they did not avail themselves of the 
services of smugglers; and/or secondly, because they were trafficked within the borders of their home country. While trafficking in persons is a crime that aims to exploit a person who may or may not be a migrant, smuggling of migrants is always cross-border and does not, by definition, involve the exploitation of the migrant.

Similar to the term modern slavery in the exploitative context, the term mixed migration is used to cover different terms in the migration context. Mixed migration generally refers to complex population movements, made up of people that have different reasons for moving and distinct needs including refugees, smuggled migrants and victims of trafficking, and often use the same routes and means of transportation on their travels.

In large-scale movements, refugees and migrants often face perilous journeys in which they risk a range of human rights violations and abuse from traffickers, smugglers and other actors. Furthermore, they may fall in and out of various legal categories in the course of their journey and different protection frameworks may become applicable to them due to changes in fundamental circumstances (that is, they become a refugee sur place; they become stateless due to arbitrary deprivation of their citizenship; or they become victims of trafficking). 


\section{Policy considerations}

- Most detected cases of trafficking in persons involve more than one country, and most (57 per cent) of the detected victims (2012-2014) moved across at least one international border (p.41). The UN Convention against Transnational Organized Crime and the supplementing UN Trafficking in Persons Protocol, which enjoy nearly universal ratification, provide States Parties with a series of tools to enhance international cooperation to tackle trafficking. Making better and more frequent use of these tools, including mutual legal assistance, joint investigations and special investigative techniques, could invigorate efforts to detect and prosecute complex cross-border cases of trafficking in persons.

- The regional and time-period analysis of the legislative and criminal justice response (p.49) shows that different parts of the world are at different stages in the implementation of effective counter-trafficking policy. Technical assistance to support Member States to prevent and combat trafficking in different parts of the world needs to be tailored accordingly. In some parts of Sub-Saharan Africa, there is a need to develop legal frameworks; in parts of the world where anti-trafficking legislation has been recently introduced (Southern Africa, North Africa, parts of the Middle East, parts of South America) capacity-building assistance to accelerate the use of national frameworks in accordance with international standards is more needed. In countries with long-standing legislation on trafficking in persons, for example, in European subregions, interventions should focus on identifying and protecting more victims, and convicting more traffickers.

- Trafficking in persons mainly affects women and girls (p. 23), while the share of women among convicted trafficking offenders is much larger than for other crimes (p.33). Laws and policies that prevent and combat trafficking should be designed to take into consideration the particular vulnerability women face with regard to trafficking crimes. Countries may also consider strengthening provisions for assistance to and protection of victims.

- After women, children remain the second largest category of detected victims of trafficking in persons across the world (p. 23). Domestic frameworks on child protection and trafficking in persons, where relevant, should address the specific risk factors that expose children, particularly unaccompanied migrant children, to trafficking situations. Moreover, undertaking enhanced prevention efforts may help highlight how children may become vulnerable to being trafficked and take practical action to address those identified vulnerabilities.
- The Global Report shows that the citizenships of detected victims of trafficking in persons broadly correspond to the citizenships of regular migrants that arrived during the same period (p. 57). Although the links between migration and trafficking in persons are not clear-cut, it appears that the vulnerability to being trafficked is greater among refugees and migrants in large movements, as recognized by Member States in the New York declaration for refugees and migrants of September 2016. Therefore, migration and refugee policies should take into consideration the vulnerability of migrants and refugees to trafficking in persons and attempt to ensure that programmes for the identification of and support to victims of trafficking are a core component of refugee protection systems.

- There is a positive correlation between the duration of existence of national trafficking in persons legislation and the number of trafficking convictions registered in a country (p.52). Most countries have now adopted legislation that criminalizes trafficking in persons according to the UN Trafficking in Persons Protocol (p. 48 ), yet global conviction rates remain low. This might be related to the relatively recent nature of national legal frameworks in many countries. Accelerating the implementation of the domestic legislation by carrying out awareness-raising, training and other capacitybuilding activities on the use of legislation may now be useful in rapidly enhancing the capacity of national criminal justice systems to identify, investigate and prosecute cases of trafficking in persons.

- This and previous editions of the Global Report have identified several enabling factors that can increase people's vulnerability to trafficking in persons, such as the presence of transnational organized crime in origin countries, levels of development, irregular migration paths and weak protection structures. This work has only scratched the surface of these complex linkages, however, and more research is needed to better understand the factors that help drive trafficking in persons. Such research would also be applicable in context of the Sustainable Development Goals, and particularly to help monitor progress towards the targets explicitly referencing trafficking in persons (16.2, 5.2 and 8.7). 


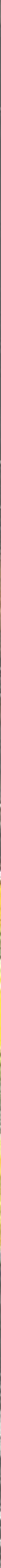





\section{CHAPTER I}

\section{GLOBAL OVERVIEW}

\section{PATTERNS OF TRAFFICKING IN PERSONS}

UNODC has been collecting data on the patterns and trends of trafficking in persons from official, national criminal justice sources since 2003, and this edition of the Global Report on Trafficking in Persons draws on statistics covering more than a decade. The focus, however, is on the 2012-2014 period.

\section{Profile of the victims}

A total of 63,251 victims were detected in 106 countries and territories between 2012 and 2014. Based on the 17,752 victims detected in 85 countries in 2014 for which sex and age were reported, a clear majority were females - adult women and girls - comprising some 70 per cent of the total number of detected victims. Females have made up the majority of detected victims since UNODC started collecting data on trafficking in persons in 2003.

\section{The share of men among detected trafficking victims is increasing}

Although women still comprise a majority of detected victims, there has been an overall decrease in the share of female victims over the past decade, from 84 per cent in

FIG. 1 Detected victims of trafficking in persons, by age* and sex, 2014 (or most recent)

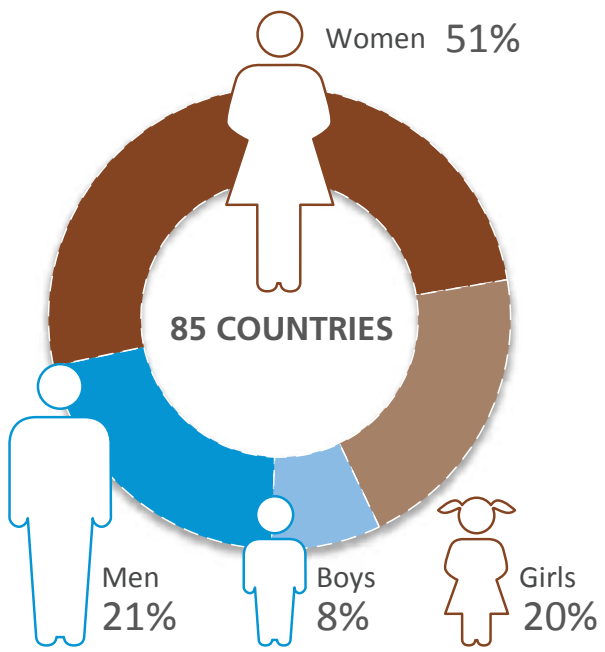

* 'Men' are males aged 18 or older; 'boys' are males 17 and below. 'Women' are females aged 18 or older; 'girls' are females 17 and below. Source: UNODC elaboration of national data.
FIG. 2 Trends in the shares of females (women and girls) among detected trafficking victims, selected years

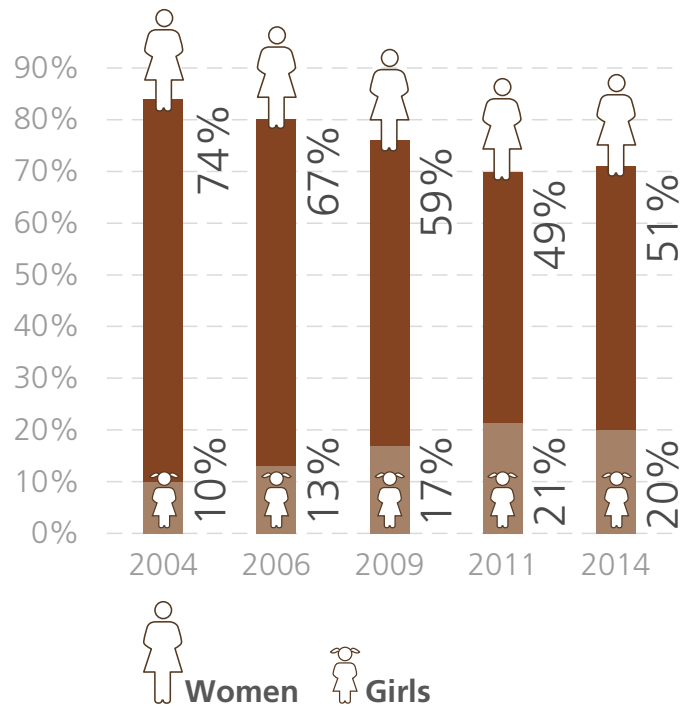

Source: UNODC elaboration of national data

2004 to 71 per cent in 2014 . The trend for detections of men, in contrast, has been increasing over the same period, and more than 1 in 5 detected trafficking victims between 2012 and 2014 were men.

FIG. 3 Trends in the shares of males (men and boys) among detected trafficking victims, selected years

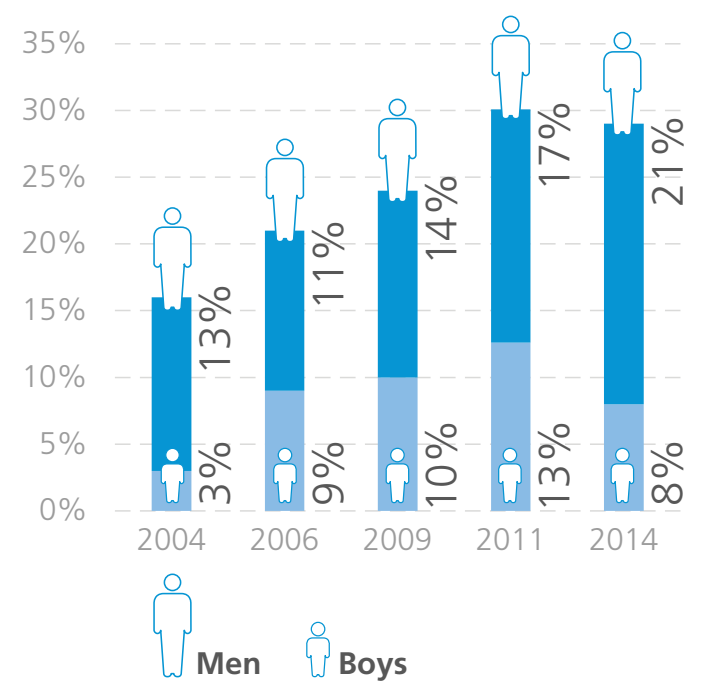

Source: UNODC elaboration of national data. 


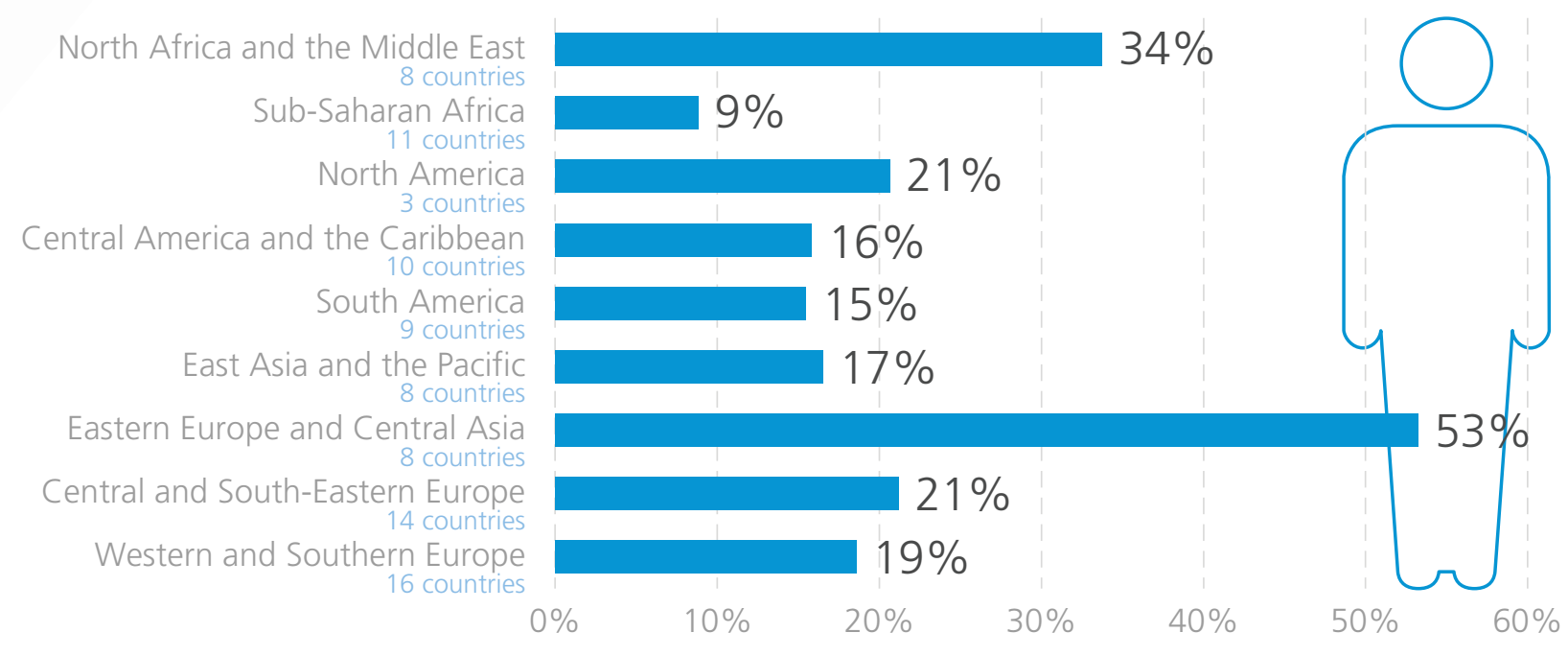

Source: UNODC elaboration of national data.

Global averages mask marked regional differences in the profile of victims. In a few regions men represent the majority of detected victims, for example in Eastern Europe and Central Asia, where the share of men exceeded 50 per cent due to widespread detections of men in Central Asia. Similarly, countries in the Middle East detected a proportion of men which was larger than the global average; about one third of the total. The high prevalence of trafficking in men in these two areas may be linked to the frequent detections of trafficking for forced labour.

In 25 countries - mostly in Europe, Central Asia and South America - the share of detected men has increased over the last eight years. However, the majority of the countries covered show stable or unclear trends for this indicator.

In other areas, such as Western and Southern Europe, Central and South-Eastern Europe, the Americas and East Asia, the shares of men among victims of trafficking seem to be relatively stable, at around 15-20 per cent. In SubSaharan Africa - where children are detected at very high levels - men represent a relatively small share of the detected victims.

Detected male victims - men and boys - are mainly trafficked for forced labour. To a limited extent, male victims are also detected in cases of trafficking for sexual exploitation or for other forms of exploitation, such as begging and the commission of crime.
FIG. 5 Trends in the shares of men among detected trafficking victims, selected countries, 2007-2015

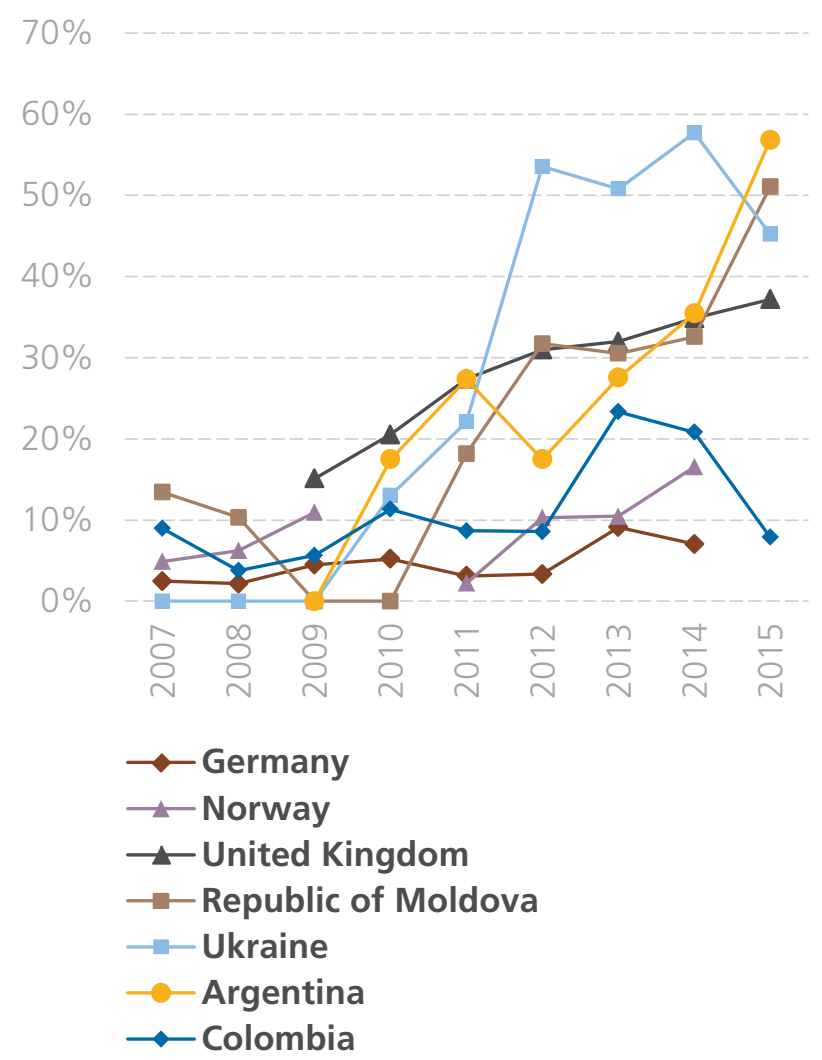

Source: UNODC elaboration of national data. 
FIG. 6 Forms of exploitation among detected male trafficking victims, 2014 (or most recent)

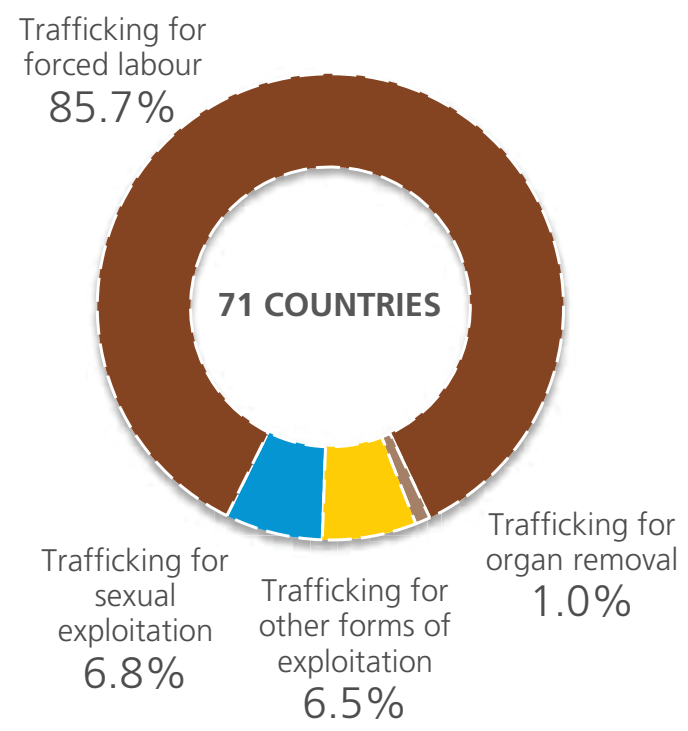

Source: UNODC elaboration of national data.

\section{Mixed trends for trafficking in children, although in some regions, most detected victims are children}

Children remain the second most commonly detected group of victims of trafficking globally after women, ranging from 25 to 30 per cent of the total over the 2012-2014 period. This represents a 5 percentage points decrease from 2011; largely due to reductions in the number of boys detected in 17 reporting countries.

The age profiles of the detected victims vary significantly by region. For instance, countries in Sub-Saharan Africa detect, by far, more child victims (64 per cent) than adult victims; a consistent trend since 2003 when data collection started. Countries in Central America and the Caribbean also mainly detect child victims. The wealthier countries of North America, Europe and the Middle East, on the other hand, typically report relatively small shares of child victims (20-25 per cent).

With current knowledge, it is not possible to provide a thorough explanation of the widely divergent regional figures regarding the detection of child victims. A detailed analysis should consider different factors and assess their impact on the detected level of child trafficking around the world. A first set of considerations relate to the demand for child trafficking, which is the demand for minors in exploitative practices such as sexual, labour and 'other'
FIG. 7 Trends in the shares of children (girls and boys) among detected trafficking victims, selected years

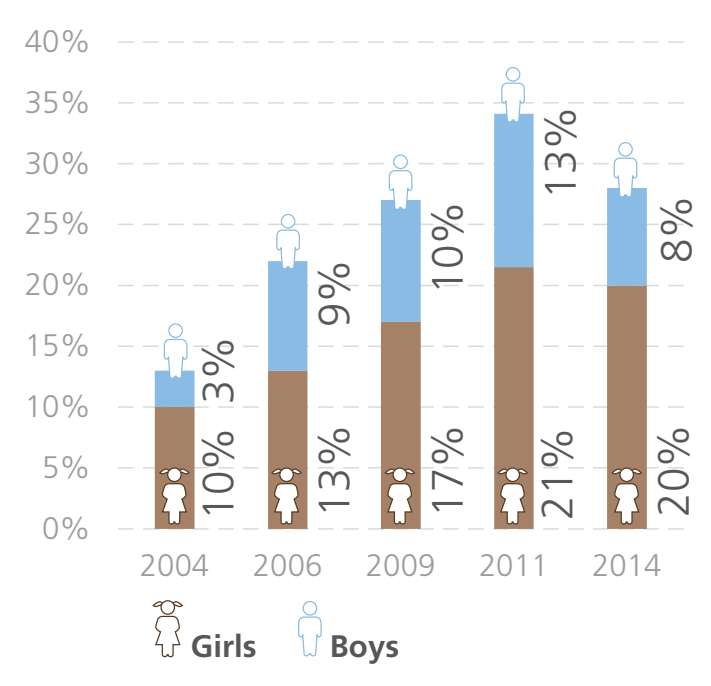

Source: UNODC elaboration of national data.

purposes. This demand includes the potential for profits. ${ }^{1}$ For instance, do traffickers more readily exploit children in specific labour sectors, as they may be less likely to demand better working conditions? The demand that drives child trafficking would also include 'cultural practices' which are not conducted by organized traffickers, but by communities. ${ }^{2}$ This includes cases of parents selling their children, households using children as domestic servants, or families or teachers forcing children to beg. ${ }^{3}$

Another set of considerations refer to the 'availability' of child victims. As a general statistical result, countries with younger populations tend to have higher levels of child trafficking. ${ }^{4}$ This may suggest that in countries where the child population is large, traffickers may target children more easily. Access to education may also be a factor.

Additionally, there are some 'enabling factors' that could help match demand with availability of child trafficking. The presence of such factors could be indicated by the absence of solid institutions dedicated to child protection,

1 See, for example, International Labour Organization (ILO) (2013). Child migration, child trafficking and child labour in India; Anti-Slavery International (2010). Ending Child Trafficking in West Africa; and IOM (2008). Human Trafficking in Eastern Africa: Research Assessment and Baseline Information in Tanzania, Kenya, Uganda, and Burundi.

2 Ibid.

3 Ibid.

4 The correlation between the share of child victims detected in 2014 (or most recent) and the share of the population aged below 18 was measured by a Pearson's correlation coefficient of 0.416 (sig 000, N $80)$. 
FIG. 8 Shares of adults and children among detected trafficking victims, by region, 2014 (or most recent)

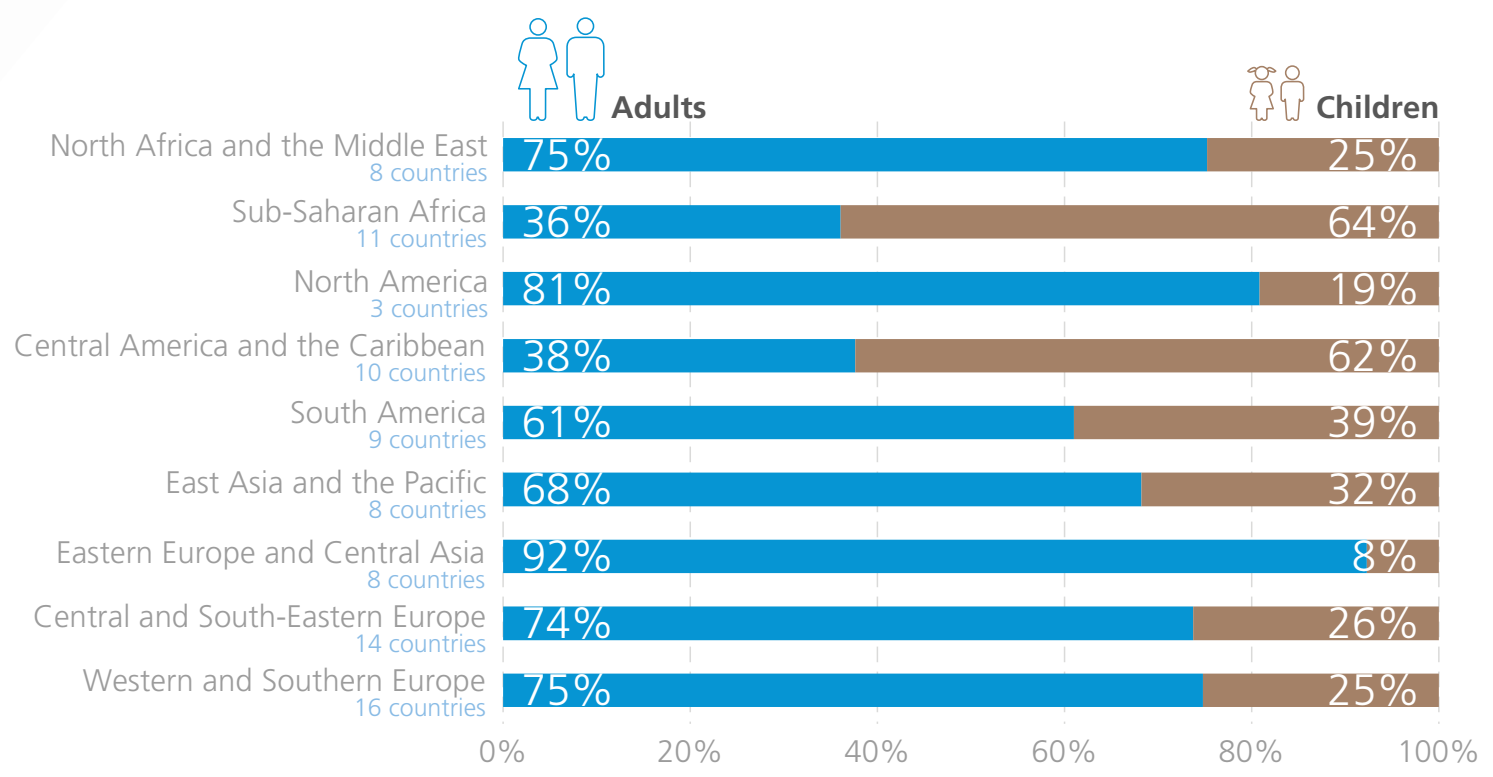

Source: UNODC elaboration of national data.

including the criminal justice system. Traffickers would encounter fewer obstacles in territories where institutions do not sufficiently protect children, convict traffickers, provide proper education or support communities in keeping children safe. ${ }^{5}$ The detection of child victims is more significant in countries with lower levels of human development, while more developed countries report less child trafficking. ${ }^{6}$

Some national anti-trafficking institutions may also have a particular focus on child trafficking. This may be the case of some countries in Sub-Saharan Africa that until very recently only had legislation on child trafficking. For this reason, anti-trafficking efforts may still target the trafficking of children more than that of adults.

\section{Women and girls trafficked for a variety of purposes}

In most areas of the world, the information on detected victims shows that trafficking in persons mainly affects women and girls. Females are chiefly trafficked for sexual exploitation, but also for sham or forced marriages, for

5 For more, see IOM 2008, op. cit.; UNICEF (2009). Reversing the trend: Child trafficking in East and Southeast Asia; UNICEF (2009). Risks and Realities of Child Trafficking and Exploitation in Central Asia; and Human Rights Watch (2003). Borderline Slavery. Child Trafficking in Togo.

6 The correlation between the share of child victims detected in 2014 (or most recent) and the Human Development Index was measured by a Pearsons correlation coefficient of 0.453 (sig 000, N 82). begging, for domestic servitude, for forced labour in agriculture or catering, in garment factories, and in the cleaning industry and for organ removal.

The Global Report employs four broad categories of trafficking in persons. This classification is based on the United Nations Trafficking in Persons Protocol, where the following list of purposes is included: "Exploitation shall include, at a minimum, the exploitation of the prostitution of others or other forms of sexual exploitation, forced labour or services, slavery or practices similar to slavery, servitude or the removal of organs." (Article 3, paragraph (a)). ${ }^{7}$

The first category is trafficking for sexual exploitation, which includes the exploitation of the prostitution of others and similar situations. The second category includes trafficking for forced labour or services, slavery and similar practices and servitude. The third category includes trafficking for the removal of organs, and the fourth and final category is trafficking for "other forms of exploitation". The broad 'other' category includes all forms of trafficking in persons that are not specifically mentioned in the UN Trafficking in Persons Protocol but identified by national legislation or jurisprudence and reported to UNODC through the Global Report questionnaire.

\footnotetext{
For a full analysis of this provision, see: UNODC, Issue Paper (2015) The Concept of "Exploitation" in the Trafficking in Persons Protocol.
} 
FIG. 9 Share of detected victims of trafficking in persons, by sex and form of exploitation, 2014 (or most recent)

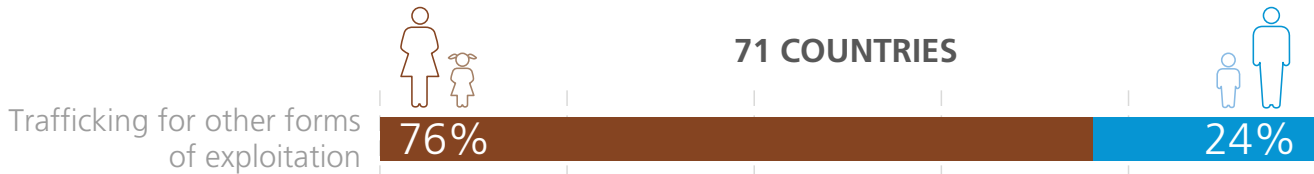

Trafficking for forced labour $37 \%$

$\begin{array}{lll}\text { Trafficking for sexual exploitation } & 96 \% & 4 \%\end{array}$

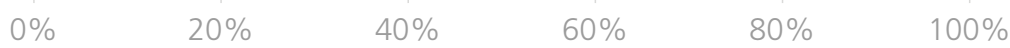

Source: UNODC elaboration of national data.

About 23,000 victims trafficked for sexual exploitation were detected and reported between 2012 and 2014. The vast majority of them were females; women or girls. The few males trafficked for sexual exploitation are concentrated in Western and Southern Europe and the Americas. During the same period, females also accounted for a considerable number of the detected victims trafficked for forced labour; making up about 37 per cent of the total number of victims for that form.

In some parts of the world, such as East Asia, females account for the majority of detected victims trafficked for forced labour. Much of this trafficking takes the form of domestic servitude, in which victims are exploited in family households. The offenders may be family members, couples acting together or individuals attracting victims from abroad with the promise of a better life.

The description of court cases can provide some examples of how this mode of trafficking is carried out. In Argentina, for example, a girl was brought to that country from the rural parts of the Plurinational State of Bolivia by her aunt. The aunt promised the victim's parents that she would give the girl a proper education in Argentina. However, the girl was exploited as a servant in the household. ${ }^{8}$ In the Dominican Republic, a Chinese-Dominican couple recruited a girl in China for exploitation in their household. ${ }^{9}$ A similar situation was prosecuted in Austria, where

8 Case provided by Argentina, which concluded with a conviction by the tribunal of Comodoro Rivadavia and a 12-month prison sentence for the offender

9 Case provided by the Dominican Republic, which concluded with a an Austrian citizen forced two Serbian victims into domestic servitude. ${ }^{10}$ These examples reveal that victims of trafficking for domestic servitude are often exploited and segregated, with limited chances of being detected and assisted.

A large number of female victims of trafficking for domestic servitude were also reported in Africa and the Middle East. In that region and in North America, females and males were equally trafficked for forced labour. In North America, domestic servitude is a common form of exploitation, but many other types of labour activities were also detected, including trafficking for forced labour in agriculture, catering and other industries.

About 76 per cent of the victims trafficked for 'other purposes' are female. This percentage is consistent across all regions where a sufficient number of cases of this type have been detected. In East Asia, for instance, forced marriages seem to be a significant form of exploitation in the Mekong area. In North America, women and girls are trafficked for mixed exploitation, meaning that the same victim is exploited for sex as well as labour purposes. Sham and forced marriages targeting adult women is also a form of trafficking that has been detected in different European countries. Trafficking for begging and adoption, in countries with legislation that includes these as forms of traf-

conviction in the Tribunal of the Province of Altagracia and a 5-year prison sentence.

10 Case provided by Austria, which concluded with conviction by the court of Feldkirch. The offender received a 9-month prison sentence and a fine of 1,200 euros. 
FIG. 10 Gender breakdown of detected victims of trafficking for forced labour, by region, 2014 (or most recent)

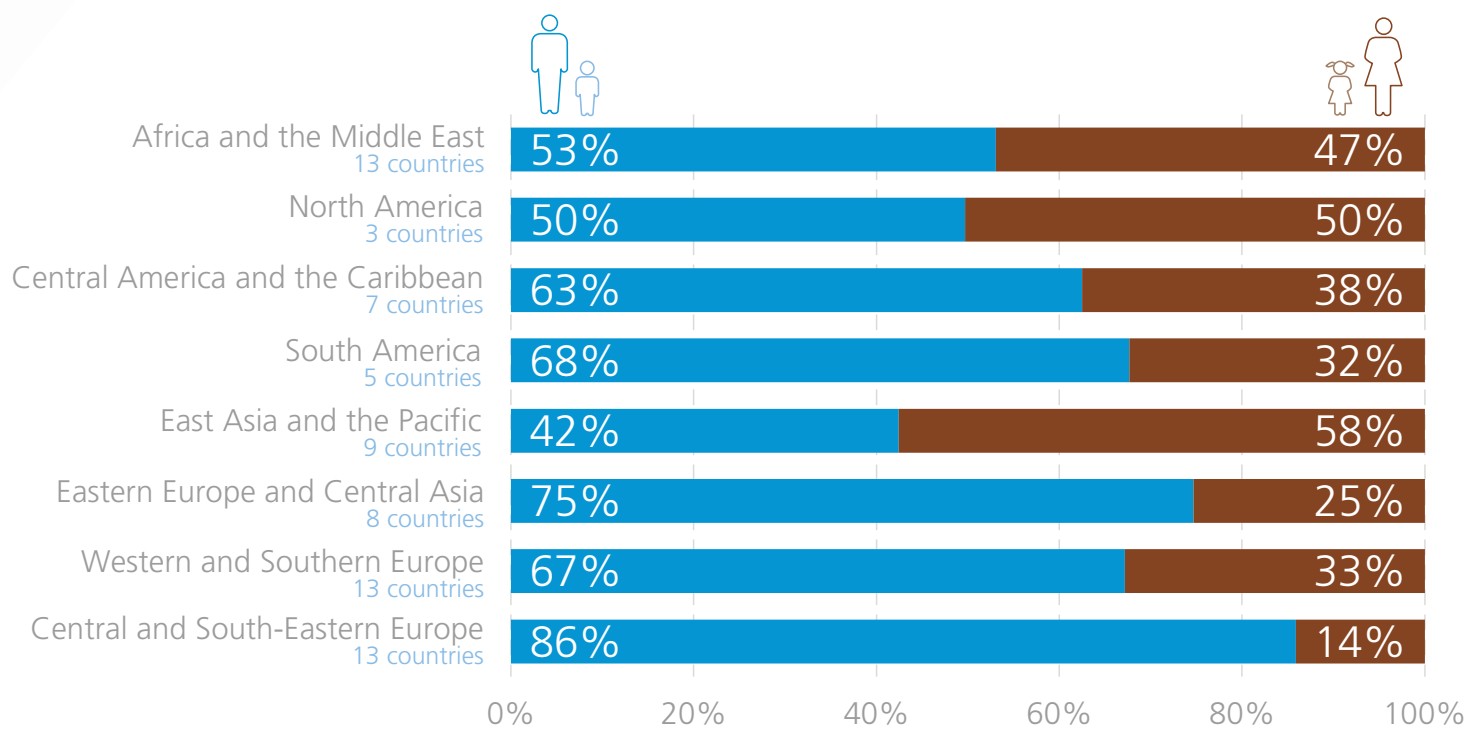

Source: UNODC elaboration of national data.

ficking, tend to include both boys and girls as victims, with slightly more girls than boys. From the limited data available, it seems that trafficking for child pornography and for committing crime may target more boys than girls.

\section{FIG. 11 Forms of exploitation among detected female trafficking victims, 2014 (or most recent)}

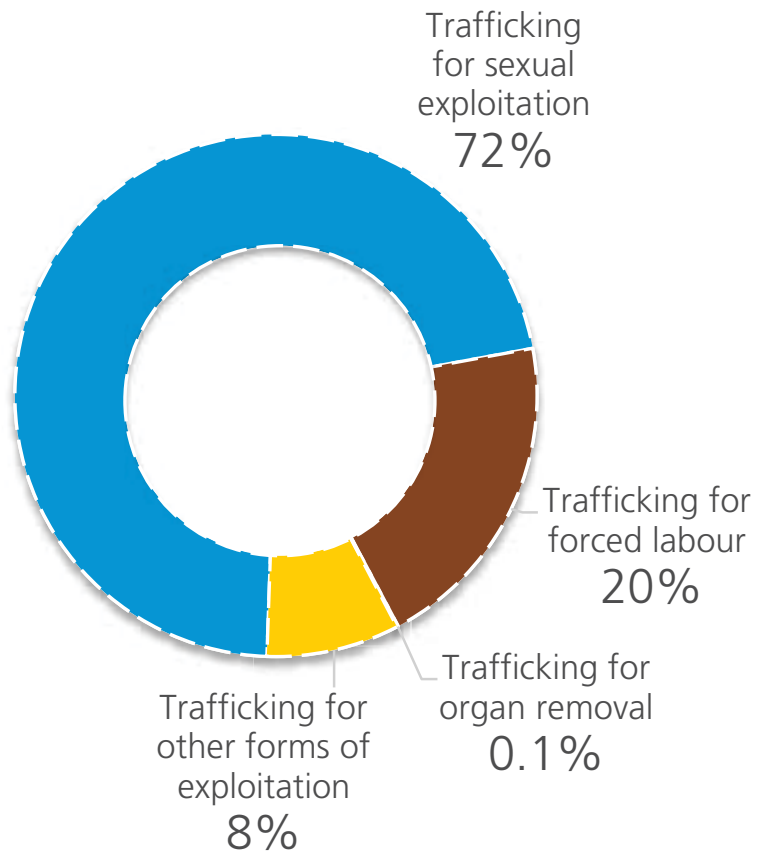

Source: UNODC elaboration of national data.

\section{Forms of trafficking in persons: wide geographical differences}

Trafficking for sexual exploitation has been the most commonly detected form as long as UNODC has been collecting data on trafficking in persons. The latest data available - for the 2012-2014 period - is in line with previous years, with about 54 per cent of the 53,700 detected victims having been trafficked for sexual exploitation. The trend for this form, however, is decreasing. Trafficking for forced labour now accounts for a larger share of the detected victims than in 2007.

The regional differences observed with regard to the profiles of detected victims are quite pronounced when considering the different forms of trafficking and exploitative purposes. For instance, the large number of men detected in Eastern Europe and Central Asia is connected to the large share of victims trafficked for the purpose of forced labour particularly in Central Asia. About 64 per cent of the victims detected in that region are exploited in different forms of forced labour; the highest level recorded by the reporting countries. There are high levels of trafficking for forced labour in other regions as well, particularly in Africa.

Victims detected in Western and Southern Europe and Central and South-Eastern Europe are largely trafficked for sexual exploitation. Trafficking for forced labour ranges around 20-30 per cent of the total number of detected victims in the countries of this region. 
FIG. 12 Trends in the forms of exploitation among detected trafficking victims, 2007-2014

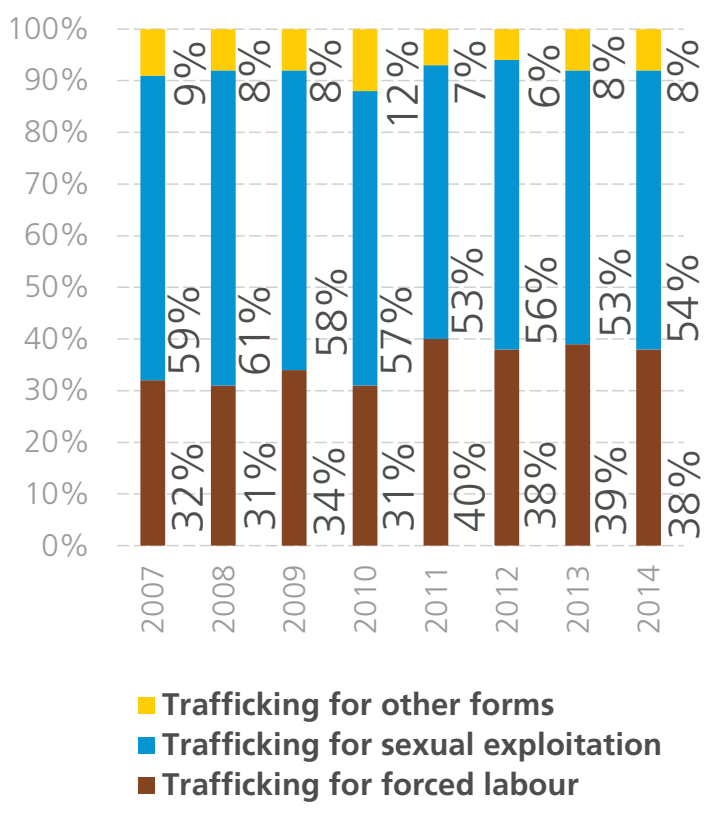

Source: UNODC elaboration of national data.
In the Americas, there is a predominance of detected trafficking for sexual exploitation, which is slightly more pronounced in Central America and the Caribbean. North America has a relatively high share of victims trafficked for forced labour; some 40 per cent of the victims detected during the 2012-2014 period. As for South America, about 30 per cent of the detected victims were trafficked for forced labour. Under-reporting of forced labour may be an issue in this region, however, due to differences in trafficking legislation and recording systems in some prominent countries.

Trafficking for forced labour is a broad category that includes a large variety of exploitative activities. It occurs across many economic sectors, industries and labour activities. One widely detected form is domestic servitude in households, which has been reported by many countries across the world. But trafficking for forced labour also happens in seasonal agricultural work such as berry picking in Nordic countries, or fruit and vegetable collection in the Mediterranean region. Victims of trafficking for forced labour have been detected in the fishing industry in South-East Asia and Africa, in catering services and restaurants in many countries, in construction and in the cleaning industry. Moreover, victims are also trafficked for

IFIG. 13 Shares of forms of exploitation among detected trafficking victims, by region of detection, 2014 (or most recent)

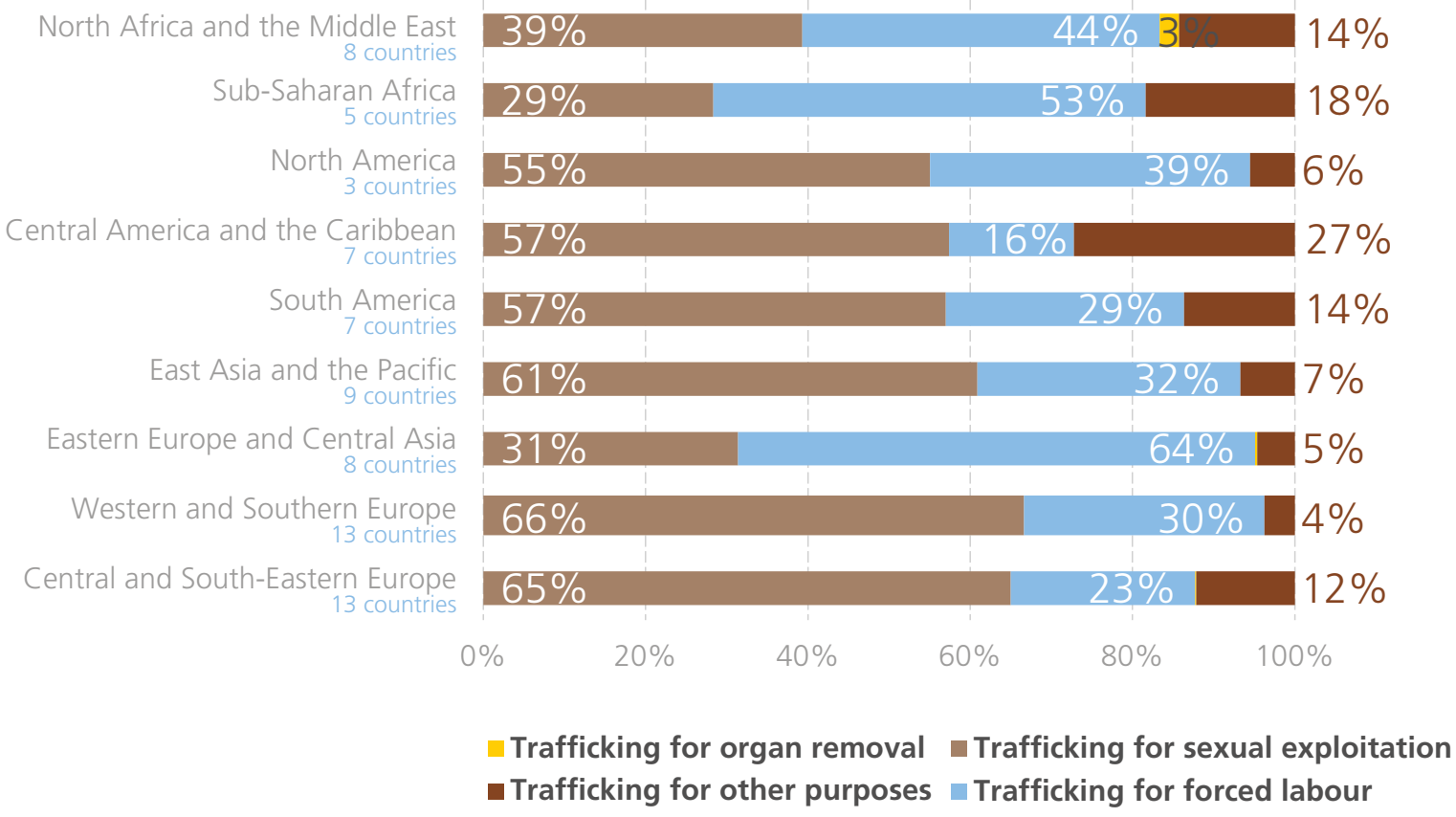




\section{The Sustainable Development Goals and trafficking in persons}

In September 2015, the international community gathered at the United Nations headquarters in New York to decide upon a new, broad development framework to replace the Millennium Development Goals. The vision was of " a world of universal respect for human rights and human dignity, the rule of law, justice, equality and non-discrimination; of respect for race, ethnicity and cultural diversity; and of equal opportunity permitting the full realization of human potential and contributing to shared prosperity. A world which invests in its children and in which every child grows up free from violence and exploitation. A world in which every woman and girl enjoys full gender equality and all legal, social and economic barriers to their empowerment have been removed. A just, equitable, tolerant, open and socially inclusive world in which the needs of the most vulnerable are met." a

To guide global efforts to reach such a world, Heads of State and Government from more than 150 countries announced a set of 17 Sustainable Development Goals (SDGs) with 169 associated targets. ${ }^{\mathrm{b}}$ The goals and targets will serve as a measurable framework for efforts to achieve this vision by 2030.

SDG 16 calls for the promotion of peaceful and inclusive societies for sustainable development, providing access to justice for all and building effective, accountable and inclusive institutions at all levels. In the context of SDG 16, the international community calls for the end of abuse, exploitation, trafficking and all forms of violence against and torture of children (SDG Target 16.2). This Target will be measured, among other indicators, by assessing the number of victims of trafficking in persons, disaggregated by age, sex and forms of exploitation (indicator 16.2.2).

Reporting soundly and accurately on indicator 16.2 .2 poses a great challenge to the international community. Measuring the total volume of trafficking in persons is not an easy task as any assessment of this crime needs to account for the coexistence of its three defining elements, the act, the means

\section{Share of children among detected victims of trafficking in persons, by gender, 2004- 2014}

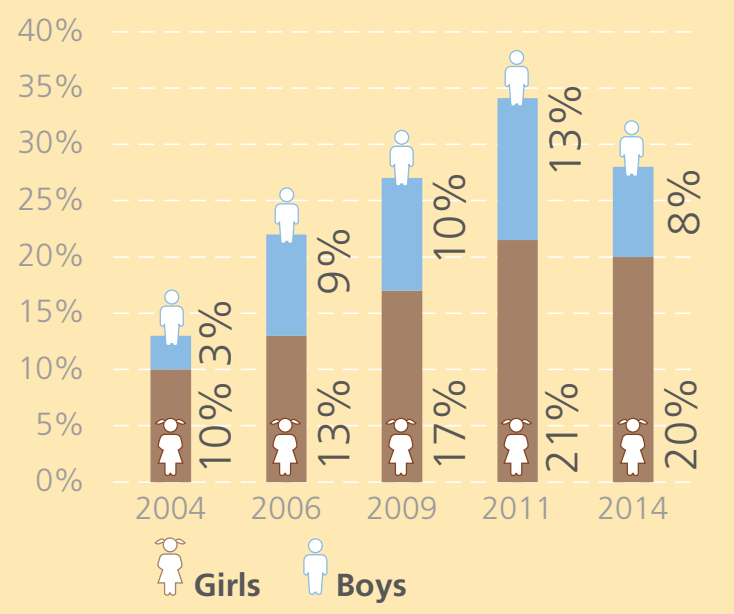

Source: UNODC elaboration of national data. and the purpose. The Global Report is currently the only international source of information on victims of trafficking in persons, detailed by age and sex, and form of exploitation suffered, for a large number of countries ( 85 for this edition). On the basis of this wealth of information, UNODC can generate some baseline data for indicator 16.2.2. concerning the segment of trafficking victims that are detected. Estimating the number of undetected victims remains a challenge.

The research community and UNODC are investing in the development of new methodologies to estimate the number of undetected victims. ${ }^{c}$ Until the coverage of these estimates allow for accurate global estimates, the indicator on detected victims can be used to inform the achievement of trafficking in persons-related targets to a certain extent. While this indicator clearly doesn't measure the volume of trafficking in persons, it can monitor how certain population groups such as children and girls are over time exposed to trafficking.

Trafficking in persons is also explicitly addressed in Target 5.2 on the elimination of all forms of violence against all women and girls in the public and private spheres, including trafficking and sexual and other types of exploitation, and in Target 8.7 on taking immediate and effective measures to eradicate forced labour, end modern slavery and human trafficking and secure the prohibition and elimination of the worst forms of child labour, including recruitment and use of child soldiers, and by 2025 end child labour in all its forms. The fact that different SDGs make reference to trafficking in persons emphasizes how this is a multifaceted phenomenon, with criminal, violence, human rights, migration, labour and gender connotations.

The data on trafficking in persons regularly collected by UNODC can also be used by Member States to track progress towards the realization of these goals. The statistics on detected victims of trafficking in persons for more than 100 countries around the world, disaggregated by age, sex and

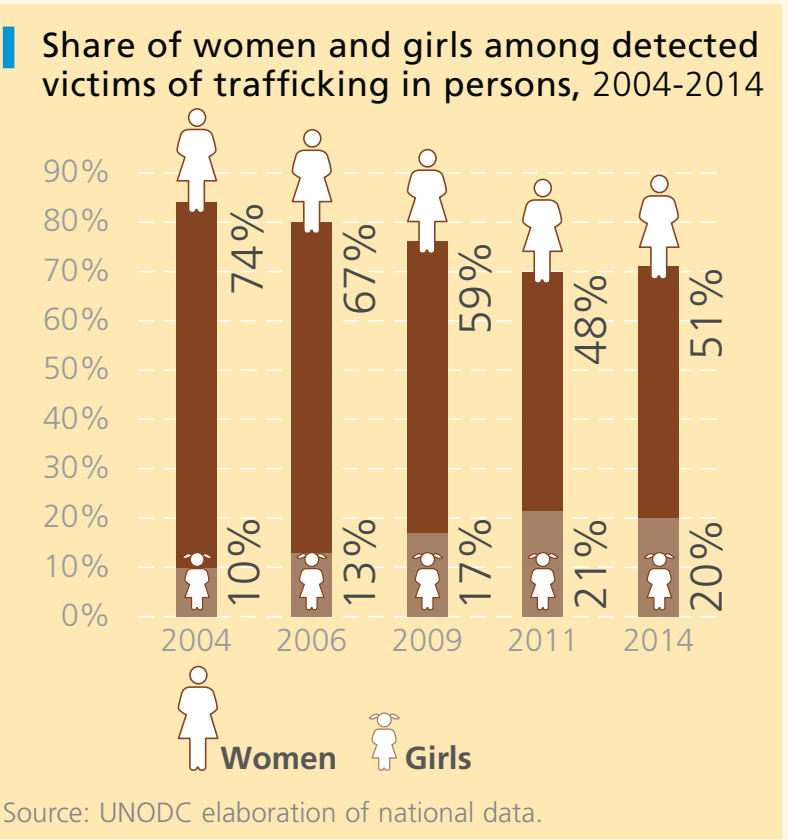


For the inaugural report on the SDGs, which takes stock of where the world stands regarding the 2030 targets, UNODC provided this data to help assess the extent of child trafficking. The data showed that the shares of girls and boys among detected victims of human trafficking peaked in 2011 at 21 per cent and 13 per cent, respectively, of the cases detected by authorities that year. More recently, for the year 2014, the share of detected girls among victims of trafficking remained stable at about 20 per cent, while the share of boys decreased to 8 per cent. As a result, the share of child trafficking among the total number of detected victims decreased from 33 to 28 per cent. ${ }^{\text {d }}$

The data collected by UNODC can also be used to monitor different components of Targets 8.7 and 5.2. For Target 5.2, the UNODC data shows that the share of women and girls among detected trafficking victims is approximately 70 per cent, which is a significant reduction from 2004, although there was a minor increase from 2011 to 2014.

In connection with Target 8.7, the UNODC data indicates that the share of victims of trafficking for forced labour among trafficking victims increased from 32 per cent in 2007 to 40 per cent in 2011. More recently, for 2014, this share remained broadly stable at about 38 per cent.

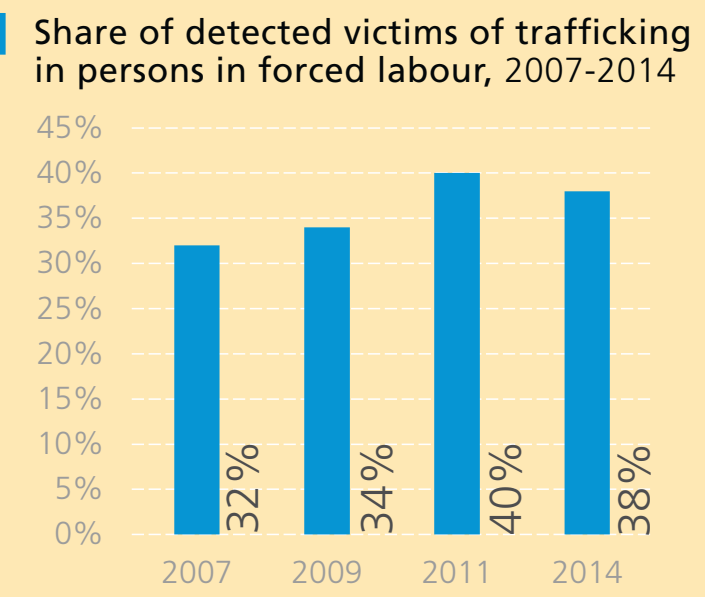

Source: UNODC elaboration of national data.

a A/RES/70/1, United Nations General Assembly, Transforming our World: the 2030 Agenda for Sustainable Development, 21 October 2015, para. 8

b For a full list, see https://sustainabledevelopment.un.org/sdgs. In 2016, UNODC conducted a promising pilot Multiple Systems Estimate (MSE) of trafficking in persons victims in the Netherlands to test this particular methodology to estimate the number of victims there. Please refer to the text box ( $p$. 47) with further details about the MSE methodology. For a comprehensive overview, see: UNODC Research Brief (2016). Multiple Systems Estimation for estimating the number of victims of human trafficking across the world (primary authors: J. Van Dijk and P. G. M. van der Heijden).

d United Nations (2016). Sustainable Development Goals Report 2016 (available at: http://unstats.un.org/sdgs/report/2016/). forced labour in the mining sector; for example, to mine diamonds in West Africa, or gold and other minerals in Central Africa, to mention some of the many areas in which trafficking victims are exploited.

A limited number of cases of trafficking for organ removal were detected during the reporting period, mainly in Central and South-Eastern Europe, Eastern Europe and Central Asia, North Africa and the Middle East, and South America. Some 120 victims of this form of trafficking were detected between 2012 and 2014 in about 10 countries in different parts of the world.

Several 'other' forms of trafficking are also detected and aggregated. These accounted for about 8 per cent of the detected victims between 2012 and 2014. During this period, the following 10 categories of exploitation were reported: trafficking for the purpose of begging, for committing various illegal activities, for forced and sham marriages, for child soldering, for baby selling/illegal adoption, for the production of pornographic material, for human sacrifice, for the removal of body parts, for different combinations of mixed exploitation (for example, sexual exploitation and forced labour in domestic servitude), as well as the trafficking of pregnant women for the purpose of selling their babies.

Begging is the most commonly reported 'other purpose' of exploitation. Nearly 1,000 victims of trafficking in persons for begging were detected in about 20 countries in different regions between 2012 and 2014, accounting for more than 2 per cent of the total number of detected victims.

In many instances, children are targeted for trafficking for the purpose of begging, as is the case of the Talibe in West Africa or street begging in Europe. Some cases prosecuted by national authorities show that this form of trafficking may also target people with disabilities. In the Republic of Moldova, for example, two persons trafficked an adult with mental health issues from their village to Moscow where the victim was forced to beg on the street under the threat of violence. ${ }^{11}$ In Austria, a man with a physical disability was forced to beg by three fellow citizens in the streets of several Austrian cities for four years. The traffickers threatened that if the victim did not collect between 300-500 euros per day, he would be beaten, isolated and deprived of food. ${ }^{12}$

11 Case provided by the Republic of Moldova, which concluded with a conviction by the Centru District Court in Chisinau. Both traffickers received 8-year prison sentences.

12 Case provided by Austria, which concluded with convictions by a court in Vienna. The sentences ranged from 15 months to 5 years of imprisonment. 


\section{Trafficking in persons for marriage}

The UN Trafficking in Persons Protocol contains a list of the minimum forms of exploitation countries should include in their legal framework. This list "...includes exploiting the prostitution of others, sexual exploitation, forced labour, slavery or similar practices and the removal of organs." Although trafficking for sexual exploitation and forced labour remain the most commonly detected forms of trafficking in many parts of the world, trafficking in persons may be conducted for a variety of other purposes as well.

The data collected by UNODC over time yields a list of exploitative forms reported by the national authorities that reflect the innovative ways traffickers operate, and how jurisprudence is enlarging the applicability of the UN Trafficking in Persons Protocol beyond the minimum forms of exploitation listed in the Protocol. One form is trafficking for marriages, which was reported by 15 countries in many parts of the world during the 2012-2014 period.

Trafficking for forced or sham marriages accounts for about 1.4 per cent of the total number of detected victims. This form of trafficking targets only female victims, and it takes on different permutations, from involved organized irregular immigration and benefit fraud schemes in Europe, to traditional practices ${ }^{\mathrm{a}}$ in Central Asia and the Middle East, to the trade of women for marriages in South-East Asia. Vietnamese and Chinese authorities reported court cases that involved trafficking for marriage from rural areas in the north of Viet Nam to China. ${ }^{\mathrm{b}}$ Cases referred to include that of a Chinese man who engaged Vietnamese persons with local knowledge to find girls for marriages in China at the price of 10,000 yuan (approximately US\$ 1,500) for each girl recruited. The recruiters then moved the victims across the border into Chinese territory where the victims were sold for marriage for the agreed-upon price. Some cases of forced child marriage involve relatives of the victims, like

Trafficking for the commission of illegal activity has also been reported, although it is a difficult form to detect. Cases of children and adults exploited in the cultivation of cannabis, trafficked for shoplifting, for theft and other forms have been reported in countries in Europe and Central Asia, South America and Africa. About 1 per cent of the total number of detected victims in 13 countries were trafficked for the commission of illegal activity.

Examples of these different forms of trafficking can be found in court cases. Two victims from Poland, for example, were trafficked to Sweden using false promises of residency in the destination country and work in the construction sector. Once at destination, the victims were forced to shoplift and subjected to violence and threats. Eventually, the victims managed to escape and return to Poland. ${ }^{13}$ Similarly, in Norway, the authorities reported a

13 Case provided by Poland, which concluded with a conviction by the district court in Szczecin, with prison sentences ranging from 6 months to 1 year. the case of a 14-year-old girl in South Africa. The teenager was forced by her grandmother and uncle to marry a 35-year-old man.

Although many sham marriages do not involve trafficking in persons, ${ }^{\mathrm{d}}$ some do. A different mode of trafficking has surfaced in the form of a large transnational organized crime group that recruited Central European women for sham marriages in Western Europe. In Latvia, an extensive criminal proceeding saw many offenders investigated and several women recognized as victims. Sham marriages were used to give Asian men the possibility of obtaining a residence permit for the European Union. Many of the victims had some form of emotional or behavioural disorder, which contributed to their vulnerability to coercion or fraud. Once they arrived in their destination country, the victims were locked in apartments, raped and abused physically and psychologically to obtain their consent to marriage. After marriage, they were treated as if they were the property of their 'husbands' and the abuse continued.

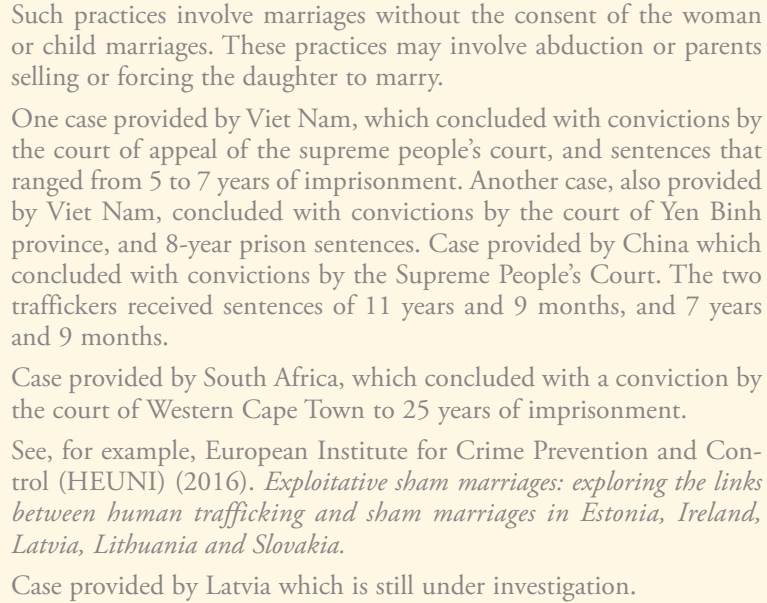

case of two traffickers who recruited victims in Romania to exploit them in Norway by making them steal petrol and beg under constant life threats. One of the traffickers was arrested in an attempt to bring another two victims from Romania to Norway. ${ }^{14}$

Other forms of trafficking detected during the reporting period included trafficking for the purpose of child soldiering, which is mainly detected in conflict and postconflict countries in Sub-Saharan Africa and the Middle East (and discussed further in Chapter 2). Baby selling and illegal adoption - in countries that consider these to be forms of trafficking in persons - have been reported in Europe, Africa, Central and South America, Central Asia and East Asia. Trafficking for the purpose of human sacrifice and removal of body parts has been reported in some countries in Sub-Saharan Africa. Trafficking for the pro-

\footnotetext{
14 Case provided by Norway, which concluded with convictions by the Oslo District Court. The sentences ranged from 10 to 30 months of imprisonment.
} 
duction of pornographic material was reported by a few countries in South-Eastern Europe, South America, the Middle East and Eastern Europe.

Trafficking for mixed exploitation has been reported by a limited number of countries, usually combining forced labour and sexual exploitation. In the Dominican Republic, for example, teenage girls were forced to wait tables in a bar and to have sexual relations with the bar's customers. ${ }^{15}$ A similar case took place in Mexico, where a 17-year-old girl who had left home due to family problems became an easy target for traffickers. She was exploited as a waitress in a bar and was also forced to have sexual relations with clients, while her earnings were withheld by the bar owners. ${ }^{16}$ Another type of mixed exploitation found in the case files was domestic servitude combined with sex slavery. In South Africa, a man asked his female worker to recruit young girls to work for him. The woman recruited three teenage girls from Mozambique, and the man exploited them sexually and for forced labour. ${ }^{17}$

In addition, for about 1 per cent of the victims detected and reported to UNODC during the 2012-2014 period, the form of exploitation could not be established, either because the victim was detected before the exploitation took place or because the form was not recorded. These victims were not considered in the above analysis.

\section{Profile of the traffickers}

\section{Most traffickers are male...}

As for nearly every other crime, most trafficking in persons offenders are male. Roughly 6 in 10 offenders are male across all stages of the criminal justice process. Even so, the significant share of women offenders is remarkable, as there are few crimes with such high levels of female participation. ${ }^{18}$

The broad pattern of more male than female offenders holds true across most regions and subregions as well. While the exact shares vary, nearly every area reports more male offenders. One notable exception is Eastern Europe and Central Asia, where the gender profiles of traffickers (and victims) is the opposite of those seen in other areas. The majority of offenders in that region are women.

\section{FIG. 14 Persons investigated for trafficked in persons, by sex and region, 2014 (or most recent)}

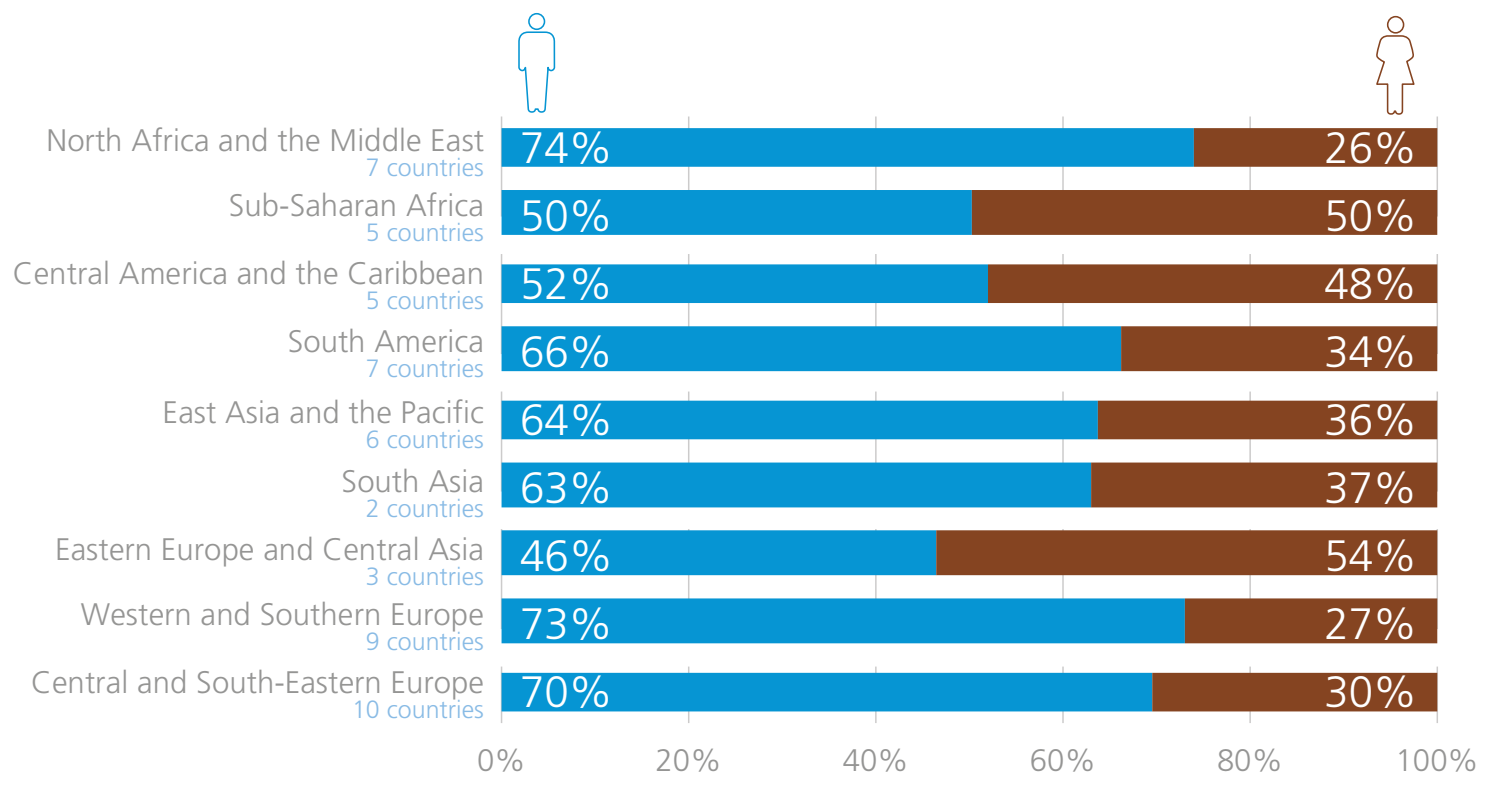

Source: UNODC elaboration of national data.

Case provided by the Dominican Republic, which concluded with convictions by the National Judicial. The two perpetrators were sentenced to 5 and 10 years of imprisonment.

16 Case provided by Mexico, which concluded with convictions by the Judicial district of Queretaro. The perpetrators were sentenced to 15 years and five months of imprisonment.

17 Case provided by South Africa, which concluded with convictions by a court in Mpumalanga. The perpetrators received life sentences.

18 See further discussion on pp. 29-31, UNODC, Global Report on Trafficking in Persons 2012 (United Nations publication, Sales No. E.13.V.1.) 
FIG. 15 Persons prosecuted for trafficked in persons, by sex and region, 2014 (or most recent)

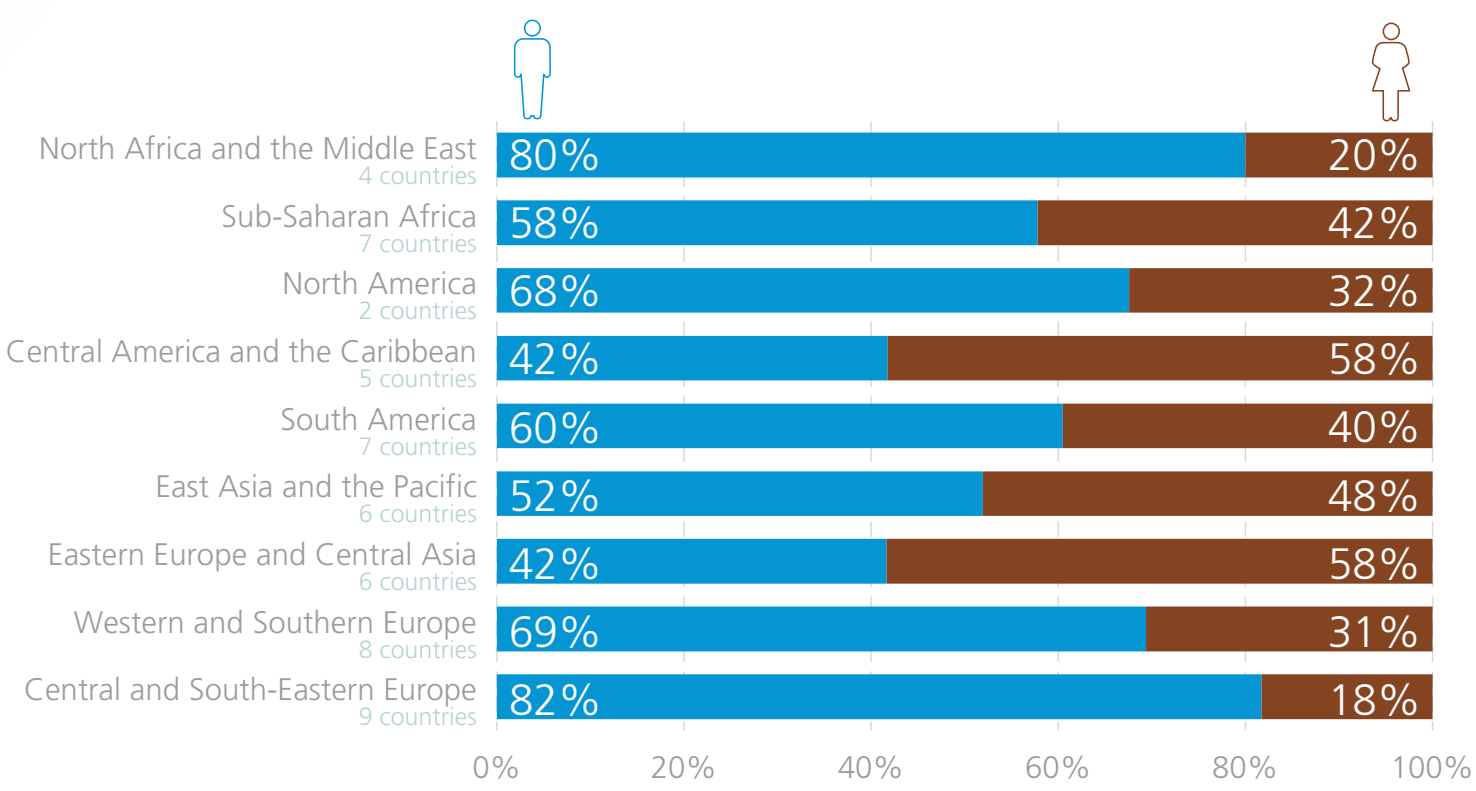

Source: UNODC elaboration of national data.

FIG. 16 Shares of persons convicted of trafficked in persons, by sex, 2014 (or most recent)

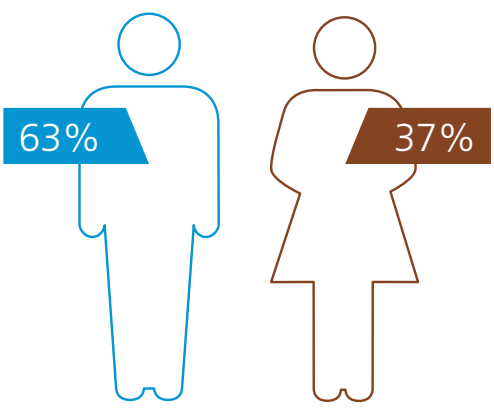

66 COUNTRIES

Source: UNODC elaboration of national data.

Looking at the profiles of persons investigated for trafficking in persons, most countries investigate more men than women. The shares are broadly similar for prosecutions.

Out of the approximately 6,800 persons who were convicted of trafficking in persons during the years 20122014 in the available data, about 60 per cent were male. The gender breakdown by geographical area is similar to that seen for investigations and prosecutions. Central and South-Eastern Europe, Western and Southern Europe, East Asia and the Pacific, and North Africa and the Middle East all convict more than 70 per cent males of trafficking in persons; in Central and South-Eastern Europe, the share is larger than 80 per cent.

\section{...but the share of female offenders is increasing}

Although the majority of offenders are male, the detected female involvement in the crime of trafficking in persons is remarkably high, compared to other crimes. This is true across all stages of the criminal justice process. The share of females involved in trafficking crimes has remained broadly stable at a high level over the past few years, with some variations between investigations, prosecutions and convictions.

The data for investigations, disaggregated by gender, only goes back to 2011. It appears that there has been a slight decrease in the share of women among those investigated for trafficking offences since then. The data for prosecutions, however, which goes back to 2007, shows a steady increase, as does the data for convictions. In 2014, women comprised well over a third of all offenders at all three criminal justice stages. Previous UNODC research on many types of crime in a large number of countries has found that women typically comprise less than 15 per cent of offenders. ${ }^{19}$

Looking more specifically at the role of women in traf-

19 See p. 30, UNODC, Global Report on Trafficking in Persons 2012 (United Nations publication, Sales No. E.13.IV.1). 
FIG. 17 Persons convicted of trafficking in persons, by sex and region, 2014 (or most recent)

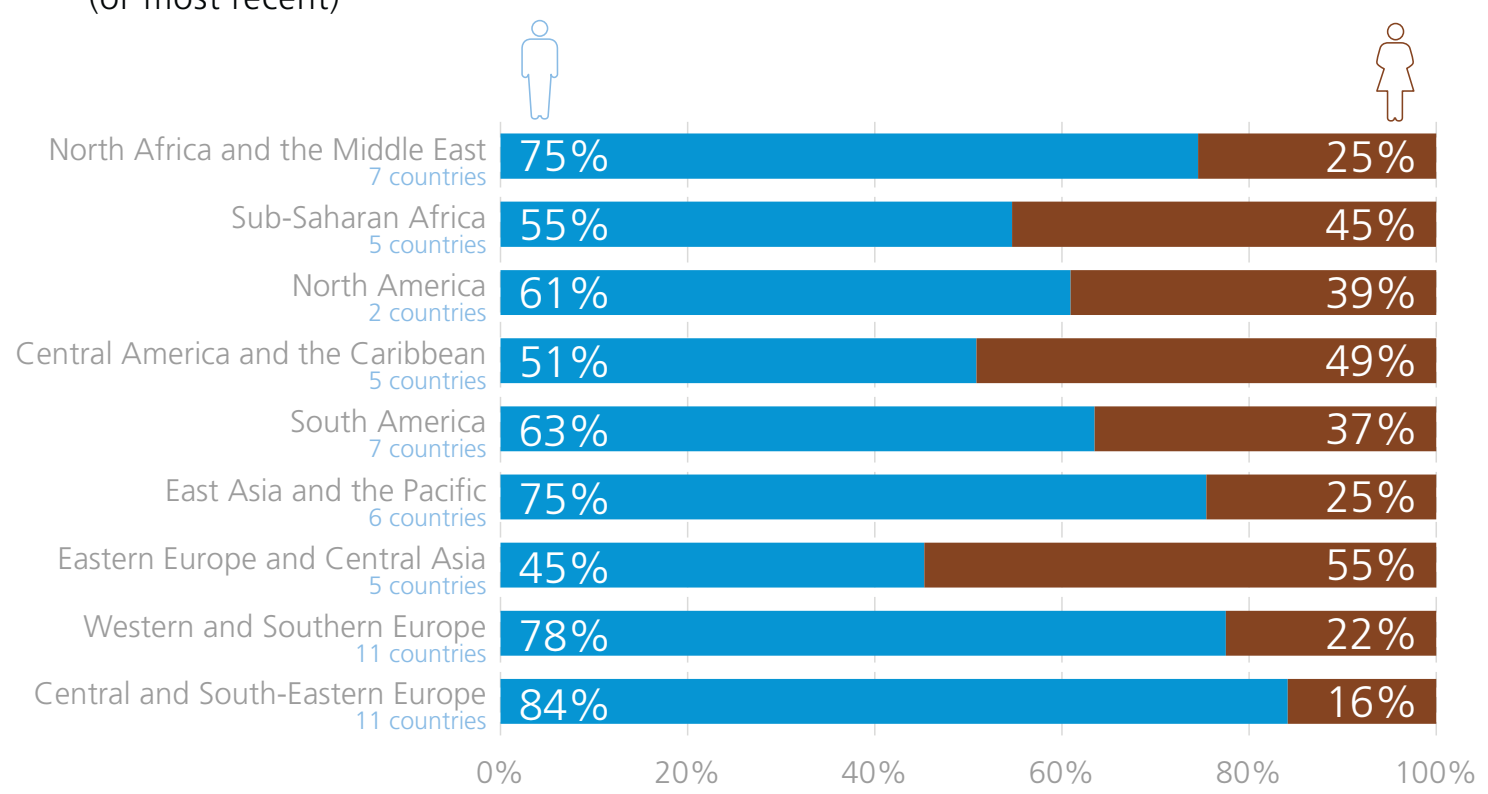

FIG. 18 Trends in the shares of females among persons investigated, prosecuted or convicted of trafficking in persons, 2007-2014

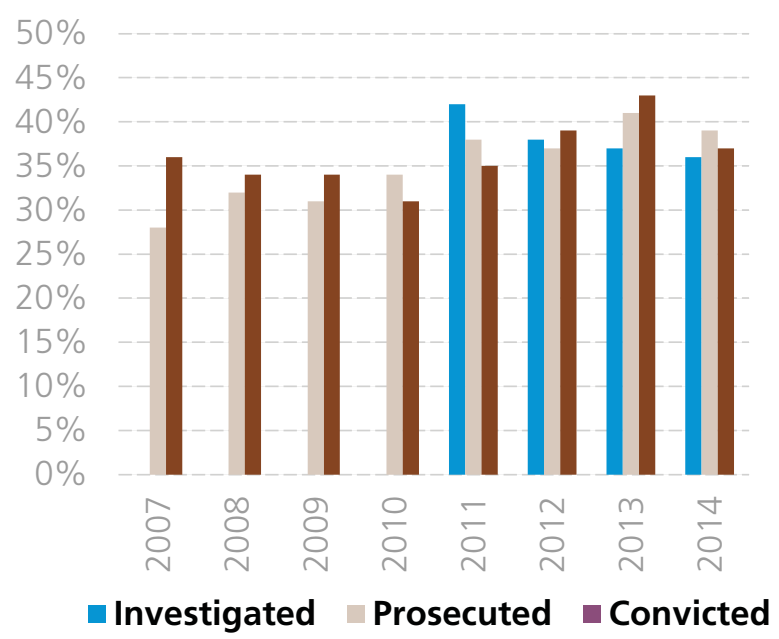

Source: UNODC elaboration of national data.

ficking crimes, a statistical correlation published in the Global Report on Trafficking in Persons 2012 suggested that adult women were more involved in the trafficking of young girls. Moreover, qualitative studies indicate that girl victims are frequently recruited or guarded by older women. ${ }^{20}$ The 2014 Global Report presented a qualitative 20 Ibid. analysis that suggested that women in organized criminal networks participated more in lower-ranking activities the recruitment of victims, in particular - while men tended to engage in organizational or exploitation roles. ${ }^{21}$ Research conducted on trafficking in persons case law indicated that female traffickers were involved in 54 per cent of the 155 cases examined for the study. Women worked either alone or with other women in 21 per cent of the cases, often playing leading roles and trafficking large numbers of other women for sexual exploitation. In the rest of the cases (33 per cent), women worked together with male traffickers. ${ }^{22}$

Women traffickers are more likely to be convicted in countries of origin. While destination countries reported an average 30 per cent share of convicted female traffickers in the period 2012-2014, the corresponding share in origin countries was 44 per cent. ${ }^{23}$

It appears that among traffickers who are not engaged in a criminal organization and who are operating in predominantly domestic trafficking flows, two typologies of operation are common. One of these types is trafficking carried out by couples, either a husband/wife or girlfriend/boy-

\footnotetext{
21 See pp. 27-29, UNODC, Global Report on Trafficking in Persons 2014 (United Nations publication, Sales No. E.14.V.10).

22 The full results of this study will be published as a Research Brief on the UNODC website in early 2017

23 The comparison refers to 49 countries; 19 of origin and 30 of destination. The statistical comparison is significant $(\mathrm{p} .<0.05)$.
} 
FIG. 19 Mean shares of females among convicted trafficking offenders, by countries of origin and destination, 2012-2014

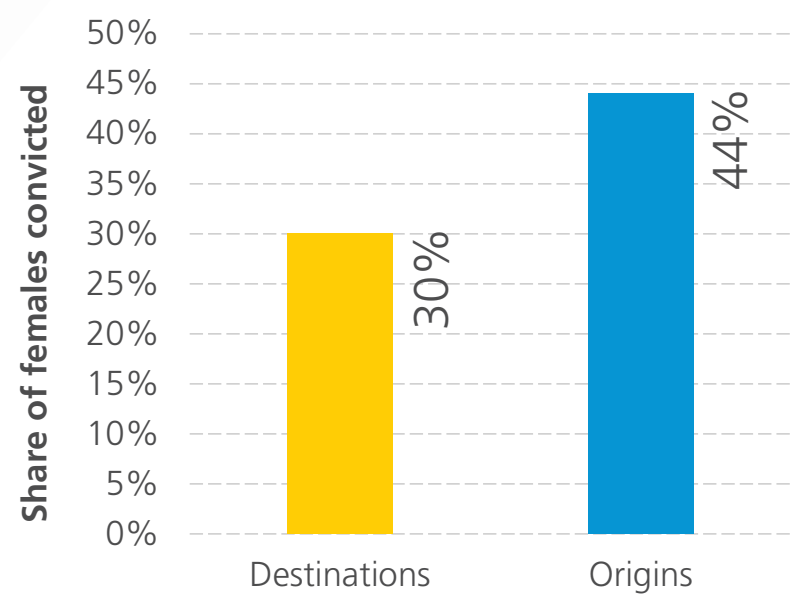

Source: UNODC elaboration of national data.

friend, who recruit and exploit victims together. The other common type sees victims being recruited by family members of both genders. In these cases, male and female offenders are more or less equally represented.

Court cases can shed light on these types of trafficking. For example, in Armenia, a couple convinced two girls to move to the Russian Federation, with the purpose of sexually exploiting them. Both the traffickers and the victims lived in an Armenian city near the Russian border. One of the two victims refused to leave while the other was exploited for two weeks in a Russian village. ${ }^{24}$ Similar cases involved a Romanian couple sexually exploiting a Romanian girl for about six months in Denmark, ${ }^{25}$ and a Tajik couple recruiting girls from Tajikistan to be exploited in the Middle East. ${ }^{26}$ In all these cases, women played a major role in the recruitment of victims. Perhaps the façade of a 'stable couple' is more reassuring for the targeted victims (or their parents) than a single male recruiter.

Another recurring element in cases of convicted female traffickers is the prevalence of former victims becoming perpetrators. Victims of trafficking in persons have been forced to commit criminal activities such as drug trafficking or shoplifting, but trafficking victims may also be

24 Case provided by Armenia, which concluded with a conviction by the tribunal of Shengavit Administrative District. The trafficker received an 11-year prison sentence.

25 Case provided by Denmark, which concluded with convictions by the Copenhagen City Court, with sentences of about two years of imprisonment.

26 Case provided by Tajikistan, which concluded with convictions by the Shohmansur district court (sentence not available). forced to recruit other victims of trafficking in persons. There is evidence that, particularly in the field of trafficking for sexual exploitation, many former victims are at some point offered the opportunity of recruiting new victims or serving as a 'madam. ${ }^{27}$ Victims' motivation to switch to such roles may be to reduce their debt to traffickers or others, or to end their own exploitation.

Traffickers may benefit from this arrangement as well, as they have a new way to reach additional victims. Moreover, once victims are engaged in the enterprise, they become accomplices to the trafficking operation and are then less likely to cooperate with law enforcement. ${ }^{28}$ For example, in Argentina, a structured criminal group trafficked many women and girls for sexual exploitation from the Dominican Republic. The group used Dominican women who were previously exploited for years in Argentina to recruit other victims back home. The recruiters used deception regarding the working activities to gain the victims' consent. In this case, the court recognized that the recruiters were previous victims of trafficking who were subsequently used by the criminal group to recruit other women. ${ }^{29}$

This is not to suggest that women convicted of trafficking in persons were all victims at some point, or that women are only represented in low-level positions within large, complex trafficking rings. In fact, court cases have also shown that some large trafficking rings are female-led. In one case, three women recruited girls from the Russian Federation to be sold to other traffickers operating in the Middle East. ${ }^{30}$ In another, a more transnational organized criminal group was led by a Russian woman. The group was divided into two branches; the first was in charge of recruiting and transporting girls, whereas the second was in charge of exploiting them. The group was very well structured and involved at least nine members in addition to the leader. At least 13 victims were trafficked for the purpose of sexual exploitation by this group. ${ }^{31}$ In a third case from the Russian Federation, another well organized

27 Lo Iacono, E. (2014). 'Victims, Sex Workers and Perpetrators: Grey Areas in the Trafficking of Nigerian Women', Trends in Organized Crime, 17:110. "Madams" are generally older women who manage the exploitation phase of trafficking for sexual exploitaiton.

28 Ibid.

29 Case provided by Argentina, which concluded with a conviction by the federal tribunal of Mar de la Plata. The tribunal gave a lighter sentence to the female recruiter to avoid re-victimization.

30 Case provided by the Russian Federation, which concluded with convictions by the Lenin District Court of Astrakhan. The sentences ranged from 8 to 12 years of imprisonment.

31 Case provided by the Russian Federation, which concluded with convictions by the court of Pyatigorsk. The sentences ranged from 4 to 11 years of imprisonment. 
transnational group of five people - led by a woman exploited at least 25 women and two girls. ${ }^{32}$

In other cases involving female-led trafficking rings, the groups were more improvised, but nonetheless managed to traffic many victims. In Azerbaijan, for example, two sisters were convicted of organizing a criminal network that trafficked at least nine women into other countries. ${ }^{33}$ Similarly, in Canada, a group of three underage girls beat, drugged and forced other girls into sexual exploitation. Seven Canadian girls were identified as victims. ${ }^{34}$

\section{Trafficking in persons largely involves national traffickers}

In the countries for which data was available, on average, about three quarters of the convicted offenders were citizens of the country in which they were convicted during the 2012-2014 period. The remaining offenders - foreigners in the country of conviction - were near-equally split between citizens of countries within and outside the region where they were convicted.

\section{FIG. 20 Shares of national and foreign citizens among convicted traffickers (relative to the country of conviction), 2014 (or most recent)}

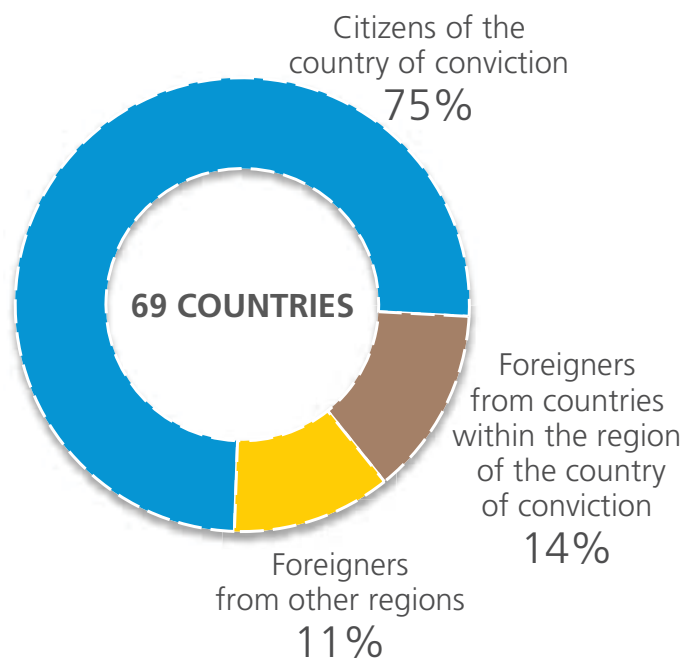

Source: UNODC elaboration of national data.

Case provided by the Russian Federation, which concluded with convictions by the court of Samara. The sentences ranged from 4 to 11 years of imprisonment.

33 Case provided by Azerbaijan, which concluded with convictions by the court of Baku. The traffickers received 8-year prison sentences.

34 Case provided by Canada, which concluded with convictions by the Ontario Court of Justice. The group leader was sentenced to 6.5 years of imprisonment.
FIG. 21 Shares of traffickers convicted in their country of citizenship, by region, 2014 (or most recent)

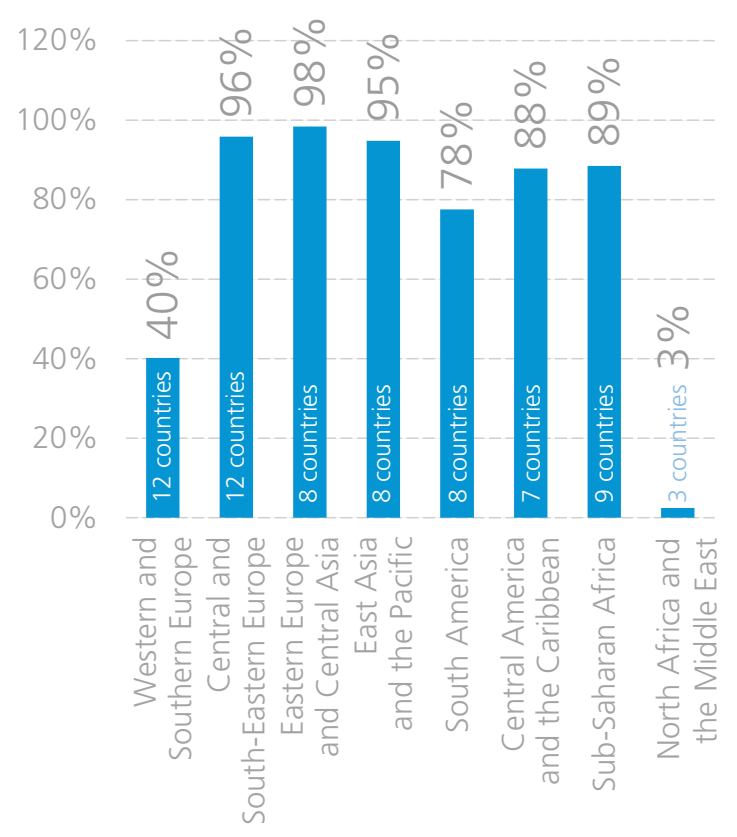

Source: UNODC elaboration of national data

The regional aggregations reflect the global average, with two exceptions. In Western and Southern Europe, foreign citizens accounted for 60 per cent of the convicted offenders, and in the Middle East, nearly all the persons convicted of trafficking in persons were foreigners.

The distinction between countries of origin and destination of cross-border trafficking has a bearing on the gender profile of convicted traffickers. The same is true - and even more so - for the citizenships of offenders. Nearly all (97 per cent) convicted traffickers in countries of origin of cross-border trafficking are citizens of the convicting country. In countries of destination, however, convicted traffickers are both own citizens and foreigners, more or less equally distributed.

Moreover, a closer look at the citizenships of foreigners convicted of trafficking in persons in destination countries reveals a general pattern. The citizenships of these offenders broadly mirror the citizenships of the victims detected there, as presented in the 2014 Global Report. ${ }^{35}$ In other words, the nationality profiles of offenders are closely connected to the profiles of the victims they traffic. Sharing a

35 See page 46, UNODC, Global Report on Trafficking in Persons 2014 (United Nations publication, Sales No. E.14.V.10). 
FIG. 22 Shares of national and foreign citizens (relative to the convicting country) among convicted traffickers, by countries of origin and destination, 2014 (or most recent)

\begin{tabular}{r|r|r|}
$\begin{array}{r}\text { Countries of } \\
\text { destination } \\
29 \text { countries }\end{array}$ & $46 \%$ & $54 \%$ \\
$\begin{array}{r}\text { Countries } \\
\text { of origin } \\
40 \text { countries }\end{array}$ & $97 \%$ & $3 \%$ \\
& $0 \%$ \\
& National offenders \\
& Foreign offenders
\end{tabular}

Source: UNODC elaboration of national data.

culture and/or language background could lead victims to more readily trust citizens of their own country when discussing 'opportunities' abroad. This might be particularly pronounced in the case of women recruiting other women.

An Australian court case illustrates the ways that this trust, and the fear associated with an irregular move to another country, are used by traffickers. In this case, a Thai girl was coerced into exploitation by a Thai woman who had promised the girl a better future in Australia. Once there, the girl was sexually exploited under the threat of being reported to the authorities as an irregular migrant and deported back to Thailand. ${ }^{36} \mathrm{~A}$ large number of cases of this sort have been reported by various national authorities, often involving victims that are not willing or ready to cooperate in the criminal justice process because they still trust their co-national traffickers, while at the same time fearing the authorities.

Cases have also been reported where victims have been recruited in their own country by foreigners, even if such cases are relatively rare. In Argentina, two cases involved Argentine citizens crossing the border into Paraguay to recruit young women for sexual exploitation in Argentina.

36 Case provided by Australia, which concluded with a conviction by the Supreme Court of the Australian Capital Territory. The sentence was 6 years and 10 months of imprisonment.
At least 4 victims were identified. ${ }^{37}$ In Portugal, a Portuguese national trafficked Brazilian women into sexual exploitation there. The victims were lured into a debt bondage scheme connected with the 'migration fee' the victims had to pay for the travel from Brazil to Portugal, plus additional costs, as is normal practice in this criminal modus operandi..$^{38}$ In all these cases, traffickers and victims shared a common language, which is an element that may serve to link the persons involved in the crime - offenders and victims - even if their citizenships differ.

Similarly, in many cases, ethno-linguistic or nationality ties can be found within the trafficking scheme. For example, in one case, two ethnic Albanian girls (one from Albania and one from Kosovo) were recruited by ethnic Albanians with Macedonian citizenship to work in a bar in the former Yugoslav Republic of Macedonia in mixed labour and sexual exploitation. ${ }^{39}$ Another case saw German citizens with a specific Russian-Kazakh background ${ }^{40}$ operating a trafficking ring to bring members of this Russianspeaking community to Belgium to be exploited in forced labour. The victims were made to clean restroom facilities on the highway for 15 hours a day, 7 days a week, for less than 3 euro per hour. These traffickers leveraged their German citizenships to easily obtain European Union work permits, and their Russian-speaking legacy to isolate and control the victims. ${ }^{41}$ Another case, from Belgium, involved victims and traffickers of the Roma ethnic group. The traffickers recruited girls by feigning a relationship and then exploiting them in prostitution. The group members were all related, and trafficked at least 40 victims in different European countries. ${ }^{42}$

In other cases, traffickers who are second or third generation migrants may exploit victims from the origin country of the parents or grandparents. In some cases, they are also assisted by members of the family who still live in that country.

37 Two cases provided by Argentina. One concluded with a conviction by the court N2 of La Plata, and the other, with a conviction by the Camera Federal de Casacion - Sala II. The sentences were not avail able.

38 Case provided by Portugal, which concluded with convictions by the court of Vila Nova de Famalicáo. The sentences ranged from 1 to 12 years of imprisonment.

39 Case provided by the former Yugoslav Republic of Macedonia, which concluded with convictions by the Basic Court of Skopje. The sentences ranged from 1 to 10 years of imprisonment.

40 Both victims and traffickers belonged to a community descended from Germans who moved to Kazakhstan in the $17^{\text {th }}$ century, and who acquired the right to German citizenship after World War II.

41 Case provided by Belgium, which concluded with a conviction by the court of Ghent (sentence not available).

42 Case provided by Belgium, which concluded with a conviction by the court of Ghent (sentence not available) 


\section{The use of detected cases of trafficking in persons to draw patterns and flows}

Crime statistics based on reported or detected cases have a limited use in research on crime. Not all crimes committed are discovered or identified. In some instances, the victim is not aware of being victimized, and would not report the crime to the authorities. If discovered, not all crimes are reported, and not all the crimes reported to the competent authorities are recorded. For these reasons, the number of arrests, convictions and victims are all inadequate in estimating the amount of crime in a society. ${ }^{a}$

The use of administrative crime statistics to conduct time or country comparisons normally reflects differences in the abilities of criminal justice systems to detect crime, differences in definitions for specific crimes in different countries and differences in socio-economic and political contexts. ${ }^{\text {b }}$

As a consequence, the use of statistics on detected cases to conduct research on trafficking in persons has some limitations. Conducting alternative data gathering, such as victimization, perception or other surveys could overcome these limitations as they are designed to also measure the crime which doesn't come to the attention of the authorities. These sources are successfully used to analyse a variety of crime, but unfortunately they are still not sufficiently developed to globally analyse trafficking in persons.

Summing up, there is often a link - or links - between the trafficker and the victim. This link may be family or affective ties, a shared gender, a common citizenship, the same hometown or village, a common language, culture or ethnic group, or a combination of these.

\section{GLOBAL OVERVIEW: TRAFFICKING FLOWS}

This chapter is based on information regarding some 34,000 victims of trafficking in persons detected between 2012 and 2014 whose citizenship was reported by the countries covered in this edition. Information has also been drawn from the profiles of about 12,500 victims who were repatriated ${ }^{43}$ during the reporting period. These two data subsets were collected and organized separately, and the analyses will also be presented separately below as they may overlap to an unknown extent. In other words, some victims detected in destination countries may be recorded again in repatriation data produced by origin countries. Aggregating these two indicators could lead to an infla-

43 "Repatriation" refers to the official return of victims of trafficking in persons from their country of detection to their country of citizenship. See the methodological section for more information about the use of repatriation data in this edition of the Global Report.
Considering these limitations, the Global Report does not use these data to estimate the size of the phenomenon, nor to conduct cross-country comparisons in terms of the severity of trafficking. When the level of conviction rates is measured for example, it is with a view to assess the capacity of countries to detect cases of trafficking and not to assess the magnitude of the trafficking problem.

Administrative data is used to analyse the characteristics of the victims and the offenders recorded by national institution in order to draw conclusions on the profile of the victims - their age, sex and citizenship - as well the profile of the offenders and the forms of trafficking recorded. Triangulating this data with other information, such as analysis of court cases, reviews of the existing literature and field research work, provides a realistic description of the current trafficking situation.

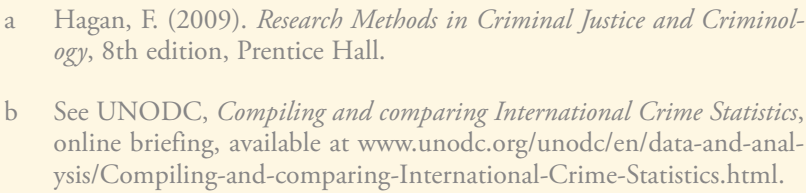

b See UNODC, Compiling and comparing International Crime Statistics, online briefing, available at www.unodc.org/unodc/en/data-and-analysis/Compiling-and-comparing-International-Crime-Statistics.html.

tion of some trafficking flows, as well as a reduction of the share of domestic trafficking. However, if analysed separately, the data is valuable as it can help fill some information gaps regarding trafficking flows to countries of destination from which UNODC has not received data during the reporting period.

Overall, the analysis of trafficking flows at local and transnational levels shows a high level of complexity. Western and Southern Europe, as well as the rich countries of the Middle East and North America, are key destination areas for transregional trafficking. In terms of main points of origin, flows from Sub-Saharan Africa and East Asia are more globally dispersed than other, significant trafficking flows (such as those from Eastern Europe and Central Asia, South America and South Asia). Most trafficking flows, however, are not of a global dimension, and trafficking in persons remains largely a regional and local phenomenon.

Around the world, victims with about 160 different citizenships have been detected in or repatriated from some 140 different countries. This data represents only the tip of the iceberg: the share of trafficking in persons cases that have been detected by national authorities and reported to UNODC. A total of more than 570 different traffick- 


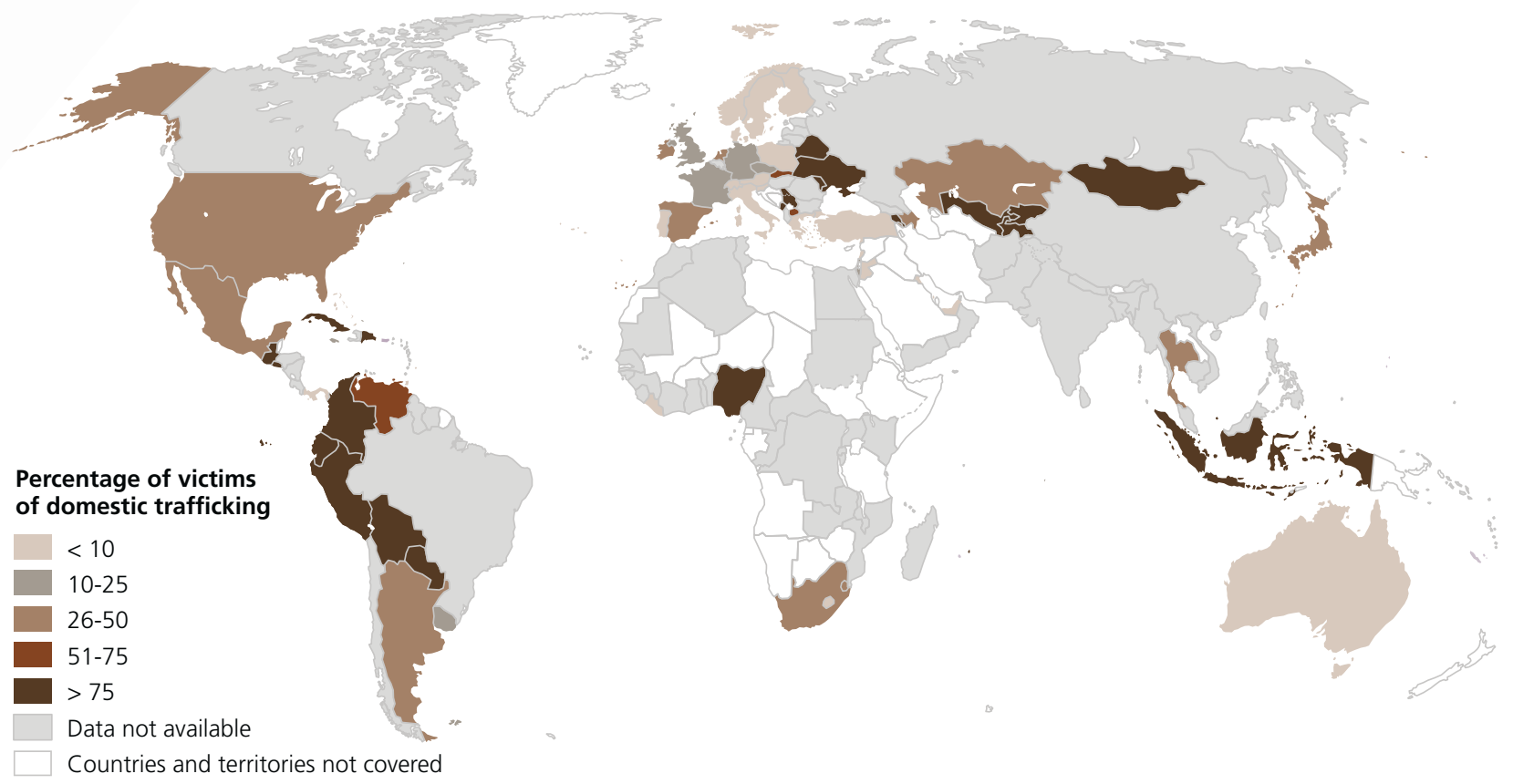

Source: UNODC.

The boundaries and names shown and the designations used on this map do not imply official endorsement or acceptance by the United Nations. Dashed lines represent undetermined boundaries. The dotted line represents approximately the Line of Control in Jammu and Kashmir agreed upon by India and Pakistan. The final status of Jammu and Kashmir has not yet been agreed upon by the parties. The final boundary between the Sudan and South Sudan has not yet been determined. A dispute exists between the Governments of Argentina and the United Kingdom of Great Britain and Northern Ireland concerning sovereignty over the Falkland Islands (Malvinas).

ing flows ${ }^{44}$ could be discerned from this data. This is a marked increase from previous editions of the Global Report, where 460 flows were detected for the period 2007-2010, and 510 for the period 2010-2012. As for all the analyses, these figures are based on detected flows only, and do not give an exhaustive picture of all trafficking flows. The more countries collect and share data on trafficking in persons, the more flows emerge.

\section{Trafficking flows at destination: where victims are exploited}

Categorizing certain countries as either origin or destination countries for trafficking in persons implies that these are two discrete categories, while in reality, this is not so. Many countries are both origins and destinations, and some countries are severely affected by both inflows and outflows of trafficking in persons. ${ }^{45}$ However, most countries tend to be either predominantly an origin or predominantly a destination of trafficking victims, and the

44 'Trafficking flow' here means one origin country and one destination country with at least five detected victims during the 2012-2014 period. This also includes domestic trafficking where the country of origin and destination is the same.

45 For more information, see the text box 'Origin or destination country?' in UNODC, Global Report on Trafficking in Persons 2014 (United Nations publication, Sales No. E.14.V.10), p. 25. subsequent analysis employs these broad classes. The available data is insufficient to delineate trafficking routes.

Data from the 2012-2014 period shows that a clear majority of victims - 57 per cent - are trafficked transnationally; that is, across at least one international border. The remaining victims are trafficked domestically; within national borders. Compared with previous Global Report editions, this represents an increase in detected domestic trafficking (from 34 per cent in 2010-2012 to 43 per cent in 2014). However, these results are most likely due to more detailed data provided by some national authorities, rather than a changing pattern.

When discussing domestic trafficking, it is important to keep in mind that the UN Trafficking in Persons Protocol does not specifically require any movement of victims in its definition of the trafficking crime. Therefore, a person does not need to cross an international border; on the contrary, victims may be exploited in their home community and still be considered victims of trafficking in persons. That said, many cases of domestic trafficking involve victims who have been moved from poorer areas of the country to richer areas, from rural zones to cities or tourist centres, or from villages to industrial or economic hubs. 
Some of the court cases submitted by national authorities can shed light on some forms of domestic trafficking. In Romania, 11 offenders trafficked several girls into sexual exploitation during the period from 2009 to 2012. The victims were recruited in rural areas and transported to the capital city of Bucharest. Once there, the girls were forced into sexual exploitation in different hotels and residences. ${ }^{46}$ In the Dominican Republic, teenage girls were recruited in the poorer suburbs of a large city. The victims were then transferred a few hundred kilometres south to affluent tourist areas along the coast where they were forced into mixed labour and sexual exploitation in bars. ${ }^{47}$ In Mexico, a mother transferred her daughter every weekend from their house inland to a well-known tourist location a few hours away. There, the mother forced her daughter to engage in prostitution. ${ }^{48}$

There are also cases in which the recruitment and exploitation take place in the same location. For instance, victims may be recruited in a suburb to be exploited for street begging in the same city, or girls may be recruited in school for prostitution just around the corner. While the UN Trafficking in Persons Protocol does not require movement to define a trafficking case, it does require a process: an act, a means and a purpose. As the cases show, most traffickers leverage an element of vulnerability to attract victims. This is often the socio-economic condition victims live in and their hope for a better situation. Most of the time, the better opportunities happen to be located somewhere other than the victims' home; either in the same country, or more often, abroad.

The second most commonly reported type of trafficking flow during the reporting period concerned victims trafficked from countries within the same geographical region. Examples of such flows involve victims trafficked from South-Eastern Europe to Western Europe (both are areas within the region of Western and Central Europe), from the Andean countries to the Southern Cone in South America, from the Mekong area to the Pacific, or victims trafficked across a single international border into neighbouring countries. About 36 per cent of the detected victims were trafficked from an origin country within the same geographical region as their destination.

Whether a trafficking flow occurs within a region or

\footnotetext{
46 Case provided by Romania, which concluded with a conviction by the court of Bucharest (sentence not available).

47 Case provided by the Dominican Republic, which concluded with convictions by the court of Santiago de los Caballeros. Two of the traffickers received 15-year prison sentences, and a third, 2 years.

48 Case provided by Mexico, which concluded with a conviction by the court of Tabares. The sentence was 8 years of imprisonment.
}

FIG. 23 Breakdown of detected trafficking flows, by geographical reach, 2014 (or most recent)

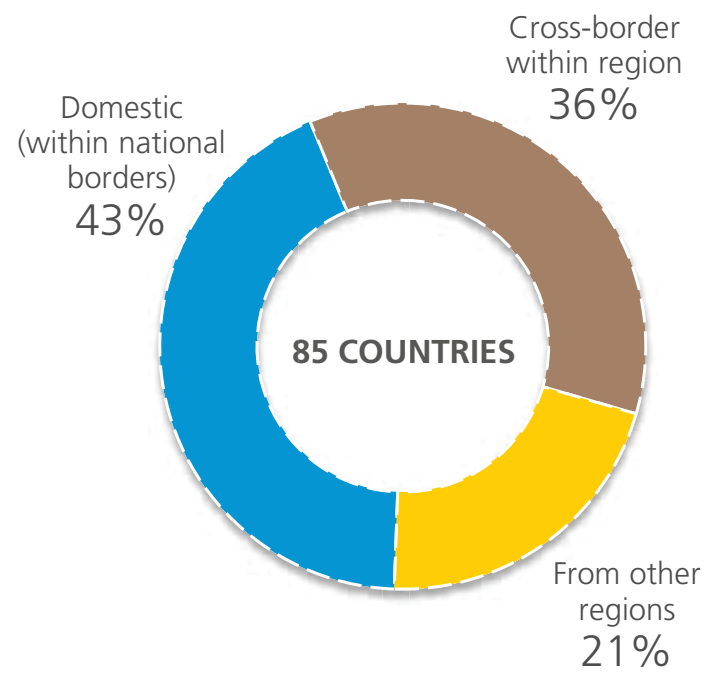

Source: UNODC elaboration of national data.

between different regions does not provide a clear indication of the geographical length of such flows or the distance between the origin and the destination. The regional aggregations used in the Global Report vary in terms of dimensions and distances, so that some transregional trafficking flows, for instance from South Asia to the countries of the Gulf Cooperation Council in the Middle East, or from Colombia to Central America, or from Ukraine to Poland, are in fact very short. On the contrary, trafficking of victims from, say, West Africa to South Africa, would be counted as a regional trafficking flow, even though the geographical distance is vast.

The subsequent analysis was carried out by considering the distance in kilometres between a victim's reported country of origin and destination. The closest border between the two countries was used as a basis for the calculation, because precise origin location data for victims is not available. This means that the figures should be considered as minimum distances. Moreover, the analysis is only indicative, of course, as domestic trafficking flows also occur across vast distances within geographically large countries. In addition, cross-border trafficking may also take place between countries that share a border, but the actual trafficking flow started and ended in locations far from this shared border. This analysis would also not capture such distances.

The analysis of the distance between countries of origin and destination confirms that most trafficking is of a local 
FIG. 24 Shares of detected trafficking flows by geographical distance, ${ }^{*} 2014$ (or most recent)

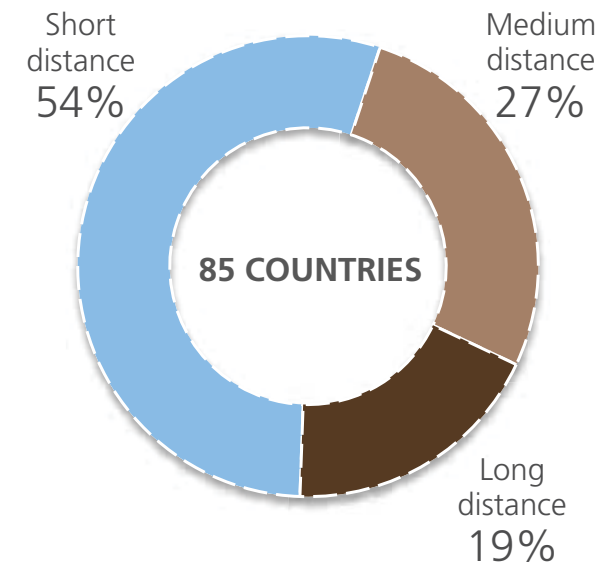

* Three categories of trafficking flows were considered: short-distance trafficking flows with victims trafficked within national borders or between neighbouring countries; medium-distance flows between two countries that do not share a border and with the border of the origin country less than 3,500 kilometres away from the closest border of the destination country; and long-distance flows in which the border of the origin country is farther than 3,500 kilometres away from the closest border of the destination country.

Source: UNODC elaboration of national data.

nature. More than half of the victims detected considered for this analysis were trafficked along short-distance trafficking flows. These include victims trafficked domestically ( 43 per cent) or from a neighbouring country (11 per cent).

With regard to medium-range trafficking flows - comprising more than a quarter of all victims trafficked cross- border - 10 per cent of victims were trafficked from a country in which the distance from the closest border to the border of the destination country was below 1,000 kilometres. For the remaining 17 per cent of the victims trafficked along medium-distance flows, the distance between origin and destination was between 1,000 and 3,500 kilometres.

Long-distance trafficking - flows of 3,500 kilometres and above - accounts for nearly 1 in 5 victims of cross-border trafficking. A significant 5 per cent of trafficking flows are very long distance, with more than 7,000 kilometres between the two countries involved. The more affluent areas of the world generally attract victims from more distant origins. The Middle East (especially the affluent Gulf Cooperation Council countries), as well as most countries in Western and Southern Europe and North America, report relatively large shares of long-distance trafficking.

More than half of the victims detected in the Middle East are trafficked in long-distance trafficking flows, 3,500 kilometres and above, and about 30 per cent of the victims detected there were trafficked medium-distance. Combining the analysis of the distance of trafficking flows with that of the subregional and transregional flows shows that the Middle East not only attracts victims from different regions (South Asia, East Asia and East Africa), but also from distant locations within the region. This is the case, for instance, for North African victims trafficked to the Gulf Cooperation Council countries.

Data on country-level gross domestic product (GDP) confirms that the richer the country of destination, the larger

\section{FIG. 25 Geographical distance of trafficking flows, by region, 2014 (or most recent)}

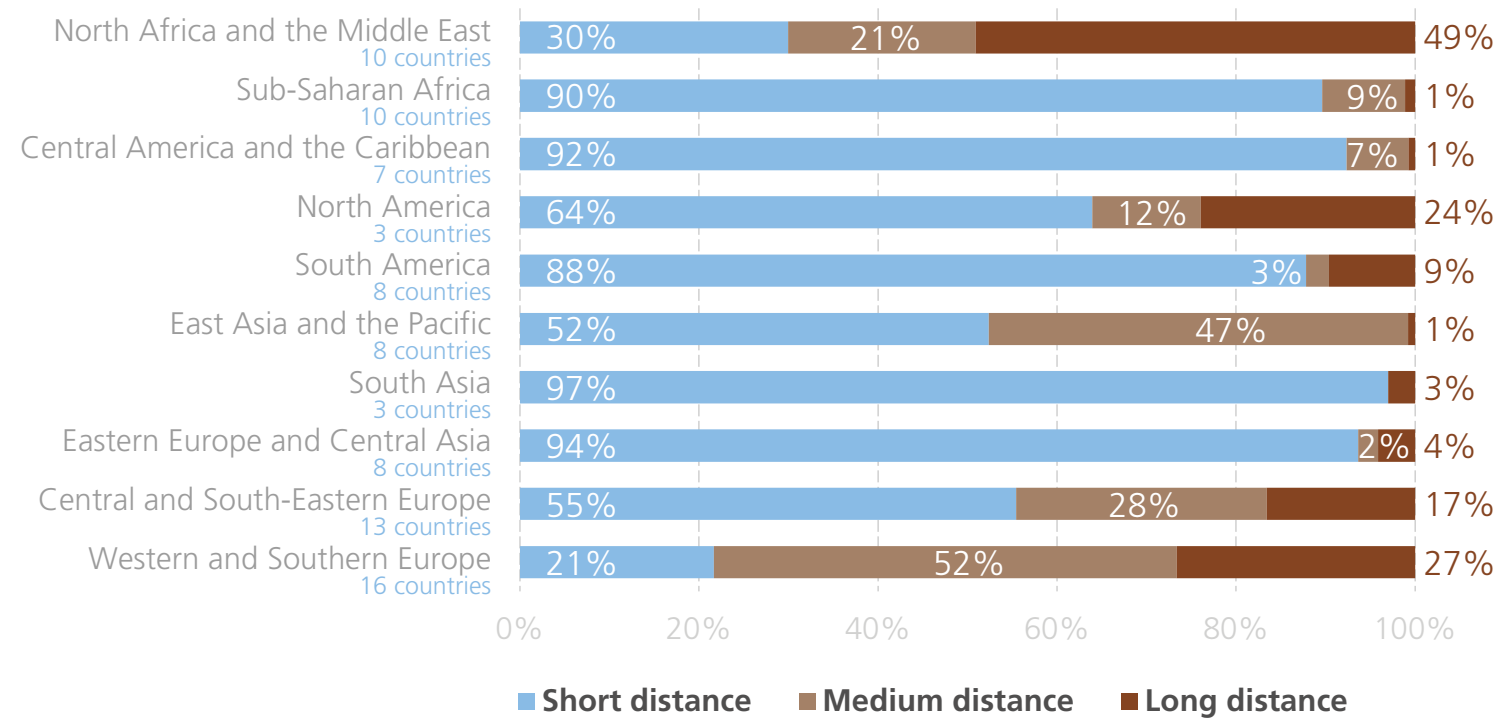

Source: UNODC elaboration of national data. 
MAP 2 Shares of detected victims by subregional and transregional trafficking, 2014 (or most recent)

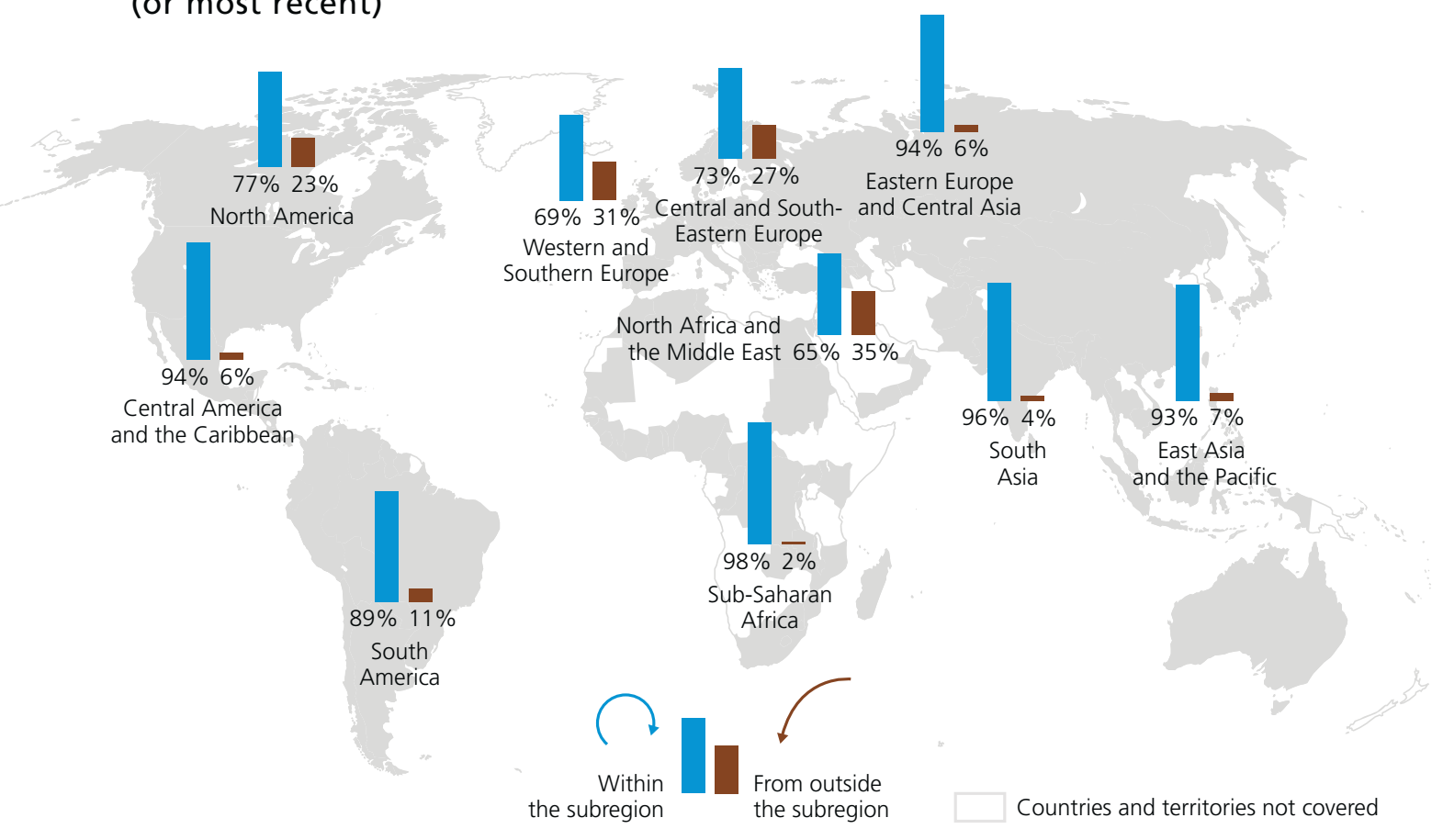

Source: UNODC elaboration of national data.

Note: The boundaries and names shown and the designations used on this map do not imply official endorsement or acceptance by the United Nations.

the share of detected victims from distant origins. These results echo a statistical correlation presented in the 2014 edition of the Global Report that linked the economic wealth of destination countries with the magnitude of detected transregional trafficking. ${ }^{49}$

During the 2012-2014 period, more than 137 different citizenships were recorded among the victims detected in Western and Southern Europe, making this the destination region with victims trafficked from the widest range of origins. Victims with many different citizenships - in particular, from Europe and Africa - were detected in this part of the world. Victims from Central and South-Eastern Europe accounted for the vast majority ( 47 per cent), with Sub-Saharan Africans (16 per cent) and East Asians (7 per cent) comprising the most significant transregional trafficking flows.

Similarly, the three North American countries detected victims from more than 90 countries of origin. They reported a particularly wide range of citizenships from Asia and the Americas. The most prominent transregional trafficking flow originated in East Asia, as 16 per cent of the detected victims in North America are citizens of East Asian countries.

49 See p. 49, UNODC, Global Report on Trafficking in Persons 2014 (United Nations publication, Sales No. E.14.V.10).
FIG. 26 Correlation between the shares of victims trafficked more than $3,500 \mathrm{~km}$ and GDP per capita of the destination country, * 2014 (or most recent)

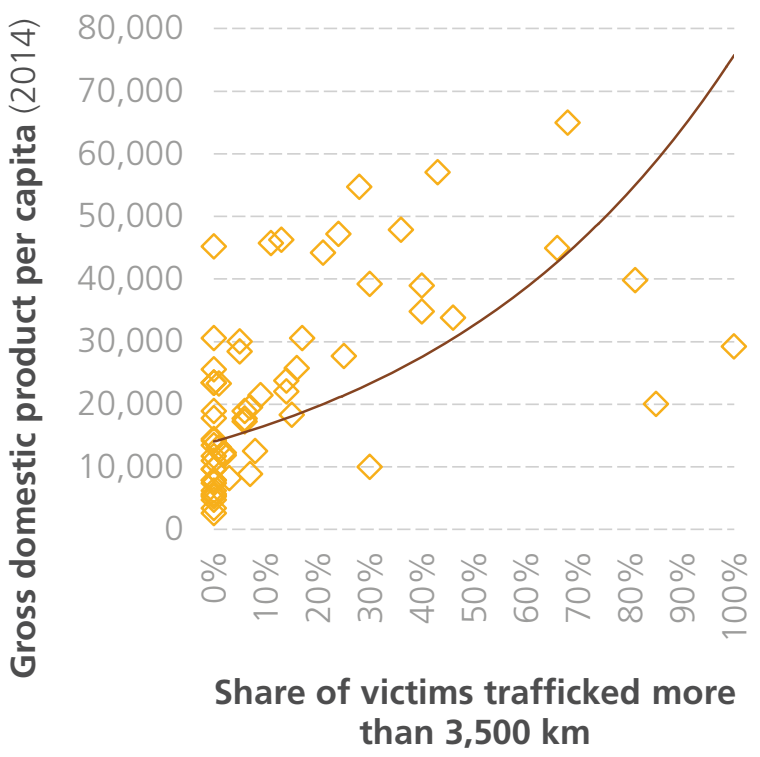

* The correlation between the share of victims trafficked more than $3,500 \mathrm{~km}$ in 2014 (or most recent) and gross domestic product per capita was measured by a correlation coefficient of 0.515 (sig 000, N 73).

Source: UNODC elaboration of national data/World Bank. 
FIG. 27 Number of citizenships among victims detected in destination countries, by region of destination, 2012-2014

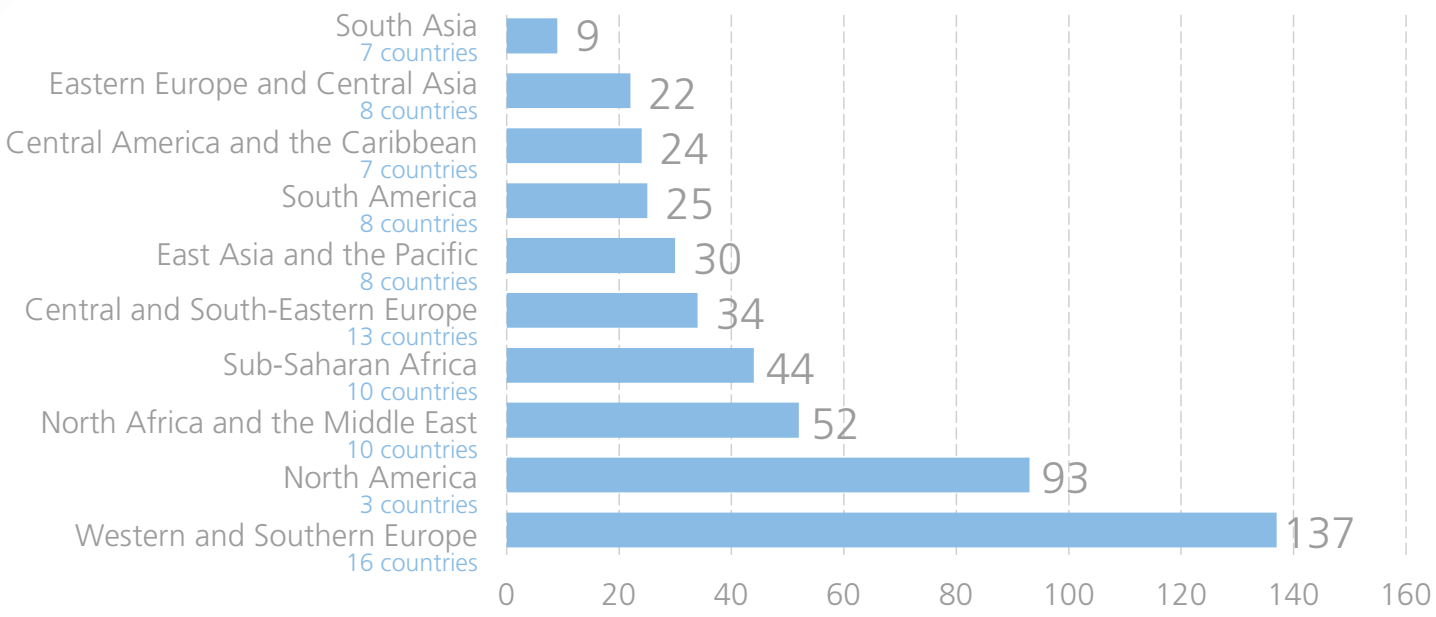

Source: UNODC elaboration of national data.

Number of citizenships detected

MAP 3 Main destinations of transregional flows and their significant origins, 2012-2014

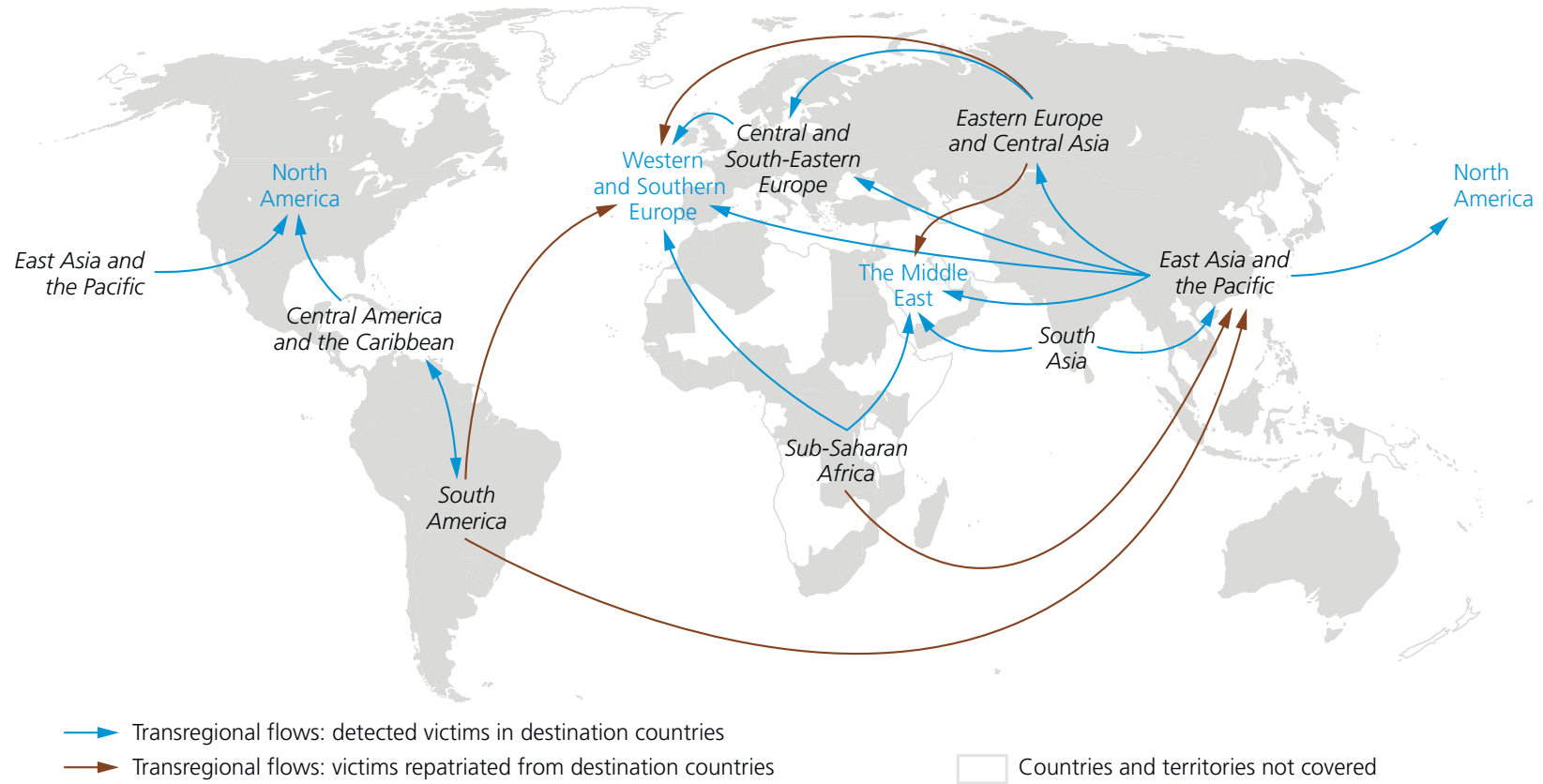

Source: UNODC.

The boundaries and names shown and the designations used on this map do not imply official endorsement or acceptance by the United Nations.

\section{Trafficking flows from origin to destination}

For the reporting period of 2012-2014, 47 countries reported about 12,550 own citizens who had been trafficked abroad and then repatriated. These countries are, of course, countries of origin reporting about the trafficking destinations of their own citizens. The significance of this data comes from the fact that it can help uncover flows not reported by destination countries. Repatriation data only refers to cross-border trafficking in persons, and domestic trafficking is not considered for the analysis below. This is the first edition of the Global Report to provide a separate analysis based on repatriation data.

What emerges from this additional data by and large confirms what existing data concerning destination countries has also shown; namely, that most of the detected trafficking is local. About 77 per cent of the victims who were repatriated during the reporting period were trafficked to 
FIG. 28 Shares of victims of trafficking repatriated to their own country, by destination, 2012-2014

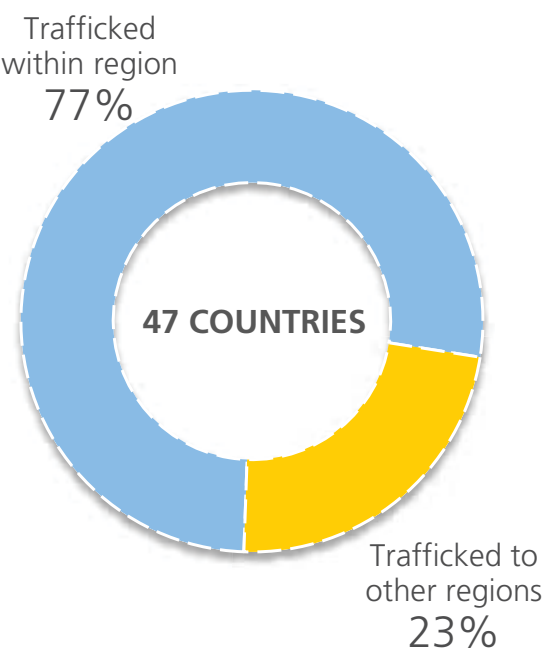

Source: UNODC elaboration of national data.

countries within the same region. The remaining 23 per cent were trafficked to other regions, and Western and Southern Europe and the Middle East are the most prominent destination areas. Out of the victims trafficked outside their region, victims from Europe, South America and West Africa are generally trafficked to Western and Southern Europe, while victims from Asia and East Africa are generally trafficked to the Middle East.
The situation becomes more intricate when looking in detail at the different areas of origin. Most victims repatriated back to Central and South-Eastern Europe were trafficked to Western and Southern Europe (85 per cent), and nearly all the others were trafficked to Eastern Europe. With regard to victims repatriated to Eastern Europe and Central Asia, the vast majority were trafficked to the rich countries within that region. About 10 per cent were trafficked to countries in Western and Central Europe, and another 5 per cent to other regions, in particular the Middle East.

A relatively large share of victims repatriated to countries in East Asia were trafficked to other regions; in particular, the Middle East. About 30 per cent of the repatriated East Asians were trafficked to that area. Many Sub-Saharan Africans were also repatriated from countries in the Middle East; some 41 per cent.

Victims repatriated to areas within the Americas were largely trafficked within the Americas. Although victims from countries in Central and South America were detected in many other regions, these flows were generally relatively small; below 10 per cent of the total number of repatriated victims from those two areas.

The repatriation data also captures trafficking flows missed by the data on victims detected at destination. For instance, Eastern Europe is not only a destination for trafficking within the region, but also for victims from Central and South-Eastern Europe. Moreover, the data regarding trafficking flows into East Asia shows that some

FIG. 29 Victims of trafficking repatriated to their own countries, by victims' region of origin and trafficking destination, 2012-2014

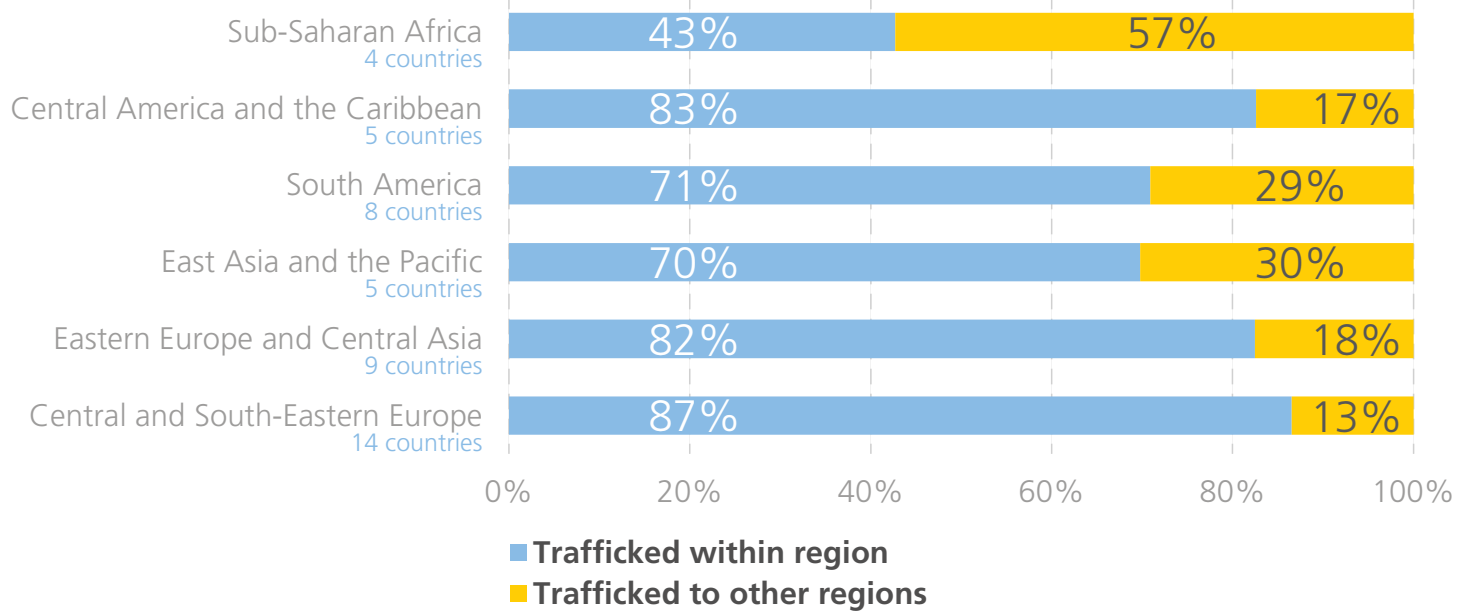


9 per cent of the victims who were trafficked to and repatriated from East Asia were citizens of South American countries, whereas 5 per cent were from Sub-Saharan Africa. This indicates that significant flows to East Asia originate from many regions, even from very far away.

\section{The diffusion of trafficking flows}

Analysing global destination and repatriation data together can generate an understanding of which trafficking flows are most diffused across the world. The concept of diffusion of trafficking flows focuses on the number of countries and areas that have detected victims originating from a particular region, without emphasizing the magnitude of those flows. Such an analysis shows that trafficking flows from Sub-Saharan Africa have global reach. Some 69 countries around the world detected or repatriated victims from this region between 2012 and 2014. Victims from Sub-Saharan Africa have been detected in significant numbers within that region, in the Middle East, Europe and East Asia, and also in North America and South Asia. Compared to analyses presented in the previous editions of the Global Report, trafficking from Sub-Saharan African countries has overtaken trafficking from East Asia as the most diffused outbound regional flow.

FIG. 30 Diffusion of trafficking flows: number of countries where victims from countries in the given subregions were detected, 2012-2014

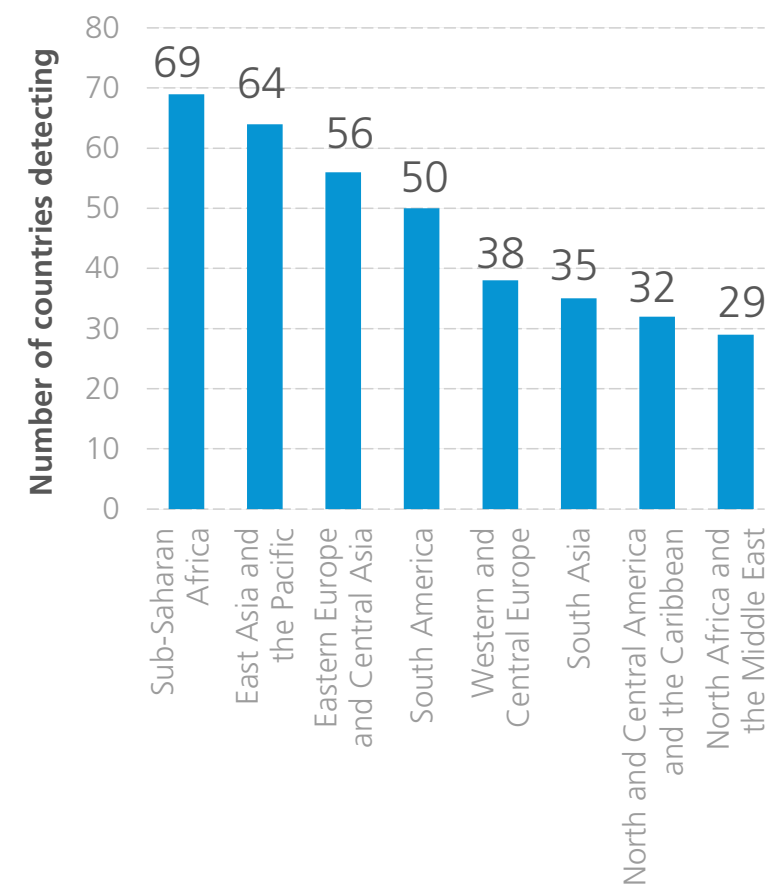

Source: UNODC elaboration of national data
FIG. 31 Share of detected trafficking victims, by area of citizenship, 2014 (or most recent)

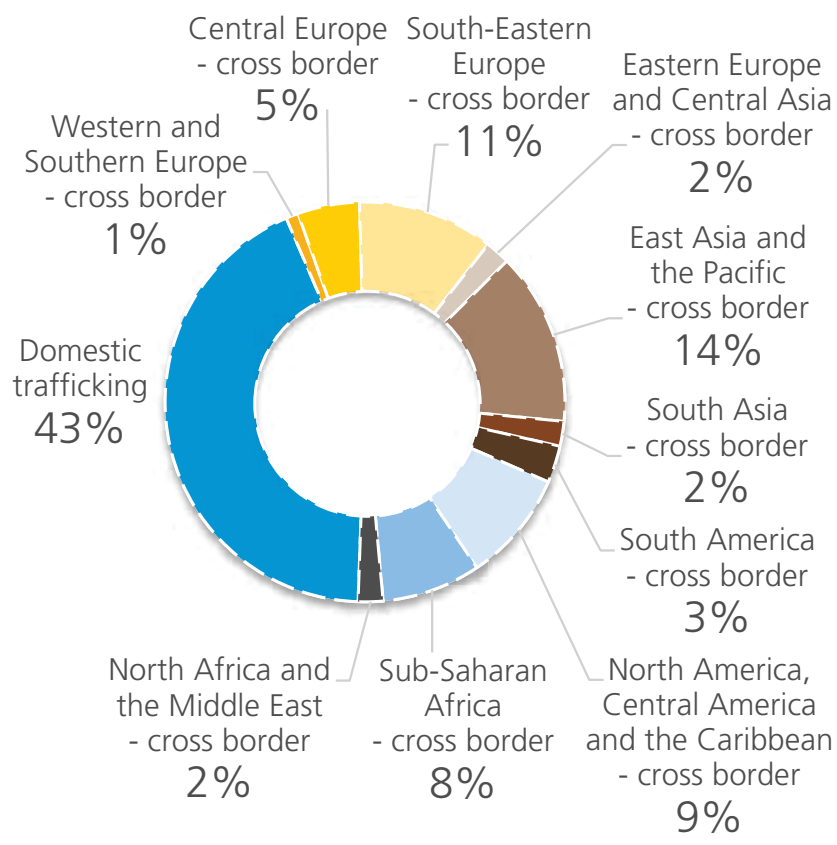

Source: UNODC elaboration of national data.

The second most diffused flow originates in East Asia. During the 2012-2014 period, victims from this region were detected in or repatriated from 64 countries across the world. East Asian trafficking flows have been detected within the region, as well as in North America, the Middle East, and in different countries in Western and Central Europe. Victims from East Asia have also been detected - in smaller numbers - in Eastern Europe and Central Asia, and in Central and South America.

East Asian victims are detected in many countries around the world, and they are also detected in relatively large numbers. The 85 countries covered for this analysis detected more East Asian victims of cross-border trafficking than any other citizenships in 2014. Victims from Sub-Saharan Africa are also detected in large numbers, which confirms the international significance of this trafficking flow.

At the same time, victims from Central and South-Eastern Europe and North and Central America and the Caribbean are also detected in relatively large numbers. However, victims with these citizenships are mainly detected in Europe and North America, respectively.

Eastern European victims were detected in more than 55 countries around the world. Though they are mainly concentrated in Europe and the Middle East, victims origi- 


\section{Multiple Systems Estimate: an innovative way to help assess the real extent of trafficking in persons}

The global research community is still searching for a sound and practicable method for estimating how many victims of trafficking in persons there are worldwide. While editions of this report have become a reference for data on detected victims, estimating the number of undetected victims remains a challenge. This search received renewed impetus when the global number of trafficking victims was selected as an indicator for Sustainable Development Goal 16.

In 2016, UNODC conducted a Multiple Systems Estimate (MSE) in the Netherlands to test this particular methodology to estimate the total number of victims there. The MSE is a capture-recapture method applied to lists of victims detected and recorded by different local authorities. ${ }^{a}$ The analysis conducted on the combination of these different lists is used to estimate those victims that are never detected, and extrapolate a number for the the entire victim population in that country.

One key advantage of the MSE method is that it estimates the total number of victims on the basis of information on victims of trafficking detected by national authorities. This is the same basis used by the Global Report. The MSE is a cost-effective and relatively simple method but can be applied only in countries with the capacity to detect and keep reliable records of victims of trafficking.

Carrying out Multiple Systems Estimations of national figures require lists of detected victims from at least two, preferably three or more sources. The number of entries on each list needs to be large enough to give an indication of the possible overlap with other lists. If the total numbers of identified victims are relatively high, this is less likely to be problematic.

A preliminary assessment of existing UNODC data shows that 50 countries, from all regions, have reported a sufficient number of detected victims in the course of a year over the

nating from Eastern Europe were also detected in or repatriated from countries in South and East Asia. South American victims were also detected in or repatriated from about 50 countries, mainly within the Americas. South Asian victims were detected in about 35 countries, mainly in South Asia, Western and Central Europe and the Middle East.
2010-2012 period to be able to apply MSE. However, it is unknown how many of these countries have three or more sources which give the possibility of matching. Within the European Union - an area with comparatively good data on trafficking in persons - some 16 countries appear to have suitable statistics to implement MSE. In those countries where MSE is not a feasible approach, UNODC is exploring ways of conducting victimization surveys based on special sampling and analytical methods, such as respondent-driven sampling and network scale-up methods. ${ }^{b}$

There is only a limited number of countries with sufficient data and capacity to apply the MSE methodology at present. In order to enhance the method, UNODC is currently supporting some countries to conduct MSE studies, and it is working with Dutch authorities to conduct a new MSE test with more detailed data and using a more sophisticated application of the method.

Upon completion of these pilots, and a critical assessment of their results, technical tools will be designed to support national authorities to estimate the true numbers of victims of human trafficking by applying MSE to statistics on detected victims. The results may also contribute to ongoing efforts to produce better global and regional estimates of human trafficking with a mixed method combining results of survey research and analyses of official statistics on detected victims.

The MSE methodology is explained in detail in: UNODC Research Brief (2016). Multiple Systems Estimation for estimating the number of victims of human trafficking across the world (primary authors: J. Van Dijk and P. G. M. van der Heijden).

For more information on approaches to measuring hidden populations, see the UNODC journal Forum on Crime and Society, vol. 8, 2015 (http://www.unodc.org/unodc/en/data-and-analysis/Forum-onCrime-and-Society.html).

\section{GLOBAL OVERVIEW:} THE LEGISLATIVE AND CRIMINAL JUSTICE RESPONSE TO TRAFFICKING IN PERSONS

A review of the global response to trafficking in persons needs to begin with an analysis of the legislation that countries use to criminalize this activity. The laws are assessed according to their compliance with the definition of trafficking as stated in the United Nations Trafficking in Persons Protocol. 
For this analysis, more countries (179) are covered than for the sections on patterns and flows of trafficking in persons (136). The status of national-level legislation is constantly monitored by UNODC and thus information is available for more countries. Data on the criminal justice response, such as investigations, prosecutions and convictions, were provided by countries during the data collection for this Global Report.

The analysis of the national legislative frameworks shows an overall improvement in the global response to trafficking in persons. During the period here considered, some countries adopted new, comprehensive legislation in line with the UN Trafficking in Persons Protocol. A large number of countries already had such legislation in place, thus the margin of improvement is limited when compared to the past decade. Conviction rates, however, have remained remarkably low in many parts of the world, and there have been no significant increases on a global scale.

\section{The United Nations Trafficking in Persons Protocol: a universal legal standard}

Few international legal instruments have been as rapidly and globally endorsed as the UN Trafficking in Persons Protocol. The Protocol entered into force in December 2003 only three years after its adoption by the General Assembly in 2000. As of early October 2016, 170 countries have ratified the Protocol.

In order to monitor the implementation of the Protocol, UNODC analyses the specific legislation on trafficking in persons to ensure that victims might, legally, include men, women, boys and girls, as well as both domestic and transnational flows. National trafficking legislation is also reviewed to determine whether the act, means and purpose elements of trafficking are present and in line with the definition contained in article 3 of the Protocol. This analysis shows that since its entry into force, the number of countries criminalizing trafficking in persons on the basis of the Protocol definition saw a near fivefold increase, from 33 in the year 2003 to 158 in August 2016 (out of the 179 countries considered here).

In the the two years prior to the publication of this edition of the Global Report, nine countries adopted a legislation with a definition of trafficking in line with the definition contained in the UN Trafficking in Persons Protocol. Five of those countries revised legislation that previously criminalized just some aspects of trafficking, whereas four had not previously considered trafficking in persons as an offence.
FIG. 32 Criminalization of trafficking in persons with a specific offence covering all or some forms as defined in the UN Protocol, numbers and shares of countries, 2003-2016

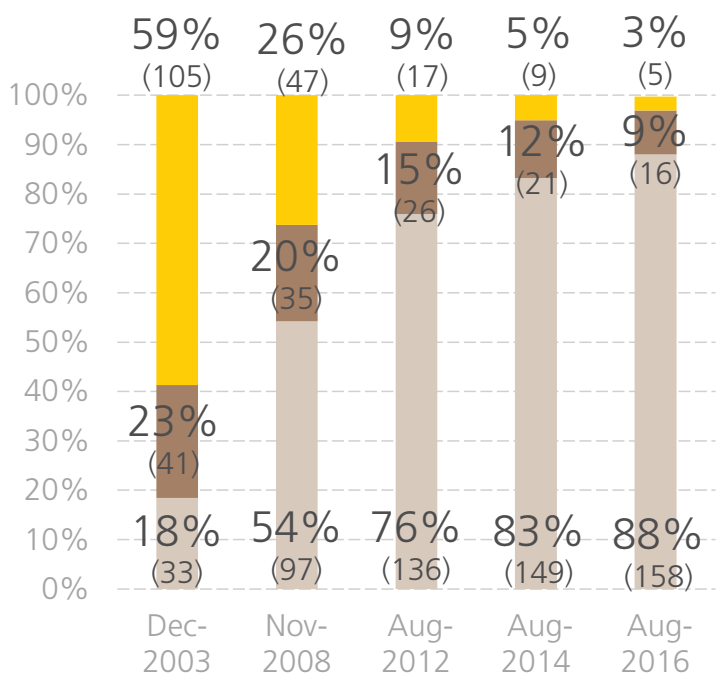

179 COUNTRIES

\section{No specific offence \\ - Partial \\ Covers most/all forms}

The analysis shows that since the end of 2003, 124 of the 179 countries here considered have adopted legislation that criminalizes all aspects of trafficking in persons. Of the approximately 105 countries that did not consider trafficking in persons a crime at that time, only five remain today, about 3 per cent of the countries for which information was available. Some 16 countries ( 9 per cent) have legislation that criminalizes only certain aspects of trafficking in persons as defined by the UN Trafficking in Persons Protocol.

The date of introduction of the specific offence of trafficking in persons in the national legislation of the countries considered varies. In order to analyse the evolution of criminalization efforts, five time periods were selected. The first period is prior to the entry into force of the UN Trafficking in Persons Protocol (23 December 2003). This date was chosen as a baseline upon which to observe the impact of this landmark legal instrument on legislation around the world. The following periods (January 2004-November 2008, December 2008 - August 2012, September 2012 - August 2014, and September 2014 August 2016) coincide with periods of UNODC data collection efforts for prior editions of the Global Report. 
FIG. 33 Share and number of countries with a specific offence on trafficking in persons that criminalizes all forms listed in the UN Protocol, by period of introduction of the offence

Period 2

Full trafficking offenc
introduced between
January 2004 and
November 2008
$66(37 \%)$
Period 3

Full trafficking offence

introduced between

December 2008 and

August 2012

$39(22 \%)$

Period 4

Full trafficking offence between September

2012 and August 2014

$12(6 \%)$

\section{Period 5}

Full trafficking offence introduced between September 2014 and

August 2016

$9(5 \%)$

Source: UNODC elaboration of national data.

FIG. 34 Share and number of countries with a specific trafficking in persons offence criminalizing all forms listed in the UN Protocol, by region and period of introduction of the offence

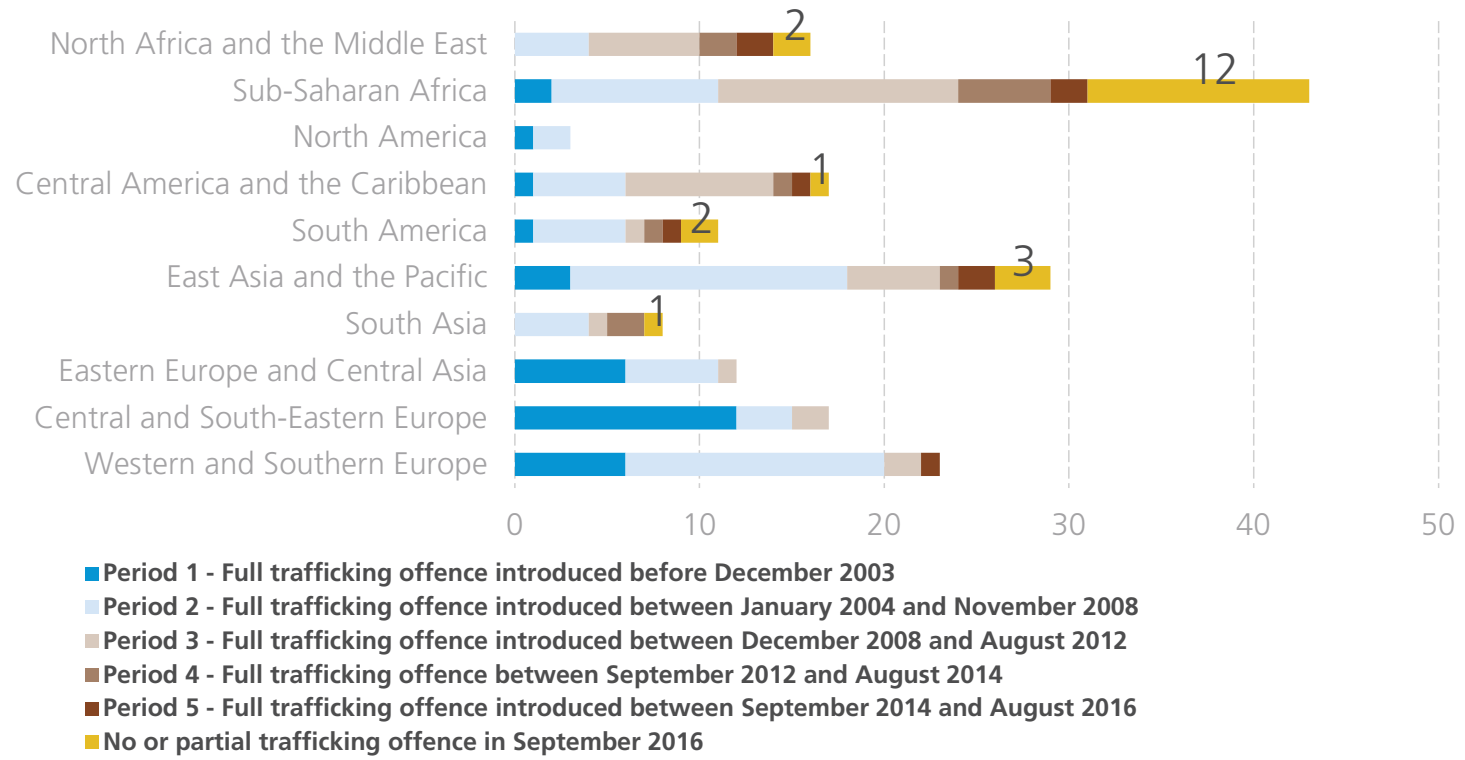

Source: UNODC elaboration of national data.

Most of the countries' legislative efforts were conducted in the five years after the entry into force of the UN Trafficking in Persons Protocol. About 37 per cent of the countries that currently have legislation against trafficking in persons introduced it between the beginning of 2004 and the end of 2008. Another 22 per cent introduced the offence in the period between December 2008 and August 2012, while 11 per cent of the 179 countries considered did so in the four years between September 2012 and August 2016. The frequency of adopting legislation against trafficking in persons has reduced over the last four years, compared to previous periods. 
The initial 'push' to enact legislation was strongest in Central and South-Eastern Europe, where most of the countries introduced a trafficking in persons offence in parallel with their national processes of ratification of the UN Trafficking in Persons Protocol, shortly after it was opened for signature. Similar patterns were followed by countries in Eastern Europe and Central Asia, where a trafficking in persons offence in line with the Protocol definition was introduced just before or in the five years following the entry into force of the Protocol.

Most Western and Southern European countries introduced their legislation after December 2003. Similar patterns were found in East Asia and the Pacific and in the Americas. Most of the countries in North Africa and the Middle East with legislation in compliance with the Protocol introduced it between 2008 and 2012. Progress was made in Sub-Saharan Africa between 2012 and 2016.

Some regions still have countries without proper legislation on trafficking in persons. In West and East Africa, some countries have partial legislation, and in North Africa, some countries are introducing a new offence with a definition of trafficking in compliance with the UN Trafficking in Persons Protocol definition. In South America, a few countries still have partial legislation or definitions that are not in line with the Protocol definition. Some small island states in the Caribbean, Africa and the Pacific, as well as large populous countries in Asia, also only have partial legislation.

These gaps in legislation leave at least two billion people around the world without adequate legal protection in line with the UN Trafficking in Persons Protocol. Since UNODC has no information on legislation in another 20 or so countries around the world, this population may be larger, since it is likely that countries for which no information on trafficking in persons is available have no relevant legislation.

\section{Investigations, prosecutions and convictions for trafficking in persons: stagnation at a low level}

The legislative response to trafficking in persons has been solid. The vast majority of countries passed or modified their domestic legislation so as to criminalize trafficking in persons in line with the provisions of the UN Trafficking in Persons Protocol more or less within a decade of that instrument's entry into force in 2003. The criminal justice system response, however, appears to be stagnating at a low level. For most countries, the number of processed
FIG. 35 Share of countries, by number of trafficking investigations and prosecutions, 2012-2014 (one year within the period)
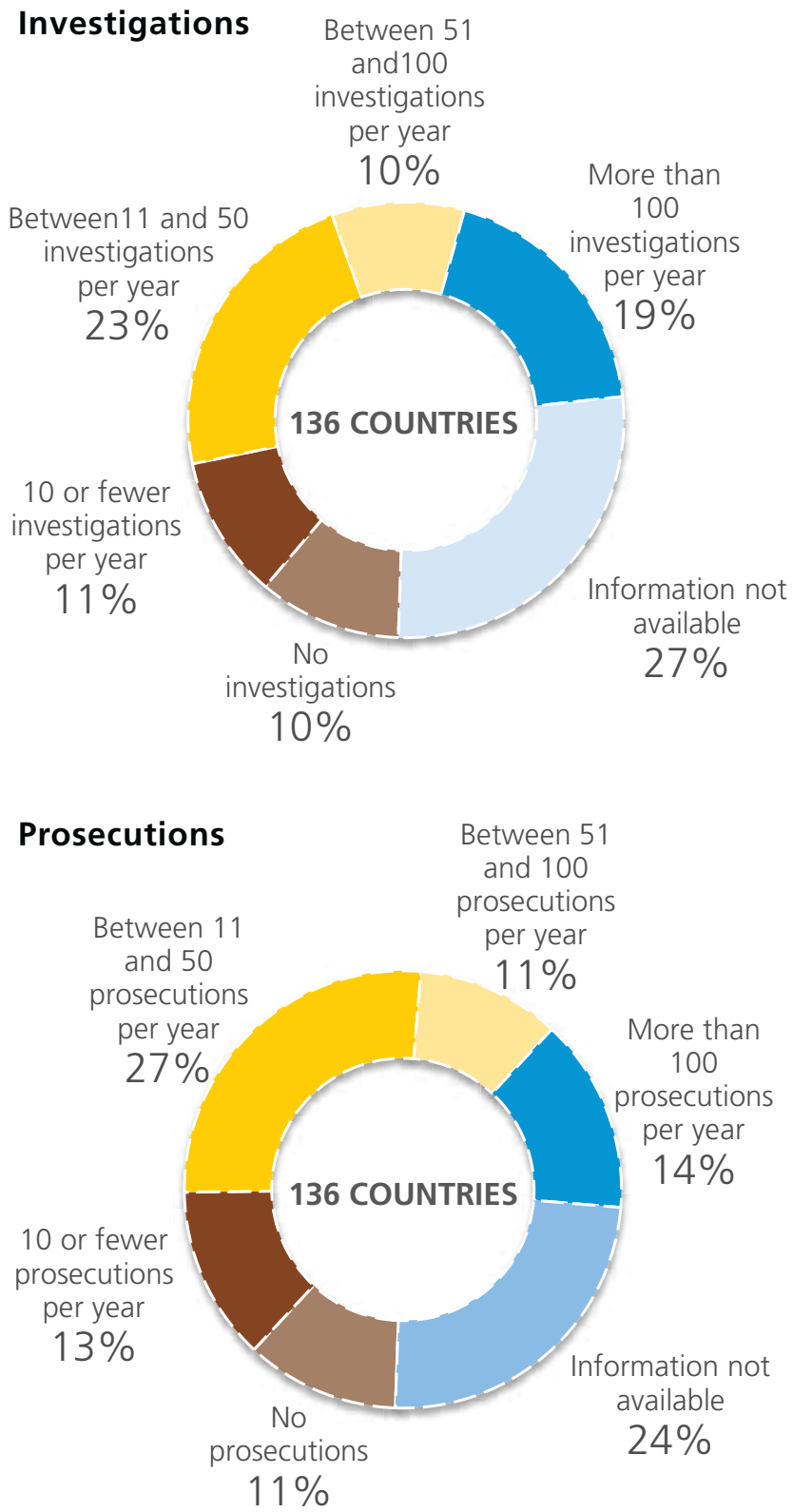

Source: UNODC elaboration of national data.

cases is limited, regardless of stage (investigation, prosecution or conviction)..$^{50}$

A review of the reporting patterns shows that the number of cases reported by most countries decreases by each stage of the criminal justice process. The number of investiga-

50 This breakdown - which is the one used in the questionnaire through which Member States submit their data to UNODC - is a simplification of the criminal justice process, which in most jurisdictions entails various other steps. 
FIG. 36 Share of countries, by number of trafficking convictions, 2012-2014 (one year within the period)

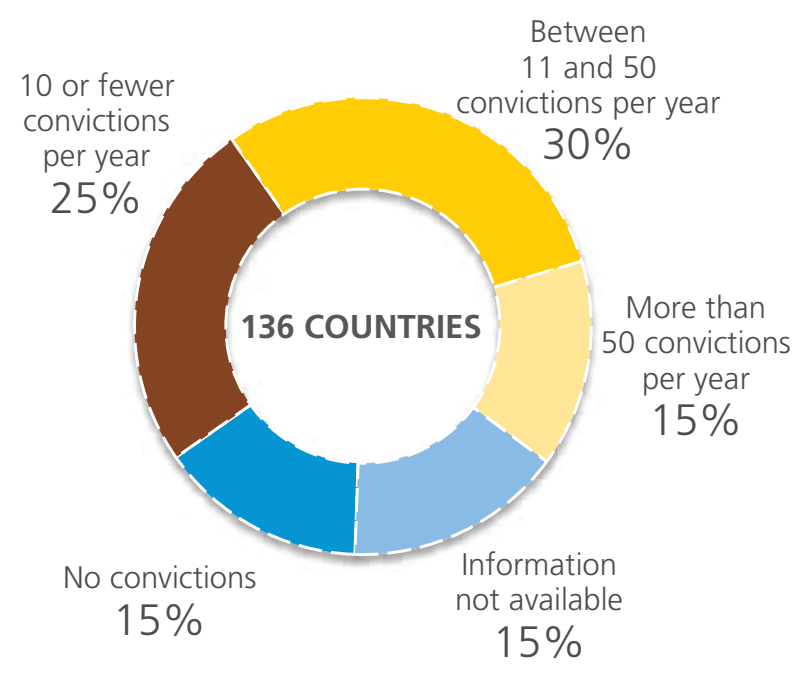

Source: UNODC elaboration of national data.

tions is generally higher than the number of prosecutions, which in turn is higher than the number of convictions. On average, 26 per cent of the number of investigated cases ended with first-instance court convictions. ${ }^{51}$ The criminal justice 'funnel' sheds cases at each step, and thus, it is to be expected that the numbers decrease as investigated cases and their suspects move through prosecution and court adjudication.

This result indicates that, on average, for each person convicted, about four persons were investigated. Additionally, an analysis based on the 76 countries that report number of victims and number of convictions shows that on average, there are five victims for every convicted offender. This ratio, between detected victims and person convicted in the first court instance, ranges from four to 16 in different regions. It is lower for Eastern Europe and Central Asia (around 4 victims for every person convicted) and higher for Sub-Saharan Africa (around 14) and Central America and the Caribbean (around 16). There may be numerous reasons for these regional discrepancies, including the apparent connection between this ratio and the correlation between persons investigated and persons convicted.

A closer look at convictions - for which data coverage is better than investigations or prosecutions - makes it clear that impunity is still rife for trafficking in persons. Of the 136 countries covered, 40 per cent reported 10 or fewer convictions per year over the 2012-2014 period.

51 These may not be exactly the same cases as the data was reported as annual totals (rather than longitudinal).
FIG. 37 Shares of investigated offenders who are convicted in the first court instance, regional and global averages, 2012-2014

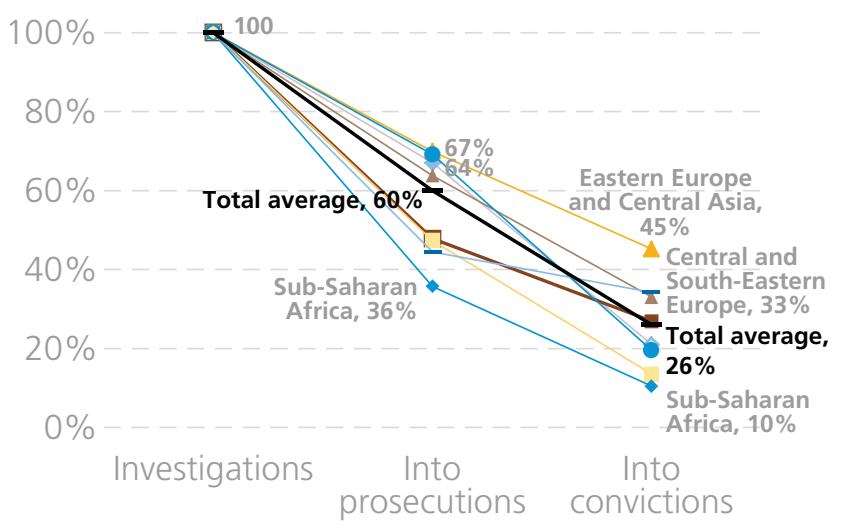

$\checkmark-$ Western and Southern Europe

$\neg$ Central and South-Eastern Europe

- Eastern Europe and Central Asia

$\rightarrow-$ East Asia and the Pacific South America

- Central America and the Caribbean

- - Sub-Saharan Africa

- North Africa and the Middle East

- Total average

Source: UNODC elaboration of national data.

About 15 per cent of the 136 countries covered did not record a single conviction for trafficking in persons per year during the 2012-2014 period; a share that has also remained stable. Nearly all are countries that either lack legislation on trafficking in persons or have only recently adopted it, while just a couple of countries have longstanding legislation but no convictions. Countries in this category include some island states in the Caribbean, the Pacific and Africa, as well as some countries in Sub-Saharan Africa and North Africa and the Middle East.

Among the countries with many convictions - more than 50 in at least one of the years covered in $2012-2014$ - are several countries in North America, Western and Southern Europe, South-Eastern Europe and South-East Asia. Although their trafficking flows and patterns are diverse, these regions generally enacted UN Trafficking in Persons Protocol-aligned trafficking legislation earlier than, for instance, Sub-Saharan Africa or the Middle East.

While countries that had legislation in place before the entry into force of the UN Trafficking in Persons Protocol had, on average, about 29 convictions in the year 2014, those who introduced the offence in the period 2003- 
2008 had about 18 convictions in the same year. Far fewer convictions were reported from countries that introduced legislation between 2009 and 2012, and those that enacted legislation after 2012 had no convictions in the year 2014 .

\section{FIG. 38 Average number of trafficking convictions in 2014, by year of introduction of a specific trafficking in persons offence}

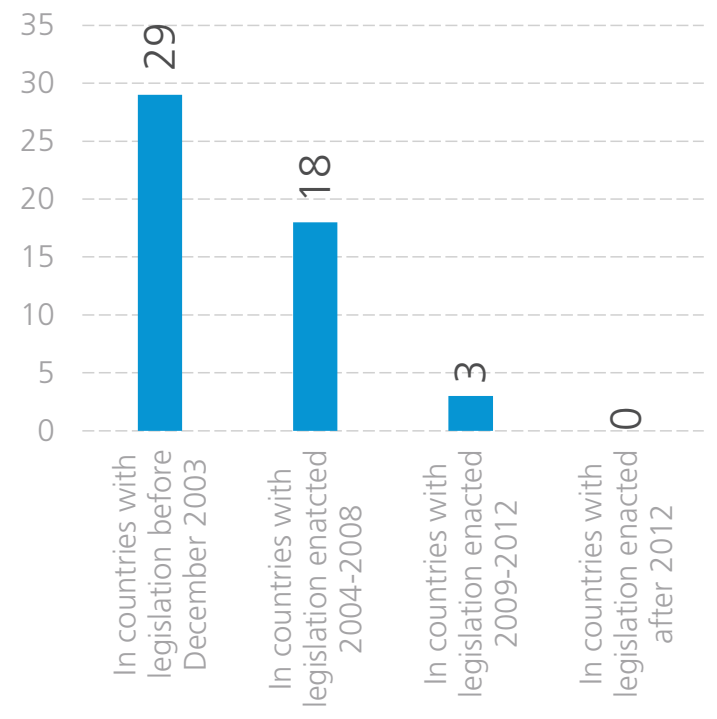

Source: UNODC elaboration of national data.
Accordingly, there seems to be a relation between the length of time a country has had legislation that criminalizes trafficking as required by the UN Trafficking in Persons Protocol, and the number of convictions for trafficking crimes in that country. While there may be multiple reasons, a contributing factor seems to be that it takes time and dedicated resources for the criminal justice system to acquire sufficient expertise in order to detect, investigate and successfully prosecute cases of trafficking in persons. In addition, countries that have criminalized human trafficking for a longer period of time tend to also have other responses in place which often facilitate prosecutions, such as victim protection schemes and national and international cooperation structures.

This relationship can also be seen when considering the number of convictions by region. Sub-Saharan Africa is clearly the region with most countries reporting $0-10$ convictions per year, and a limited number of countries reporting 11 or more. Countries in Western and Central Europe, and in the Americas, tend to record more convictions.

The trends for convictions are also broadly stable. Some 40 per cent of the countries covered convicted 10 or fewer persons for the offence of trafficking in persons during the 2012-2014 period. This is similar to the levels for the periods 2010-2012 and 2007-2010. The shares of countries reporting 10 or more convictions have also remained

FIG. 39 Number of countries reporting trafficking convictions, by region and number of convictions, 2012-2014

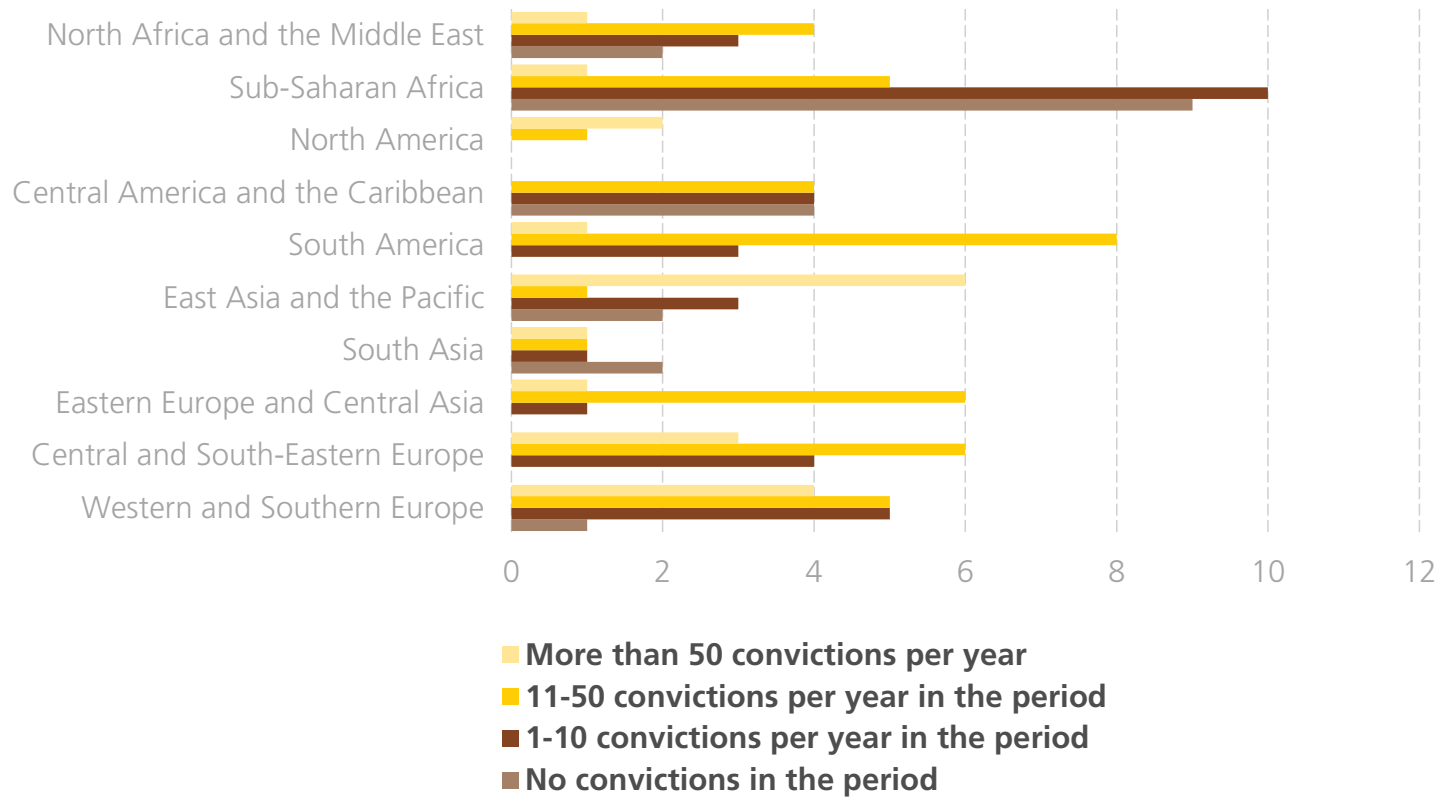

Source: UNODC elaboration of national data. 
FIG. 40 Shares of countries, by number of trafficking convictions

2010-2012 (one year within the period)

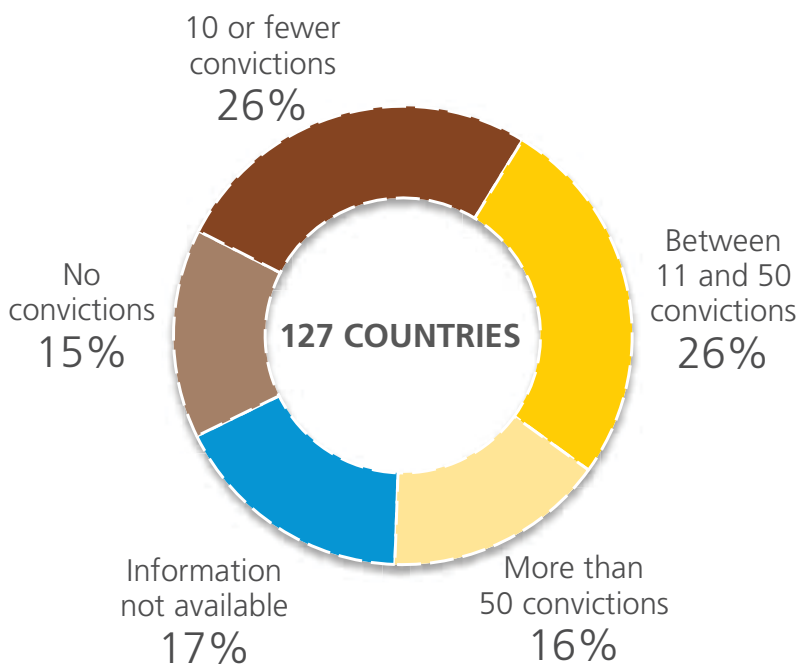

Source: UNODC elaboration of national data.

similar, although a markedly smaller share of countries reported convicting more than 50 persons over the 20122014 period compared to prior years.
2007-2010 (one year within the period)

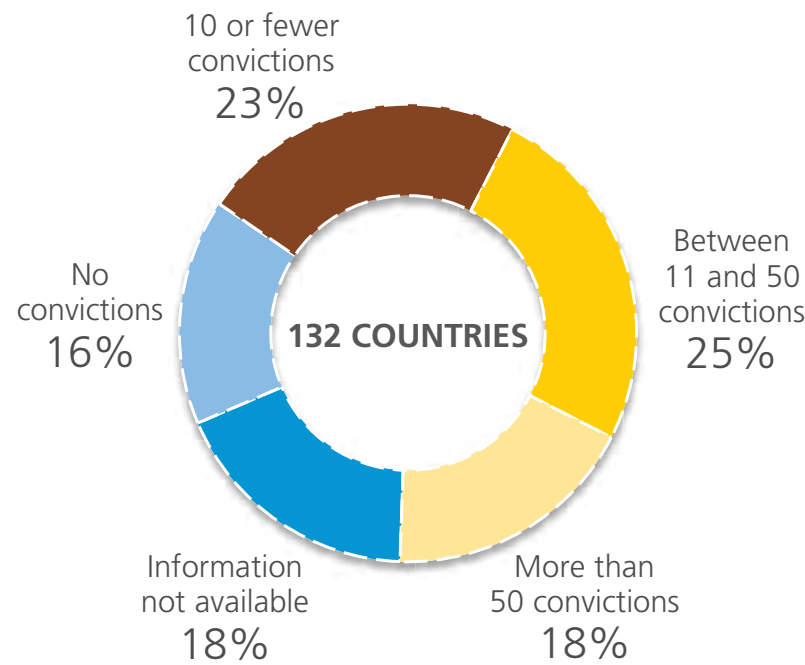







\section{CHAPTER II}

\section{HUMAN TRAFFICKING, MIGRATION AND CONFLICT}

This chapter explores the connection between migration flows and trafficking flows. In particular, it analyses how certain trafficking in persons flows resemble migration flows, and the factors that may increase the vulnerability of migrants to human trafficking. The chapter also looks at the role of criminal groups; how they leverage the aspirations of people willing to migrate in order to deceive or coerce them for exploitative purposes.

Persons who escape persecution and conflict in search of protection are particularly vulnerable to being trafficked. This vulnerability, and the elements that link trafficking victims and refugees, are also examined. Finally, the chapter explores trafficking in conflict areas, especially trafficking carried out by armed groups.

\section{The link between human trafficking and migration flows}

Most detected victims of trafficking in persons (approximately 60 per cent) are foreigners in the country of detection. Most are international migrants ${ }^{52}$ who have moved from one country to another. A move to another country is, for most, a life-changing decision that can be motivated by a range of factors. People may decide to migrate for the dream of a better life with better jobs, better schools, political stability or simply for a new life in a new environment. People may be 'pushed' away from their community of origin by conflict, natural disasters, lack of decent employment, high crime levels, destructive relationships or poor educational options, to mention some. For some, however, their experience may become one of trafficking in persons. Criminals exploit the human desire to improve one's lot in life, and generate vast profits from the exploitation of victims in myriad ways.

As presented in the global analysis and the regional sections of this Global Report, as a general pattern, trafficking victims are trafficked from areas of lower economic activ-

\footnotetext{
52 The United Nations (ST/ESA/STAS/SER.M/58/Rev.1, United Nations Department of Economic and Social Affairs, Population Division, United Nations Recommendations on Statistics of International Migration, Revision 1, 1998) has defined an international migrant as "any person who changes his or her country of usual residence” (para. 32, p. 9). An international migrant who changes his or her place of usual residence for at least one year is defined as a long-term migrant, while a person who changes his or her place of usual residence for more than three months but less than one year is considered to be a short-term migrant. In practice, national definitions and methods of data collection vary, which present challenges of comparability. Countries that collect and publish data on the flows of international migrants use different criteria to identify migrants and use different concepts to determine their origin and destination.
}

ity to wealthier regions, from rural to urban areas, from poorer suburbs to economically more attractive parts. This broad pattern holds for both domestic and cross-border trafficking. Moreover, the share of foreigners among victims of trafficking is higher in more affluent countries, ${ }^{53}$ lower in developing countries, and very limited in least developed countries where domestic trafficking is more prevalent.

The patterns of detected cross-border trafficking elaborated in this report in many cases broadly resemble discernible regular migration flows. For instance, the most intense regular migration flows from Central and SouthEastern Europe are directed towards the wealthier Western European countries, and at the same time, citizens of Central and South-Eastern European countries are widely detected as victims of trafficking in persons in Western and Southern Europe. Similarly, in the Americas, there are sizable migration flows from Paraguay and the Plurinational State of Bolivia into Argentina, and from Central America to the United States of America. These flows are largely reflected in trafficking flows from these origins into Argentina and the United States of America. Regardless of the political or socio-economic factors that help define these areas as mainly origins of trafficking in persons, they are linked to those specific trafficking destinations also by migration flows. The data collected for this edition of the Global Report shows that there are few or no victims from South-Eastern Europe detected in the Southern Cone, or from Central America in Europe.

The qualitative analysis of information from court cases submitted by countries from all over the world shows that most cases of trafficking involve persons recruited with a promise of a better life somewhere else; outside or within their country's borders. Traffickers leverage their aspiration for a brighter future, which is a significant pull factor for most migrants.

\section{How are migration and trafficking flows connected?}

The limitations of the available data on trafficking in persons is discussed at length in the methodological section. Data on international migration flows is perhaps more

\footnotetext{
53 This is true at the global level, as the richest areas - Western Europe, North America and the Middle East - are key destinations for crossborder trafficking. But it is also true within some regions. For example, the Southern Cone countries are not among the most affluent in the world, but within the region - South America - they are wealthy, and a key destination area there.
} 
readily available, but subject to vast differences in terms of both national definitions and data collection practices. The scarcity of information does not permit an in-depth analysis of broad, international scope. For this reason, it is not possible to explore all facets of the relationship between migration and human trafficking. The analysis in this section is an attempt to use available data on trafficking in persons cases from different parts of the world, combined with data on migration flows, to explore patterns of trafficking in relation to migration..$^{54}$

The results show that the citizenships of trafficking victims detected in a country are often correlated with the citizenships of the flows of regular migrants into that country during the same period. In these countries, the citizenships of victims of trafficking would largely correspond to the citizenships of the migrants that arrived during the same period.

This can be illustrated by using the example of Germany. The majority ( 65 per cent) of the victims of trafficking detected in Germany - as in the rest of Western and Southern Europe - come from the neighbouring subregion of Central and South-Eastern Europe. At the same time, migrants from the different countries in Central and South-Eastern Europe represent the majority of the recent migrant flows into Germany, ${ }^{55}$ as in most of Western and Southern Europe. Statistical analyses show that the citizenship profiles for recent regular migration flows and detected trafficking flows are similar. Similar results to those found for Germany are also found for other Western European countries, including Italy, the Netherlands and Norway. ${ }^{56}$

The statistical similarities between cross border human trafficking flows and recent international migration flows were found for other destinations as well. In the United States of America, the citizenship profiles of foreign victims of trafficking in persons broadly reflect the newly arrived migrant groups. There, the largest share of the victims of trafficking detected over the 2012-2014 period were citizens of countries close-by to the south (Central

54 The selected countries were in North America, the South Cone of South America, the Middle East, Western Europe and Central Asia. For further information, see Annex I (Methodology, available at www. unodc.org/unodc/en/data-and-analysis/glotip.html).

55 United Nations, Department of Economic and Social Affairs, Population Division (2015). International Migration Flows to and from Selected Countries: The 2015 Revision (POP/DB/MIG/Flow/ Rev.2015). The international migration data in Germany are derived from the population register. The data on immigration refer to persons arriving from abroad who register their dwelling as their only or main place of residence in Germany during a specific year.

56 See Annex IV (available at www.unodc.org/unodc/en/data-and-analysis/glotip.html)..
FIG. 42 Share of international migrants arriving in Argentina, by country of origin, 2011-2014

Bolivia

(Plurinational State of) $24 \%$

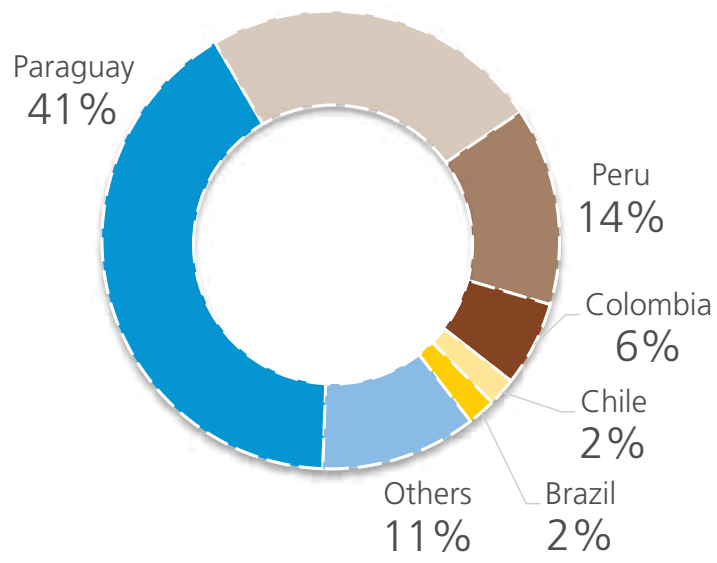

Source: UN DESA population data

FIG. 43 Share of foreign victims of trafficking detected in Argentina, by country of origin, 2011-2014

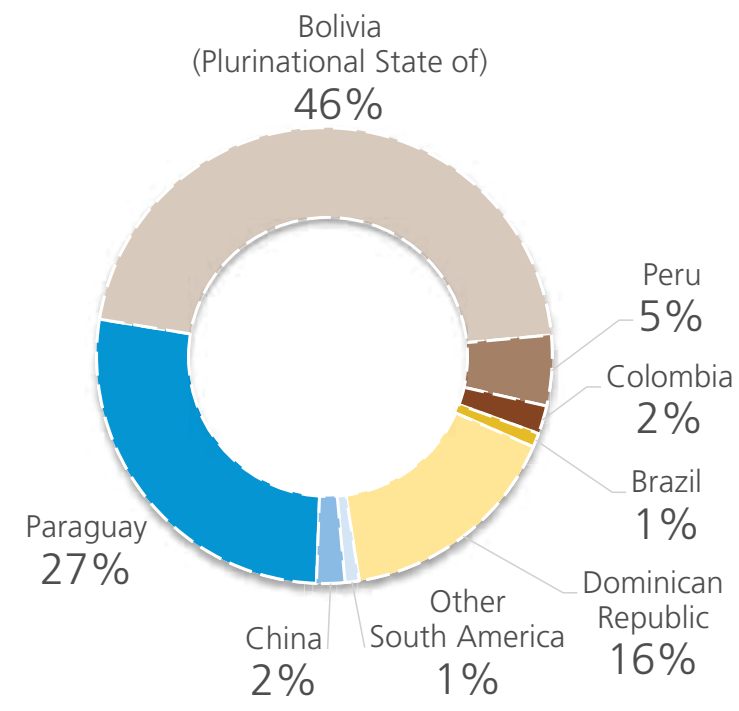

Source: UNODC.

America, the Caribbean and Mexico) as well as from East Asia. These trafficking flows to a certain extent reflect the major migration flows during the same period. As in European countries, the data shows that the origins of recent international migration and cross-border human trafficking flows are statistically similar. ${ }^{57}$

The countries of the Gulf Cooperation Council in the Middle East are prominent destinations for victims of

7 See Annex IV (available at www.unodc.org/unodc/en/data-andanalysis/glotip.html). 
cross-border trafficking in persons. Victims are trafficked from many parts of the world, in particular, from South Asia and East Asia. These are also common origin areas among migrants in this area. The data from the United Arab Emirates again confirms that cross-border trafficking flows follow the profile of the foreign workers officially registered as residing in the country. ${ }^{58}$

Similar results are also found in destinations for crossborder trafficking in other parts of the world. As the richest area in South America, the Southern Cone is a regional destination for migration flows. Trafficking flows into Argentina broadly resemble the regular migration flows into this country. ${ }^{59}$

Broadly similar citizenship profiles were recorded for international regular migrants and foreign victims of trafficking detected in Argentina between 2011 and 2014. However, Bolivian citizens, for example, had a significantly stronger representation among detected trafficking victims compared to migration flows.

Like Argentina, Kazakhstan is also a destination, mainly for regional trafficking in persons. Victims trafficked to Kazakhstan from other countries are, by and large, citizens of other Central Asian countries, and to a lesser extent from East Asia. The citizenship profiles of trafficking victims is correlated with the profiles of migration flows recorded during the same period also here. ${ }^{60}$

Keeping data limitations in mind, the results not only indicate that detected human trafficking flows tend to follow the broader migration flows, but also that factors other than regular migration have an impact on trafficking flows. For instance, in the Western and Southern European destination countries considered, citizens of countries in South-Eastern Europe and West Africa comprise a large share of the total number of detected trafficking victims, but a relatively small share of recently arrived regular migrants in Germany, the Netherlands, Norway and Italy. At the same time, Polish citizens comprise a large share of regular migrants moving to these destinations, while the number of Polish victims of trafficking detected in Germany or the Netherlands is relatively limited.

The situation is similar for Central American citizens detected as trafficking victims in the United States. Citizens from Honduras, Guatemala and El Salvador repre-

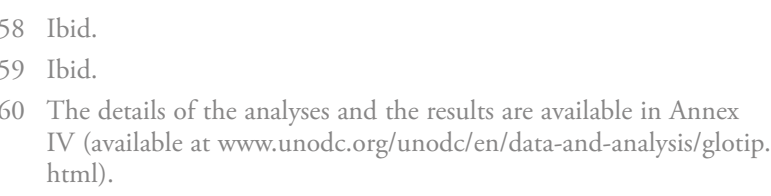

FIG. 44 Correlation between migration flows and trafficking flows in the Netherlands, 2011-2013

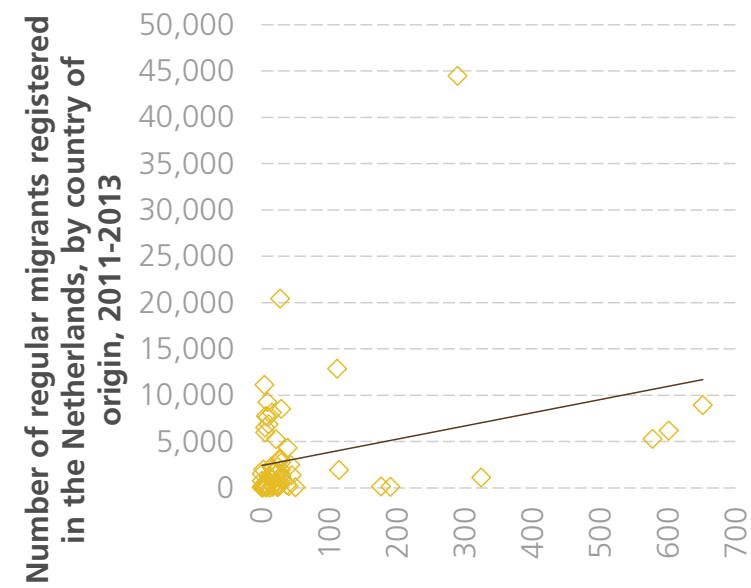

Number of victims of trafficking detected in the Netherlands, by country of origin, 2011-2013

Source: UNODC elaboration of UNDESA and national data

sented about 20 per cent of the foreign detected victims of trafficking in the United States during the period considered, while the recent regular migration flows into the United States from these countries is limited to about 5 per cent of the total. Similarly, in Argentina, a relatively large share of victims of trafficking from countries in the Caribbean has been detected, compared to the level of regular migration flows from this area to Argentina.

\section{What factors can influence the vulnerability of certain migration flows to trafficking in persons?}

Among the many factors that could increase the risks for some migrants falling prey to human traffickers, the presence of transnational organized crime in the territory of origin seems to be particularly relevant. The 2014 Global Report discussed the role of organized criminal groups in trafficking in persons, and the analysis found that the higher the prevalence of organized crime in origin countries, the more victims of these countries are detected in major destinations. ${ }^{61}$ That edition looked at how trafficking in persons is conducted by a variety of criminal actors, and not necessarily by structured transnational criminal organizations. Many cases of trafficking are carried out by individuals who exploit a relative or partner. However, a trafficking organization is needed to sustain cross-border trafficking flows over time. ${ }^{62}$

\footnotetext{
61 See pp. 43-49, UNODC, Global Report on Trafficking in Persons 2014 (United Nations publication, Sales No. E.14.V.10)

62 See pp. 48-49, UNODC, Global Report on Trafficking in Persons 2014
} 
The relevance of transnational organized crime in origin countries as a risk factor that may expose migrants to trafficking is also highlighted in the court cases collected for this Global Report. Several cases point to a modus operandi in which the recruitment is conducted in origin countries by groups that traffic co-national victims and carry out the exploitation at destination, sometimes in cooperation with local traffickers there. In most cases, trafficking in persons starts with an act of recruitment, and thus, the stronger the presence of traffickers in the territory of recruitment, the more victims tend to be trafficked from these origins.

Another element to be considered is the socio-economic profile of the migrant, and in connection with this, his or her possibility of accessing legal ways to work and reside in the destination country. A lack of economic resources, a low level of education and other factors could mean that a large number of people wanting to migrate may experience greater difficulties in finding a legal means to do so.

Statistical analyses in three selected destination countries may suggest that people with citizenships that are less likely to satisfy the requirements to legally reside in a country are more frequently detected as victims of trafficking in that country ${ }^{63}$ However, the situation is different for the main trafficking flows into the European Union. The main origin countries for trafficking victims detected in the EU are other EU countries. In addition, major flows of trafficking also occur within the countries' borders in the form of domestic trafficking.

Traffickers target everyone who could be valuable for their trade; domestically or across borders. They may traffic victims who can move freely across borders, those who require visas or people who already live in the country of destination. In cases where people are willing to migrate but unable to obtain regular access to the desired destination, traffickers may leverage this limitation during recruitment. They lure victims by promising safe travel and entry into the desired destination country, and then deceive them into exploitative situations.

Qualitative analyses of court case briefs find a clear pattern linking a desire to migrate to criminal groups and trafficking in persons. Many cases start with people eager to migrate but with no other option than to rely on someone who they believe will facilitate their irregular migration into a better life. In this process, once at destination, traffickers can also use the threat, among others, of report-

(United Nations publication, Sales No. E.14.V.10).

63 See Annex IV (available at www.unodc.org/unodc/en/data-and-analysis/glotip.html) ing to the migration authorities, knowing that most victims do not trust the authorities and fear deportation.

In some cases, the 'means' by which victims are trafficked can take the form of debt bondage schemes in which traffickers require the victim(s) to work under exploitative conditions in order to pay back expenses incurred in the smuggling process. Nigerian criminal groups typically 'offer' victims an irregular migration package to Europe for about 50-70,000 Nigerian naira (roughly 250 euros) during the recruitment in Nigeria. Such a package promises land, sea or air transportation, making use of counterfeit documents or other means. The person accepts the price with the idea of paying it back by working in Europe. Once at destination, the debt is converted into 50-70,000 euros to be paid by forced prostitution for a period that could last up to three years or longer. ${ }^{64} \mathrm{~A}$ long list of similar cases were reported by different countries around the world, indicating that this might be a frequent means to traffic victims. ${ }^{65}$

Trafficking networks may also use schemes involving counterfeit documents to facilitate the migration of their victims. Such documents are used to cross borders illegally, but also to evade controls in the country of residence. In Belgium, an Algerian victim was lured to the country with the promise of a legal job. The victim crossed the border from Morocco to Spain with a fake Spanish passport bought for 3,500 euros. Once at destination, the victim was sexually exploited, and traffickers also leveraged the victim's fear of being reported to the authorities as an undocumented migrant. ${ }^{66}$ In other cases, the trafficking networks may organize sham marriages. The scheme entails arranging a sham marriage in order to obtain a residence permit for the victim in the country of the false partner. Once at destination, those who organized the sham marriage exploit the victim, who at that point is dependent on the traffickers, and afraid of reporting to the authorities.

\footnotetext{
64 See p. 56, UNODC, Global Report on Trafficking in Persons 2014 (United Nations publication, Sales No. E.14.V.10)

65 Case provided by Australia, which concluded with a conviction by the supreme court of the Australian Capital Territory, and a sentence of 8 years and 10 months of imprisonment. Case provided the United States of America, which concluded with a conviction by the District Court for the District of Minnesota and a prison sentence of 1 year. Case provided by Denmark, which concluded with convictions by the city court of Hjoerring, with sentences of 30 months of imprisonment. Case provided by Portugal, which concluded with convictions by the court of Vila Nova de Famalicáo. The sentences ranged from 1 to 12 years of imprisonment

66 Case provided Belgium, which concluded with a conviction by the court of Termonde (sentence not available)
} 
In this context, traffickers may use corruption as an enabler for moving victims across international borders. Corruption can be used to facilitate irregular migration at different stages of the process, for example, to obtain official documents that victims do not have the right to access, such as passports, visas or residence permits. It can also be used to make border control officers look the other way at checkpoints or to buy the silence of police officers in various situations.

A court case from Argentina demonstrates some of the ways that corruption plays a role in trafficking crimes. It involved Dominican victims trafficked by a criminal network into Argentina. The local law enforcement authorities proved the corruption of certain officers at the department for migration in order to fraudulently obtain residence permits for victims who were not legally entitled to residency. The traffickers were also 'taxing' the victims in order to cover the costs connected with the bribes. This was an additional way of controlling the victims, on top of taking advantage of their fear of deportation because of their irregular migration status. ${ }^{67}$

In the context of migrants and refugees particularly vulnerable to trafficking, an additional concern is the increasing numbers of unaccompanied and separated children who have irregularly migrated to the European Union over the last two years. In 2014, over 23,000 asylum applicants in the EU were considered to belong to this category. ${ }^{68}$ From January to October 2015, more unaccompanied and separated children had sought asylum in Sweden alone $(23,300)$ than in the entire EU in 2014. ${ }^{69}$ In Italy, between January and June 2016, the number of unaccompanied minors reaching the country by sea more than doubled compared to the same period in 2015 , reaching about $10,000 .^{70}$

A study conducted by the international non-governmental organization Save the Children in Italy looked at links between unaccompanied minors and trafficking in persons. It indicated that many of these children end up in sexual exploitation (West African girls), forced labour and begging (North African and South Asian boys), or exploited in city markets or in the streets to pay back the debt their families incurred for their travel to Europe. The

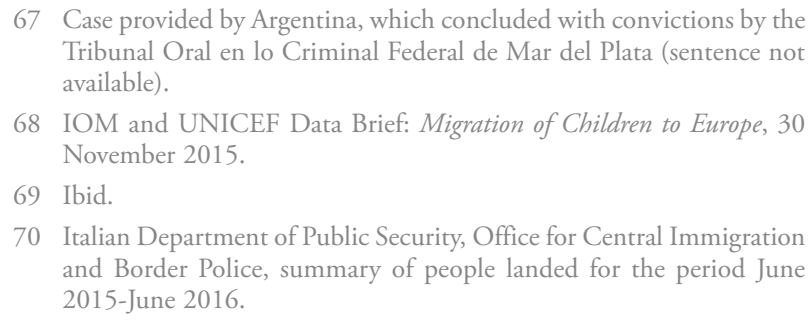
Tribunal Oral en lo Criminal Federal de Mar del Plata (sentence not available).

68 IOM and UNICEF Data Brief: Migration of Children to Europe, 30 November 2015.

69 Ibid.

70 Italian Department of Public Security, Office for Central Immigration and Border Police, summary of people landed for the period June 2015-June 2016.

study documented how sometimes these children fall prey to traffickers en route to Europe, and are sold to other organized groups at destination. ${ }^{71}$

\section{Trafficking people who are escaping persecution and conflict}

Persons who are fleeing armed conflicts and humanitarian emergencies are highly vulnerable to trafficking in persons in their search for safety and protection. Faced with insufficient channels for regular migration and family reunification, refugees, asylum seekers and internally displaced people fleeing armed conflicts often have no other option than to resort to the services of illegal actors in their search for a safer place. The urgent need and pressure to move may lead them to make dangerous migration decisions.

A report on the effects of the conflict on trafficking in persons in the Syrian Arab Republic and neighbouring countries published by the International Centre for Migration Policy Development (ICMPD) in 2015 highlighted the increasing numbers of Syrian victims of trafficking in the Middle East over the last few years, in line with UNODC's data. According to the study, the incidence of trafficking has substantially increased since the beginning of the crisis in 2011, although trafficking cases often remain unreported. ${ }^{72}$

The same study points out that for Syrian victims, the trafficking process often starts in the country of asylum where they moved for protection from the conflict zone. Traffickers take advantage of the vulnerabilities that stem from displacement. These victims, even when granted international protection, are trafficked within the host country or to other countries in the region.

Most of the time, the trafficking is not committed by highly organized criminal networks, but rather by family members, acquaintances and neighbours. ${ }^{73}$

Trafficking in persons also occurs along the route to a safer place. A survey conducted between December 2015 and March 2016 by the International Organization for Migration (IOM) on the recent mixed migration flows along the Western Balkan route from Turkey and Greece to Western Europe captures the severity of this phenomenon. More than 7 per cent of the 2,385 people surveyed by IOM reported at least one trafficking or other exploitative

\footnotetext{
1 Save the Children (2016). Piccoli Schiavi Invisibili (Small Invisible Slaves), Save the Children Italia Onlus.

72 International Centre for Migration Policy Development (ICMPD) (December 2015). Targeting vulnerabilities: The Impact of the Syrian War and Refugee Situation on Trafficking in Persons.

73 Ibid.
} 


\section{Trafficking of migrants for extortion and organ removal on some African routes}

Migrants handing over their lives to someone who promised a safe passage into a desired destination and later finding themselves sexually exploited or in forced labour is a wellknown modus operandi for traffickers. There are also reports of migrants who are eventually trafficked for the purpose of ransom or organ removal along the migration routes.

Growing public awareness of the issue, and an intensified security presence, has led to a significant reduction of the trafficking of African refugees to the Sinai. Notwithstanding, the number of those disappearing on the Eastern African route to North Africa is not falling as rapidly and kidnappings are reported in different parts along the route, which suggests that the trafficking flow has now been rerouted. ${ }^{a}$

The trafficking of African migrants and refugees who, on their journey along the East African routes to North Africa and eventually to Europe are kidnapped for ransom by those who they thought were facilitating their travel, came to light for the first time in 2010 . $^{\mathrm{b}}$

Since then, this practice has been documented by a number of NGOs and international organizations and has gained growing public exposure. ${ }^{c}$ The trafficking of African refugees along this route has also been documented by the UN Monitoring Group on Somalia and Eritrea, established by the UN Security Council under the Somalia and Eritrea Sanctions Committee. ${ }^{d}$

This trafficking, which dramatically intensified as of 2010, involved an estimated 25,000-30,000 people between 2009 and 2013. More than 4,000 people are believed to have died in the context of trafficking along the route from Eastern Sudan and the Horn of Africa since the beginning of 2008 .

The victims of trafficking in persons involved in this flow are mainly Eritrean - including men, women and children - fleeing widespread human rights violations and indefinite military service. ${ }^{\mathrm{f}}$ Once they have crossed the border into Eastern Sudan - usually with the help of smugglers migrants and refugees are abducted by nomadic groups living in Eastern Sudan and North-Western Eritrea. ${ }^{\text {S Some- }}$ times victims are sold to traffickers by the smugglers who helped them leave Eritrea.

The Monitoring Group on Somalia and Eritrea and UNHCR have provided evidence that officers of the Eritrean military collaborate with traffickers from nomadic tribes and are often direct beneficiaries of the payments extorted from the victims. ${ }^{\text {h }}$

After being kidnapped, the victims are transported by car to the desert and forced to pay around US $\$ 3,000$ per person for the journey. They are handed over or sold to nomadic tribes, who first gather them in warehouses, and then sell them to different gangs along the route. Chained together and locked in the so-called 'torture houses', victims are exposed to extreme heat during the day and freezing cold temperatures at night, deprived of food, water and sleep, subjected to sexual abuse and forced labour, and routinely tortured for extortion. While tortured, they are forced to call their relatives and to ask them to pay ransoms up to US\$50,000 for their release. ${ }^{\mathrm{i}}$
Ransoms are collected with the help of middlemen, and transfers are usually made through large, international payment services. The hostages provide the traffickers with the code to withdraw the money transferred by their relatives.' If the traffickers realise that a hostage cannot pay, that person may be killed as an example for others. ${ }^{k}$ There have also been reports of traffickers continuing to collect ransoms when hostages have already died, or demanding new ransoms after the required amount of money has been paid. ${ }^{1}$

The issue of forced removal of organs in the context of trafficking in persons and migrant smuggling in North-Eastern Africa gained renewed international attention in July 2016, when the Italian authorities arrested 38 people suspected of being members of an transnational organised criminal group involved in these crimes. The investigation revealed that Eritrean migrants, who had been kidnapped along the route to North Africa and who were unable to pay ransoms, were killed to remove their organs. The organs were then sold for around US\$15,000. ${ }^{\mathrm{m}}$

a Connell, D., 'The rerouted trafficking of Eritrean refugees', Middle East Report - MER, n.278, Life in Exile, Spring 2016; UNHCR (2013), op. cit., p.11

b In December 2010, the United Nations High Commissioner for Refugees (UNHCR) expressed serious concern about the situation of 250 Eritrean refugees kidnapped for ransom and held hostage by traffickers in the desert of the Sinai peninsula. Far from being an isolated case, the incident brought to light a trafficking flow originating from Eastern Sudan and the Horn of Africa, and being held captive in this part of the world. See UN High Commissioner for Refugees, UNHCR urging Egypt to intervene to secure release of Eritreans held hostage, statement by UNHCR spokesperson Adrian Edwards, 7 December 2010. See UN High Commissioner for Refugees, UNHCR urging Egypt to intervene to secure release of Eritreans held hostage, statement by UNHCR spokesperson Adrian Edwards, 7 December 2010.

See, for instance, UNHCR (2014). Smuggling and Trafficking from the East of Africa: Progress Report, October 2014; Human Rights Watch (2014). "I Wanted to Lie Down and Die" - Trafficking and Torture of Eritreans in Sudan and Egypt; Van Reisen, M., Estefanos, M. and Rijken, C., (2013), The Human Trafficking Cycle: Sinai and Beyond, Wolf Legal Publishers, Oisterwijk, Netherlands; Van Reisen, M., Estefanos, M. and Rijken, C., (2012), Human trafficking in the Sinai: Refugees between Life and Death, Wolf Legal Publishers, Oisterwijk, Netherlands.

d See the 2011-2013 Reports of the Monitoring Group on Somalia and Eritrea (United Nations Security Council) available at: https://www. un.org/sc/suborg/en/sanctions/751/work-and-mandate/reports.

UNHCR (2014), op. cit., p.2.

Ibid.

g UNHCR (2013). Refugees and the Rashaida: human smuggling and trafficking from Eritrea to Sudan and Egypt, p.10.

h S/2011/433, United Nations Security Council, Report of the Monitoring Group on Somalia and Eritrea pursuant to SC resolution 1916 (2010), 18 July 2011, p. 118; S/2013/440, United Nations Security Council, Report on Eritrea of the Monitoring Group on Somalia and Eritrea pursuant to SC resolution 2060 (2012), 25 July 2013, p. 35-37. See also: UNHCR, 2013, op. cit., p.13.

Van Reisen, Estefanos and Rijken (2012), op. cit., p.4.

Ibid. p.43

Ibid. p.62-63.

Van Reisen, Estefanos and Rijken (2013), op. cit., p.65.

m Procura della Repubblica presso il Tribunale di Palermo Direzione Distrettuale Antimafia, Arrest warrant decree - art. 384 c.p.p. Proc. Pen. n.20523/2015 DDA R.G. notizie di reato - mod. 21. 
experience during their journey. The rate recorded among Syrian nationals was about 9 per cent. ${ }^{74}$

The United Nations Special Rapporteur on trafficking in persons, especially women and children, has highlighted that persons fleeing conflict situations could also be vulnerable to, among other forms of trafficking in persons, trafficking for the purpose of organ removal, ${ }^{75}$ as reported in the text box on p.62.

Like those fleeing violence, people at risk of individual persecution based, for example, on their ethnicity, religion or political opinion, are also vulnerable to human trafficking. This is the case, for instance, of some ethnic minorities in South-East Asia at risk of being trafficked ${ }^{76}$ within the region. About 4 per cent of the victims detected in East Asia and the Pacific are stateless; lacking the protection of a state which increases vulnerability. Similarly, there is a sizable trafficking flow of Eritreans to the Middle East, about 8 per cent of all victims detected in the Middle East between 2012 and 2014. In light of the challenging human rights situation in Eritrea, which is one of the top-ten origin countries for refugees, ${ }^{77}$ the vulnerability to be trafficked of people escaping from persecution appears clear. ${ }^{78}$

Finding refuge in a safe country does not always shield an individual from the risk of becoming victimised by human trafficking. According to the relevant international and regional legal instruments, a person fleeing persecution for any of the reasons listed in the same legal instruments and unable to avail themselves of the protection of their country of citizenship or escaping from general violence should be granted international protection. However, in the country where protection is sought, an individual may not have access to asylum procedures or may face a long

74 International Organization for Migration (IOM) (March 2016). Mixed Migration Flows in the Mediterranean and Beyond, About the Human Trafficking and other exploitative practices Prevalence Indication Survey.

75 A/HRC/32/41, United Nations General Assembly, Human Rights Council, Report of the Special Rapporteur on trafficking in persons, especially women and children, 3 May 2016, p. 7.

76 For more information, see A/HRC/32/18, Situation of human rights of Rohingya Muslims and other minorities in Myanmar: Report of the United Nations High Commissioner for Human Rights, 28 June 2016 (Advance Edited Version).

77 See UNHCR (2015). UNHCR Global Trends, Forced Displacement in 2014: World at War; UNHCR Refugees/Migrants Emergency Response - Mediterranean (http://data.unhcr.org/mediterranean/ regional.php).

78 The trafficking of Eritreans to the MENA region has been the subject of several reports in the last few years. Among the most recent ones: Human Rights Watch (2014). "I Wanted to Lie Down and Die" - Trafficking and Torture of Eritreans in Sudan and Egypt; Amnesty International (2013). Egypt/Sudan: Refugees and asylum-seekers face brutal treatment, kidnapping for ransom, and human trafficking. wait before their application for international protection is assessed. Moreover, even if they are granted protection, refugees may still experience limited access to labour market or to education opportunities. Such circumstances, and the lack of an appropriate durable solution, put the person asking for asylum in a limbo, which makes them vulnerable to trafficking.

The link between people escaping persecution and human trafficking is sometimes determined by the fact that the persecution is carried out by the traffickers. Being a trafficking victim can sometimes be the basis why refugee status or complementary forms of protection are granted to the victim.

A relevant example is that of a Nigerian girl who was trafficked to France and granted refugee status in 2015 based on the probable retaliation she could face in her home country from the organization that brought her to Europe, or, similarly, the case of an Albanian woman who was domestically trafficked, managed to flee to the United Kingdom, and received asylum there in $2010 .{ }^{79}$ In these two cases, as in many others, the scenario envisages victims of trafficking who escaped from their exploiters and fear reprisal or re-trafficking by members of the trafficking network in their home country. In some other scenarios where the victim of trafficking is granted refugee status, there is a well-founded fear of persecution related to the stigmatization the victim may suffer in the community of origin.

Not all victims of trafficking or persons at risk of being trafficked are eligible for refugee status or complementary forms of protection. As documented by the cases described above, in order to be eligible, such persons must be able to establish that there is a reasonable possibility that they would face persecution in case of return to their home country, and that their country of origin would be unable or unwilling to protect them. The United Nations High Commissioner for Refugees has issued specific guidelines on the matter, ${ }^{80}$ and the link between human trafficking and the need for international protection is now acknowledged in the asylum jurisprudence of several countries, though not always recognized in practice.

79 See, for example, Décision No. 10012810, 24 mars 2015, France: Cour nationale du droit d'asile, 24 March 2015; United Kingdom, Upper Tribunal (Immigration and Asylum Chamber), $A M$ and $B M$ (Trafficked women) Albania CG [2010] UKUT 80 (IAC), 2010.

80 UNHCR (2006), Guidelines on International Protection: The application of Article 1A(2) of the 1951 Convention andlor 1967 Protocol relating to the Status of Refugees to victims of trafficking and persons at risk of being trafficked. 


\section{Trafficking in persons in conflict situations}

The complex linkages between trafficking in persons and conflict have been acknowledged and investigated by the United Nations in various contexts. ${ }^{81}$ During an armed conflict, many elements that appear to increase individual and group vulnerability to trafficking - such as lack of economic opportunities, discrimination and gender-based violence - are exacerbated. Moreover, as a result of forced displacements, community and family support networks are weakened or destroyed, which further increases individual vulnerability to trafficking.

At the same time, armed conflicts represent an opportunity for traffickers. The state of impunity originating from the erosion of the rule of law and the breakdown of order allows traffickers to operate more easily and their business to thrive. As discussed above, refugees fleeing armed conflicts may end up in trafficking situations in their search for a safer place. ${ }^{82}$ Research has also shown that, during an armed conflict, trafficking in persons often stems from the use of negative coping mechanisms and risky survival strategies. Faced with physical and economic insecurity, families may see early forced marriage as a way of alleviating poverty and protecting girls from difficult living conditions. Similarly, they may fall prey to traffickers who claim to offer their children a safer place and job opportunities. According to research by the International Organization for Migration and the International Centre for Migration Policy Development, for instance, the incidence of trafficking for forced marriage and labour stemming from negative coping mechanisms has significantly increased in Iraq and the Syrian Arab Republic as a result of conflict there. ${ }^{83}$

The ICMPD study mentioned above also notes that many of the forms of trafficking which are prevalent in the context of the current war in the Syrian Arab Republic and the consequent refugee situation were also observed prior to 2011. But some forms of trafficking, namely sexual slavery, forced marriages and exploitation committed by the armed forces active in the conflict, have emerged since

\footnotetext{
81 See, for example, A/HRC/32/41, op. cit.; S/PRST/2015/25, United Nations Security Council, Statement by the President of the Security Council, 31 December 2015; and S/2016/361, United Nations Security Council, Report of the Secretary-General on conflict-related sexual violence, 20 April 2016 ( p. 7).

82 A/HRC/32/41, op. cit., p.4.

83 IOM (2015). Addressing human trafficking and exploitation in times of crisis: evidence and recommendations for further action to protect vulnerable and mobile populations; ICMPD (2015). Targeting vulnerabilities: The Impact of the Syrian War and Refugee Situation on Trafficking in Persons.
}

the beginning of the crisis and can be directly related to the war. ${ }^{84}$

The situations described in the ICMPD study concerning the Syrian conflict also occur in the context of many other conflicts. While some forms of trafficking are the result of increased vulnerability among the persons affected, such as people escaping conflict areas, other forms are carried out directly by armed groups operating in the conflict zones.

Trafficking of children for exploitation as combatants in armed conflicts is widely documented in different regions of the world. There is also evidence of children - but also men and women - who have been forcibly recruited by armed groups to fight and provide labour and sexual services. For instance, in the Central African Republic - a country which has been wracked by civil war over the past four years - boys are domestically trafficked to serve as combatants in the armed forces. In 2014, as many as 6,000 children were estimated to be associated with different armed groups involved in this conflict. ${ }^{85}$ Similarly, between 2010 and 2013, the United Nations documented 4,194 cases of children forcibly recruited to serve as combatants, escorts, cooks, porters, guards and sex slaves in the Democratic Republic of the Congo by many of the armed groups operating in that country and in neighbouring countries. ${ }^{86}$ Between June and September 2013 alone, it was documented that 2,234 children (426 girls and 1,808 boys) had escaped or had been separated from armed forces and groups. ${ }^{87}$ Children are recruited in villages, at school or even in refugee camps. The United Nations Mission in the Central African Republic and Chad (MINURCAT) documented how, between 2008 and 2010, the different armed groups operating in territories under MINURCAT competence were recruiting children in at least two large camps, giving shelter to refugees who had fled to eastern Chad from the conflict in Darfur. ${ }^{88}$

\footnotetext{
84 ICMPD ibid.

85 S/2014/142, United Nations Security Council, Report of the Secretary-General on the Central African Republic submitted pursuant to paragraph 48 of Security Council resolution 2127 (2013), 3 March 2014; S/2014/562, United Nations Security Council, Report of the Secretary-General on the situation in the Central African Republic, 1 August 2014.

86 S/2014/453, United Nations Security Council, Report of the Secretary-General on children and armed conflict in the Democratic Republic of the Congo, 30 June 2014.

87 S/2013/581, United Nations Security Council, Report of the Secretary-General on the United Nations Organization Stabilization Mission in the Democratic Republic of the Congo, 30 September 2013.

88 S/2010/217, United Nations Security Council, Report of the Secretary-General on the United Nations Mission in the Central African Republic and Chad, 29 April 2010; S/2009/535, United Nations Security Council, Report of the Secretary-General on the United Nations Mission in the Central African Republic and Chad, 14 October 2009;
} 
West African countries have also experienced trafficking for child soldiering. In April 2012, former Liberian president Charles Taylor was convicted by the UN Special Court for Sierra Leone for crimes violating Article 3 Common to the Geneva Conventions and of Additional Protocol II, crimes against humanity and other serious violations of international humanitarian law during the civil war in Sierra Leone in the 1990s. The court convicted him of planning, aiding and abetting the commission of crimes, including the use of child soldiers, sexual slavery and sexual violence and enslavement, as well as for other charges under the competence of the Court. There was evidence that about 2,200 children under the age of 15 had been abducted between 1996 and 2002. ${ }^{89}$

More recently, reports have surfaced that children in northern Nigeria are being forced by the terrorist group Boko Haram to carry out suicide attacks, ${ }^{90}$ the ultimate form of exploitation. In May 2015, for example, a 12-yearold girl was used to detonate a bomb at a bus station in Damaturu. Seven people were killed. ${ }^{11}$ Earlier this year, UNICEF reported that suicide attacks by Boko Haram rose 11-fold from 2014 to 2015 , and that 20 per cent of the attacks were committed by children as young as eight. ${ }^{92}$

Child soldiering is not limited to Africa. A 2015 report by the International Organization for Migration (IOM) found that in 2013-2014, armed opposition groups in Iraq were actively and forcibly recruiting children as young as 13 to serve as fighters. ${ }^{93} \mathrm{~A}$ number of official documents and reports from human rights organisations also provide evidence of the recruitment of children for exploitation in armed conflict by the different armed factions involved in the Syrian conflict, including the Islamic State in Iraq and the Levant (ISIL, also known as Da'esh), the Kurdish People's Protection Units (YPG) and the Nusra Front. ${ }^{94}$

S/2008/760, United Nations Security Council, Report of the Secretary-General on the United Nations Mission in the Central African Republic and Chad, 4 December 2008.

89 Special Court for Sierra Leone, Trial Chamber II, Prosecutor v. Charles Taylor, Judgement (SCSL-03-01-T), 18 May 2012 (p. 497).

90 S/PRST/2015/4, United Nations Security Council, Statement by the President of the Security Council, 19 January 2015.

91 A/HRC/30/67, United Nations General Assembly, Violations and abuses committed by Boko Haram and the impact on human rights in the countries affected, Report of the United Nations High Commissioner for Human Rights (Advance Unedited Version), 29 September 2015.

92 UNICEF, Beyond Chibok, briefing, April 2016.

$93 \operatorname{IOM}$ (2015), op. cit.

94 See, for instance, A/HRC/26/CRP.2, United Nations General Assembly, Oral Update of the Independent International Commission of Inquiry on the Syrian Arab Republic, 16 June 2014; A/HRC/28/69, United Nations General Assembly, Report of the Independent International Commission of Inquiry on the Syrian Arab Republic, 5 February 2015
The United Nations Special Rapporteur on trafficking in persons, especially women and children, notes that, although child trafficking often involves abduction or coercion, recruiters also appeal to notions of martyrdom and indoctrination to enlist children. ${ }^{95}$ In an armed conflict situation, trafficking in persons is also used as a strategy to target ethnic and religious minorities. According to IOM, for example, armed groups have deliberately recruited and exploited members of ethnic and religious minorities in Iraq since the beginning of the civil war in $2014 .{ }^{96}$

In conflict situations, women and girls are particularly vulnerable to sexual and gender-based violence, including trafficking in persons for sexual exploitation. Women and girls are reportedly kidnapped and forced to marry or serve as sexual slaves in many conflict-affected countries around the world. ${ }^{97}$ One widely reported example of this practice is the trafficking in persons and enslavement of women and children of the Yazidi ethno-religious group by ISIL in Iraq and the Syrian Arab Republic. The United Nations Assistance Mission for Iraq (UNAMI) and the United Nations Office of the High Commissioner for Human Rights (OHCHR) reported in October 2015 that Islamic State was holding approximately 3,500 civilians, mostly women and children, primarily Yazidi. ${ }^{98}$ Nadia Murad, a young Yazidi woman who was appointed UNODC Goodwill Ambassador for the dignity of survivors of human trafficking in September 2016, has spoken publicly about how she was sexually enslaved by ISIL soldiers alongside her two sisters. Their mother was executed as she was 'too old' to be enslaved. She also witnessed young children being given to ISIL soldiers as 'sexual gifts'. ${ }^{99}$ Moreover, in 2014, a media campaign raised awareness about the abduction of 276 schoolgirls in Chibok by the Boko Haram terrorist group active in northern Nigeria. The group itself reported that the intention was to sell the girls for forced marriages or as slaves. ${ }^{100}$

\footnotetext{
95 A/HRC/32/41, op. cit., p. 8.

96 IOM (2015), op. cit. In this regard, it is important to note that, although trafficking in persons is not expressly enumerated in the Statute of the International Criminal Court, a number of practices associated with trafficking can, subject to certain specific conditions, be identified as both war crimes and crimes against humanity. See International Criminal Court (2011). Elements of Crimes.

97 A/HRC/32/41, op. cit., p. 9; S/2016/361, op. cit., p.7.

98 OHCHR/UNAMI, Report on the Protection of Civilians in the Armed Conflict in Iraq: 1 May-31 October 2015,p. 17. (This report uses the alternative spelling "Yezidi".)

99 More information about Nadia Murad's story is available at: www. nadiamurad.org.

100 See, for example, Guardian, 'Boko Haram leader: 'We will sell the girls on the market'- video, 6 May 2014, available at: https://www. theguardian.com/world/video/2014/may/06/boko-haram-sell-girlsmarket-video; UNICEF, Beyond Chibok, briefing, April 2016.
} 
In Sub-Saharan Africa, international organizations active in the Central African Republic reported that sexual and gender-based violence against women and girls is being committed by all groups in the context of sectarian violence. According to a government estimate, around 44.5 per cent of the population in the Central African Republic suffered sexual violence in 2014. ${ }^{101}$ The crimes included forced marriage and sexual slavery. Peacekeeping personnel documented the abduction of women and sexual slavery by members of armed groups in many parts of the country. ${ }^{102}$ Sexual slavery and forced marriages were documented by the UN Special Court for Sierra Leone during the civil war there. In this case, different armed groups involved in the conflicts systematically abducted women and girls for the purpose of holding them in captivity as sex slaves. An atmosphere of coercion prevailed, also involving the beating or killing of women. Among combatants, the practice of using women as sex slaves was accepted, open and endemic. Senior commanders enjoyed priority over lower ranking subordinates in their choice of the captured women assigned as wives. Some victims were as young as eight. ${ }^{103}$

Finally, armed forces in conflict zones also recruit civilians for the purpose of exploitation in forced labour, slavery and slavery-like practices. Beside what was mentioned above on forced wives and sexual slaves used for forced domestic work during the civil war in Sierra Leone, the same case reported that the armed forces operating there systematically abducted people from villages they looted to carry arms and ammunition, to provide food, to farm and to mine for diamonds. ${ }^{104}$ To claim 'ownership' of a slave, the armed groups had the letters 'RUF' and/or 'AFRC' carved on to the skin of some victims. ${ }^{105}$ The recruitment was organized by the groups, with officers in charge of finding and managing the victims. The coercive recruitment for diamond mining was particularly wellorganized. Between 600 and 1,000 civilians per day were gathered and exploited in one mining site alone. ${ }^{106}$ Similar

\footnotetext{
101 S/2014/562, United Nations Security Council, Report of the Secretary-General on the situation in the Central African Republic, 1 August 2014, para. 17.

102 S/2014/142, United Nations Security Council, Report of the Secretary-General on the Central African Republic submitted pursuant to paragraph 48 of Security Council resolution 2127 (2013), 3 March 2014; S/2014/562, United Nations Security Council, Report of the Secretary-General on the situation in the Central African Republic, 1 August 2014.

103 Special Court for Sierra Leone, Trial Chamber II, Prosecutor v. Charles Taylor, Judgement (SCSL-03-01-T), 18 May 2012 (pp. 393394).

104 Special Court for Sierra Leone, op. cit. (pp. 383-393).

105 Special Court for Sierra Leone, op. cit. (p. 607).

106 Special Court for Sierra Leone, op. cit. (pp. 583-637).
}

reports have emerged from the Democratic Republic of the Congo, in the provinces where mineral resources are extracted. The United Nations peacekeeping operation there, MONUSCO, has reported how armed forces - regular and irregular - forced civilians to work in the mines. ${ }^{107}$

In conflict areas, armed groups exploit civilian populations under any circumstances. The most frequently documented forms are trafficking for sexual exploitation, for using children as combatants and for forced labour. Persons within the affected areas are not the only ones targeted, as victims from outside are also trafficked into the conflict territories for sexual or forced labour purposes. ${ }^{108}$ In this regard, the United Nations Special Rapporteur on trafficking in persons, especially women and children, has highlighted the trafficking of persons into conflict zones to provide services at military worksites, for example, in the case of Asian workers trafficked to conflict areas in the Middle East. ${ }^{109}$

Trafficking in persons also finds favourable conditions in post-conflict situations. Absent or dysfunctional law enforcement and justice institutions, destroyed communities, lack of basic resources and militarized societies tolerant of high levels of violence fuel trafficking in persons in post-conflict contexts. Moreover, the deployment of peacekeeping forces may have, in some cases, increased the demand for sexual services, with possible attendant increases in human trafficking. ${ }^{110}$
107 A/HRC/13/64, United Nations General Assembly, Report of the
United Nations High Commissioner for Human Rights on the situation of
human rights and the activities of her Office in the Democratic Republic
of the Congo, 28 January 2010.
108 IOM (2015) op. cit. and ICMDP (2015) op. cit.
109 A/HRC/32/41, op. cit., p. 10.
110 Ibid., p.11. 



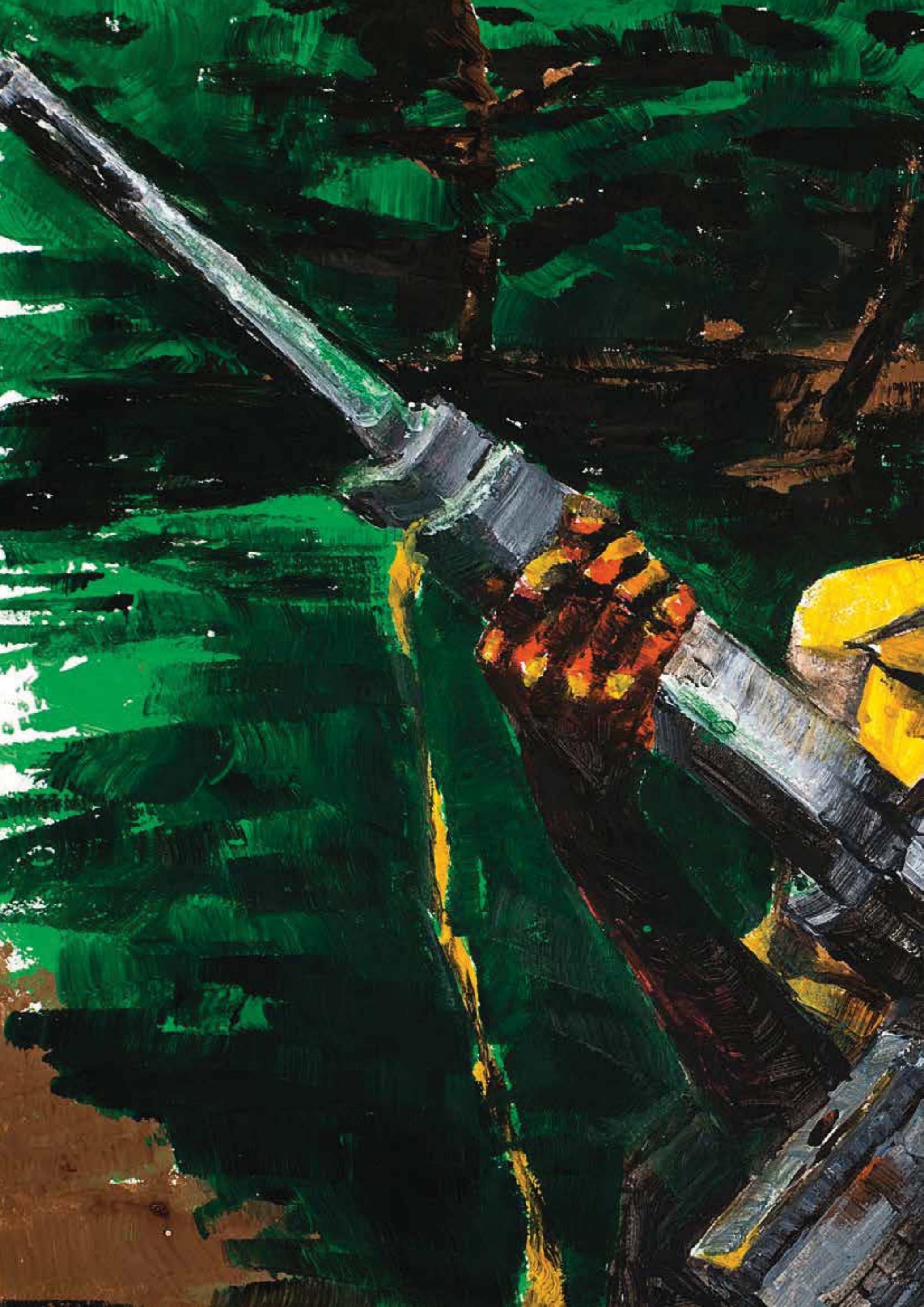




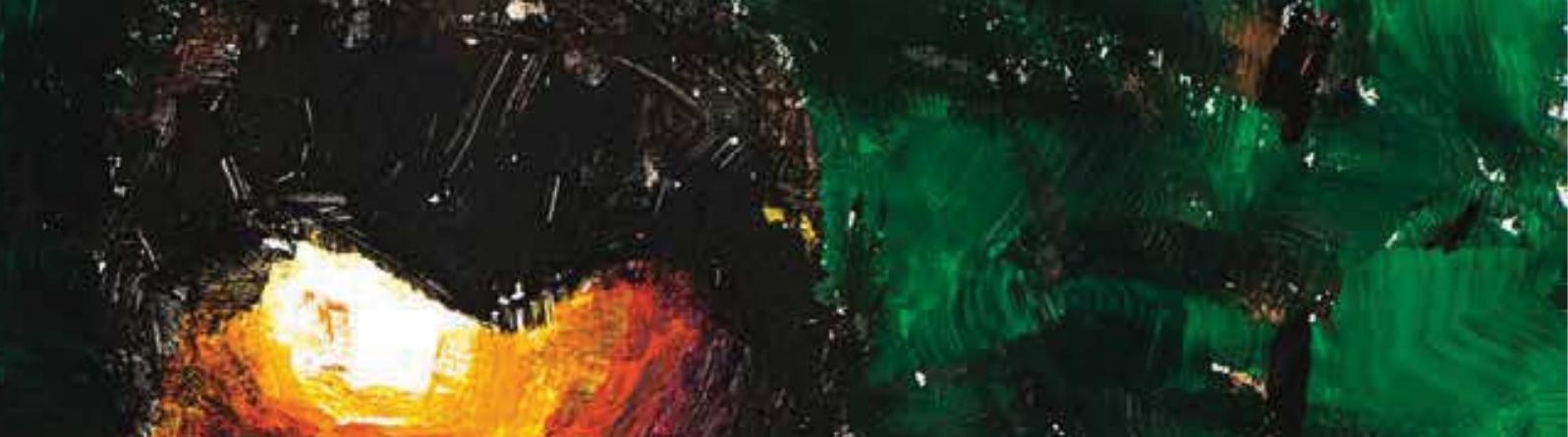

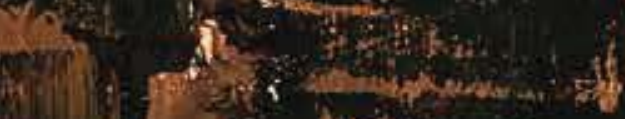

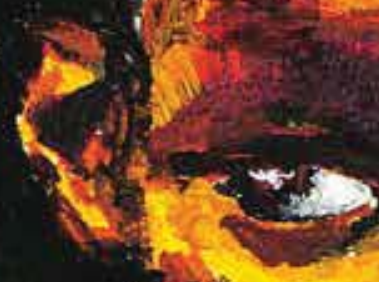

ㄹ. 6

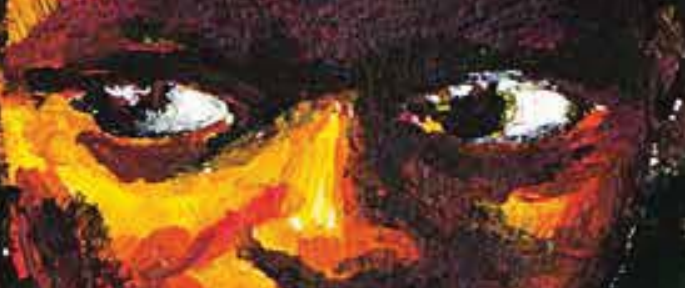
$y+2)=y^{2}$

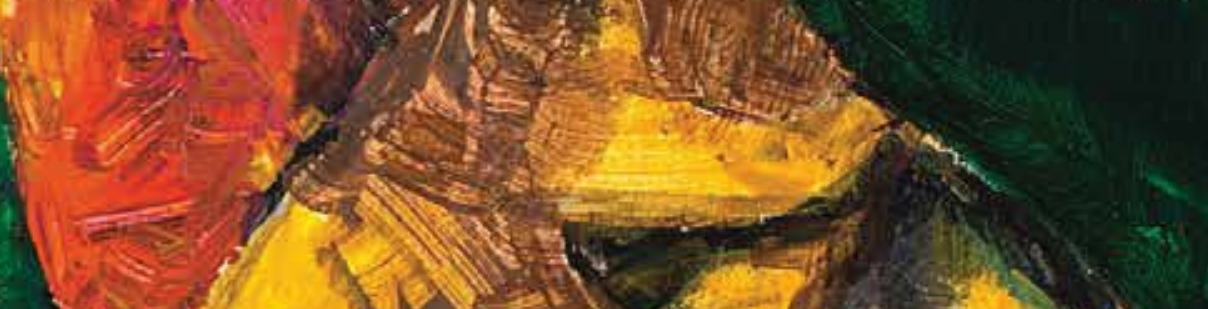
19.

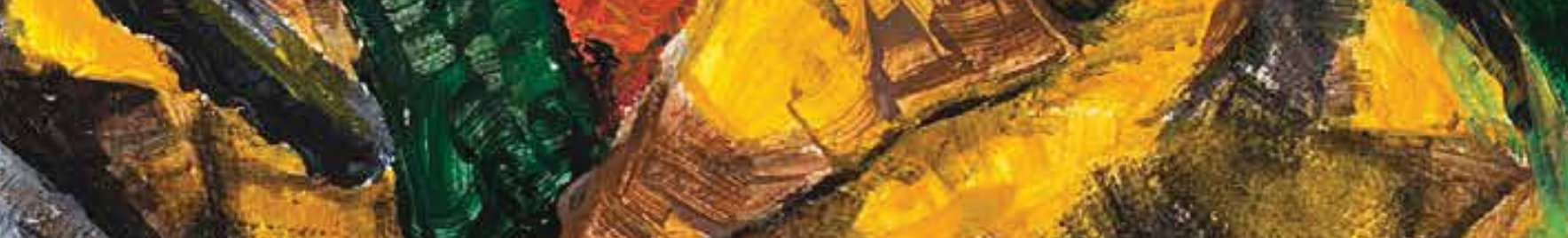
1. 1 ry? $x+2, y=124$ (4) औरำ
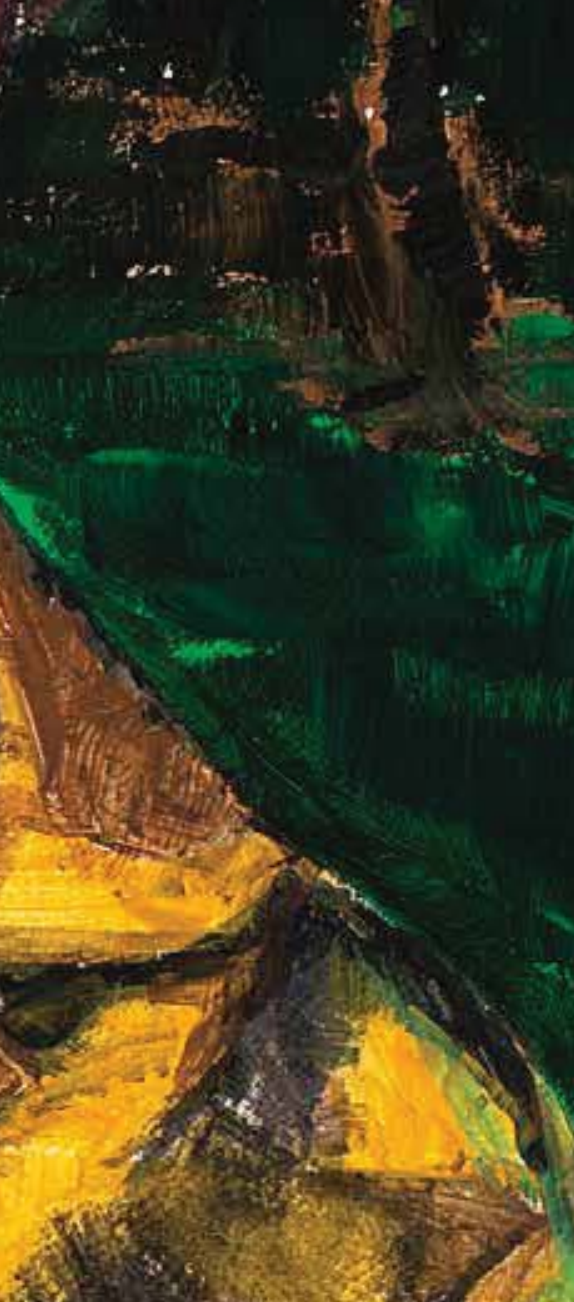



\section{CHAPTER III}

\section{REGIONAL OVERVIEWS}

\section{WESTERN AND CENTRAL EUROPE}

Due to the differences in trafficking patterns and flows, Western and Central Europe has been split into two geographical areas, or subregions. Countries in the subregion of Western and Southern Europe ${ }^{111}$ are among the world's wealthiest. The subregion of Central and South-Eastern Europe $^{112}$ includes some countries of the European Union - of which, some are part of the Schengen area, ${ }^{113}$ and some not - as well as the countries of the Western Balkans. Most of the countries in this subregion have transitional economies.

\section{WESTERN AND SOUTHERN EUROPE}

\section{Key findings}

Most frequently detected victim profile: Women, 56\%

Most frequently detected form of exploitation: Sexual exploitation, 67\%

Gender profile of convicted offenders: $78 \%$ males

Share of national citizens among offenders: $40 \%$

Summary profile of trafficking flows: Destination; particularly for medium-distance trafficking.

Emerging trend: Increasing significance of trafficking for forced labour.

\section{Profile of the victims}

The countries in the two subregions report similar patterns regarding the profiles of detected victims. A clear majority of the approximately 15,200 victims detected, with gender and age reported, in Western and Southern

111 Western and Southern Europe: Andorra, Austria, Belgium, Denmark, Finland, France, Germany, Greece, Ireland, Italy, Malta, Netherlands, Norway, Portugal, Spain, Sweden, Switzerland, Turkey and the United Kingdom.

112 Central and South-Eastern Europe: Czechia, Estonia, Hungary, Latvia, Poland and Slovakia (Central Europe); Albania, Bulgaria, Montenegro, Romania, Serbia, Slovenia and the former Yugoslav Republic of Macedonia (South-Eastern Europe).

113 An area that includes 26 European countries that have abolished passport and any other type of border control at their mutual borders, enabling citizens to cross internal borders without being subjected to border checks.

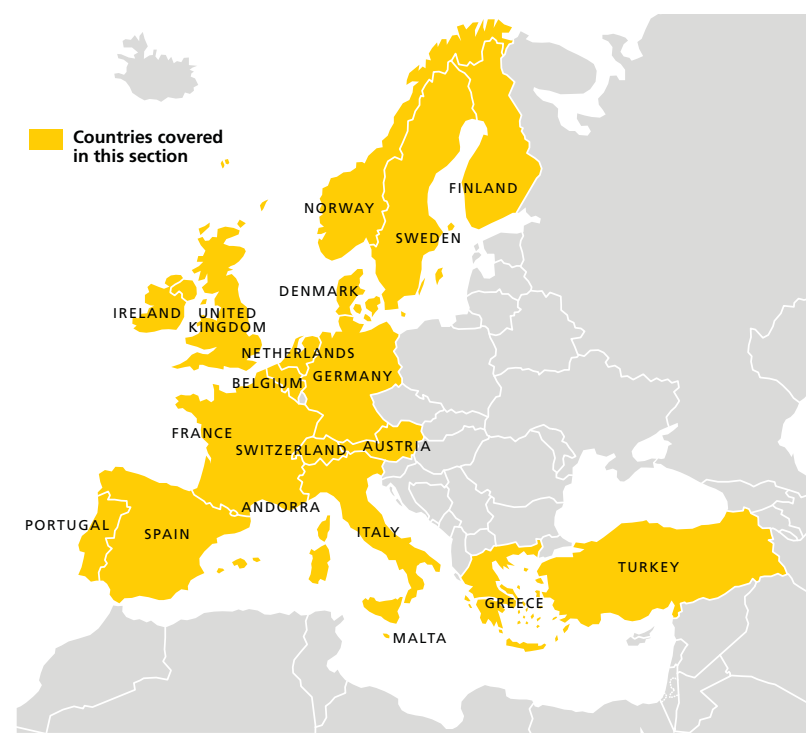

Note: The boundaries and names shown and the designations used on this map do not imply official endorsement or acceptance by the United Nations.

FIG. 45 Detected victims of trafficking in Western and Southern Europe, by age and sex, 2014 (or most recent)

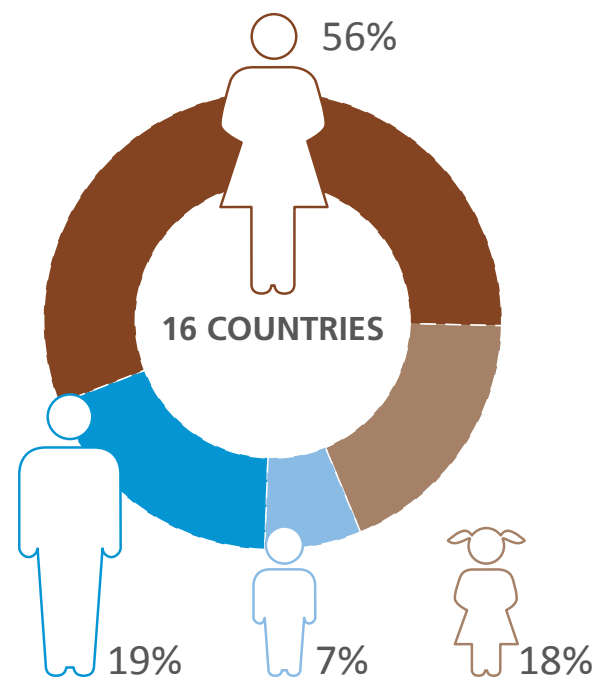

Source: UNODC elaboration of national data.

Europe between 2012 and 2014 were women. Men and girls were detected in near-equal numbers.

The increasing global trend in detections of men is also reflected in the national data from some of the countries in this subregion. Between 2012 and 2014, Austria, Denmark, Germany, Greece, Norway and the United Kingdom all registered clearly increasing shares of adult male 
FIG. 46 Trends in the sex and age profiles of victims detected in Western and Southern Europe, 2007-2014

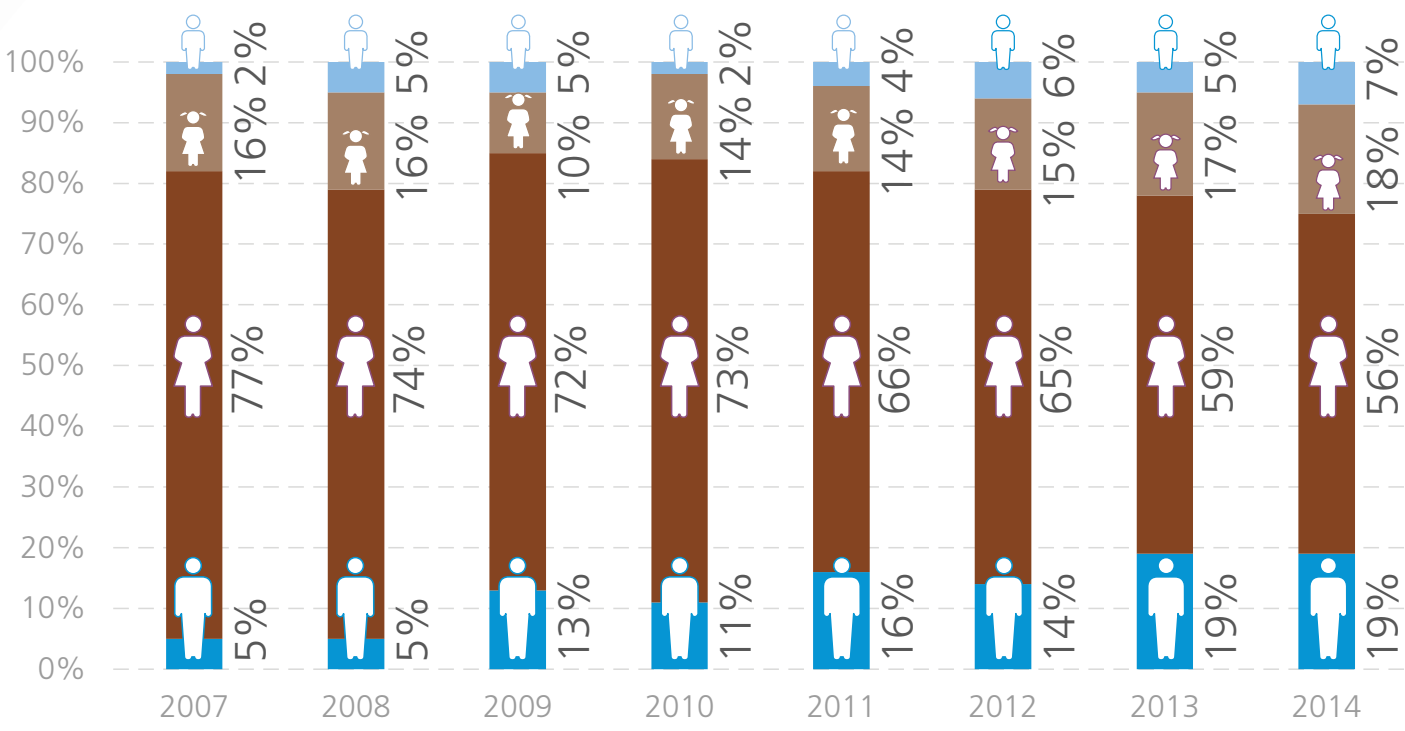

Source: UNODC elaboration of national data.

victims, compared to two years before. Other countries reported stable shares; the Netherlands, for example, around 10 per cent, and Turkey, less than 1 per cent.

Considering data from the last seven years, detections of men and children have fluctuated year-on-year, but clearly increased over the period. The shares of detected women, on the other hand, have decreased consistently and significantly.

\section{Forms of exploitation}

Trafficking for the purpose of sexual exploitation is the most commonly reported form in this part of the world. Out of the 12,775 victims detected between 2012 and 2014 whose form of exploitation was reported, some 67 per cent were exploited for sexual purposes and 30 per cent for forced labour. Trafficking for forced labour includes exploitation in a range of sectors, such as agriculture, construction, commercial cleaning and domestic servitude.

Nearly 4 per cent of the victims were trafficked for 'other' purposes, including about 0.7 per cent for begging, and another 0.7 per cent for the commission of crime. In addition, victims were trafficked for sham and forced marriages and for mixed forms of exploitation (usually involving a combination of sexual exploitation and some type of forced labour). About 85 per cent of the victims trafficked for other purposes were females, especially girls.
FIG. 47 Forms of exploitation among detected victims of trafficking in Western and Southern Europe, 2014 (or most recent)

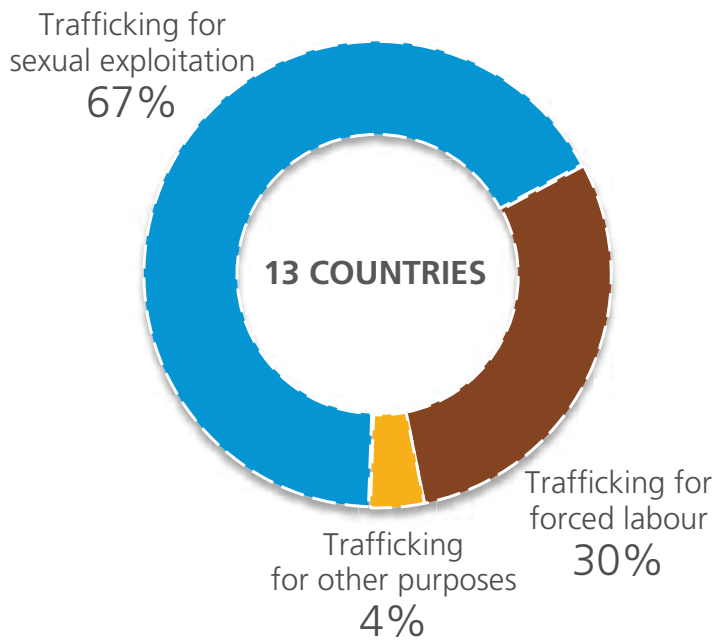

Source: UNODC elaboration of national data.

Women and girls are mostly trafficked for the purpose of sexual exploitation. Some 4 per cent of the detected victims who were trafficked for sexual exploitation in this subregion were males. Females were also trafficked into Western and Southern Europe for forced labour, however. During the reporting period, nearly one third of the victims trafficked for different forms of forced labour were females. 
FIG. 48 Trends in the forms of exploitation among detected victims in Western and Southern Europe, 2007-2014 (or most recent)

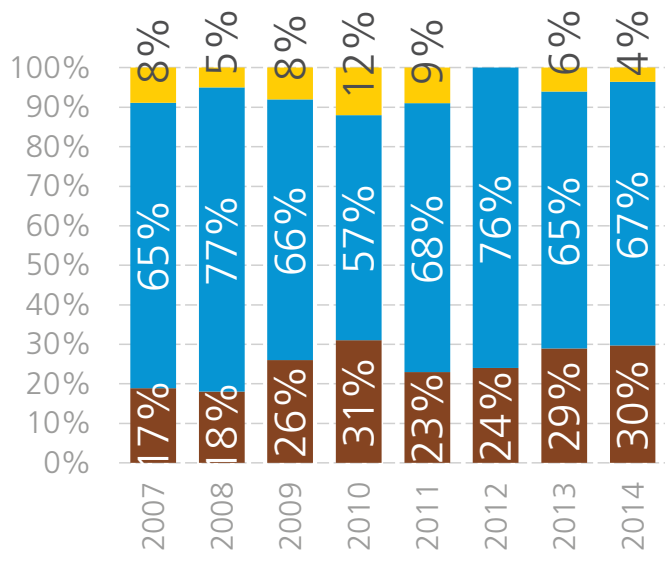

- Trafficking for other forms - Trafficking for sexual exploitation - Trafficking for forced labour

Source: UNODC elaboration of national data.

\section{Profile of the offenders}

Despite the fact that the vast majority of the detected victims in this area are females, either women or girls, and that the reported level of trafficking for sexual exploitation is among the highest in the world, the share of prosecuted and convicted female offenders is among the lowest. About 31 per cent of the persons prosecuted and 22 per cent of the persons convicted of trafficking in persons in 2014 (or most recent) were women.

A clear majority (58 per cent) of the convicted offenders were foreigners from outside Western and Southern Europe. Only North Africa and the Middle East reports a larger share of foreign trafficking offenders. The largest group of convicted foreigners were citizens of countries in South-Eastern Europe, and the third-largest group were citizens of Sub-Saharan Africa (mostly West Africans). Significant numbers of traffickers from the Americas and Asia were also convicted, which demonstrates that trafficking in persons in Western and Southern Europe is a highly international crime.

The citizenships of the convicted foreign traffickers in Western and Southern Europe were clearly connected to the citizenships of the foreign victims during the reporting period. ${ }^{114}$ The most commonly detected flow of for-

\section{FIG. 49 Persons investigated for trafficking in persons in Western and Southern Europe, by sex, 2014 (or most recent)}

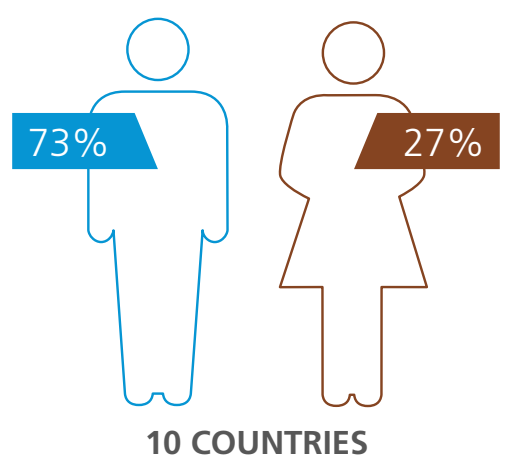

Persons prosecuted for trafficking in persons in Western and Southern Europe, by sex, 2014 (or most recent)

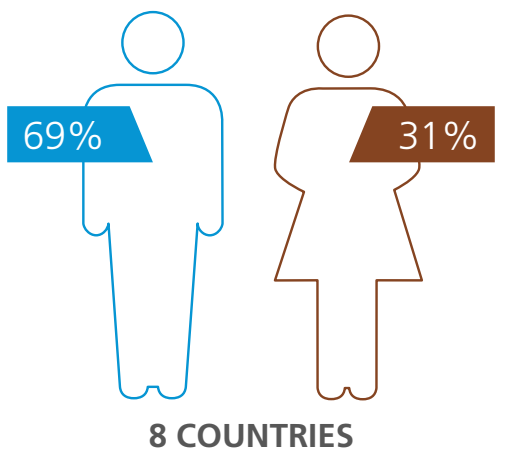

Persons convicted of trafficking in persons in Western and Southern Europe, by sex, 2014 (or most recent)

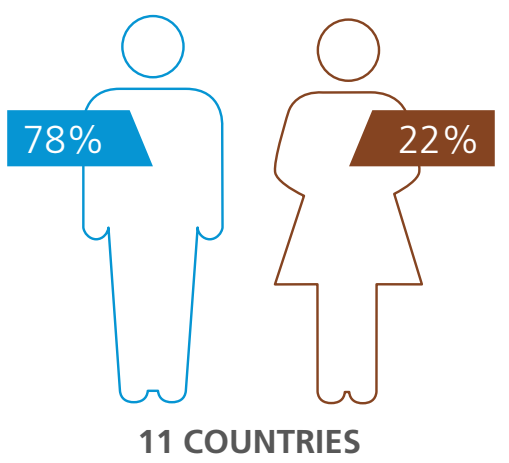

Source: UNODC elaboration of national data.

eign victims originates from South-Eastern Europe. The second most frequently detected regional origin is SubSaharan Africa, especially West Africa. Asian victims are also often detected in this subregion. 
FIG. 50 Share of offenders convicted in Western and Southern Europe, by their area of citizenship, 2014 (or most recent)

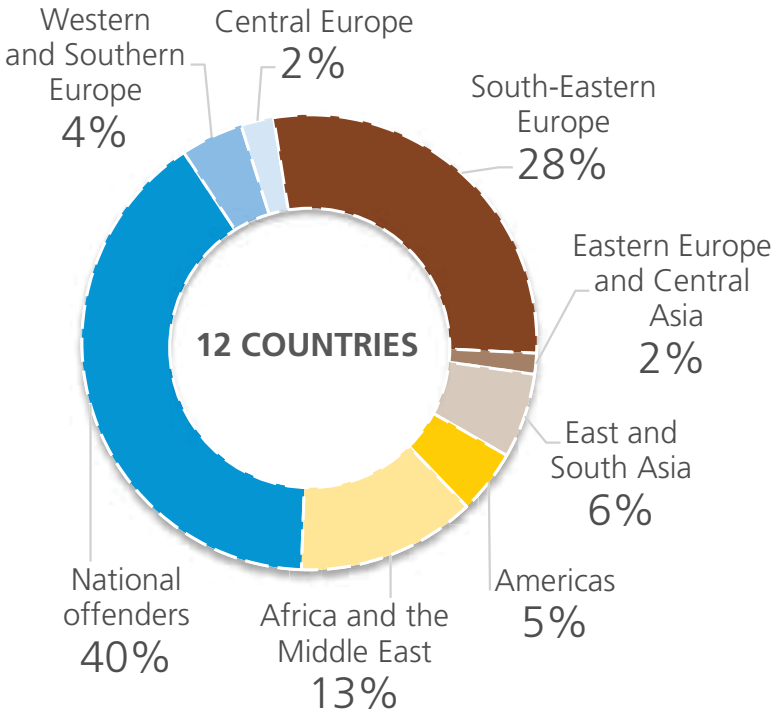

Source: UNODC elaboration of national data.
FIG. 51 Correlation between the citizenships of detected victims and the citizenships of convicted offenders in Western and Southern Europe, 2014 (or most recent)

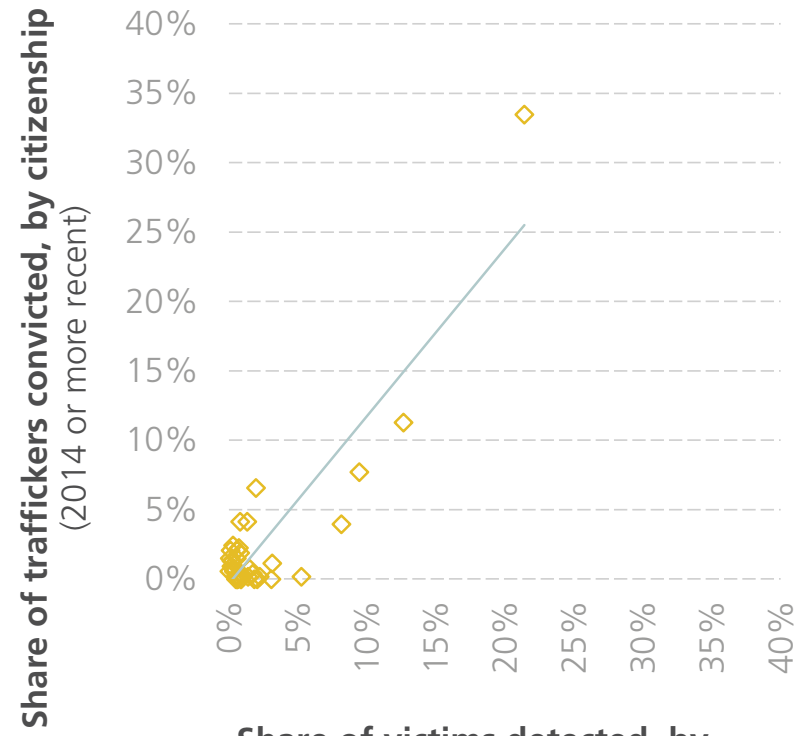

Share of victims detected, by citizenship (2014 or more recent)

MAP 4 Countries of origin for victims detected in Western and Southern Europe, 2012-2014

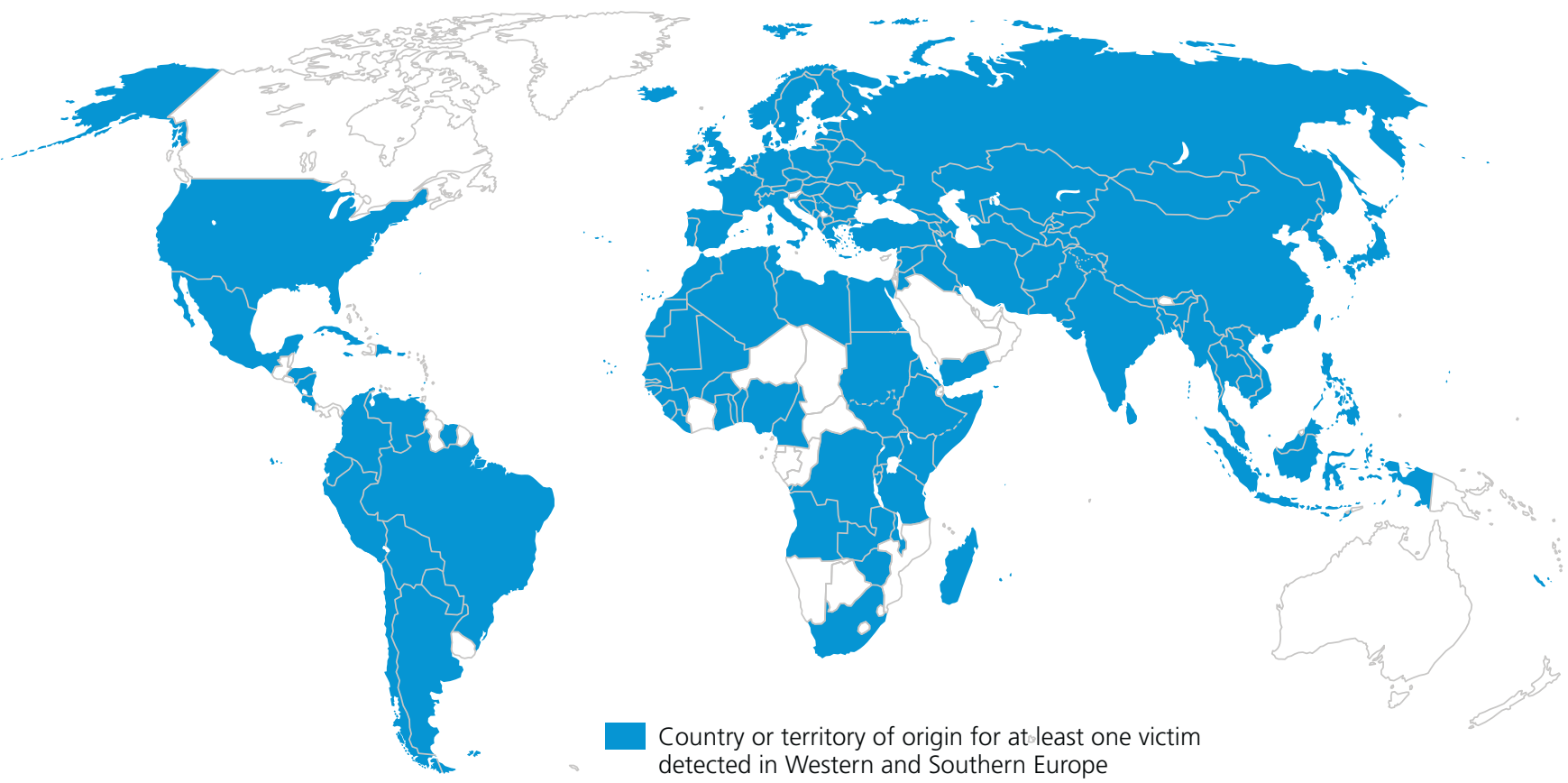

Source: UNODC.

Note: The boundaries and names shown and the designations used on this map do not imply official endorsement or acceptance by the United Nations. The dotted line represents approximately the Line of Control in Jammu and Kashmir agreed upon by India and Pakistan. The final status of Jammu and Kashmir has not yet been agreed upon by the parties. The final boundary between the Republic of Sudan the Republic of South Sudan has not yet been determined. A dispute exists between the Governments of Argentina and the United Kingdom of Great Britain and Northern Ireland concerning sovereignty over the Falkland Islands (Malvinas). 


\section{Trafficking flows affecting Western and Southern Europe}

Western and Southern Europe is a destination area for trafficking flows originating in many different regions. During the 2012-2014 period, 137 different citizenships from all regions were detected in or repatriated from these countries. Nevertheless, many trafficking flows are of short geographical distance. About 18 per cent of the about 13,000 victims detected in this subregion between 2012 and 2014 whose citizenships were reported were trafficked domestically.

Countries within the European Union are the most significant origins of trafficking into Western and Southern Europe. During the 2012-2014 period, about 47 per cent of the victims detected in this part of the world were trafficked from Central and South-Eastern Europe. Victims from Bulgaria or Romania, in particular, were detected in almost every country of this subregion. Victims from the Western Balkans, however, were not detected in significant numbers. Trafficking flows originating from Central Europe were detected in France, Germany, the Netherlands and the United Kingdom, as well as in some other countries.
With regard to trafficking distance, for the reference year 2014 (or most recent), about half of the victims detected at destination were trafficked medium distance. Just over a quarter were trafficked long distance, and strikingly, 7 per cent of victims were trafficked from very distant countries, which again confirms that this area is attractive as a destination for trafficking in persons.

Some victims seem to be trafficked all over Western and Southern Europe, particularly victims from South-Eastern and Central Europe, but also from East Asia and West Africa. There are also trafficking flows that are not widely detected in the whole region, but frequently reported in specific countries, such as East Africans to the United Kingdom, Eastern Europeans to Turkey, South Americans to Spain and France, and North Africans to France.

Apart from intra-European flows, Sub-Saharan Africa was the most commonly detected origin of trafficking into Western and Southern Europe, representing about 16 per cent of the victims. Many of these victims were from West Africa, and citizens of West African countries were detected in large numbers. Nigerian victims, in particular, were detected in Scandinavia, Southern Europe, France, Germany, Ireland, the Netherlands and the United King-

\section{MAP 5 Origins of trafficking victims detected in Western and Southern Europe,} by subregion, 2014 (or most recent)

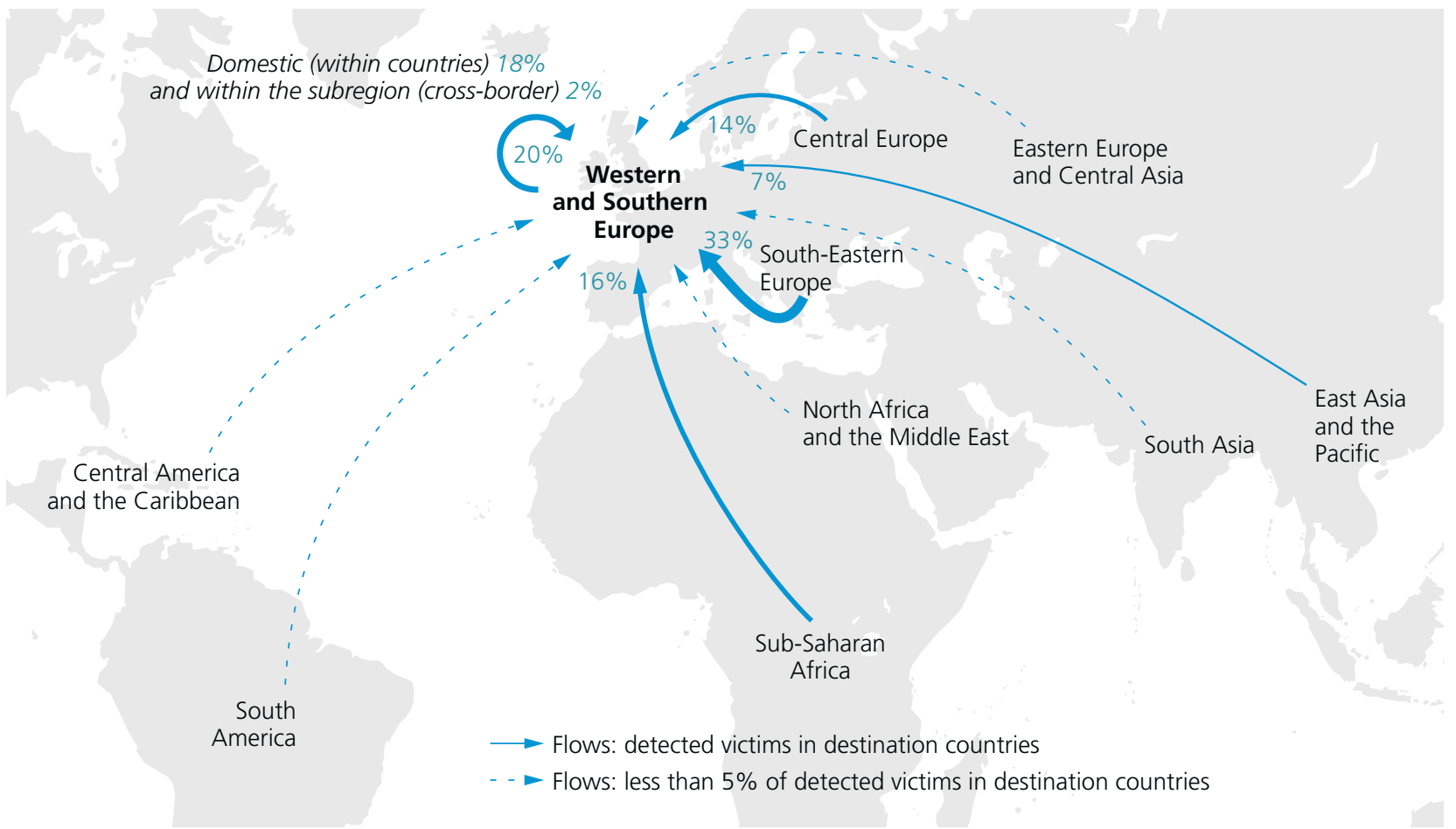


FIG. 52 Shares of detected trafficking flows in Western and Southern Europe, by geographical distance, ${ }^{*} 2014$ (or most recent)

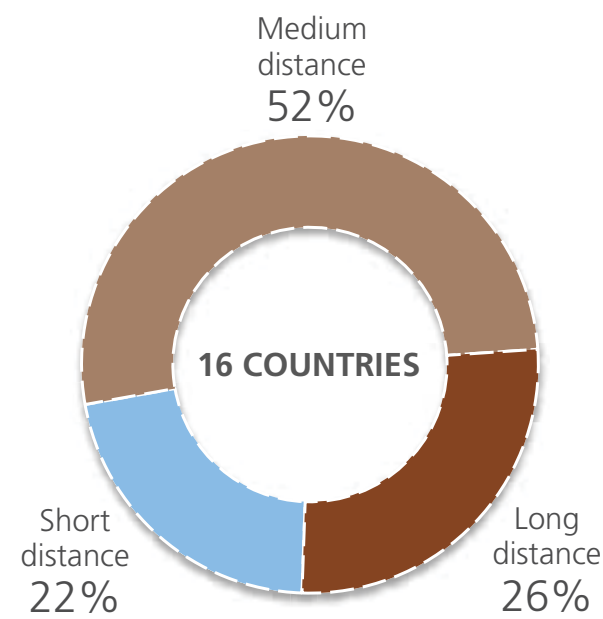

* Short-distance trafficking flows see victims trafficked within national borders or between neighbouring countries; medium-distance flows are between two countries that do not share a border and with the border of the origin country less than 3,500 kilometres away from the closest border of the destination country; and long-distance flows connect countries in which the border of the origin is farther than 3,500 kilometres away from the closest border of the destination.

Source: UNODC elaboration of national data.

dom, accounting for about 7 per cent of the total number of victims detected in 2014 (or most recent). Victims from Cameroon, Ghana, Guinea and Sierra Leone were also widely detected. East Africans were also detected in several countries, and in the United Kingdom, more than 5 per cent of the detected victims were East Africans.
The East Asian trafficking flow into Western and Southern Europe largely comprises victims from China, Indonesia, the Philippines, Thailand and Viet Nam. They comprise some 7 per cent of the detected victims; a share that is relatively consistent across a number of countries. Trafficking of South Asians is limited here; reported by a couple of countries.

Trafficking flows originating in the Americas account for about 3 per cent of victims in Western and Southern Europe. Most of these victims come from South America and are mainly detected in France and Spain. Reductions have been observed for these flows in recent years.

There is a limited flow into Western and Southern Europe from Eastern Europe and Central Asia. There is no specific country of origin, as both Eastern European and Central Asian victims are detected. However, there is a prominent country of destination, as many of these victims were detected in Turkey. Moreover, the vast majority of the victims detected in Turkey (86 per cent) are citizens of countries in Eastern Europe and Central Asia. Thus, this trafficking flow - small in the broader European picture - mainly concerns Turkey.

There is also a limited trafficking flow from North Africa and the Middle East into Western and Southern Europe. It originates mainly in the countries of the Maghreb. These victims can be found especially - though not exclusively - in France, where they comprise 3.4 per cent of victims.

The overall picture regarding long-term trends has not changed considerably. Trafficking from South-Eastern

\section{FIG. 53 Trends in trafficking flows to Western and Southern Europe, by area of origin, 2009-2014}

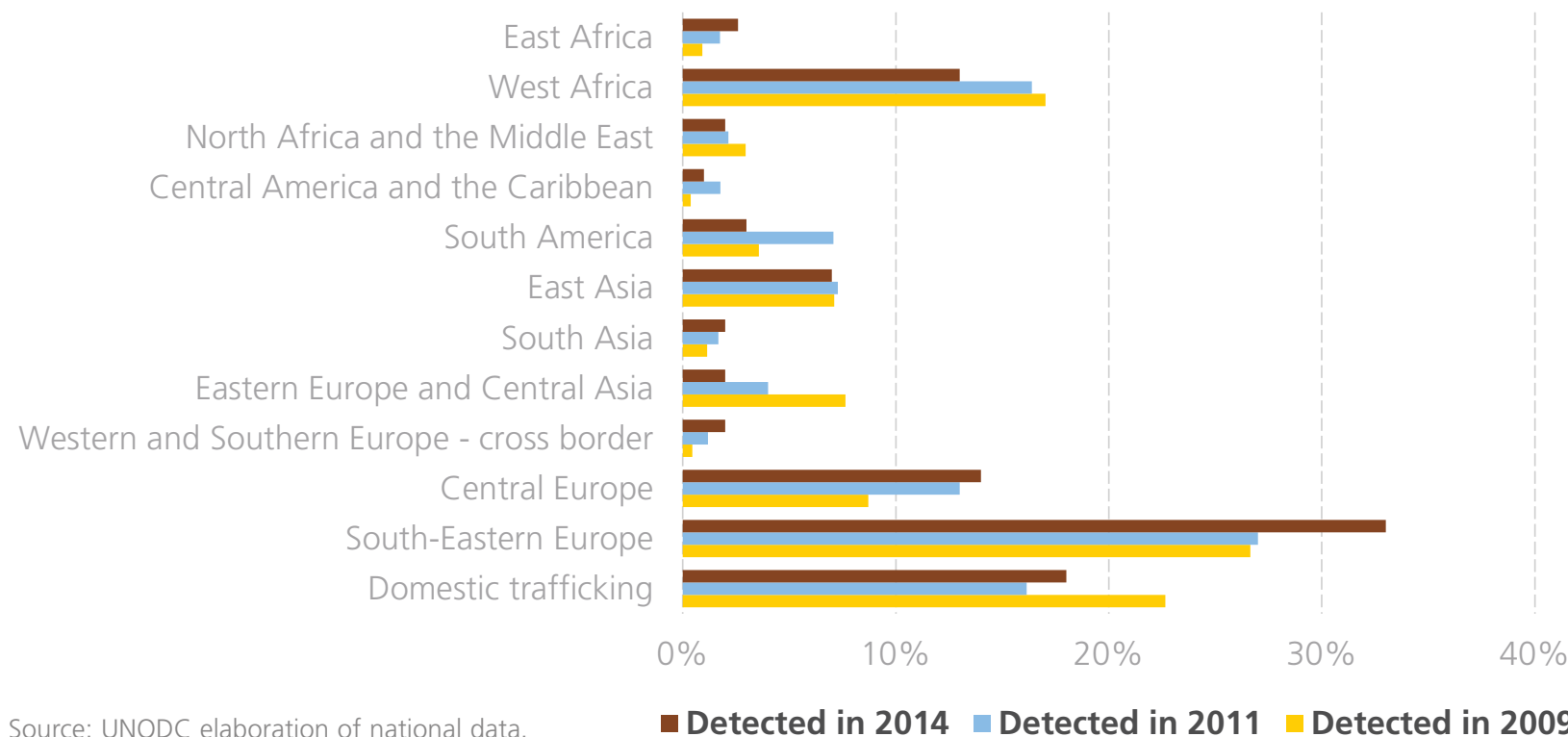


FIG. 54 Trends in trafficking flows to Western and Southern Europe, by major area of origin, 2009-2014

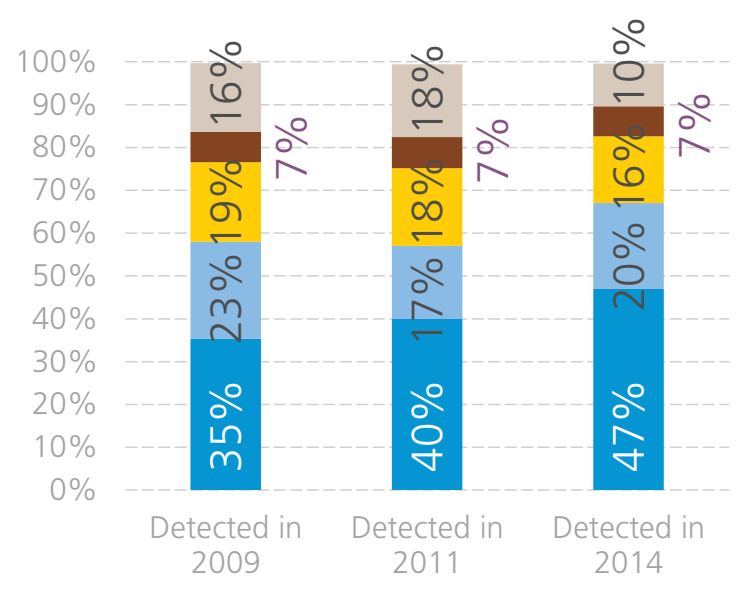

Other regions

- East Asia

Sub-Saharan Africa

Domestic trafficking and sub-regional cross-border

- Central and South-Eastern Europe

Source: UNODC elaboration of national data.

Europe has been the most prominent trafficking flow into Western and Southern Europe for a number of years now, and it continues to increase, according to the most recent data.

With regard to the smaller flows, there have been some changes. Trafficking from Central Europe has been increasingly detected for a few years, rising from 9 to 14 per cent of victims from 2009 to 2014. Trafficking from Eastern Europe and Central Asia, on the other hand, has been decreasing for the last decade, and does not affect countries equally. Flows from West Africa declined somewhat recently. This decrease was, however, compensated by increased flows from East Africa. Trafficking from the Americas and North Africa also appeared to be decreasing during the reporting period.

If current trends continue over the next years, trafficking into Western and Southern Europe will become even more regional and local. Most transregional flows appear to be decreasing, while intraregional flows are growing. This is particularly true for flows from Central and South-Eastern Europe.

\section{Criminalization of trafficking in persons}

Nearly all the countries in this region had enacted a specific trafficking in persons offence with a definition of trafficking in compliance with the UN Trafficking in Persons Protocol definition by the end of 2012. A majority of countries did so during the five years after the entry into force of the Protocol.

In many countries in this region, the offence of trafficking in persons predated the adoption of the UN Trafficking in Persons Protocol; however, it often only covered trafficking for sexual exploitation. This was the situation in the Netherlands and Germany, where the offence of trafficking for sexual exploitation was introduced in 1911 and 1971, respectively. The offence was amended in both countries in 2005 to include the other forms of trafficking as defined by the Protocol. Similar processes took place in Austria, Ireland, Portugal, Spain and Switzerland.

While Denmark and Greece have had legislation in compliance with the UN Trafficking in Persons Protocol since 2002, the other Nordic countries, as well as France, Italy and the United Kingdom, introduced full-fledged legislation between 2003 and 2004. Just recently, Andorra amended its criminal code to align it with the Protocol.

With the exception of Andorra, where the legal framework is too recent to record convictions, all the countries from which information was available reported at least one conviction during the period considered. However, about one third of the countries had less than 10 . On the other end of the scale, about one quarter of the countries had more than 50 convictions per year, in particular the Netherlands and Germany, which convict between 90 and 150 persons per year. This may be connected with the long-standing existence of the offence of trafficking in persons - albeit partial until 2005 - in the penal law of these two countries. The Nordic countries and Malta reported less than 10 convictions per year during the reporting period under the specific offence of trafficking in persons. In general, the number of convictions recorded during the reporting period has increased, with just a couple of countries having marked decreases.

On average, 62 per cent of the persons who were investigated for trafficking were prosecuted during the 20122014 period. About 32 per cent of those prosecuted received first instance convictions. About 20 per cent of the persons who were initially investigated were convicted in the court of first instance in Western and Southern Europe. ${ }^{115}$ 
FIG. 55 Share and number of countries in Western and Southern Europe with a specific offence on trafficking in persons that criminalizes all forms listed in the UN Protocol, by period of introduction of the offence

Period 2

Full trafficking

offence introduced

between January 2004

and November 2008

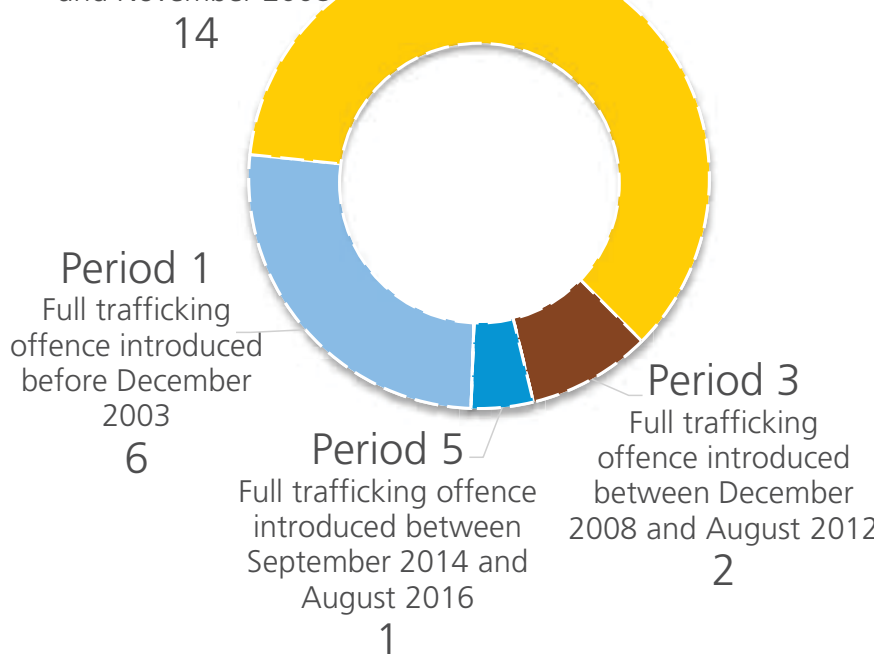

Share of countries in Western and Southern Europe, by number of trafficking convictions, 2012-2014 (one year within the period)

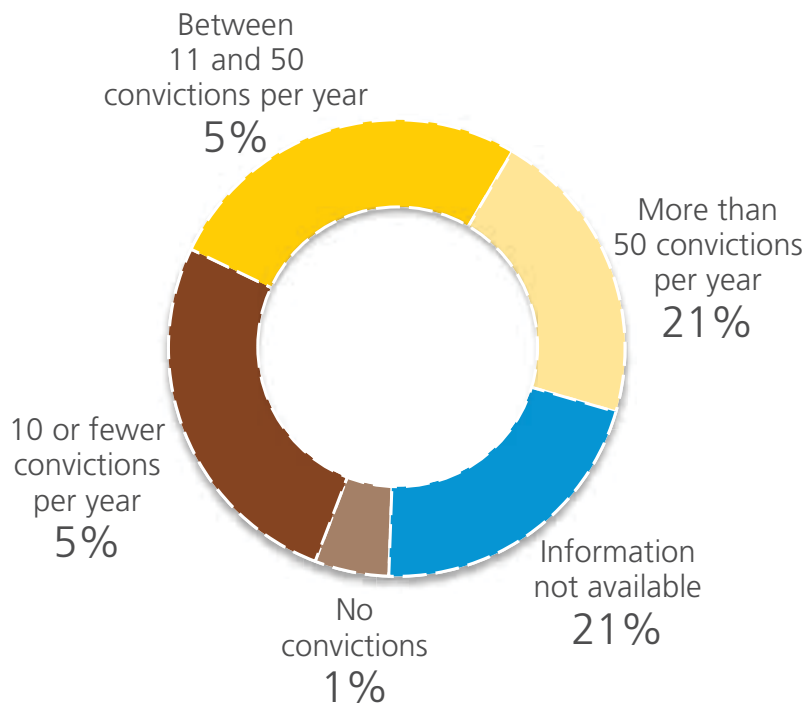

Source: UNODC elaboration of national data.

Note: For the criminalization analysis, more countries are covered than for the section on patterns and flows.

\section{CENTRAL AND SOUTH-EASTERN EUROPE}

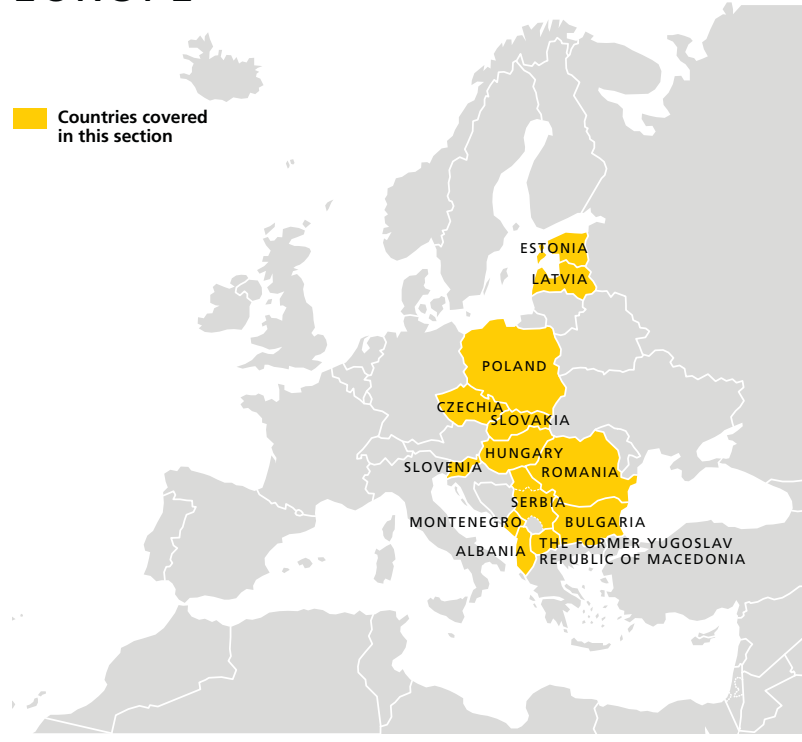

Note: The boundaries and names shown and the designations used on this map do not imply official endorsement or acceptance by the United Nations.

\section{Key findings}

Most frequently detected victim profile:

Women, 54\%

Most frequently detected form of exploitation: Sexual exploitation, $65 \%$

Gender profile of convicted offenders: $84 \%$ males

Share of national citizens among offenders: $96 \%$

Summary profile of trafficking flows: Origin for trafficking within Western and Central Europe. Destination for intraregional trafficking and from Eastern Europe and Central Asia.

Emerging issue: Trafficking for begging and for forced marriage reported by various countries.

\section{Profile of the victims}

About 75 per cent of the approximately 6,870 victims detected in Central and South-Eastern Europe between 2012 and 2014 whose age and gender profiles were reported were female, either women or girls.

This subregion has reported decreasing shares of trafficking in males, both boys and men, over the last six years. However, this is not representative of all the countries; Czechia and Serbia reported increasing numbers of male victims. Decreasing detections of adult men were reported 
FIG. 56 Detected victims of trafficking in Central and South-Eastern Europe, by age and sex, 2014 (or most recent)

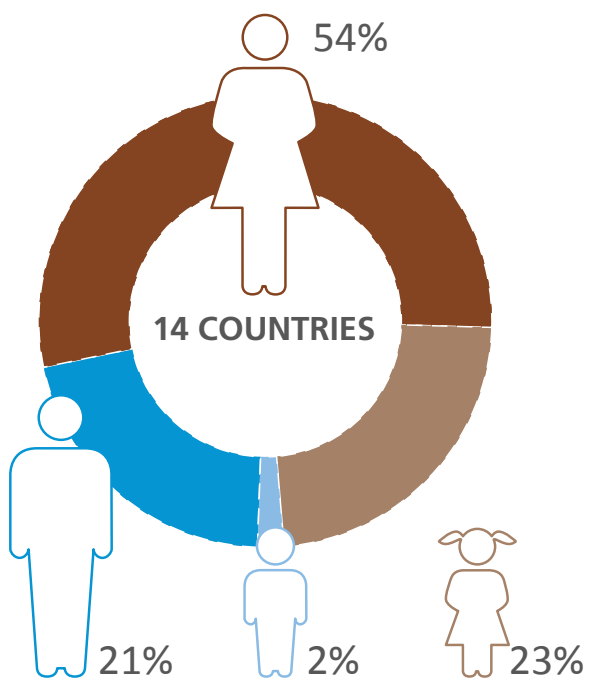

Source: UNODC elaboration of national data.

FIG. 57 Trends in the sex and age profiles of victims detected in Central and South-Eastern Europe, 2009-2014

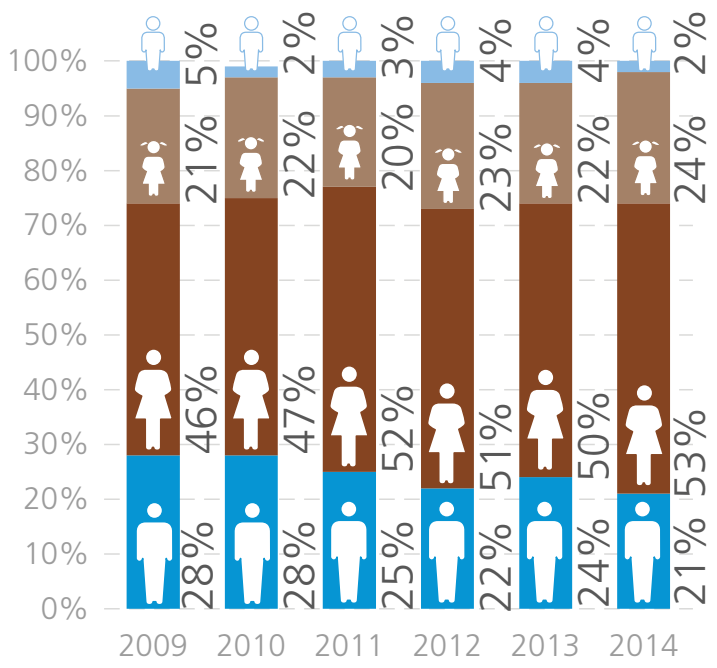

Source: UNODC elaboration of national data.

by Romania, while the other countries had stable trends compared to previous years.

\section{Forms of exploitation}

The vast majority of victims - more than two thirds - were trafficked for sexual exploitation. Of these victims, 97 per cent were females. Trafficking in persons for the purpose
FIG. 58 Forms of exploitation among detected victims of trafficking in Central and South-Eastern Europe, 2014 (or most recent)

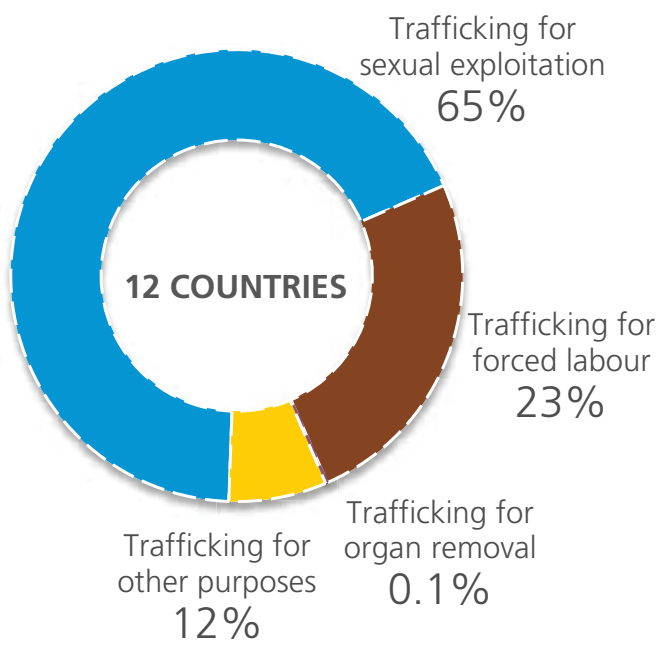

Source: UNODC elaboration of national data.

FIG. 59 Victims of trafficking for forced labour detected in Central and South-Eastern Europe, by sex, 2014 (or most recent)

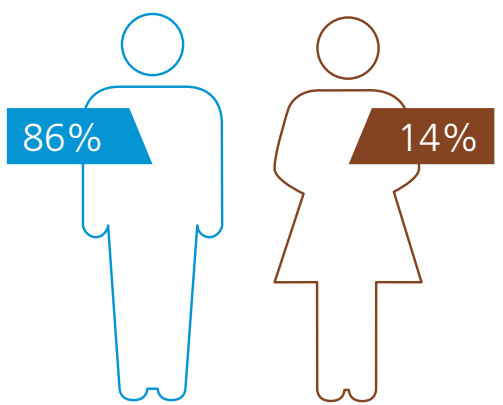

13 COUNTRIES

Source: UNODC elaboration of national data.

of forced labour accounts for one quarter of the trafficking detected in this part of the world; the overwhelming majority of these victims are males. The share of female victims of trafficking for forced labour (14 per cent) is small compared to other areas.

About 12 per cent of the detected victims were trafficked for purposes other than sexual exploitation or forced labour. Nearly half of these were trafficked for the purpose of begging, and 1 per cent for the purpose of sham or forced marriages. Other forms of exploitation reported were trafficking for the commission of crime, for mixed exploitation, for pornography, and trafficking of pregnant 
women for the purpose of selling their babies. Seven cases of trafficking for the purpose of organ removal were also reported in this subregion between 2012 and 2014.

\section{Profile of the offenders}

Most of the persons prosecuted for and convicted of trafficking in persons during the 2012-2014 period in Central and South-Eastern Europe were males. Men comprised more than 70 per cent of the approximately 700 persons investigated for trafficking in persons, and more than 80 per cent of the 2,400 persons prosecuted for, and 550 convicted of this crime. The share of convicted females was large in Latvia, where female participation resembles the levels reported in most Eastern European countries. Albania, Montenegro and the former Yugoslav Republic of Macedonia rarely prosecute or convict women of trafficking in persons.

Almost the entire offender population for trafficking in persons in this subregion were citizens of the countries where they were convicted. Only some 4 per cent were foreigners. Due to the high level of national offenders convicted in this subregion, it appears unlikely that traffickers from other regions operate in these countries. As seen in other parts of the world, this feature of 'monopoly' is typical for countries of origin for international trafficking flows. These traffickers, whether they operate alone or in groups, not only exploit fellow citizens domestically, but also transfer or sell them for exploitation abroad, mainly in Western and Southern Europe. Groups from South-Eastern Europe seem to be involved in trafficking in persons throughout most of Europe.

An illustrative court case from Hungary concerned a loose trafficking network of at least four traffickers, three operating in Hungary, and one in Switzerland. The victims - Hungarian women - were recruited by Hungarian group members operating in Hungary. The victims were transferred to a Hungarian citizen residing in Zurich, which is where the women were sexually exploited. The money was laundered via money transfers back to Hungary. ${ }^{116}$ A different case - reported by Portugal - concerned trafficking for forced labour. At least 30 victims were trafficked. The victims were Romanian citizens recruited in Romania by Romanian traffickers, but the exploitation took place in the agricultural sector in Portugal. The traffickers were aware of the victims' difficult financial situation, which helped force them into exploitation at destination. ${ }^{117}$

\footnotetext{
116 Case provided by Hungary, which concluded with a conviction by the Metropolitan Court of Budapest (sentence not available).

117 Case provided by Portugal, which concluded with convictions by the Court of Beja, with sentences ranging from 3 to 5 years of imprisonment.
}

FIG. 60 Persons investigated for trafficking in persons in Central and SouthEastern Europe, by sex, 2014 (or more recent)

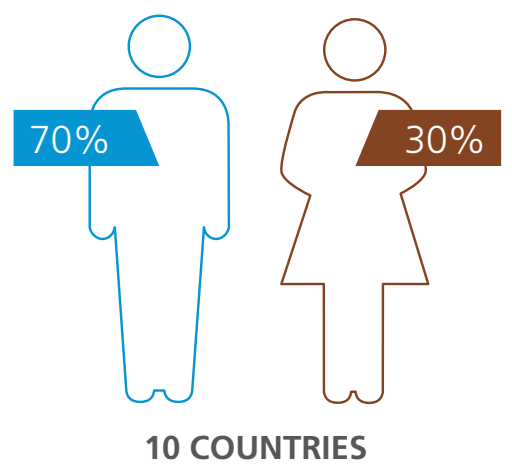

Persons prosecuted for trafficking in persons in Central and South-Eastern Europe, by sex, 2014 (or most recent)

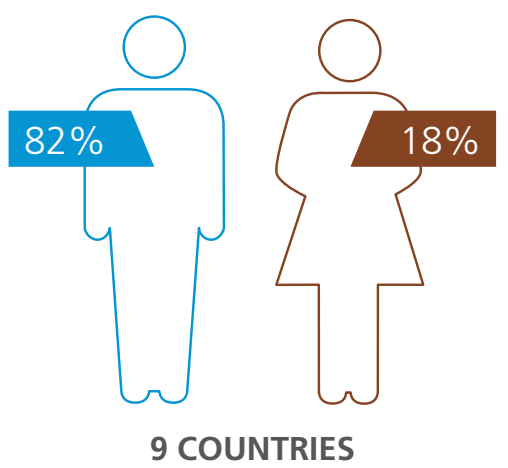

Persons convicted of trafficking in persons in Central and South-Eastern Europe, by sex, 2014 (or most recent)

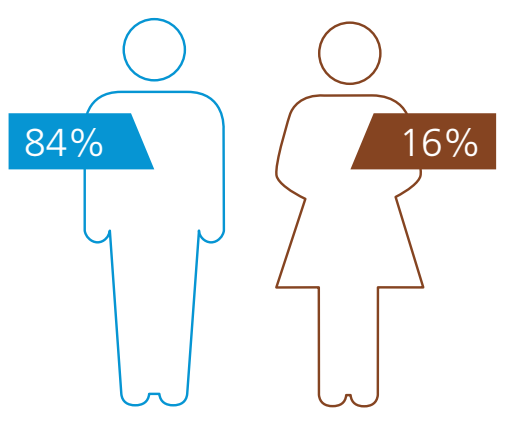

11 COUNTRIES 
FIG. 61 Share of offenders convicted in Central and South-Eastern Europe, by their area of citizenship, 2014 (or most recent)

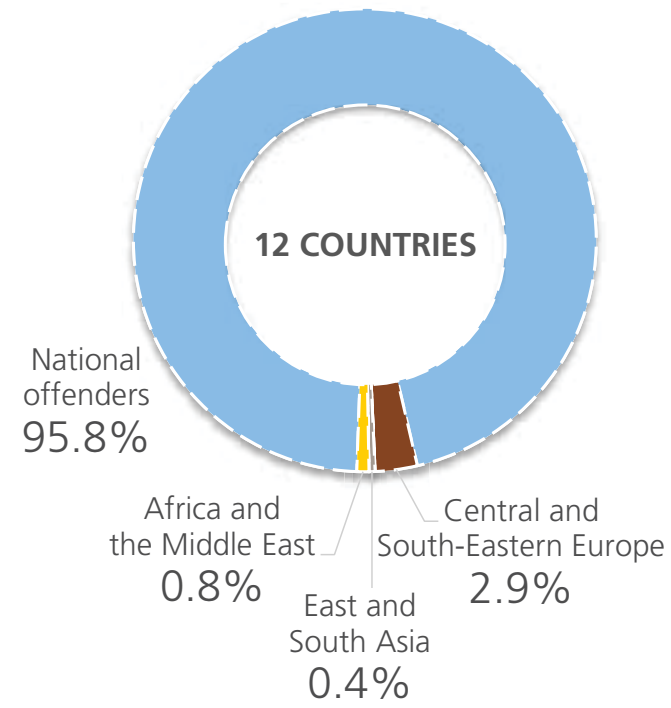

Source: UNODC elaboration of national data.

\section{Trafficking flows affecting Central and South-Eastern Europe}

As discussed above, Central and South-Eastern Europe is mainly an area of origin for international trafficking. The information concerning the victims that have been repatriated to their origin countries in this subregion sheds some light on the relevant trafficking flows. Most of the trafficking originating in this region is directed towards Western and Southern Europe. However, victims from South-Eastern Europe, and less commonly Central Europe, have also been repatriated from the richer countries of Eastern Europe.

A large share of victims detected in Central and SouthEastern Europe are trafficked within national borders (41 per cent). The most prominent international trafficking flow into this area is intraregional; more specifically, from South-Eastern Europe to the Central European countries. That said, Central and South-Eastern Europe is also a destination for trafficking in persons; not only domestic and intraregional flows, but also, to a limited extent, for victims trafficked from other regions. Both Czechia and Poland have detected victims trafficked from Eastern Europe, particularly from Ukraine, as well as victims from East and South Asia. Victims from West Africa were also detected in Czechia during the reporting period.

The vast majority of trafficking flows into this subregion are short-distance. A large part of the victims have been
FIG. 62 Victims of trafficking repatriated to countries in Central and SouthEastern Europe, by destination, 2012-2014

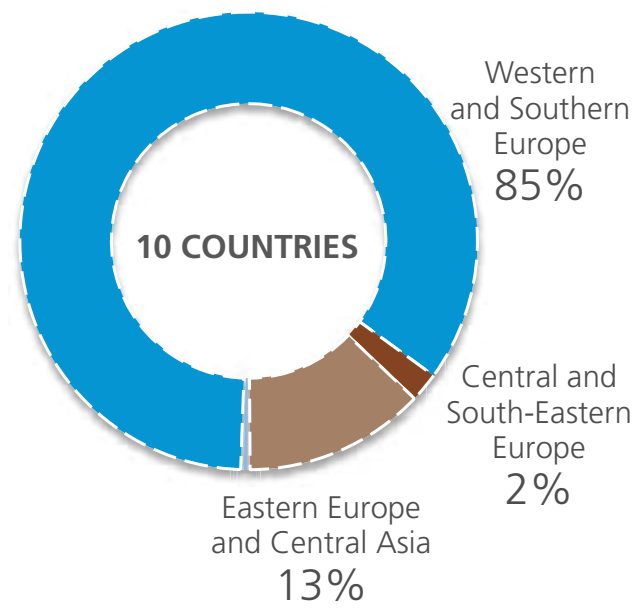

Source: UNODC elaboration of national data.

FIG. 63 Detected victims of trafficking in Central and South-Eastern Europe, by citizenship, 2014 (or most recent)

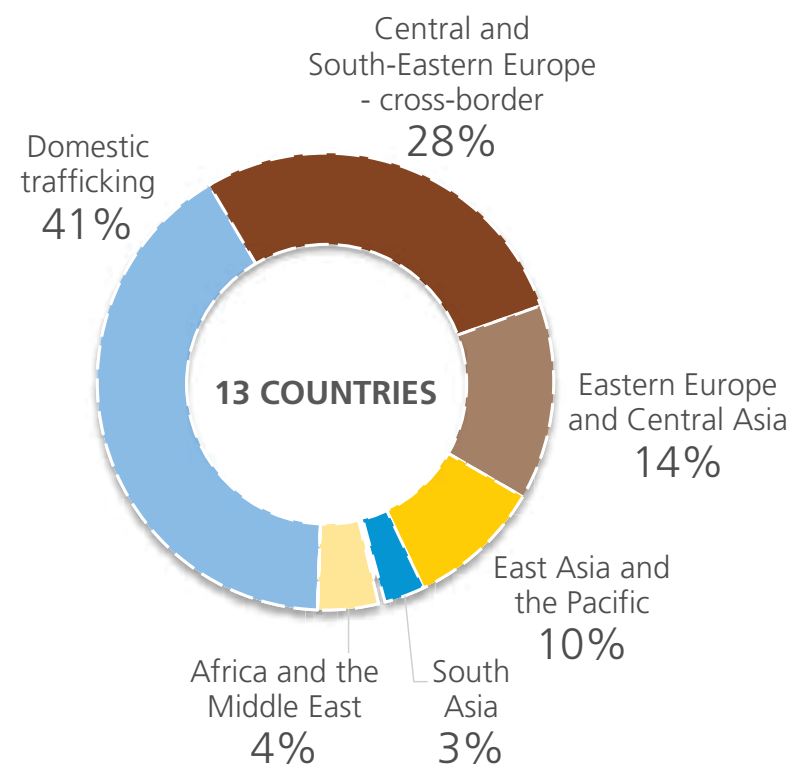

Source: UNODC elaboration of national data.

trafficked domestically, and about 15 per cent of the victims were trafficked from a neighbouring country, especially victims from Eastern Europe trafficked across the border. Long-distance flows mainly involve Asian victims trafficked to Central Europe. 
MAP 6 Destinations of detected trafficking victims from Central and South-Eastern Europe, by subregion, 2012-2014

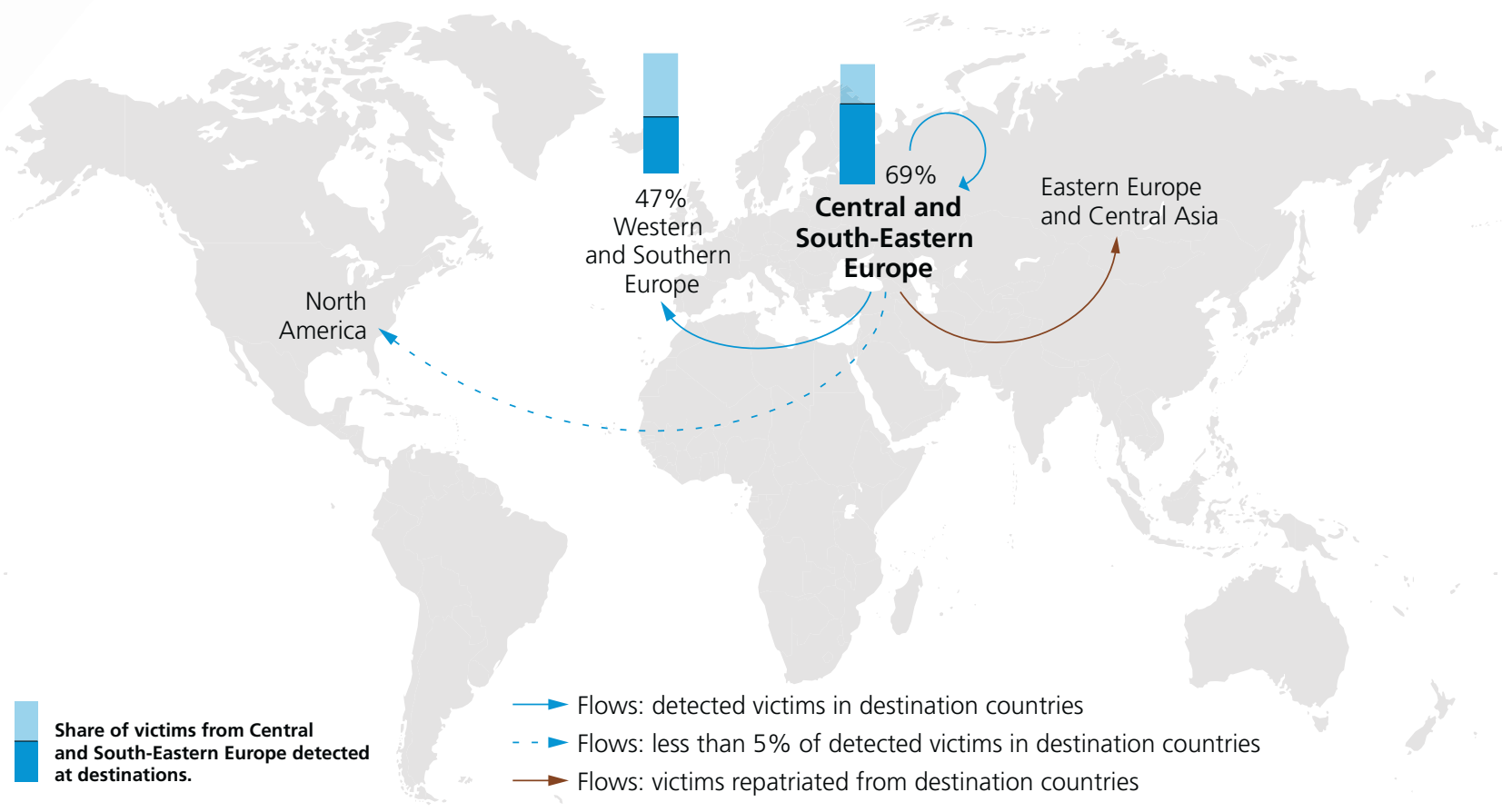

Source: UNODC elaboration of national data.

Note: The boundaries and names shown and the designations used on this map do not imply official endorsement or acceptance by the United Nations.

MAP 7 Origins of trafficking victims detected in Central and South-Eastern Europe, by subregion, 2012-2014

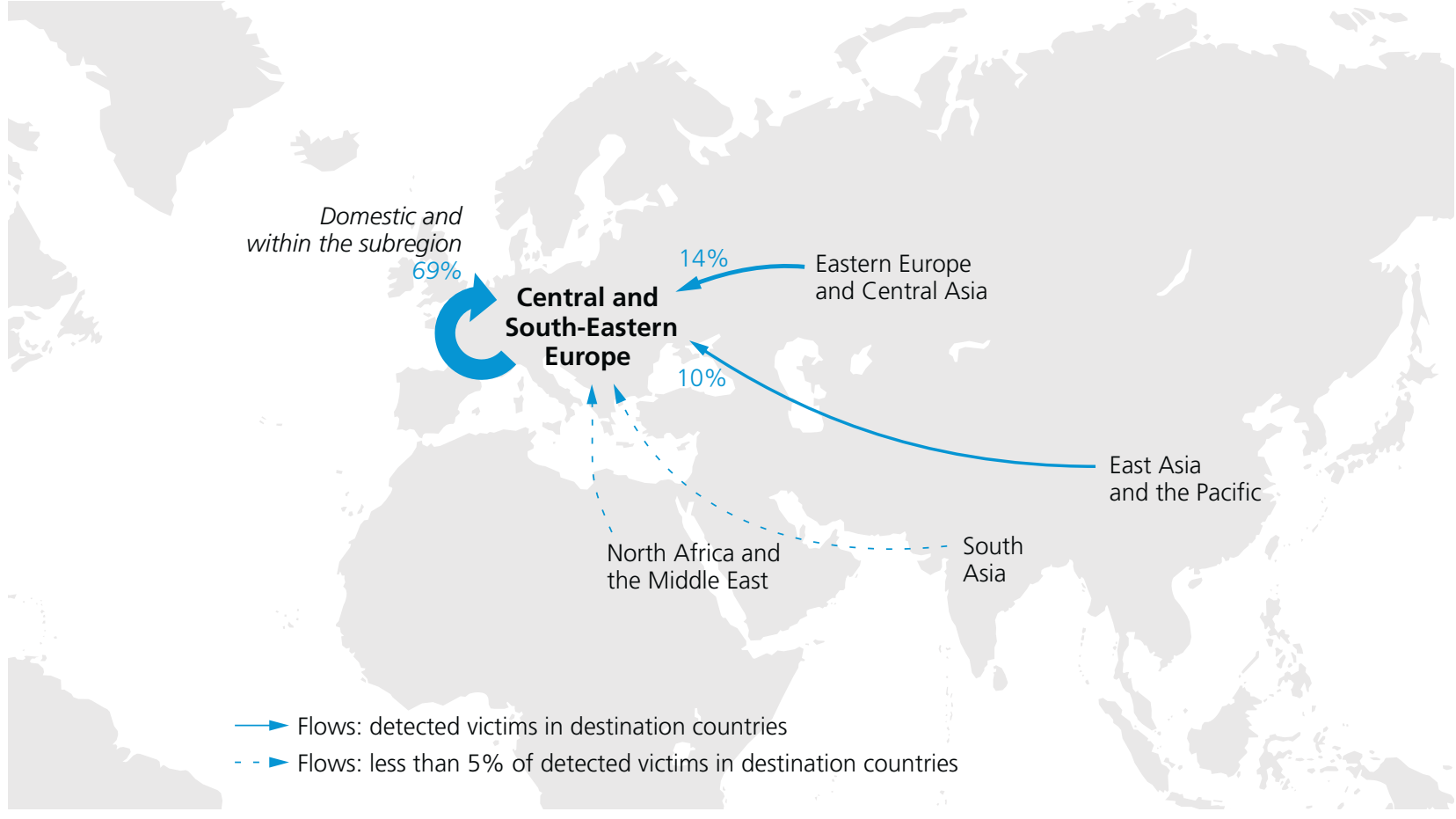

Source: UNODC elaboration of national data.

Note: The boundaries and names shown and the designations used on this map do not imply official endorsement or acceptance by the United Nations. 
FIG. 64 Shares of detected trafficking flows in Central and South-Eastern Europe, by geographical distance, * 2014 (or most recent)

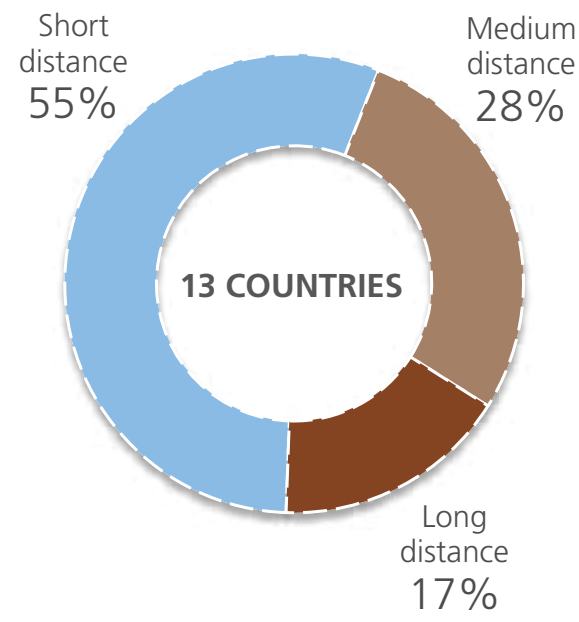

* Short-distance trafficking flows see victims trafficked within national borders or between neighbouring countries; medium-distance flows are between two countries that do not share a border and with the border of the origin country less than 3,500 kilometres away from the closest border of the destination country; and long-distance flows connect countries in which the border of the origin is farther than 3,500 kilometres away from the closest border of the destination.

Source: UNODC elaboration of national data.

\section{Criminalization of trafficking in persons}

Countries in this subregion were among the first to enact legislation with a definition of trafficking in line with the UN Trafficking in Persons Protocol definition and all countries in Central and South-Eastern Europe had such legislation before 2012. The South-Eastern European countries of Albania, Bulgaria, Romania, Serbia and Montenegro (the latter two having been a single state at the time) introduced the offence of trafficking in persons before the entry into force of the Protocol, between 2002 and December 2003. Similar developments took place in Latvia, Lithuania and other Central European countries. A few other countries expanded their existing definitions in order to comply with the Protocol after December 2003.

Bulgaria and Romania convicted more traffickers than other countries in the subregion during the reporting period, between 60 and 100 per year. Other countries in South-Eastern Europe, like Serbia and the former Yugoslav Republic of Macedonia, also reported relatively high numbers of convictions. This supports the theory that offences that have been in use for a longer period of time lead to more convictions.
FIG. 65 Share and number of countries in Central and South-Eastern Europe with a specific offence on trafficking in persons that criminalizes all forms listed in the UN Protocol, by period of introduction of the offence

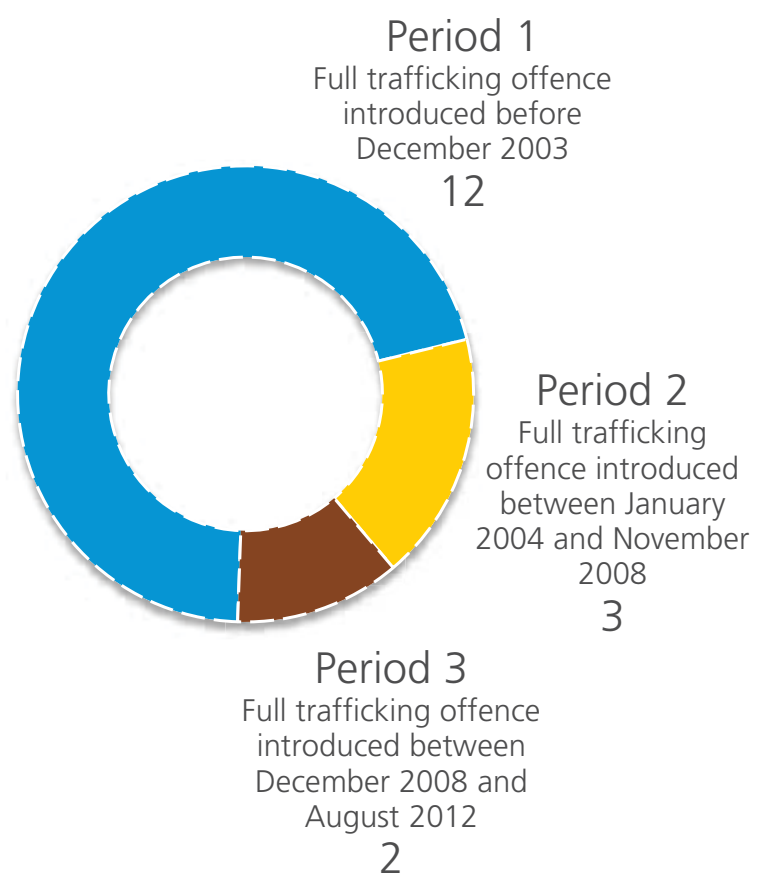

Share of countries in Central and South-Eastern Europe, by number of trafficking convictions, 2012-2014 (one year within the period)

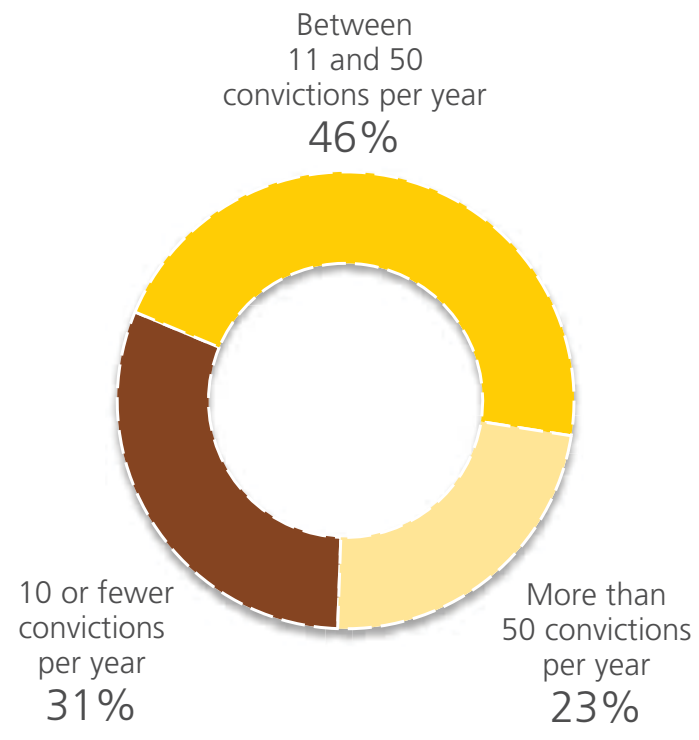

Source: UNODC elaboration of national data.

Note: For the criminalization analysis, more countries are covered than for the section on patterns and flows. 
In Central and South-Eastern Europe, 33 per cent of the persons suspected of or investigated for trafficking in persons receive first instance court convictions. This figure is much higher than the corresponding share for Western and Southern Europe. Looking at the criminal justice process in more detail, 64 per cent of investigated persons are prosecuted, and 56 per cent receive first-instance convictions (in other European subregions, this latter share is 33 per cent). No Central or South-Eastern European country reported an increasing number of convictions during the reporting period, and half of the countries saw decreasing trends.

\section{EASTERN EUROPE AND CENTRAL ASIA}

\section{Key findings}

Most frequently detected victim profile: Men, $53 \%$

\section{Most frequently detected form of} exploitation: Forced labour, 64\%

Gender profile of convicted offenders: $55 \%$ females

Share of national citizens among offenders: $98 \%$

Summary profile of trafficking flows: Destination for intraregional and origin for transregional trafficking.

Emerging trend: Trafficking from poorer to richer countries within the region.

Two distinct areas can be identified in this region, Eastern Europe, and Central Asia. ${ }^{118}$ Although the data is insufficient to analyse the two areas separately, references will be made to only Eastern Europe or Central Asia where appropriate. The countries in this region vary in terms of socio-economic characteristics.

\section{Profile of the victims}

A total of 27,800 victims of trafficking whose age and gender profiles were known were detected in this region between 2012 and 2014. More than 90 per cent were adults and a majority were men. Even though men comprise the majority of detected victims, there are marked geographical differences within the region. Eastern Euro-

118 Eastern Europe: Armenia, Azerbaijan, Belarus, Georgia, Republic of Moldova, Russian Federation and Ukraine. Central Asia: Kazakhstan,

Kyrgyzstan, Tajikistan and Uzbekistan.
FIG. 66 Detected victims of trafficking in Eastern Europe and Central Asia, by age and sex, 2014 (or most recent)

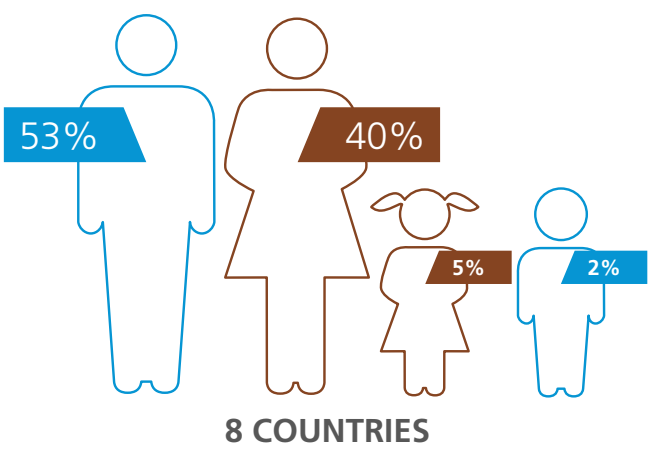

Source: UNODC elaboration of national data.

FIG. 67 Detected victims of trafficking in Eastern Europe, by age and sex, 2014 (or most recent)

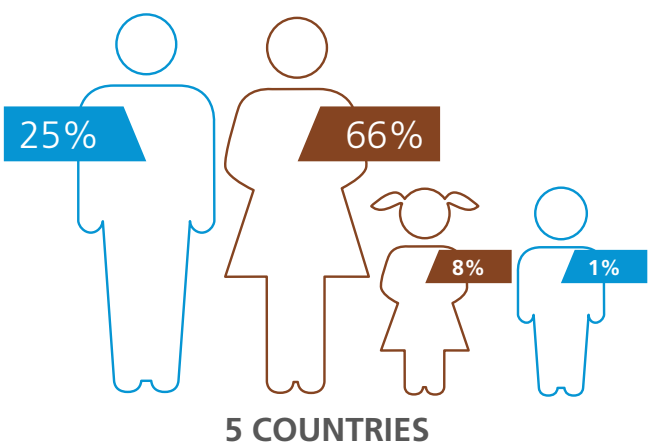

Source: UNODC elaboration of national data.

FIG. 68 Detected victims of trafficking in Central Asia, by age and sex, 2014 (or most recent)

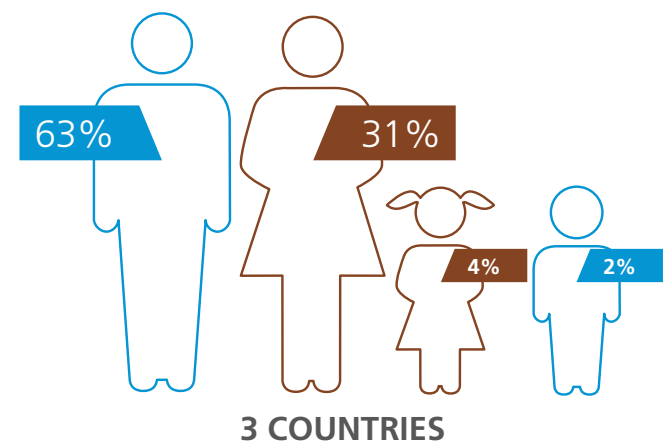

Source: UNODC elaboration of national data. 
FIG. 69 Trends in the shares of men among detected trafficking victims, selected countries in Eastern Europe and Central Asia, 2007-2015

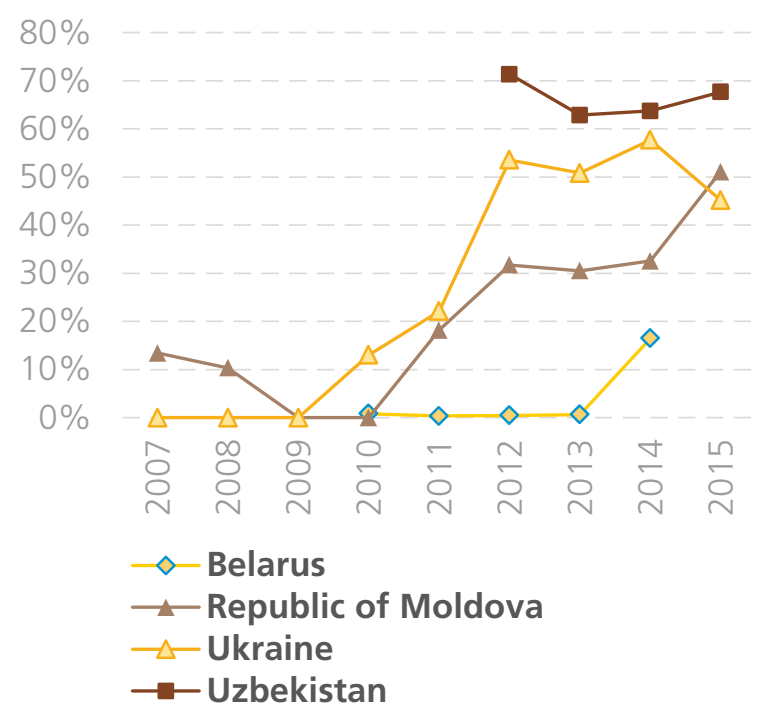

Source: UNODC elaboration of national data.

pean countries detected a larger number of women, and Central Asian countries detected more men. Countries across the region, however, reported increased shares of adult male victims over the last few years, which is related to the increasing share of detected victims of trafficking for forced labour.

\section{Forms of exploitation}

The increasing prevalence of men among trafficking victims across the region is also reflected in the detection of cases of trafficking for forced labour. Considering the 10,950 victims detected during the reporting period whose forms of exploitation was known, trafficking for forced labour accounted for more than twice as many victims as trafficking for sexual exploitation. Although the available information is scattered, covering different years and countries, an increasing trend in the detection of trafficking for forced labour can be observed in different countries of Eastern Europe and Central Asia.

Geographic variations can also be observed for forms of exploitation, even among countries that are very close or share a border. In Eastern Europe, victims of trafficking for sexual exploitation were more frequently detected in most countries, whereas Ukraine reported more victims of trafficking for forced labour. In Central Asia, Kazakhstan and Uzbekistan detected more victims for forced labour while in Tajikistan, sexual exploitation was more frequently detected.

Regional overviews - Eastern Europe and Central Asia

\section{FIG. 70 Forms of exploitation among detected victims of trafficking in Eastern Europe and Central Asia, 2014 (or most recent)}

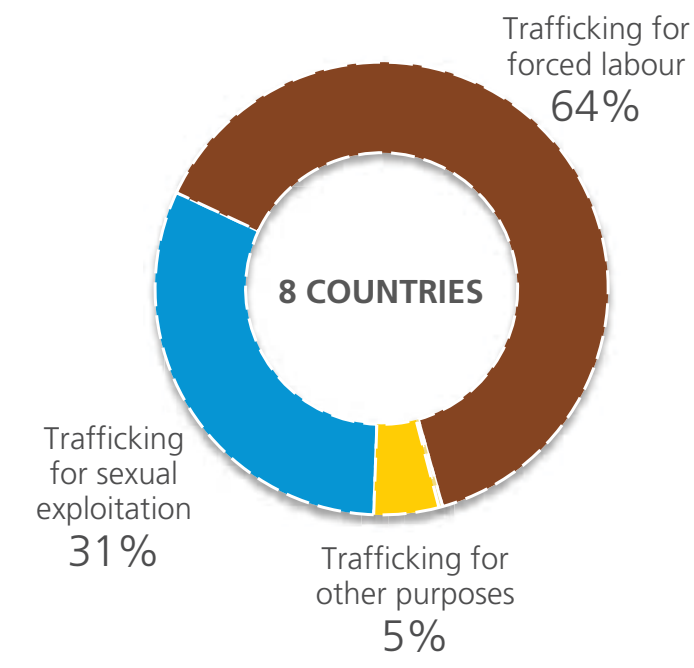

Source: UNODC elaboration of national data.

FIG. 71 Trends in the shares of detected victims who were trafficked for forced labour, selected countries, 2006-2015

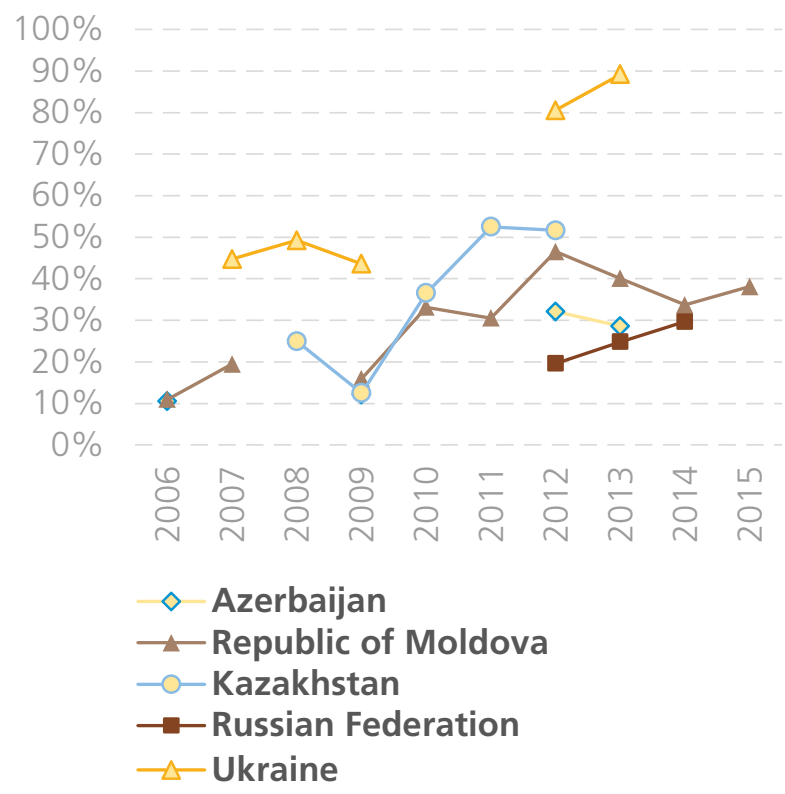

Source: UNODC elaboration of national data

The profiles of victims trafficked for forced labour also change between the two main geographical areas of the region. In Eastern Europe, about 40 per cent of victims trafficked for forced labour were women, whereas in Central Asia, the corresponding share was far lower, less than 10 per cent. 


\section{FIG. 72 Detected victims of trafficking for forced labour in Eastern Europe and Central Asia, by sex, 2014 (or most recent)}

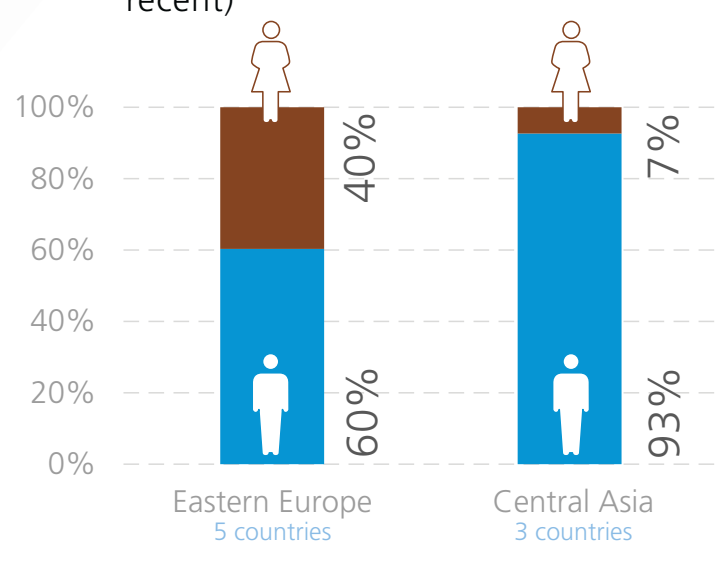

Source: UNODC elaboration of national data.

About 5 per cent of the victims detected in Eastern Europe and Central Asia between 2012 and 2014 were trafficked for purposes other than sexual exploitation or forced labour. Many of these victims were trafficked for begging, with females and males detected in equal numbers. Mixed forms of exploitation and trafficking for the purpose of committing crime were also sporadically reported.

\section{Profile of the offenders}

In this region, the share of females among the persons investigated, prosecuted or convicted of trafficking in persons is higher than in other parts of the world. This is a long-standing pattern, and previous editions of the Global Report have also flagged the preponderance of female offenders in Eastern Europe and Central Asia.

The shares of female involvement are similar across the different steps of the criminal justice process, and the profile of the offenders is broadly homogenous across the region. Most of the traffickers are citizens of the countries in which they were convicted. Very few foreign citizens were convicted of trafficking in these countries, and when such convictions were made, the offenders were either from other countries within the region or from Western and Central Europe.

\section{Trafficking flows into Eastern Europe and Central Asia}

This region has traditionally been considered mainly as an origin of transnational and local trafficking flows. The information collected regarding detected as well as repatriated victims, however, shows that it is also a destination of cross-border trafficking flows.
FIG. 73 Persons investigated for trafficking in persons in Eastern Europe and Central Asia, by sex, 2014 (or most recent)

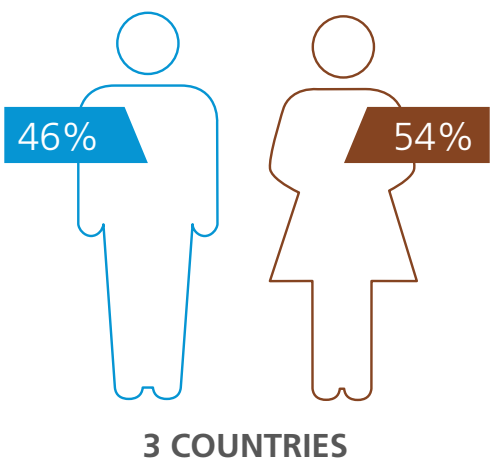

Persons prosecuted for trafficking in persons in Eastern Europe and Central Asia, by sex, 2014

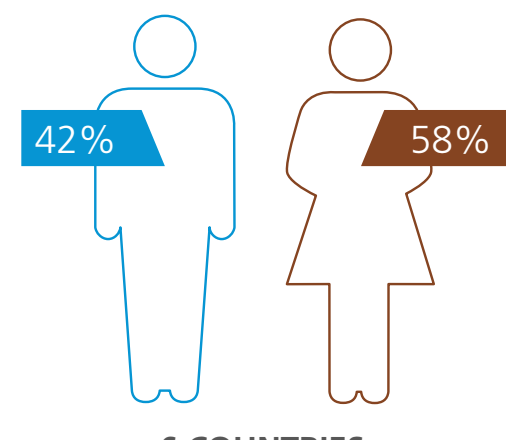

6 COUNTRIES

Persons convicted of trafficking in persons in Eastern Europe and Central Asia, by sex, 2014 (or most recent)

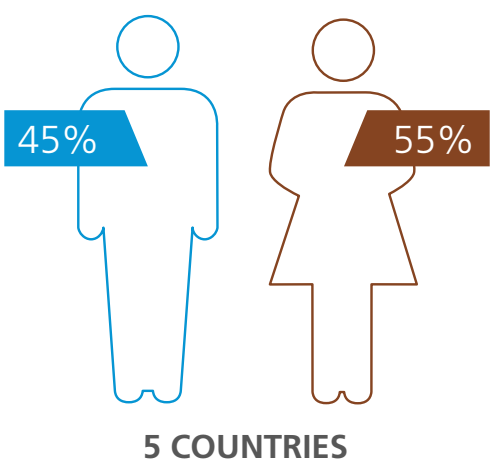

Source: UNODC elaboration of national data.

More than 7 in 10 of the approximately 1,700 victims detected in this region between 2012 and 2014 whose citizenships were reported were trafficked within national borders. Another 22 per cent of victims were trafficked cross-border within the region. 
FIG. 74 Share of offenders convicted in Eastern Europe and Central Asia, by their area of citizenship, 2014 (or most recent)

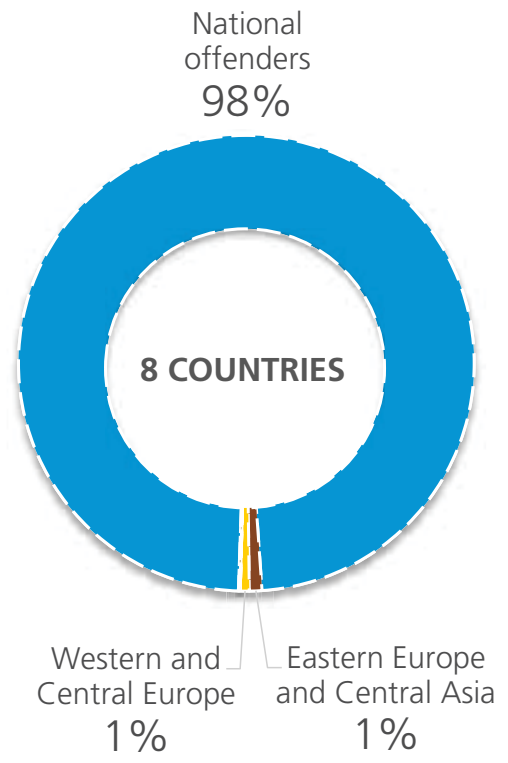

Source: UNODC elaboration of national data.

The cross-border trafficking flows within the region follow patterns that have also been observed in other regions. Just like countries in Western and Southern Europe tend to attract victims from Central and South-Eastern Europe, in this region, the trafficking generally flows from poorer to richer countries.
Regional overviews - Eastern Europe and Central Asia

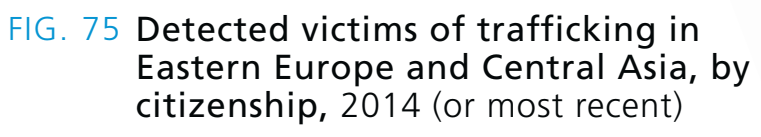

FIG. 75 Detected victims of trafficking in Eastern Europe and Central Asia, by citizenship, 2014 (or most recent)

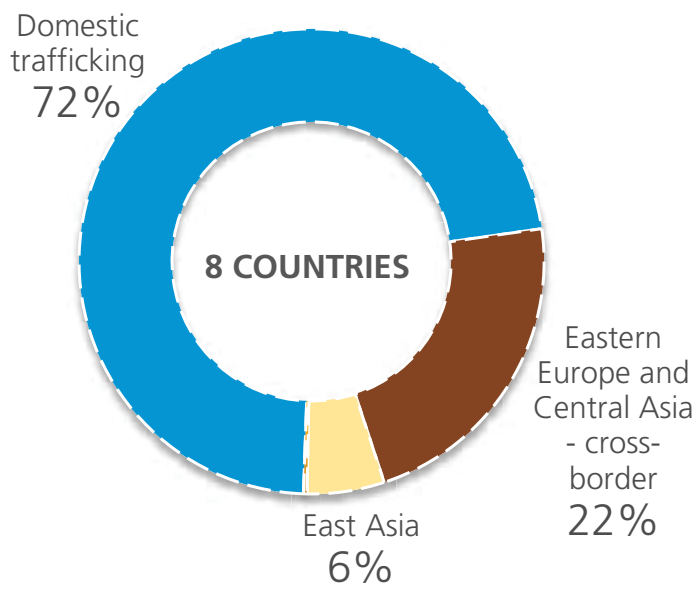

Source: UNODC elaboration of national data.

The richest countries in the region, Kazakhstan and the Russian Federation, are both destinations for trafficking in persons, as victims from other countries have been detected here. Victims from these two countries are less frequently detected in other countries. Flows from the poorer countries of Central Asia head towards both of these destinations, though more prominently to Kazakhstan. Another origin country of trafficking to these destinations is Ukraine; most prominently to the Russian Federation.

\section{FIG. 76 Cross-border trafficking flows and gross domestic product per capita in selected}

countries in Eastern Europe and Central Asia, 2011-2014

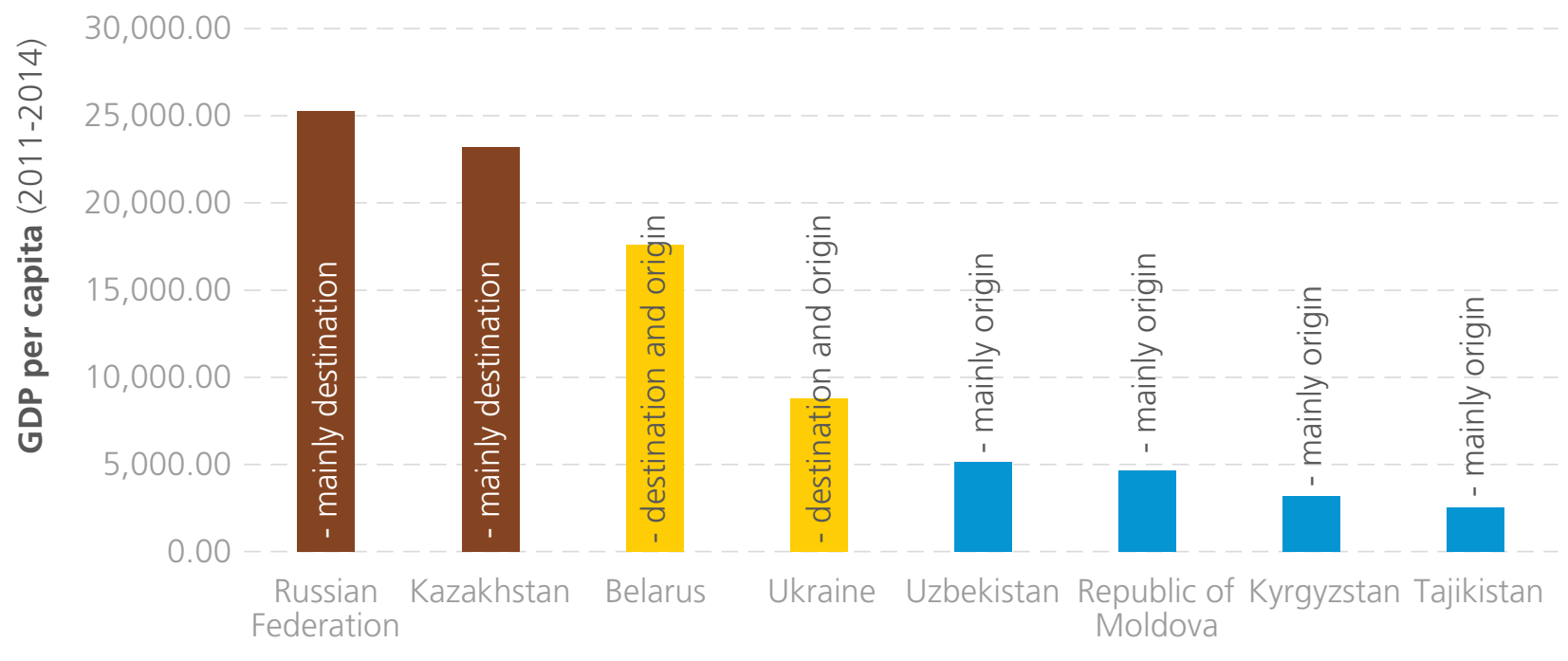


FIG. 77 Shares of detected trafficking flows in Eastern Europe and Central Asia, by geographical distance, * 2014 (or most recent)

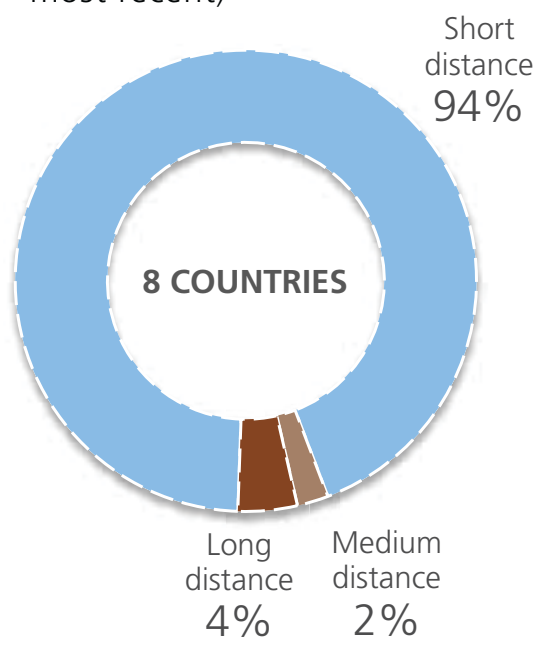

* Short-distance trafficking flows see victims trafficked within national borders or between neighbouring countries; medium-distance flows are between two countries that do not share a border and with the border of the origin country less than 3,500 kilometres away from the closest border of the destination country; and long-distance flows connect countries in which the border of the origin is farther than 3,500 kilometres away from the closest border of the destination.

Source: UNODC elaboration of national data.
Victims from Ukraine were also detected in Belarus, and victims from the Republic of Moldova were detected in Kazakhstan, the Russian Federation and Ukraine. Victims from Belarus were detected in the Russian Federation, and victims from Uzbekistan were detected in the South Caucasus. Belarus and Ukraine are both destinations and origins, while limited information is available for the countries of the South Caucausus.

The data also reveal some trafficking flows that originate in other regions, specifically East Asia. Moreover, repatriation data reveals that some 120 victims from South-Eastern and Central Europe were trafficked to the richer Eastern European countries during the 2012-2014 period.

\section{Trafficking flows out of Eastern Europe and Central Asia}

Victims who were trafficked outside their countries were mostly trafficked to other countries within the region. About 8,100 citizens of Eastern European and Central Asian countries were detected in and repatriated back from other countries between 2012 and 2014; the vast majority from other countries in the region. However, a significant number of victims were also trafficked to other

MAP 8 Destinations of detected trafficking victims from Eastern Europe and Central Asia, by subregion, 2011-2014

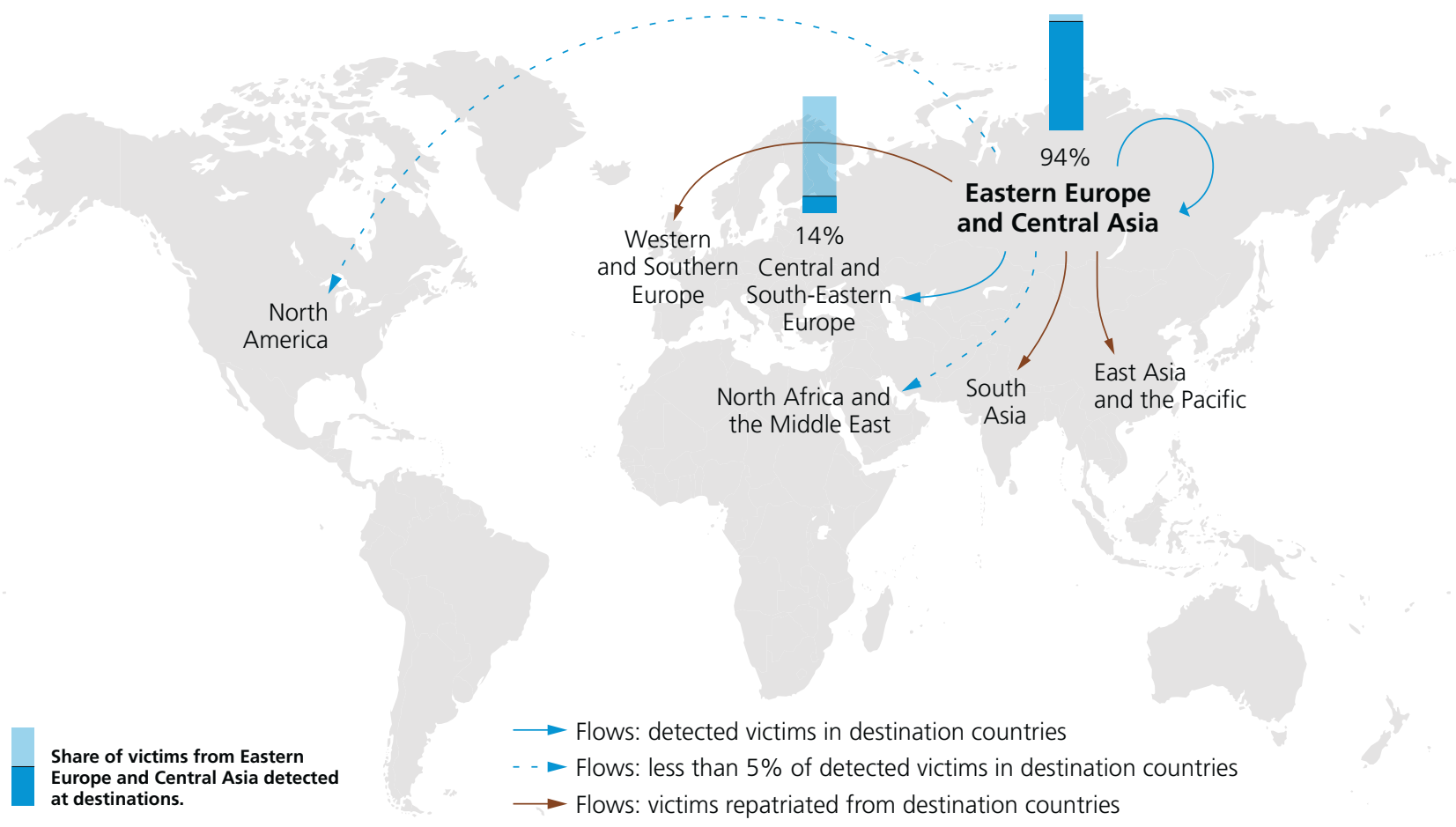


FIG. 78 Share and number of countries in Eastern Europe and Central Asia with a specific offence on trafficking in persons that criminalizes all forms listed in the UN Protocol, by period of introduction of the offence
Period 1

Full trafficking offence introduced

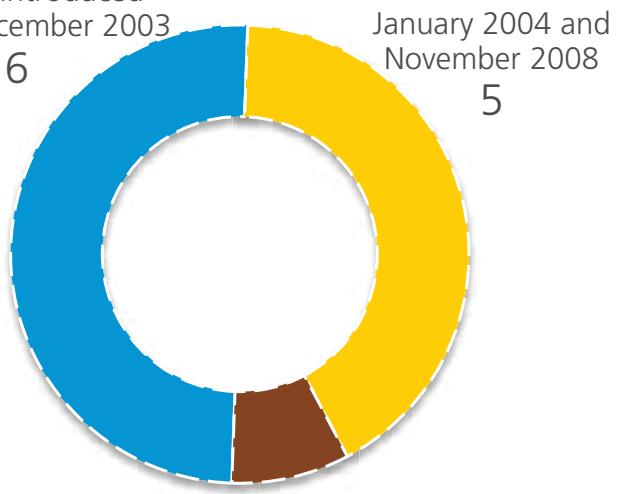

Period 3

Full trafficking offence introduced between December 2008 and August 2012 1 before December 2003

Source: UNODC elaboration of national data.

Note: For the criminalization analysis, more countries are covered than for the section on patterns and flows.

regions. About 10 per cent were trafficked to Western and Central Europe, and about 25 countries in Western and Central Europe detected or repatriated victims from Eastern Europe and Central Asia. This particular trafficking flow appears to have declined over the years, however.

Another significant trafficking flow out of the region heads to the Middle East, where seven countries have detected or repatriated victims from this region. At the same time, about 7 per cent of the victims detected in the Middle East are citizens of countries in Eastern Europe and Central Asia, which means that both data sources reflect the significance of this flow.

\section{Criminalization of trafficking in persons}

Half of the countries considered in this region had legislation with a definition of trafficking in line with the UN Trafficking in Persons Protocol before its entry into force. Many Central Asian countries introduced the offence of trafficking in persons shortly after the Protocol entered into force. However, many countries have also amended their legislation - some even multiple times - in the last few years, and all countries now have legislation defining trafficking according to the UN Trafficking in Persons Protocol definition.

Most countries in the region report making between 10 and 30 convictions per year. This number remained stable over the 2012-2014 period.

This region has a high ratio of convictions to investigations, although, due to lack of data, this only reflects the situation in Armenia, Belarus and the Republic of Moldova. On average, 45 per cent of the persons investigated in these three countries were convicted in the court of first instance.

\section{NORTH AND CENTRAL AMERICA AND THE CARIBBEAN}

\section{Key findings: North America}

Most frequently detected victim profile: Women, 60\%

Most frequently detected form of exploitation: Sexual exploitation, 55\%

Gender profile of convicted offenders: $61 \%$ males

Summary profile of trafficking flows: Mostly local trafficking, but also a significant destination for long-distance flows.

Emerging trend: Many women and girls trafficked for forced labour.

\section{Key findings:}

Central America and the Caribbean

Most frequently detected victim profile: Girls, 46\%

Most frequently detected form of exploitation: Sexual exploitation, 57\%

Gender profile of convicted offenders: $51 \%$ males

Share of national citizens among offenders: $88 \%$

Summary profile of trafficking flows: Mainly domestic and intraregional flows.

Emerging trend: Many children among the detected victims. 
The countries considered under this section of the report can be separated into North America, ${ }^{119}$ which includes countries with medium to high levels of socio-economic development, and Central America and the Caribbean, ${ }^{120}$ with medium to low levels.

\section{Profile of the victims}

Both North America and Central America and the Caribbean detect many female victims. About 70 per cent of the approximately 8,900 victims detected across the region whose age and sex profiles were reported were females. However, while girls are more frequently detected in Central America and the Caribbean, in North America, women predominate.

\section{FIG. 79 Detected victims of trafficking in North America, by age and sex, 2014 (or most recent)}

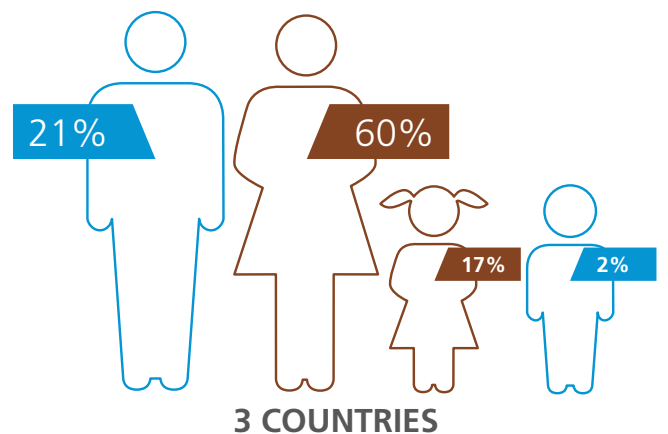

Detected victims of trafficking in Central America and the Caribbean, by age and sex, 2014 (or most recent)

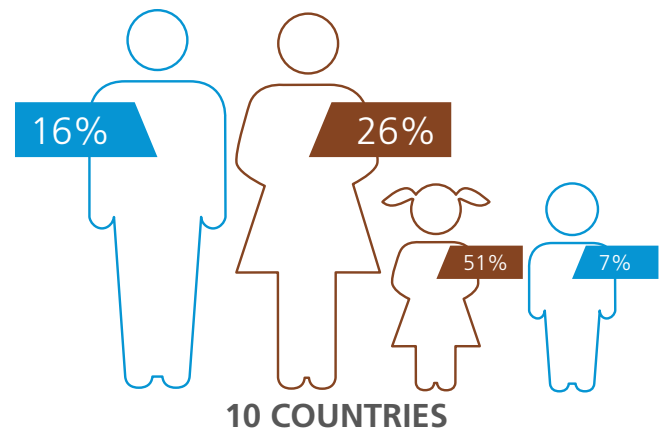

Source: UNODC elaboration of national data.

In North America, the share of children among the detected victims ranges around 20 per cent. Over the years, the trend in detections of child victims followed

119 North America: Canada, Mexico and United States of America.

120 Central America and the Caribbean: Bahamas, Barbados, Costa Rica, Cuba, Dominican Republic, El Salvador, Guatemala, Haiti, Honduras, Jamaica, Nicaragua, Panama and Trinidad and Tobago.
FIG. 80 Trends in the shares of adults and children among detected victims in North America, 2007-2014

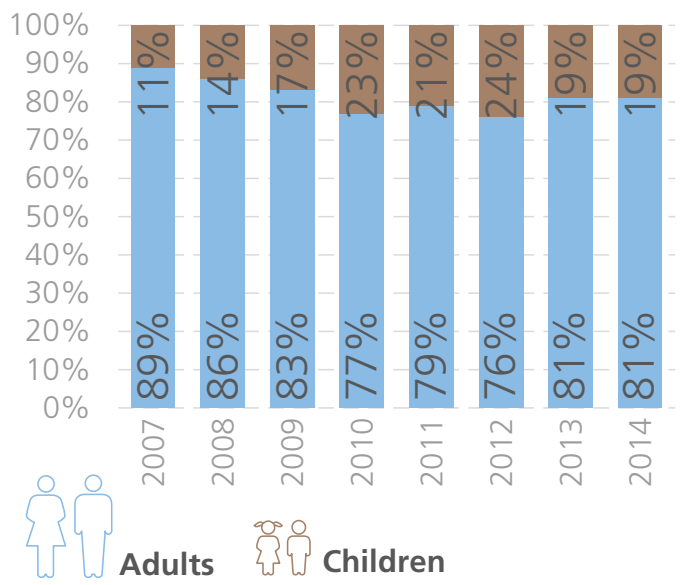

Source: UNODC elaboration of national data.

FIG. 81 Trends in the shares of adults and children among detected victims in Central America and the Caribbean, 2009-2014

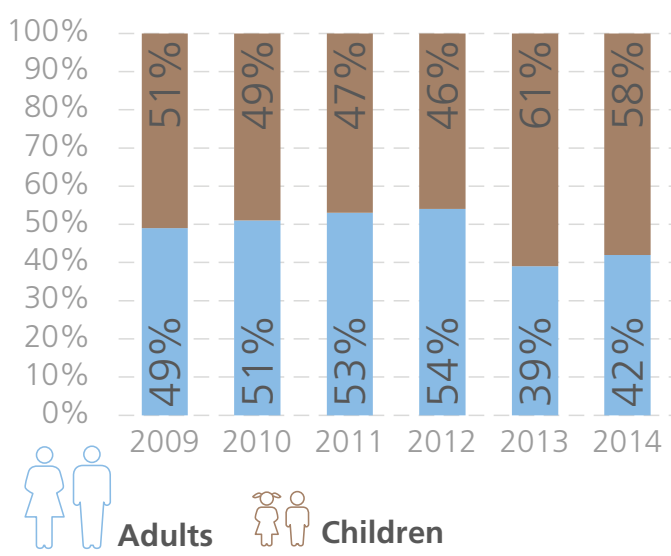

Source: UNODC elaboration of national data.

global patterns, with some increases during the 2010-2012 period, and stabilization more recently.

In Central America and the Caribbean, child trafficking is the most frequently detected form of trafficking. This area has the second-highest level of child trafficking detected globally, after Sub-Saharan Africa. Although the data for this subregion is not homogenous over a longer time period, large shares of children among detected victims have been recorded over the last six years.

\section{Forms of exploitation}

Trafficking for sexual exploitation is the most frequently detected form in Central America and the Caribbean, 
FIG. 82 Forms of exploitation among detected victims of trafficking in Central America and the Caribbean, 2014 (or most recent)

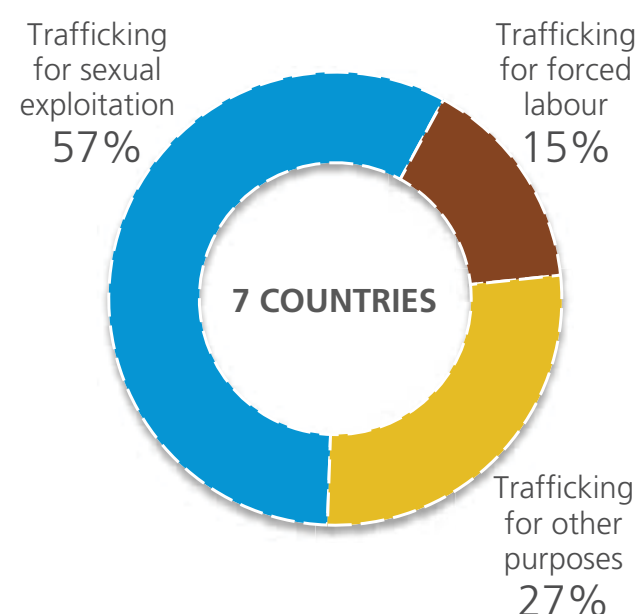

Source: UNODC elaboration of national data.

with about 57 per cent of the victims detected in 2014 (or most recent). The share in North America is similar; about 55 per cent.

The two areas differ in terms of the second most common form of exploitation, however. In Central America and the Caribbean, trafficking for 'other' purposes is frequently reported, accounting for about 27 per cent of the victims detected there. Many of these victims were trafficked for begging, and some, for illegal adoption. The share of victims who were trafficked for forced labour is small in a global perspective.

In North America, on the other hand, the level of forced labour is quite high, accounting for about 40 per cent of the approximately 6,800 victims detected between 2012 and 2014 for whom the form of exploitation was reported. Few victims were trafficked for 'other' purposes; most of the 6 per cent of victims in this category were subjected to mixed exploitation.

Looking at the gender profiles of victims trafficked for forced labour, North American countries report large shares of women and girls. About half of the victims trafficked for forced labour in North America are females, whereas the global average is 37 per cent. Women and girls trafficked for forced labour may be exploited in different economic sectors as well as for domestic servitude.

A court case from the United States of America illustrates how some women are trafficked for forced labour in this part of the world. A woman - citizen of the United States
FIG. 83 Forms of exploitation among detected victims of trafficking in North America, 2014 (or most recent)

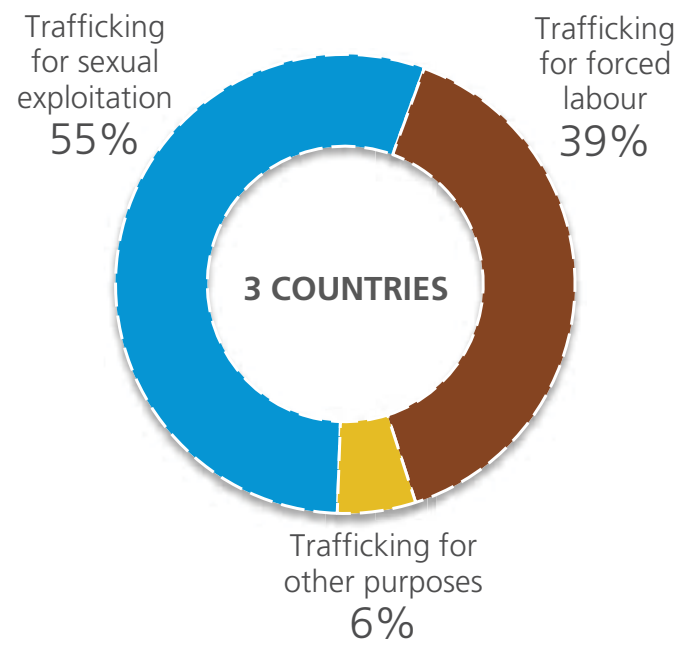

Source: UNODC elaboration of national data.

FIG. 84 Detected victims of trafficking for forced labour in North America, by sex, 2014 (or most recent)

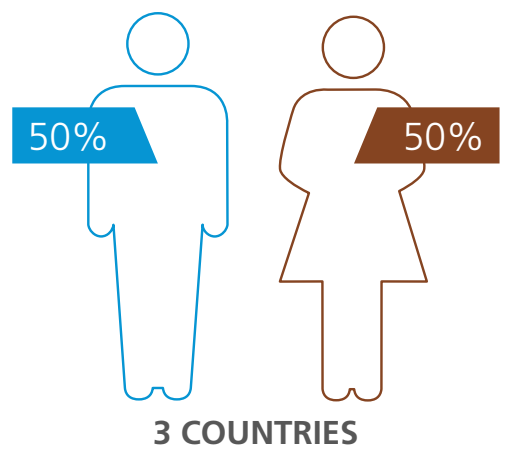

Source: UNODC elaboration of national data.

but born in Viet Nam - recruited women from Viet Nam. She convinced them to travel to the United States by making false promises of legal immigration status and a job. The victims were made to cross the United States Mexico border illegally, and once at destination, they were exploited in forced labour in a restaurant that belonged to the trafficker's son in order to pay down the debt connected with the irregular migration. ${ }^{121}$

Trafficking for domestic servitude is illustrated by a case from Canada. A young Filipino woman signed a two-year contract to work for a family in Hong Kong, China, to

121 Case provided the United States, which concluded with a conviction by the District Court for the district of Minnesota, and a 1-year prison sentence for the trafficker. 
FIG. 85 Persons convicted of trafficking in persons in North America, by sex, 2014 (or most recent)

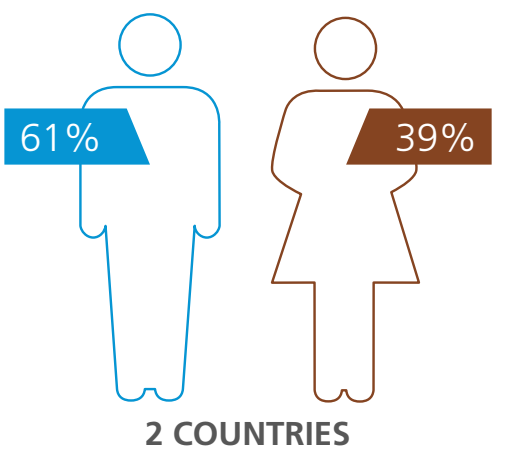

Source: UNODC elaboration of national data

take care of their children. After approximately one year, the family moved to Canada. The family promised the woman that she would retain the working conditions she had had in Hong Kong. Once in Canada, however, she was exploited within the household. ${ }^{122}$

\section{Profile of the offenders}

The gender composition of the detected victims of trafficking in this region - particularly in Central America and the Caribbean - is also reflected in the relatively large shares of women offenders. Many female victims are detected, and many women offenders are sanctioned. Approximately half of the persons convicted of trafficking in persons in Central America and the Caribbean are females, with a share of about 40 per cent in North America.

All the covered countries in Central America reported large shares of convicted women traffickers. This was also echoed in the data concerning persons prosecuted and investigated for trafficking crimes in this subregion, while there is only scarce information on the sex profiles of persons investigated and prosecuted in North America.

The prevalence of female offenders may be related to the local nature of the trafficking enterprise. It is often conducted by a few individuals targeting one or two victims. The offenders may be couples or relatives or friends of the victim(s). For cross-border trafficking, Central America and the Caribbean is mostly an origin, which suggests that female traffickers might be more likely to be involved in the recruitment of women or children.

122 Case provided by Canada, which concluded with a conviction by the Supreme Court of British Columbia. The case is currently under appeal.
FIG. 86 Persons investigated for trafficking in persons in Central America and the Caribbean, by sex, 2014 (or most recent)

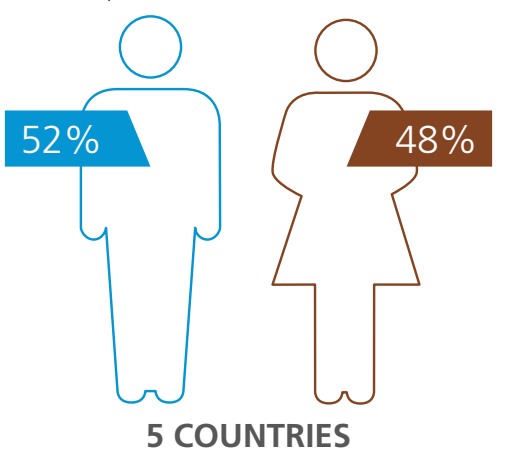

Persons prosecuted for trafficking in persons in Central America and the Caribbean, by sex, 2014 (or most recent)

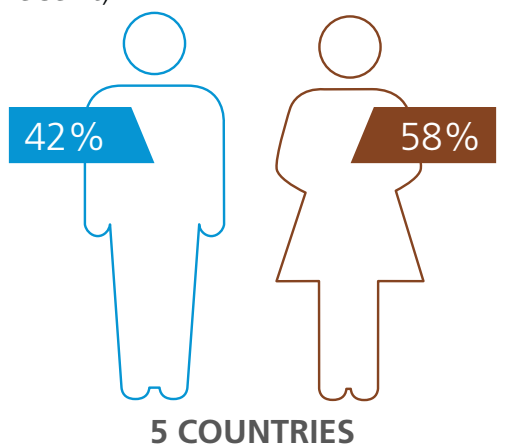

Persons convicted of trafficking in persons in Central America and the Caribbean, by sex, 2014 (or most recent)

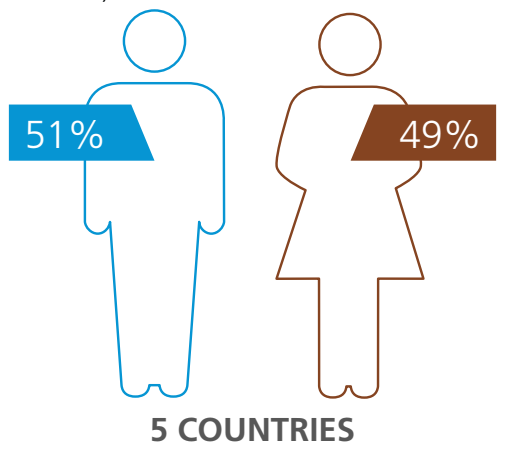

Source: UNODC elaboration of national data.

Similar observations can be made regarding the citizenships of the offenders. Most of the convicted traffickers in Central America and the Caribbean are citizens of the country of conviction. About 8 per cent were from South America; especially from countries geographically close to the Caribbean and Panama. 
FIG. 87 Share of offenders convicted in Central America and Caribbean, by their area of citizenship, 2014 (or most recent)

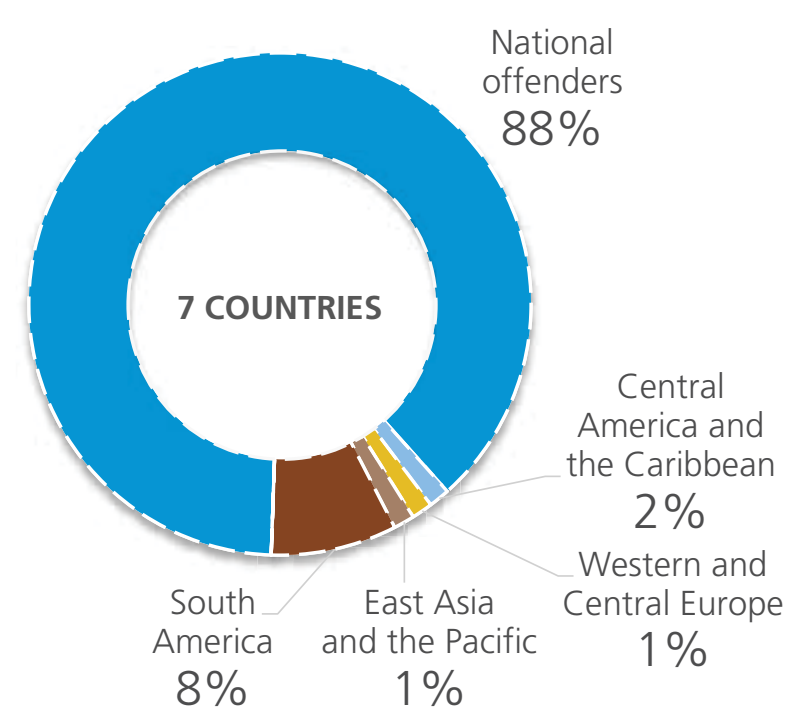

Source: UNODC elaboration of national data.

Near-identical situations were reported in Mexico and Canada for the year 2014 (or most recent), as the vast majority of traffickers were citizens of the country where they were convicted. Some 11 per cent of the convicted traffickers in these two countries were foreigners. In Mexico, most of the convicted foreigners were citizens of Central American countries.

\section{Trafficking flows affecting North and Central America and the Caribbean}

Most of the detected trafficking flows in this region are short-distance flows. A large number of victims were trafficked domestically, such as citizens of the United States of America trafficked within that country. This type of trafficking comprised nearly half of the detected victims in this region.

That said, North America is one of three areas of the world - alongside the Middle East and Western and Southern Europe - in which long-distance trafficking is significant. Nearly a quarter of the victims detected in the three countries of this subregion in 2014 (or most recent) were trafficked from origins at least 3,500 kilometres away, and notably, 7 per cent were trafficked more than 7,000 kilometres. Victims detected in or repatriated from North America during the reporting period came from more than 90 different countries of origin, from all parts of the world.

\section{FIG. 88 Shares of detected trafficking flows in North America, by geographical distance, * 2014 (or most recent)}

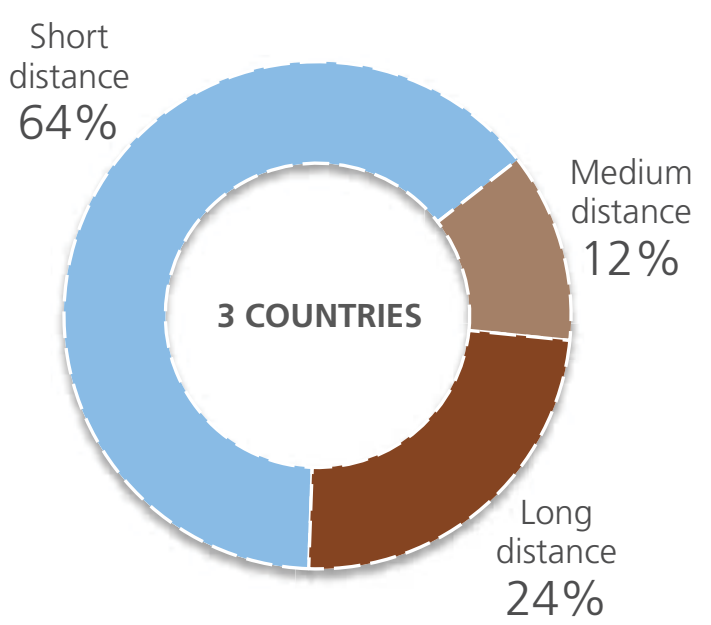

* Short-distance trafficking flows see victims trafficked within national borders or between neighbouring countries; medium-distance flows are between two countries that do not share a border and with the border of the origin country less than 3,500 kilometres away from the closest border of the destination country; and long-distance flows connect countries in which the border of the origin is farther than 3,500 kilometres away from the closest border of the destination.

Source: UNODC elaboration of national data.

In terms of the intensity of trafficking flows, East Asia continues to be the most significant origin of transregional trafficking flows into North America. About 16 per cent of the victims detected in the year 2014 (or most recent) were East Asians. The United States detected many victims from the Philippines, in particular, as well as Chinese and Thai citizens. Smaller trafficking flows from South Asia (involving victims from nearly all countries in this region) and Africa and the Middle East were also detected in North America.

Despite the relative proximity of the two regions, there are relatively few victims trafficked from South America to North America, only about 2 per cent of the detected victims. This is equivalent to the trafficking flows from Europe to North America.

Cross-border trafficking within the region is also significant. Such trafficking - originating from Central America and the Caribbean - accounts for about 12 per cent of the victims detected in North America, especially in Mexico and the United States.

Central America is mainly a region of origin, but also a destination. Guatemala and El Salvador detect victims from Honduras and Nicaragua, among others, and trafficking between countries in this area is frequently detected. The 6 per cent of victims detected in Central 
MAP 9 Countries of origin for victims detected in North America, 2014 (or most recent)

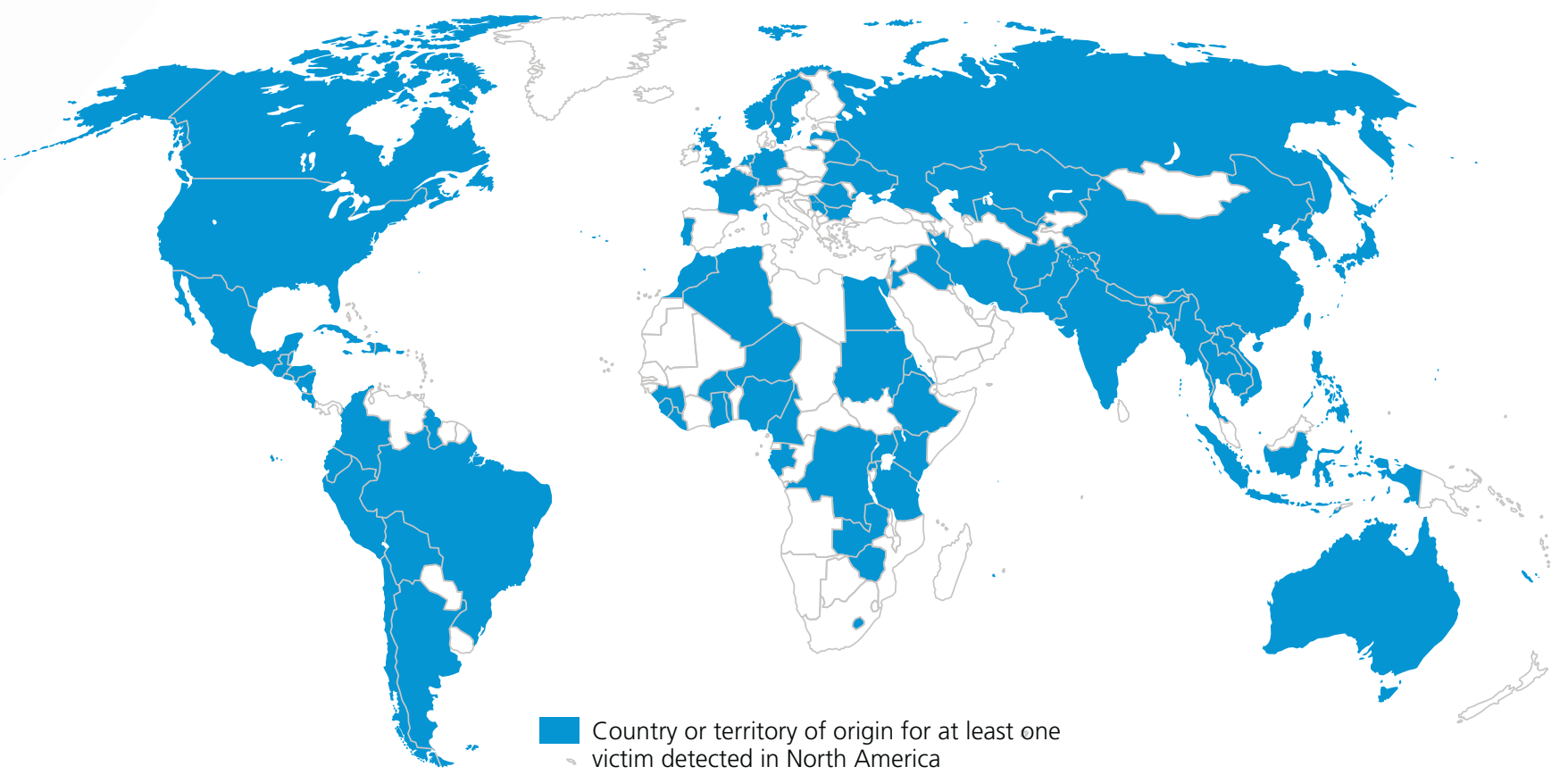

Source: UNODC elaboration of national data.

Note: The boundaries and names shown and the designations used on this map do not imply official endorsement or acceptance by the United Nations. The dotted line represents approximately the Line of Control in Jammu and Kashmir agreed upon by India and Pakistan. The final status of Jammu and Kashmir has not yet been agreed upon by the parties. The final boundary between the Republic of Sudan the Republic of South Sudan has not yet been determined. A dispute exists between the Governments of Argentina and the United Kingdom of Great Britain and Northern Ireland concerning sovereignty over the Falkland Islands (Malvinas).

MAP 10 Origins of trafficking victims detected in North America, by subregion, 2014 (or most recent)

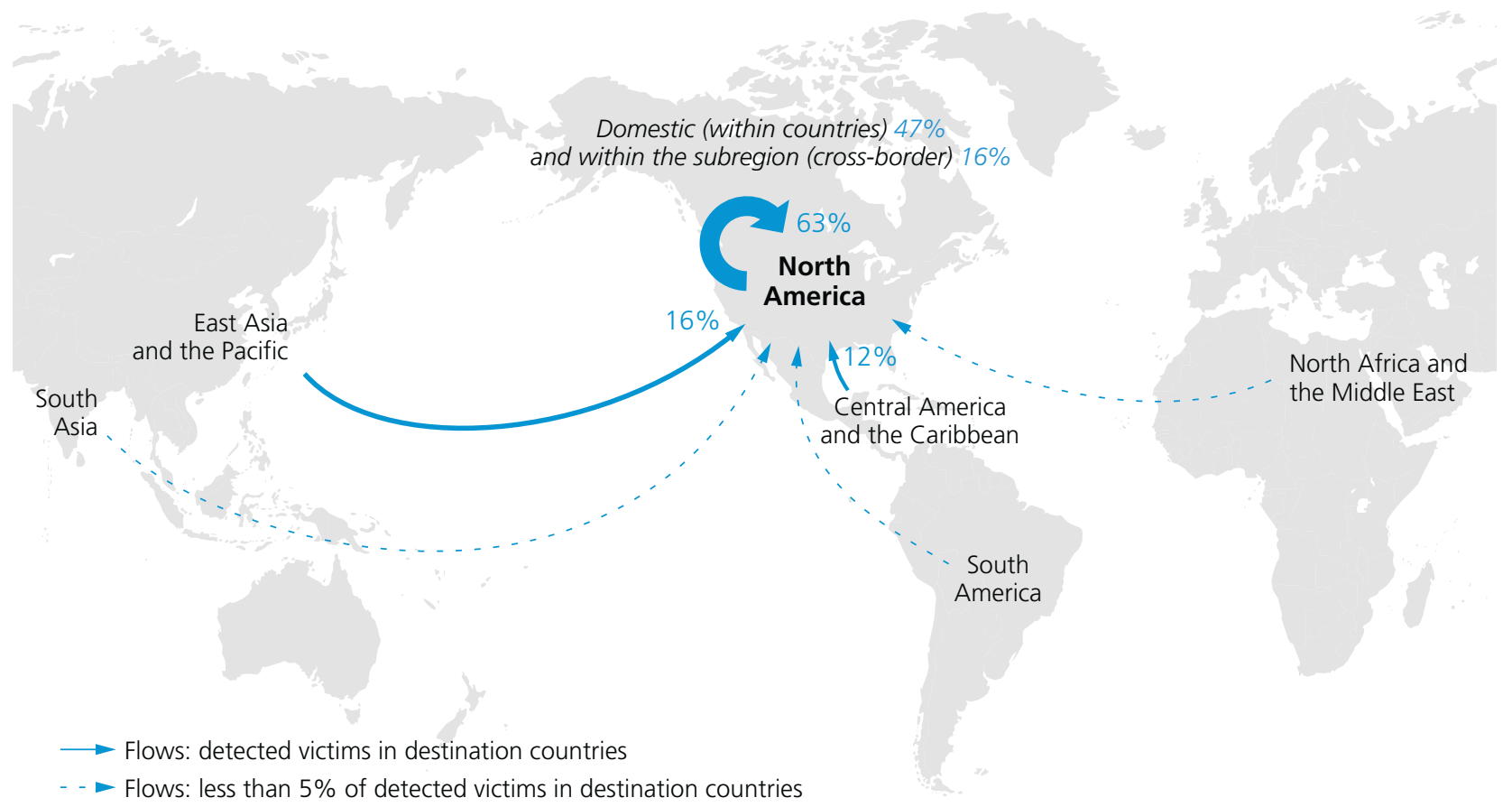


FIG. 89 Shares of detected trafficking flows in Central America and the Caribbean, by geographical distance, * 2014 (or most recent)

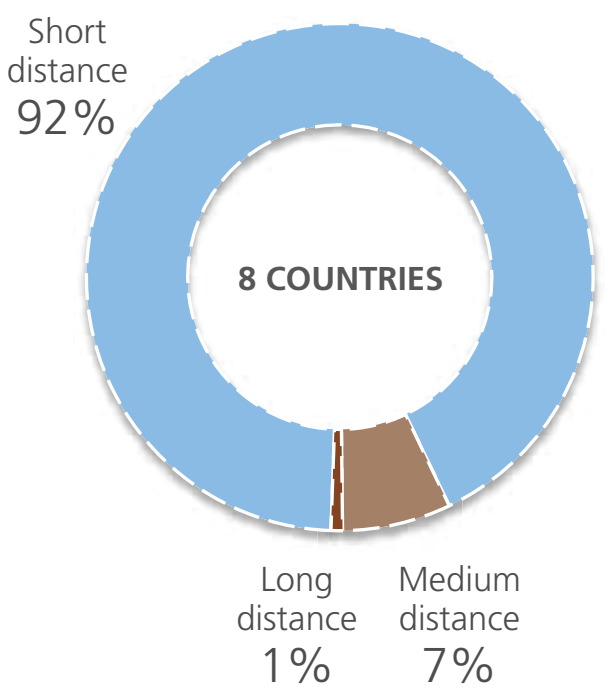

* Short-distance trafficking flows see victims trafficked within national borders or between neighbouring countries; medium-distance flows are between two countries that do not share a border and with the border of the origin country less than 3,500 kilometres away from the closest border of the destination country; and long-distance flows connect countries in which the border of the origin is farther than 3,500 kilometres away from the closest border of the destination.

Source: UNODC elaboration of national data.

FIG. 90 Flows of trafficking in persons between North and Central America and the Caribbean and per capita gross domestic product, 2011-2014

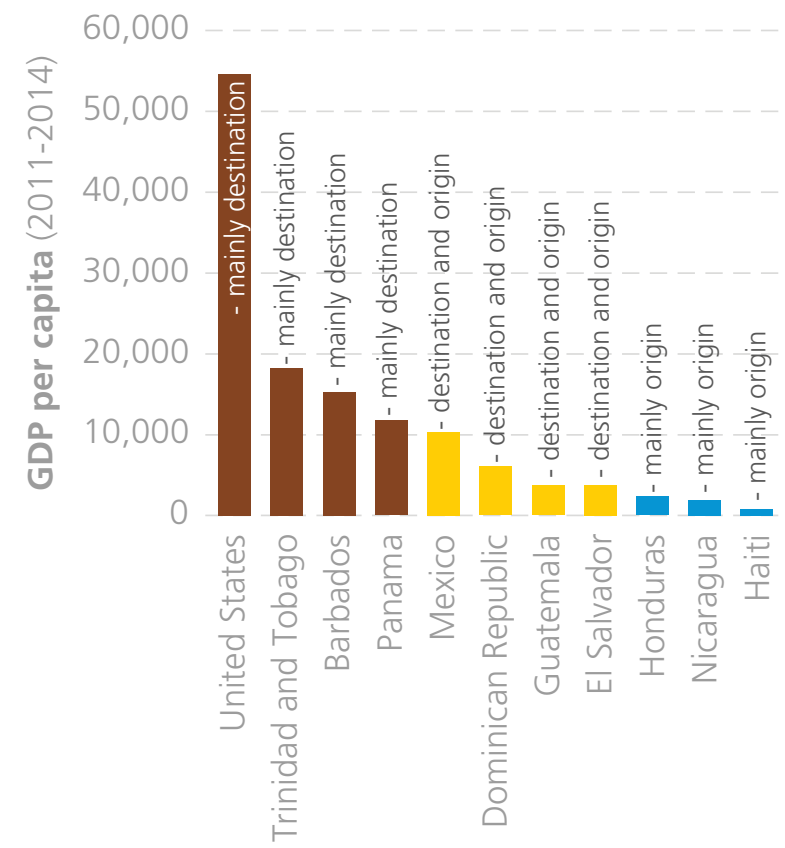

Source: UNODC elaboration of national data/World Bank.
MAP 11 Origins of trafficking victims detected in Central America and the Caribbean, by subregion, 2014 (or most recent)

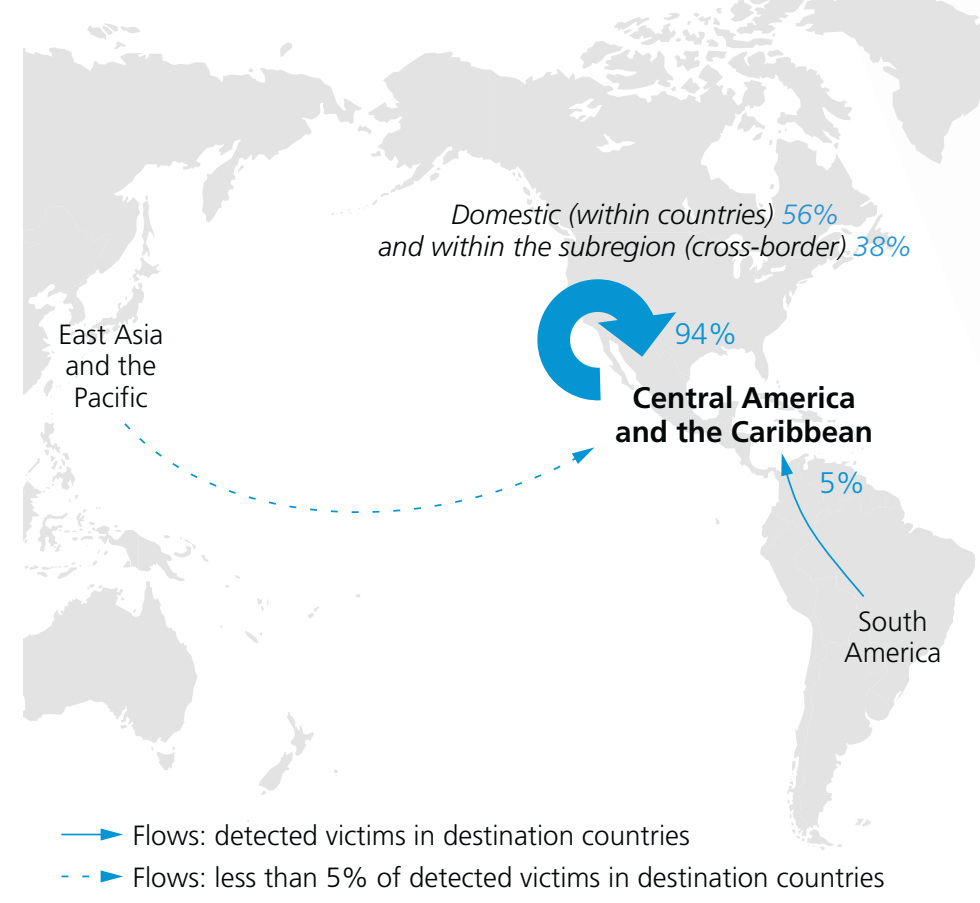

Source: UNODC elaboration of national data.

Note: The boundaries and names shown and the designations used on this map do not imply official endorsement or acceptance by the United Nations.

America and the Caribbean who were neither trafficked domestically nor between neighbouring countries were mainly trafficked from origins less than a few hundreds kilometres from the border of the country where they were detected. Most of these victims were from South America.

Most of the cross-border trafficking flows follow the broad patterns of economic differences; victims are trafficked from poorer to relatively richer countries nearby. This was seen in several parts of Central America and the Caribbean; to some extent in connection with flows originating from or directed towards South America. Victims detected in the richer countries of the Caribbean - such as Barbados, Panama and Trinidad and Tobago - originated from neighbouring or close South American countries, such as the Bolivarian Republic of Venezuela, Colombia and Guyana. Moreover, victims from Haiti were frequently detected in the Dominican Republic.

Central America and the Caribbean is also an origin of trafficking outside the region. Trafficking from these countries accounted for about 10 per cent of the victims detected in South America. Most of these victims are traf- 
MAP 12 Destinations of detected trafficking victims from Central America and the Caribbean, by subregion, 2012-2014 (or most recent)

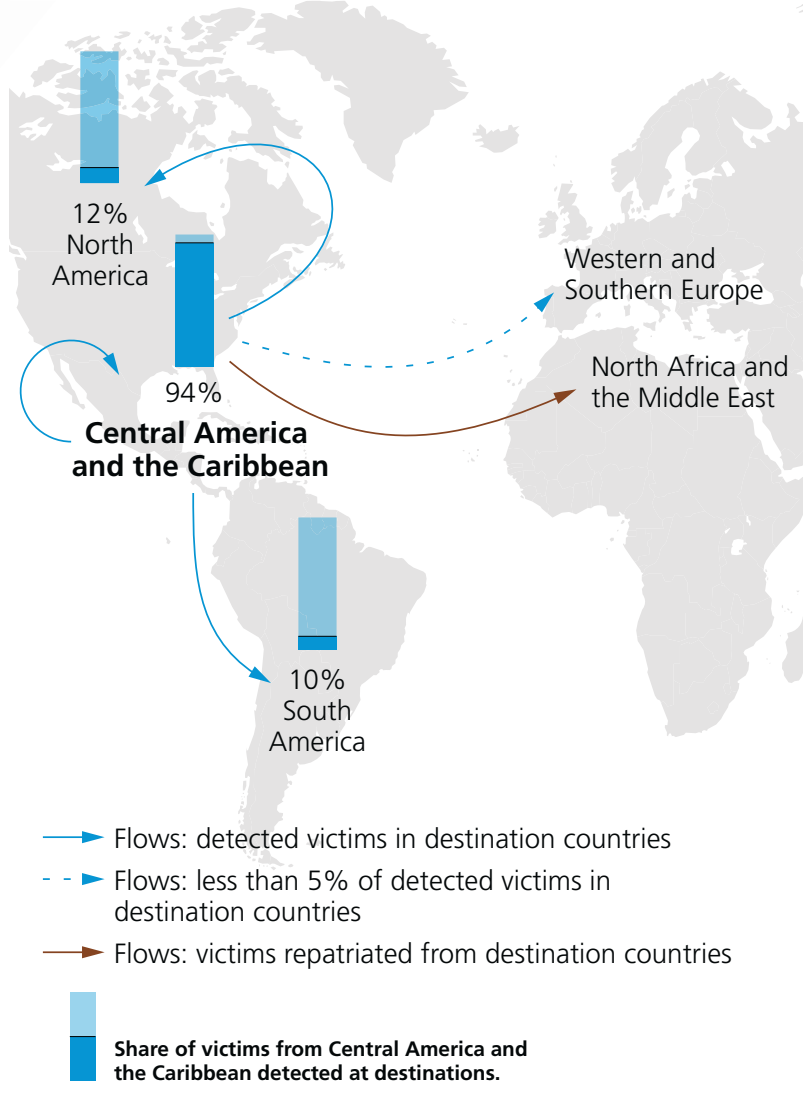

Source: UNODC elaboration of national data.

Note: The boundaries and names shown and the designations used on this map do not imply official endorsement or acceptance by the United Nations.

ficked from the Caribbean to countries of the Southern Cone, as well as to the Andean countries. Smaller flows of victims from Central America and the Caribbean were detected in several regions outside of the Americas as well. In total, victims from this part of the world have been detected in more than 30 countries around the world.

\section{Criminalization of trafficking in persons}

Legislation in the North American countries, Canada, Mexico and the United States of America, evolved quite rapidly towards the criminal definition of trafficking presented in the UN Trafficking in Persons Protocol. Both Canada and Mexico had an offence on trafficking in persons before the entry into force of the Protocol in December 2003, but while Canada only criminalized international trafficking, Mexico only criminalized child trafficking. Both countries amended their legislation to comply with the UN definition by 2008. In the United States, the
FIG. 91 Share and number of countries in North and Central America and the Caribbean with a specific offence on trafficking in persons that criminalizes all forms listed in the UN Protocol, by period of introduction of the offence

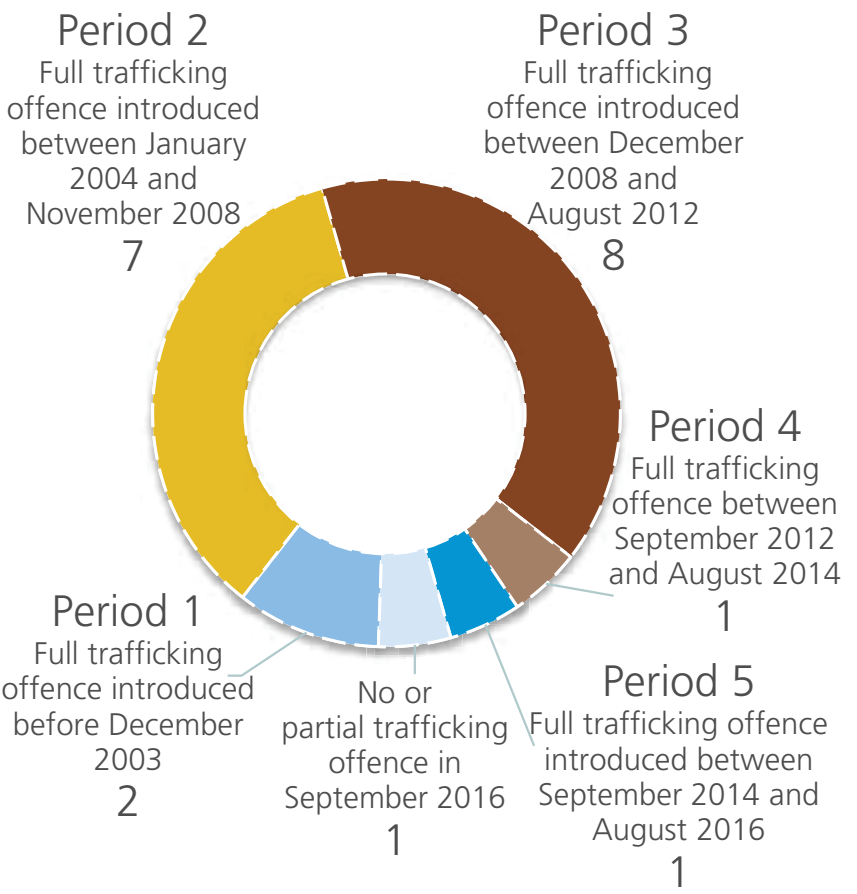

Source: UNODC elaboration of national data.

Note: For the criminalization analysis, more countries are covered than for the section on patterns and flows.

Trafficking Victims Protection Act (TVPA) was introduced in the year 2000 .

The number of convictions in North America is high compared to the rest of the world. The United States reports around 150 - 200 convictions per year, while Mexico has between 60 and 100. In Canada, there are 10 to 15 convictions per year. Mexico and the United States reported increasing numbers of convictions over the 20122014 period. It appears that, on average, about half of the persons prosecuted receive first-instance convictions. There is no information about the number of persons investigated for trafficking in the region.

In Central America and the Caribbean, only the Dominican Republic had legislation with a definition of trafficking in line with the UN Trafficking in Persons when it entered into force. Before December 2003, many countries in Central America had an offence of trafficking in persons that only criminalized trafficking for sexual exploitation, while most countries in the Caribbean did not include the legal concept of trafficking in persons in 
their criminal codes at all. Most of the countries in this area developed their legislation to align with the UN standard during the 10 years following the entry into force of the Protocol.

Due to the relatively recent introduction of the offence of trafficking in persons, about one third of the countries in the region, particularly in the Caribbean, have still not recorded a single conviction. The other two thirds reported fewer than 20 convictions per year. The limited numbers of convictions may be related to these countries' small populations. Most of the countries reported stable numbers of convictions, with a couple of countries reporting an increasing trend.

However, a relatively large number of investigations are generally reported in Central America. The analysis shows that, on average, 29 per cent of the persons prosecuted and 20 per cent of the persons initially suspected or investigated by the police authorities receive first instance court convictions. These shares are somewhat lower than the global average, but higher than the corresponding ones in South America.

\section{SOUTH AMERICA}

\section{Key findings:}

Most frequently detected victim profile: Women, $45 \%$

Most frequently detected form of exploitation: Sexual exploitation, 57\%

\section{Gender profile of convicted offenders:} $63 \%$ males

\section{Share of national citizens among offenders: $77 \%$}

\section{Summary profile of trafficking flows:} Destination for intraregional trafficking. Origin for trafficking flows to other regions.

\section{Emerging trend: Southern Cone countries as destinations and Andean countries as origins of regional and transregional trafficking.}

The countries considered ${ }^{123}$ in the following analysis represent a geographically large area that neighbours Central America and the Caribbean to its north, but is relatively distant from the rest of the world. South America has

123 South America: Argentina, Bolivia (Plurinational State of), Brazil, Chile, Colombia, Ecuador, Guyana, Paraguay, Peru, Suriname, Uruguay and Venezuela (Bolivarian Republic of). many geographically large countries and wide socio-economic differences; both within each country and within the region.

\section{Profile of the victims}

The vast majority of the approximately 5,800 victims detected in South America whose gender and age were reported between 2012 and 2014 were females. While most were adult women ( 45 per cent), girls were also frequently detected. About one quarter of the victims were males; more men than boys.

FIG. 92 Detected victims of trafficking in South America, by age and sex, 2014 (or most recent)

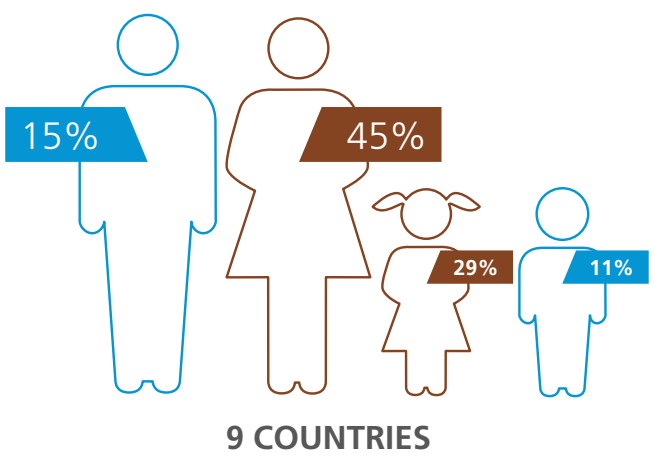

Source: UNODC elaboration of national data.

The level of child trafficking was particularly high, representing around 40 per cent of the victims detected during the reporting period. Child trafficking was detected more frequently than adult trafficking in the Andean countries of Ecuador, Peru and the Plurinational State of Bolivia. Adult victims were more frequently detected in the Southern Cone countries of Argentina, Chile and Uruguay.

\section{Forms of exploitation}

More than half of the 4,500 detected victims of trafficking in persons for whom the form of exploitation was reported between 2012 and 2014 were trafficked for sexual exploitation. Around one third were trafficked for forced labour. It should be noted that Brazil reported a large number of victims, around 3,000 per year, for offences such as slave labour and forced labour. It is unclear how many of these victims were in exploitative situations as the result of a trafficking process.

Countries in this region reported wide differences in the prevalence of trafficking for forced labour. Countries like Chile and the Plurinational State of Bolivia had large numbers of victims trafficked for forced labour compared to sexual exploitation. Argentina and the Bolivarian 
FIG. 93 Forms of exploitation among detected victims of trafficking in South America, 2014 (or most recent)

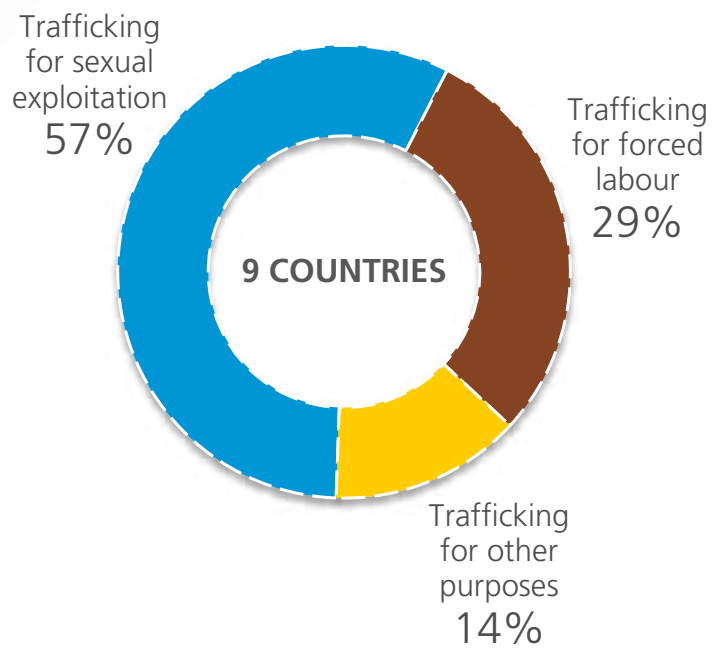

Source: UNODC elaboration of national data.

Republic of Venezuela reported equal shares of victims trafficked for forced labour and sexual exploitation. In Colombia, Ecuador, Paraguay, Peru and Uruguay, trafficking for sexual exploitation is more frequently detected. The definitional issues related to the legislation in force in Brazil during the period considered make it difficult to undertake a comprehensive regional analysis. However, the implementation of the new Brazilian legislation passed by the Senate in September 2016 - may bring about changes in the Brazilian data, which, in turn, would impact the regional totals.

While most of the victims trafficked for forced labour are males, either men or boys, this form of trafficking also affects many females. Several South American court cases describe trafficking for domestic servitude following a pattern where girls are trafficked by individuals or couples for exploitation in a household. In Argentina, one case involved a girl who was brought from the rural parts of the Plurinational State of Bolivia to Argentina by her aunt. Her parents were promised that she would receive a proper education, but instead, she was exploited as servant in the aunt's household. ${ }^{124}$ Similarly, a Peruvian girl was trafficked to the Bolivarian Republic of Venezuela by a couple of friends of the family. Again, the victim (and her family) was promised a good education, but instead, she was exploited in forced household labour. ${ }^{125}$

124 Case provided by Argentina, which concluded with a conviction by the tribunal of Comodoro Rividavia. The two traffickers were sentenced to 11 and 10 years of prison.

125 Case provided by the Bolivarian Republic of Venezuela (court and sentence information not available).
FIG. 94 Detected victims of trafficking for forced labour in South America, by sex, 2014 (or most recent)

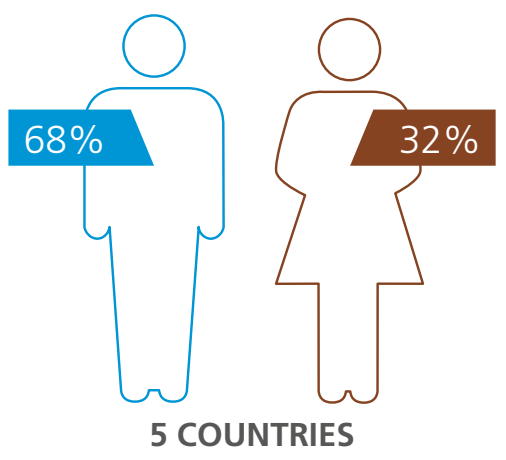

Source: UNODC elaboration of national data.

FIG. 95 Detected victims of trafficking for 'other' purposes in South America, by sex, 2014 (or most recent)

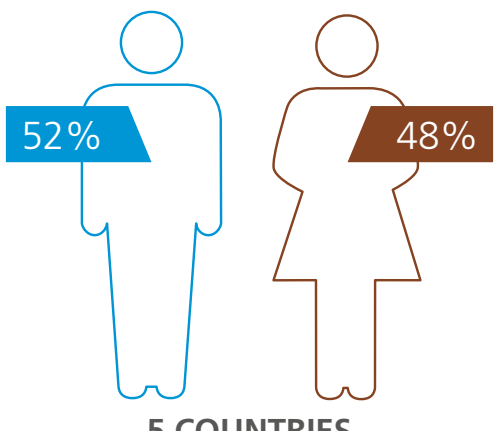

Source: UNODC elaboration of national data

South American countries reported a relatively large share of trafficking for 'other' purposes. A significant portion were victims of illegal adoption or baby selling; about 4 per cent of the detected victims in South America between 2012 and 2014. About 2.5 per cent of the victims were trafficked for the production of pornographic material. Trafficking for the purpose of begging, for the commission of crime and for forced marriage were also reported.

\section{Profile of the offenders}

The gender profiles of trafficking offenders in this region are largely in line with global patterns. While the majority of those investigated, prosecuted or convicted of trafficking crimes are men, women participate in much larger numbers than what is seen for most other crimes.

About 40 per cent of the approximately 430 persons who received first-instance court convictions between 2012 and 2014 were female. Similar shares were reported for 
FIG. 96 Persons investigated for trafficking in persons in South America, by sex, 2014 (or most recent)

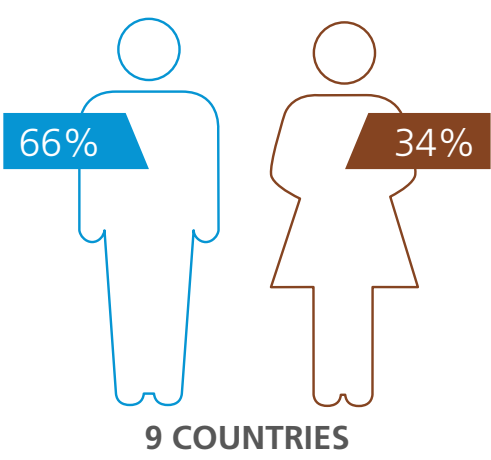

Persons prosecuted for trafficking in persons in South America, by sex, 2014 (or most recent)

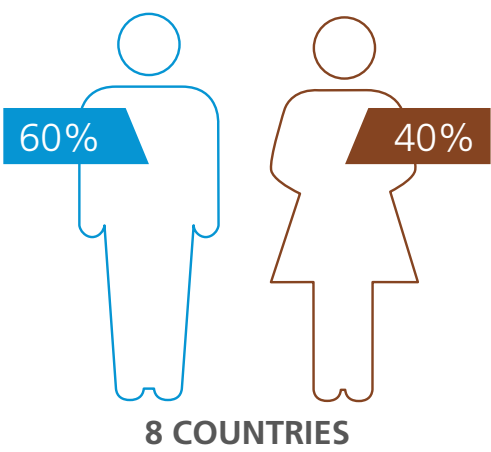

Persons convicted of trafficking in persons in South America, by sex, 2014 (or most recent)

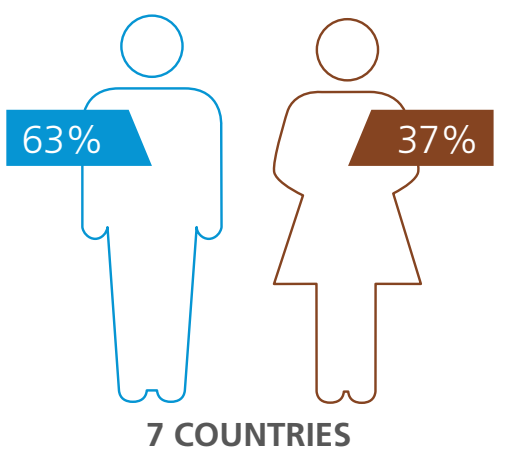

Source: UNODC elaboration of national data.

those officially suspected or prosecuted, but in larger numbers (about 1,200 persons were prosecuted, and more than 6,000 were suspected in the covered countries during the reporting period). The share of women among those investigated, prosecuted and convicted of trafficking in persons was somewhat larger in the Bolivarian Republic of Venezuela and Colombia.
FIG. 97 Share of offenders convicted in South America, by their area of citizenship, 2014 (or most recent)

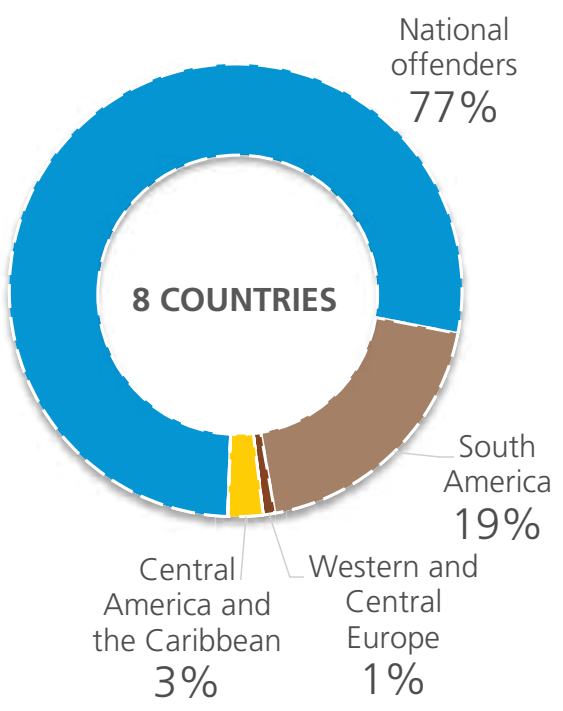

Source: UNODC elaboration of national data.

The citizenships of the persons convicted of trafficking in persons in South America follow the global patterns in that the vast majority of the offenders are citizens of the countries in which they were convicted. Most trafficking appears to be conducted by offenders operating within their countries. However, more than 20 per cent of the persons convicted in South America in 2014 were foreigners, mainly from other South American countries.

As for other regions, the citizenships of convicted offenders tend to mirror the trafficking flows of the region, which are mainly domestic and regional. Nevertheless, the citizenships of offenders vary significantly between countries of origin and destination of cross-border trafficking. While destination countries tend to report larger shares of foreigners among the convicted traffickers, convictions of foreign citizens are limited in origin countries. This is in line with the global pattern.

About 60 per cent of the persons convicted in countries of destination for cross-border trafficking in 2014 were citizens of the country in which they were convicted. In Chile, for instance, which is a destination country, half of those convicted of trafficking in persons between 2012 and 2014 were foreigners. This share is far higher than what was reported by countries of origin (4 per cent).

When foreigners are convicted in typical countries of origin, they tend to be involved in the trafficking of fellow citizens into these countries. 
FIG. 98 Convictions of foreign offenders (relative to the convicting country), by countries of origin and destination of cross-border trafficking in the Americas, 2014 (or most recent)

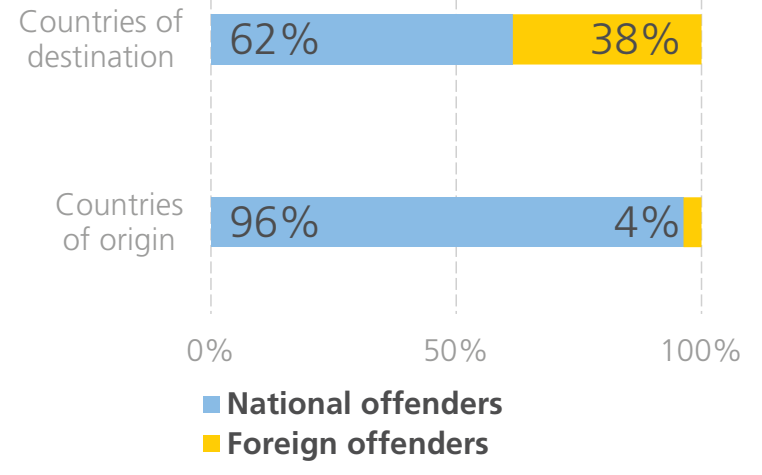

Source: UNODC elaboration of national data.

\section{Trafficking flows into South America}

Most of the inbound trafficking involved South American victims, either originating from the country of detection (domestic trafficking) or from other countries in the region. Domestic trafficking accounted for about 78 per cent of the flows detected in 2014 (or most recent). South American trafficking is largely regional, which can be explained by the diversity within this region, the geo- graphical distance from the rest of the world, and the size of the region and its constituent countries.

Cross-border trafficking flows in the region run mainly between neighbouring countries. Between 2012 and 2014, victims trafficked from the Plurinational State of Bolivia were detected in Argentina and Chile, and victims from Paraguay were detected in Argentina. Citizens of Paraguay, Peru and the Plurinational State of Bolivia were detected in or repatriated from Brazil. Colombian victims were detected in Ecuador and Peru.

What emerges is an intricate picture of multiple trafficking flows; limited in terms of geographical reach, but severe in terms of the numbers of victims involved. The Southern Cone countries of Argentina, Chile and Uruguay are mainly destinations for cross-border trafficking, while Paraguay and the Plurinational State of Bolivia in the south, and Colombia and Guyana in the north, are mainly origin countries. The other South American countries are both origins and destinations for cross-border trafficking, and are at the same time affected by domestic trafficking, as is the whole region.

A significant trafficking flow into the region originates from the Caribbean. About 10 per cent of the victims detected in South America in 2014 were citizens of the Dominican Republic, Haiti and, to a lesser extent, Cuba. There are also minor trafficking flows from East and South Asia.

MAP 13 Origins of trafficking victims detected in South America, by subregion, 2014 (or most recent)

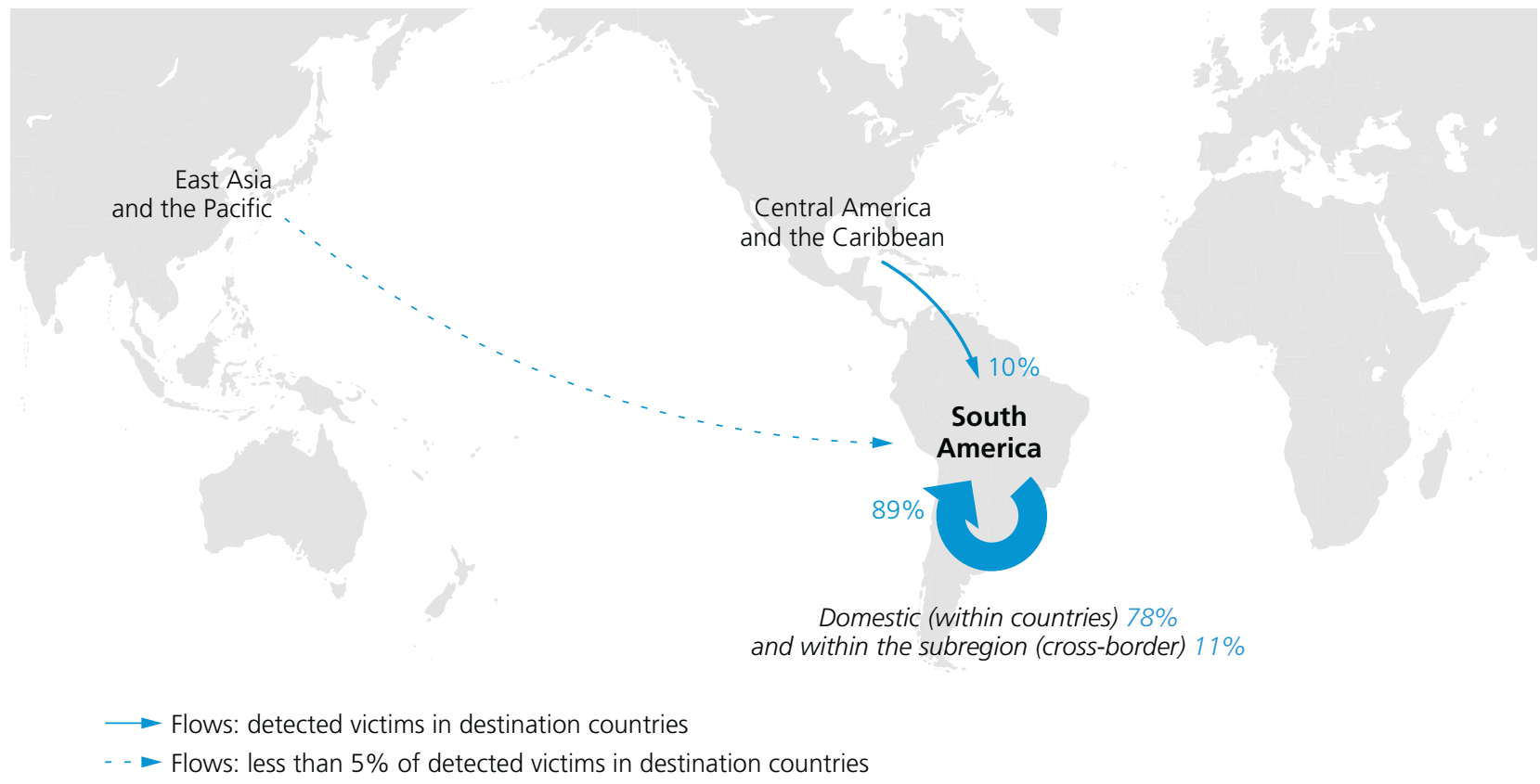


FIG. 99 Shares of detected trafficking flows in South America, by geographical distance, * 2014 (or most recent)

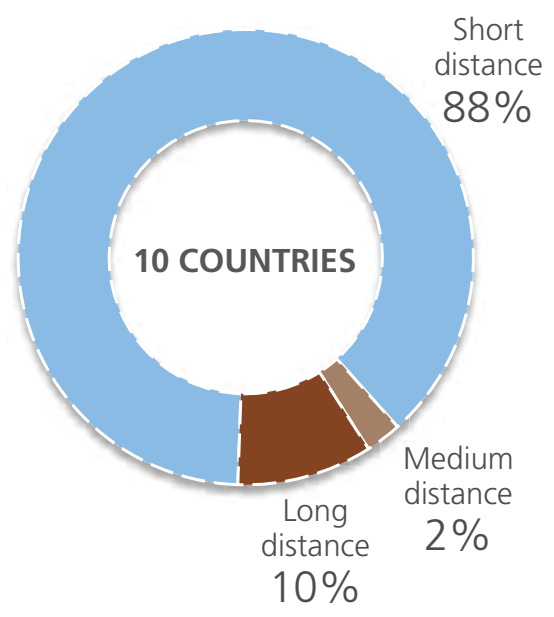

* Short-distance trafficking flows see victims trafficked within national borders or between neighbouring countries; medium-distance flows are between two countries that do not share a border and with the border of the origin country less than 3,500 kilometres away from the closest border of the destination country; and long-distance flows connect countries in which the border of the origin is farther than 3,500 kilometres away from the closest border of the destination.

Source: UNODC elaboration of national data.

\section{Trafficking flows out of South America}

As a destination of trafficking in persons, South America plays mainly a regional role, but as an origin, the region has transregional significance. South American trafficking victims have been detected in or repatriated from about 50 countries around the world, mainly from the Americas and Europe, but also from East Asia and the Middle East.

While these flows are widely diffused, their intensity is limited. In Western and Southern Europe, the share of victims from South America has been decreasing over the last years to about 3 per cent in 2014. Similar values are reported in North America. In Central America and the Caribbean, it reached approximately 5 per cent, mainly comprised of relatively short distance trafficking from the northern countries of South America to nearby areas like Panama and various Caribbean countries.

The repatriation data brings out additional trafficking flows that are not discernible from data provided by destination countries. About 9 per cent of the 600 South Americans who were repatriated between 2012 and 2014 were trafficked to and repatriated from countries in East Asia. This data also confirms the flows within South America, and outside the region to Western and Southern Europe, Central America and the Caribbean, and North America.

MAP 14 Destinations of detected trafficking victims from South America, by subregion, 2014 (or most recent)

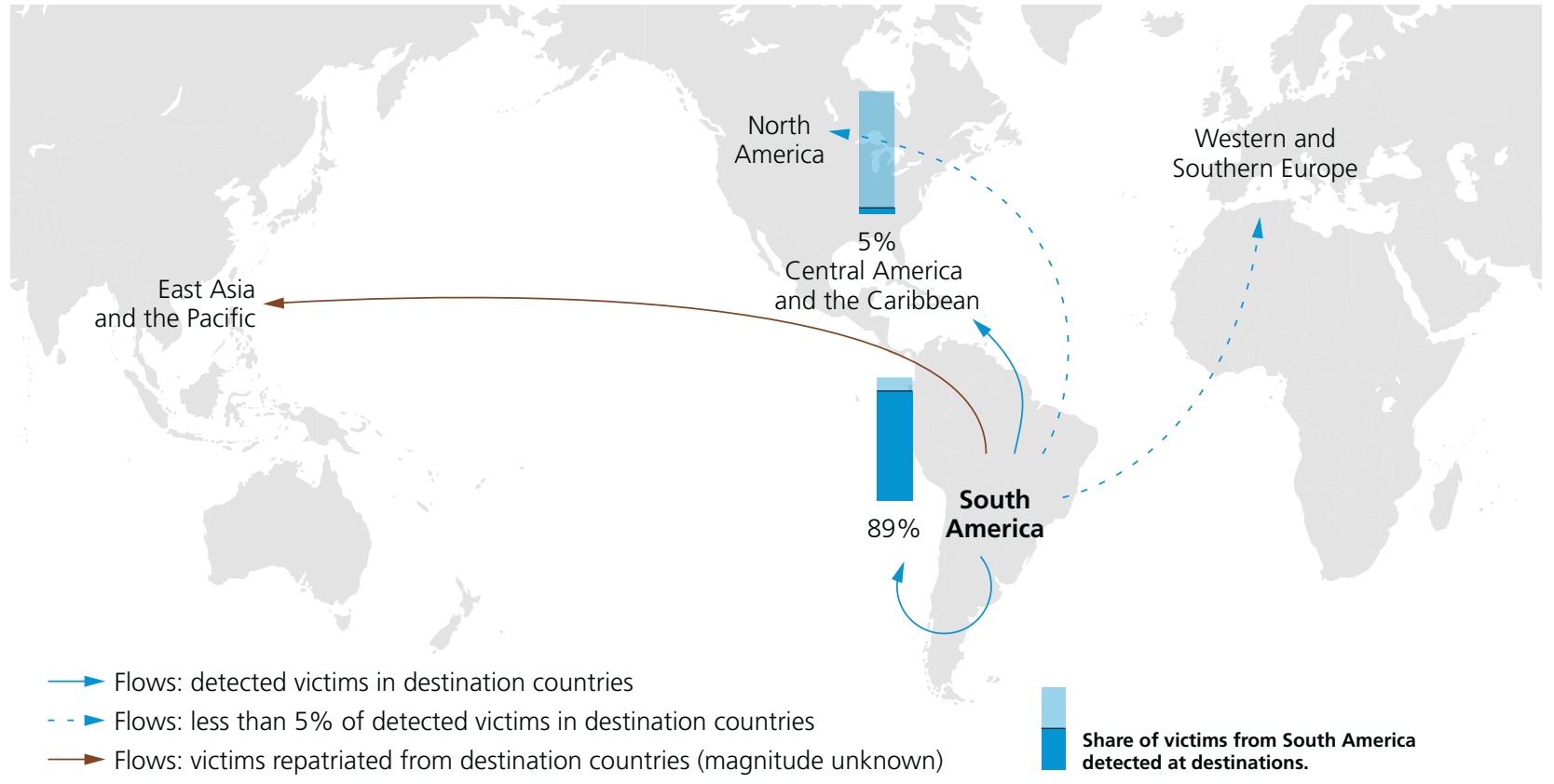


FIG. 100 Share and number of countries in South America with a specific offence on trafficking in persons that criminalizes all forms listed in the UN Protocol, by period of introduction of the offence

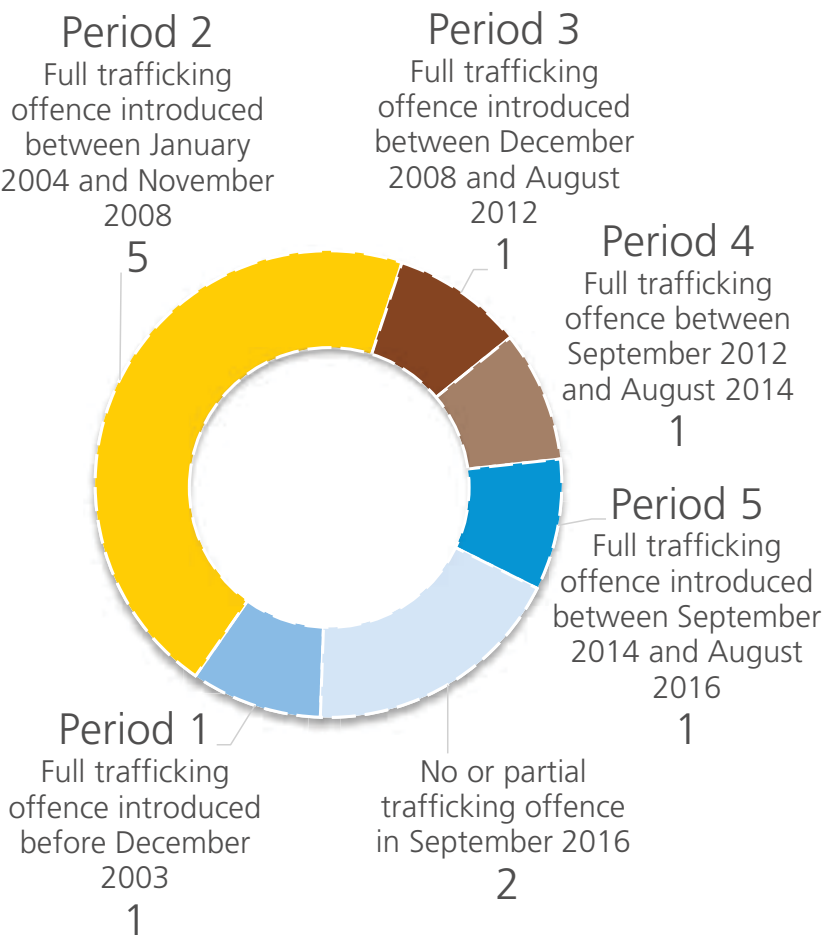

Share of countries in South America, by number of trafficking convictions, 2012-2014 (one year within the period)

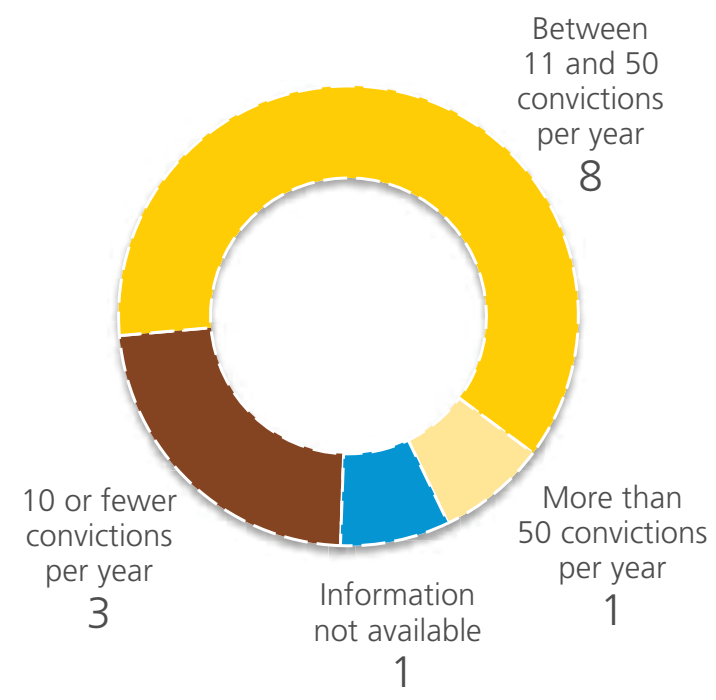

Source: UNODC elaboration of national data.

Note: For the criminalization analysis, more countries are covered than for the section on patterns and flows.

\section{Criminalization of trafficking in persons}

Among the South American countries, Colombia has had a trafficking in persons offence in the criminal code since 2002. This offence addressed all forms of exploitation included in the UN Trafficking in Persons Protocol from the beginning. At the time of entry into force of the Protocol, most of the other South American countries only criminalized some aspects of trafficking, such as international trafficking or trafficking for sexual exploitation.

Many countries introduced a trafficking offence or amended existing offences in order to comply with the Protocol definition after December 2003. Most of the changes and amendments focused on the inclusion of domestic trafficking as part of the crime of trafficking in persons.

At the time of writing (September 2016), two South American countries have legislation that defines the offence of trafficking not fully in line with the definition in the UN Trafficking in Persons Protocol. Uruguay's offence only criminalizes trafficking in persons in cases of cross-border trafficking, while the Bolivarian Republic of Venezuela's criminal justice system uses offences from different parts of the criminal code to prosecute all forms of trafficking in persons identified in the UN Trafficking in Persons Protocol.

All the countries covered reported at least one conviction between 2012 and 2014, and most countries ranged between 1 and 20 convictions per year. Only Argentina had more, with yearly totals between 30 and 60 . The number of investigations is very high in South America; Argentina, Brazil, Ecuador, Peru and the Plurinational State of Bolivia all recorded investigations in the hundreds. Less than half ( 46 per cent) are prosecuted, while less than one third of the number of prosecuted persons ( 28 per cent) are convicted. On average, for every 100 persons officially suspected or investigated by the police, 13 are convicted in the court of first instance.

\section{EAST ASIA AND THE PACIFIC}

\section{Key findings:}

Most frequently detected victim profile: Women, $51 \%$

Most frequently detected form of exploitation: Sexual exploitation, $61 \%$

Gender profile of convicted offenders: $60 \%$ males 
Share of national citizens among offenders: 95\%

\section{Summary profile of trafficking flows: \\ Destination for intraregional trafficking. Origin for trafficking flows to other regions.}

\section{Emerging trend: South-East Asia as destination for short, medium and long-distance trafficking.}

This region includes highly developed areas, small Pacific islands, transitional and emerging economies, as well as least developed countries. ${ }^{126}$ As a consequence, it includes a variety of socio-economic contexts that are reflected in the patterns and flows of trafficking in persons. Unfortunately, the available information on trafficking in persons in this region is not as rich as for several other regions.

\section{IFIG. 101 Detected victims of trafficking in East Asia and the Pacific, by age and sex, 2014 (or most recent)}

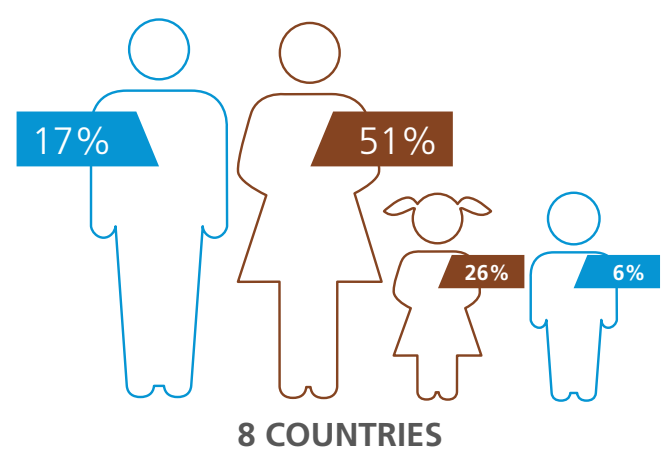

Source: UNODC elaboration of national data.

\section{Profile of the victims}

Most of the approximately 2,700 victims detected during the 2012-2014 period whose age and sex profiles were reported were females, including a significant number of girls. Due to the frequent trafficking of girls, children comprise nearly a third of the victims detected in East Asia and the Pacific. Trafficking of males is broadly in line with the global average.

Although there are significant differences within the region, females are widely detected across the board. Australia and Japan detect more women than girls, whereas girls are more detected than adults in some of the covered countries in South-East Asia.

126 East Asia and the Pacific: Australia, Cambodia, China including Taiwan Province of China, Fiji, Indonesia, Japan, Malaysia, Marshall Islands, Mongolia, Myanmar, Philippines, Republic of Korea, Solomon Islands, Thailand and Viet Nam.
FIG. 102 Detected victims of trafficking, selected areas, by sex, 2012-2014

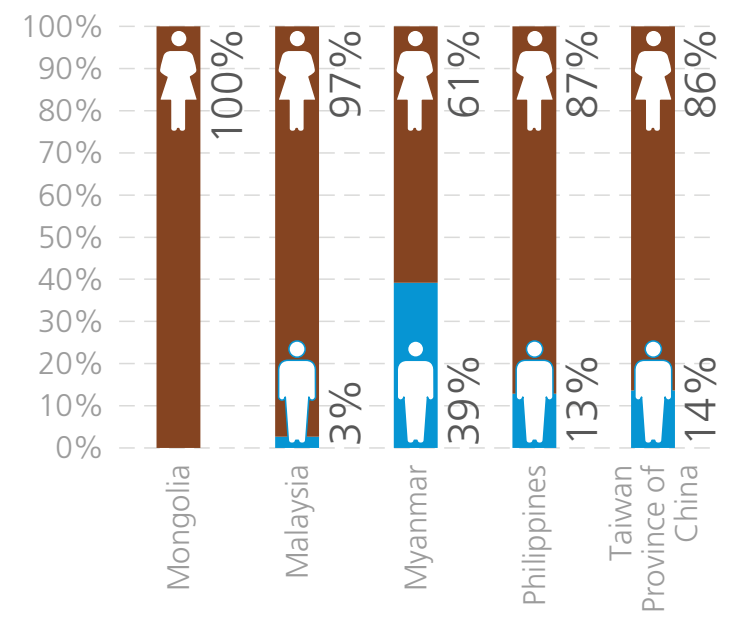

Source: UNODC elaboration of national data.

FIG. 103 Detected victims of trafficking, selected countries, by age and sex, 2014 (or most recent)

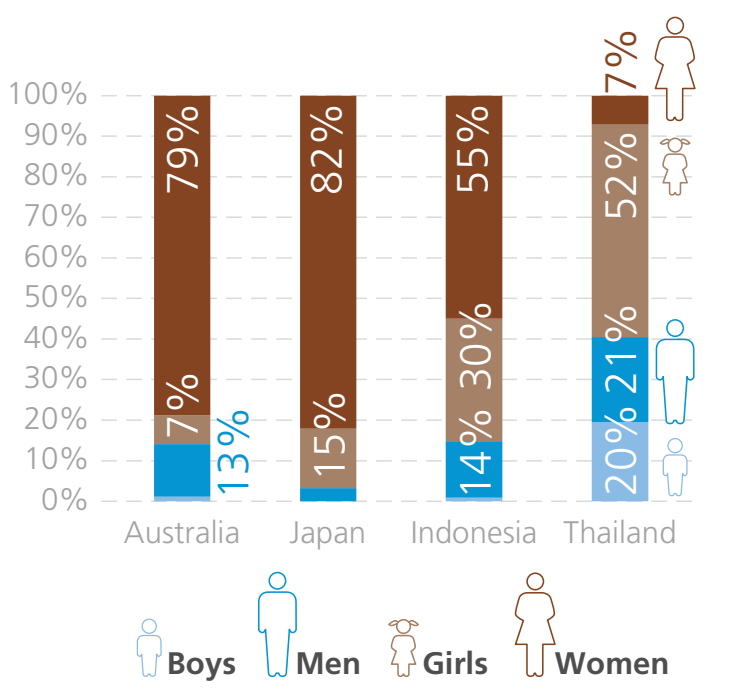

Source: UNODC elaboration of national data.

\section{Forms of exploitation}

Most victims in East Asia and the Pacific were trafficked for sexual exploitation. This was true for more than 60 per cent of the 7,800 or so victims detected between 2012 and 2014 whose exploitation was recorded. About a third of the detected victims were trafficked for forced labour. Among the most frequently reported types of forced labour was trafficking in the fishing industry, which was detected in Cambodia, Indonesia and Thailand. Domestic 


\section{Trafficking for forced labour in the fishing industry}

One form of trafficking which has recently been more prominently reported is trafficking for forced labour in the fishing industry. South-East Asia is one of the areas where such trafficking is frequently detected, and several relevant court cases have been reported. Indonesia provided one case involving about 200 Indonesian ship crew. These workers were sent by two Indonesian companies to work for a Taiwan Province of China-based company that owned ships operating in waters off West Africa and the Caribbean. The crew members were forced to work 20 hours per day with no salary for almost two years. ${ }^{a}$

Moreover, Thailand reported cases involved trafficking syndicates from Myanmar recruiting victims in Myanmar for exploitation in Thai waters. In March 2013, one case was reported by a local NGO to the Thai authorities in which 11 victims were rescued, and the ring leader was sentenced to 33 years of prison. In another case, also prosecuted by the Thai authorities in 2013, the trafficking was carried out by a loose network of people from India, Myanmar and Thailand. Indian brokers recruited Indian workers through the promise of employment in Thailand. At destination, the victims were handed over to other network members who forced them to work on fishing boats without compensation. The six traffickers were arrested, and later also convicted. ${ }^{\text {b }}$

Trafficking for the purpose of exploitation in this economic sector is not restricted to South-East Asia, however. Countries in different parts of the world reported cases of trafficking in the fishing industry. Traffickers may operate in international waters, which makes this particular type of trafficking very hidden and difficult to detect, or victims may be exploited in poor and rural locations around the African lakes. ${ }^{\circ}$

Case provided by Indonesia, which concluded with a conviction by the Jakarta Barat court. The traffickers received prison sentences and fines.

Office of anti-trafficking in persons committee, National operation center on prevention and suppression of human trafficking, Ministry of Social Development and Human Security, 2013 Thailand Situation and progress report on prevention and suppression of trafficking in persons.

See, for example, Commission Nationale Independante des Droits de l'Homme, Etude Sur l'exploitation et le traffic des enfants au Burundi, May 2014; A/HRC/25/73, UN General Assembly, Human Rights Council, Report of the Independent Expert on the situation of human rights in Côte d'Ivoire, January 2014; A/HRC/23/43/Add.2, UN General Assembly, Human Rights Council, Report of the Special Rapporteur on contemporary forms of slavery, including its causes and consequences, Gulnare Shahinian, Mission to Madagascar (10-19 December 2012).
FIG. 104 Forms of exploitation among detected victims of trafficking in East Asia and the Pacific, 2014 (or most recent)

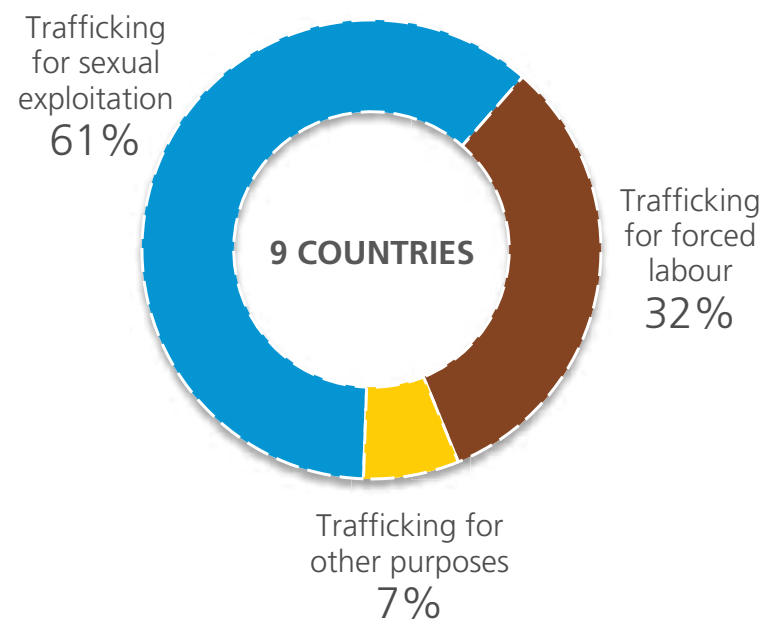

Source: UNODC elaboration of national data

servitude was also reported in many countries in the region; both in origin and destination countries.

The high prevalence of females among trafficking victims is connected to the fact that women and girls are not only trafficked for sexual exploitation, but also for forced labour and other purposes. A clear majority of the victims of trafficking for forced labour were females.

Within the broad category of 'other' forms of exploitation, trafficking for forced marriage was prominently detected, accounting for 4 per cent of the victims detected in East Asia and the Pacific between 2012 and 2014. Forced marriages were reported in the Mekong area, Cambodia, China, Myanmar and Viet Nam. This form of trafficking involves the recruitment of young women or girls to be sold as wives, often abroad (see also Box on page 32 ).

A different issue that also occurs in this part of the world is the use of sham marriages as a means of deception for the purpose of exploitation. A court case from Australia is illustrative. The case concerned a victim of trafficking for forced labour and domestic servitude. The offenders, a couple residing in Australia, convinced a Filipino woman to marry a friend of theirs in order to obtain a residence permit. Once at destination, the couple forced her to work in their shop for long hours, as well as to take care of three children. ${ }^{127}$

127 Case provided by Australia, which concluded with convictions by the
Queensland Supreme Court. The sentences ranged from 4 to 12 years of imprisonment. 
FIG. 105 Victims of trafficking for forced labour in East Asia and the Pacific, by sex, 2014 (or most recent)

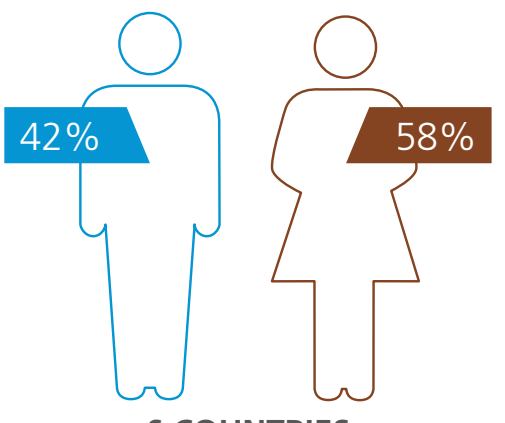

6 COUNTRIES

Source: UNODC elaboration of national data.

Trafficking for begging was also detected, accounting for around 2.3 per cent of the victims in East Asia and the Pacific. Other forms more sporadically reported include trafficking for illegal adoption and baby selling, and mixed forms of labour and sexual exploitation.

\section{Profile of the offenders}

Out of the 4,800 or so persons prosecuted for trafficking in persons whose gender was reported in this region during the 2012-2014 period, nearly half were females. The corresponding share for convictions was smaller. Of the 1,300 persons who were convicted during the reporting period, 40 per cent were females.

The vast majority of the more than 1,875 convicted offenders whose citizenship was reported were citizens of the country in which they were convicted. Only 30 convicted offenders during this period were foreigners; mainly detected in destination countries for cross-border trafficking, such as Australia and Japan. The connection between the citizenships of offenders and victims can again be seen in the countries of destination in this region.

\section{Trafficking flows into East Asia and the Pacific}

The vast majority - more than 85 per cent - of the victims detected in East Asia and the Pacific were trafficked from within the region. This also holds true for victims trafficked into richer countries like Australia and Japan. About 6 per cent of the victims were trafficked from South Asia, in particular from Bangladesh and India. Another 5 per cent of victims detected during this time period belonged to ethnic minorities in South-East Asia whose members are often deprived of citizenship. ${ }^{128}$
Regional overviews - East Asia and the Pacific

FIG. 106 Persons investigated for trafficking in persons in East Asia and Pacific, by sex, 2012-2014

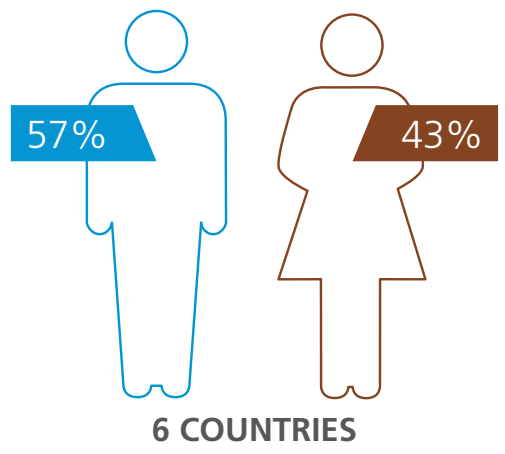

Persons prosecuted for trafficking in persons in East Asia and the Pacific, by sex, 2012-2014

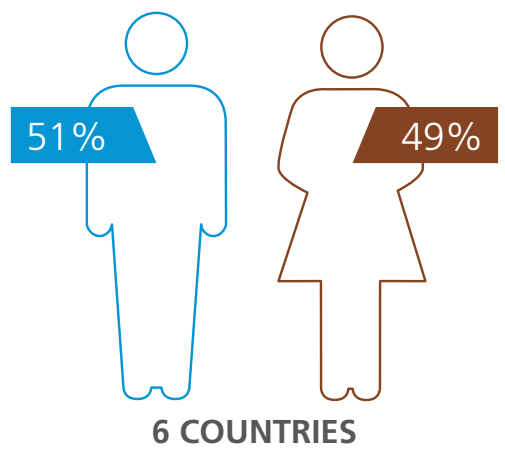

Persons convicted of trafficking in persons in East Asia and the Pacific, by sex, 2012-2014

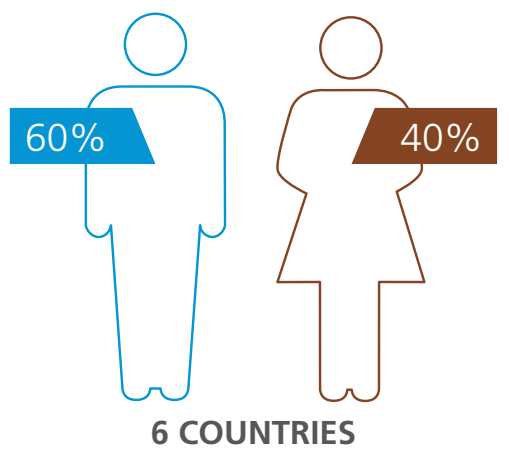

Source: UNODC elaboration of national data.

More than half of the victims detected in East Asia and the Pacific are trafficked along short-distance flows as a large part of the trafficking is either domestic or between neighbouring countries. Trafficking flows within the region are complex. The wealthiest countries, Australia and Japan, are destination countries. However, China, Malaysia and Thailand are also reported as destinations;

United Nations High Commissioner for Human Rights (Advance Edited Version), 28 June 2016. 
primarily for trafficking from countries close by. Thailand mainly detects victims from neighbouring countries such as Cambodia, Lao People's Democratic Republic and Myanmar, in addition to victims of domestic trafficking. Malaysia detects victims from Indonesia, as well as from the Philippines and Viet Nam.

\section{FIG. 107 Share of offenders convicted in East Asia and the Pacific, by their area of citizenship, 2014 (or most recent)}

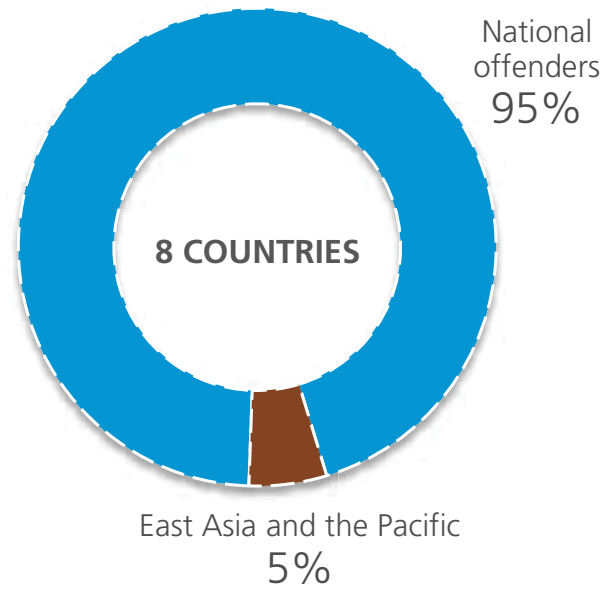

Source: UNODC elaboration of national data.
Victims from Cambodia, Indonesia, Mongolia and Viet Nam have been repatriated from China, and victims from Indonesia, the Philippines and other countries in SouthEast Asia have been detected in or repatriated from the area of Taiwan Province of China. In addition, victims from China have been detected in the Pacific Islands. In Japan, most of the detected victims were from South-East Asia, although domestic trafficking is also reported there. Australia detected some victims from the Republic of Korea.

About 47 per cent of the victims detected in East Asia and the Pacific were trafficked from origins relatively far from the country of detection, along medium-distance flows. This would generally include victims from South Asia detected in South-East Asia - a few hundred kilometres between origin and destination - or South-East Asian victims detected in the regional destinations reported above.

Three significant, additional flows emerge from repatriation data. The first saw about 115 victims, mainly from countries in Central Asia, but also from Eastern Europe, trafficked to different South-East Asian countries and repatriated during the reporting period. The second involved more than 50 South American victims who were

MAP 15 Origins of trafficking victims detected in East Asia and the Pacific, by subregion, 2014 (or most recent)

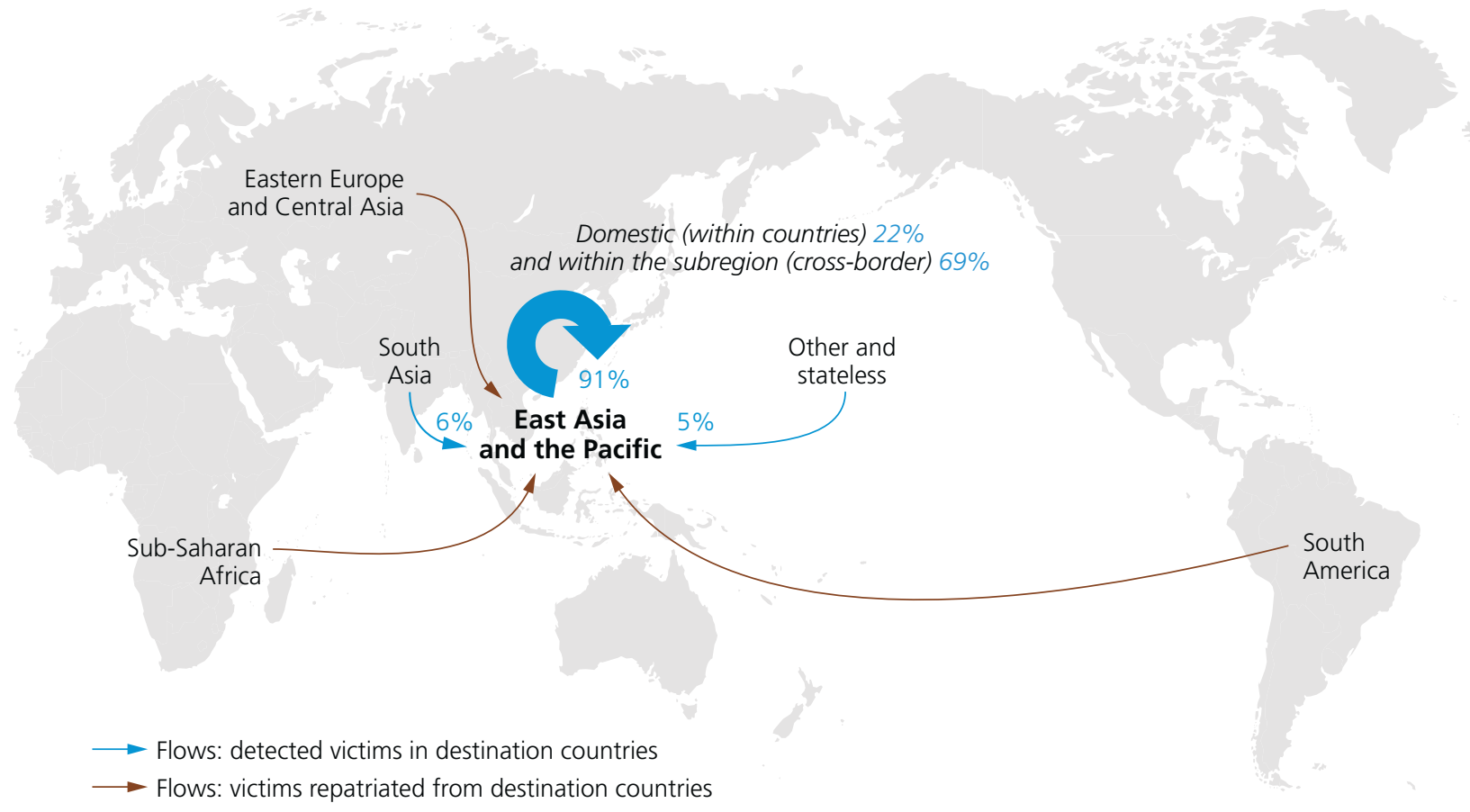


FIG. 108 Shares of detected trafficking flows in East Asia and the Pacific, by geographical distance, * 2014 (or most recent)

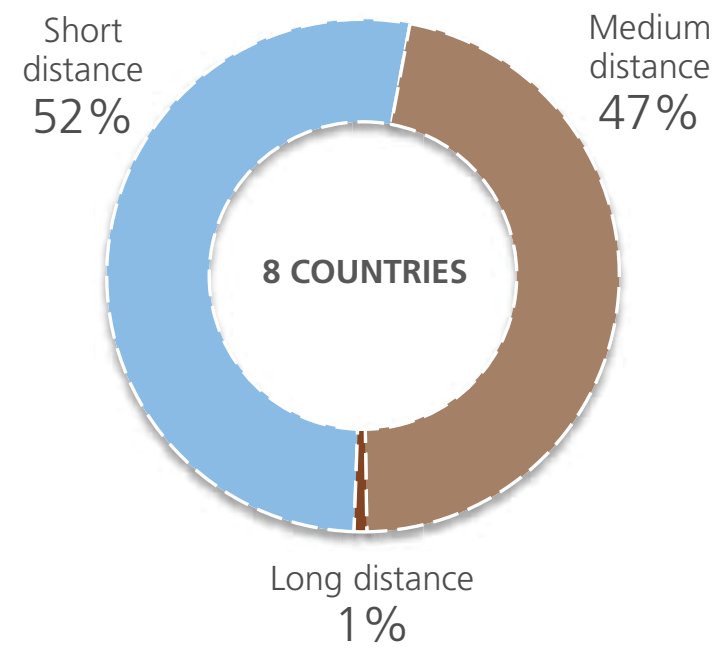

* Short-distance trafficking flows see victims trafficked within national borders or between neighbouring countries; medium-distance flows are between two countries that do not share a border and with the border of the origin country less than 3,500 kilometres away from the closest border of the destination country; and long-distance flows connect countries in which the border of the origin is farther than 3,500 kilometres away from the closest border of the destination.

Source: UNODC elaboration of national data.

trafficked to East Asia and later repatriated. Countries in South America reported significant numbers of citizens trafficked to at least seven East Asian countries. The third flow that emerged from repatriation data originated in Sub-Saharan Africa. More than 60 victims where trafficked from Sub-Saharan Africa to at least five East Asian countries and repatriated once detected.

About 28 different citizenships were recorded among the trafficking victims detected in or repatriated from countries in East Asia and the Pacific. Of these, 13 are countries within the region and 15 from other areas, including Europe, the Americas, South Asia and Africa. Considering destination and repatriation data together, it appears that East Asia and the Pacific is not only an origin of longdistance trafficking, but also a destination.

\section{Trafficking flows from East Asia and the Pacific}

This region is affected by a variety of trafficking flows, of shorter and longer range, that broadly reflect the migratory and socio-economic realities in East Asia and the Pacific. What sets the region apart from most others, however, is that the trafficking flows that originate here have a global dimension. Victims from this region have been detected in and/or repatriated from more than 60 countries in all regions and subregions of the world. Moreover, there is no main origin country of transregional trafficking. Victims from different countries - such as China, Indonesia, Philippines, Thailand and Viet Nam - are detected in a variety of destinations around the world.

Significant trafficking flows from East Asia and the Pacific have been detected by many countries in Western and Southern Europe, North America and the Middle East. Most other regions and areas have also detected East Asian victims, which demonstrates the wide geographical diffusion of trafficking flows from this region.

The repatriation data broadly confirms trafficking flows that were already apparent from destination data. Most of the victims repatriated to their East Asian home country were trafficked to other East Asian countries or to the Middle East.

\section{Criminalization of trafficking in persons}

Most of the countries in East Asia and the Pacific introduced an offence with a definition of trafficking in line with the UN Trafficking in Persons Protocol definition within five years after the entry into force of the Protocol. A few countries, mainly some Pacific islands and the Philippines, criminalized trafficking for sexual exploitation, forced labour and the other purposes included in the Protocol before December 2003. A few more countries adopted the Protocol definition of trafficking in persons in their domestic legislation between 2012 and 2014.

China and some Pacific islands have specific trafficking in persons offences that criminalize some of the forms of exploitation listed in the UN Trafficking in Persons Protocol. These countries may also prosecute trafficking crimes under other offences.

Countries with very recently enacted legislation did not report any convictions during the reporting period. Three countries had less than 10 convictions, while the others had between 50 and a few hundred convictions per year. There is an overall stagnation in the number of convictions in East Asia and the Pacific. Most countries reported stable numbers, although the Philippines reported a clear increase, and Indonesia a clear reduction.

Information from a limited number of South-East Asian countries shows that 28 per cent of the persons investigated for trafficking in persons are convicted in the court of first instance. This is in line with the global average. 
MAP 16 Countries where victims from East Asia and the Pacific have been detected, 2012-2014 (or most recent)

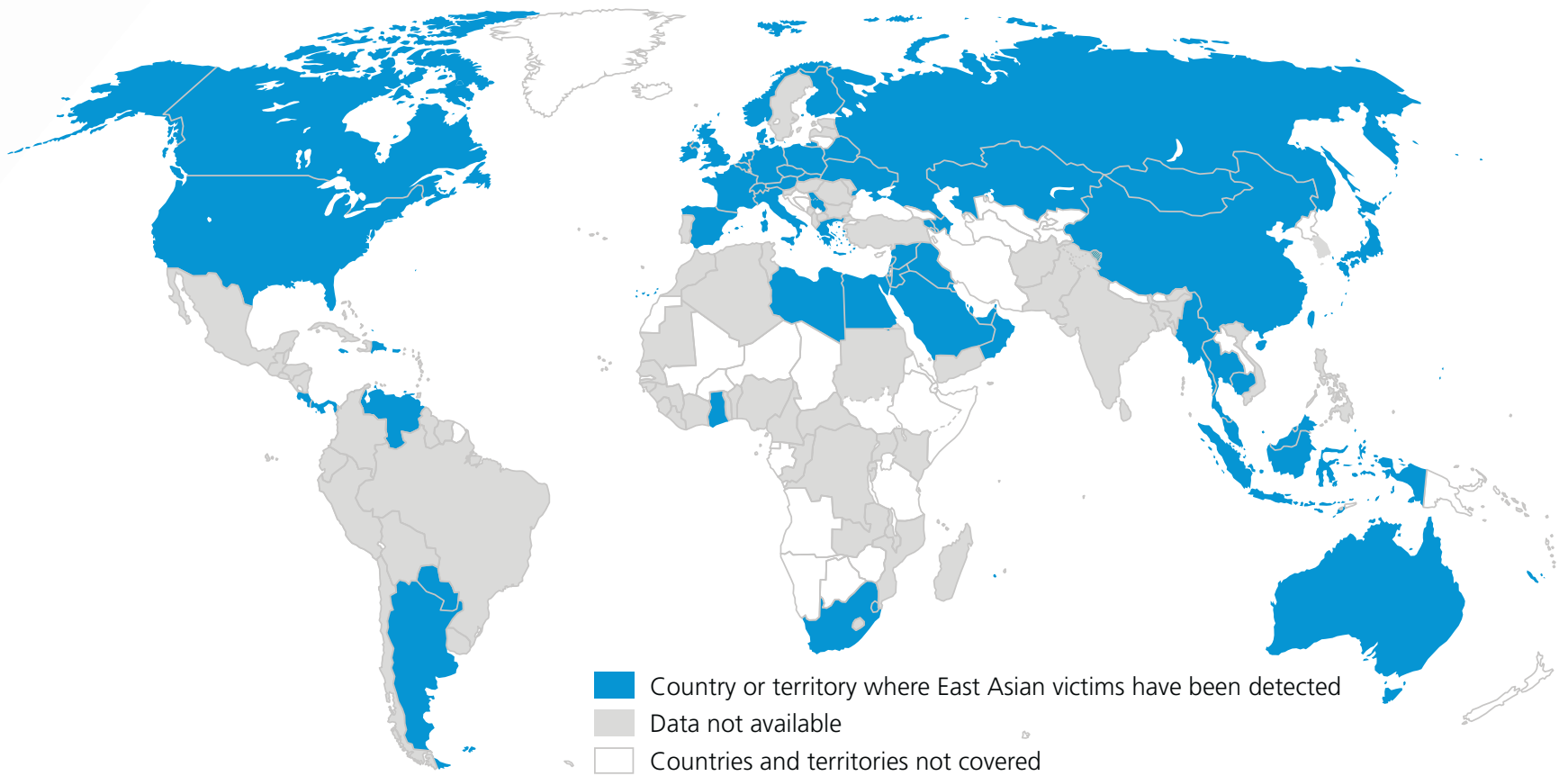

Source: UNODC elaboration of national data.

Note: The boundaries and names shown and the designations used on this map do not imply official endorsement or acceptance by the United Nations. The dotted line represents approximately the Line of Control in Jammu and Kashmir agreed upon by India and Pakistan. The final status of Jammu and Kashmir has not yet been agreed upon by the parties. The final boundary between the Republic of Sudan the Republic of South Sudan has not yet been determined. A dispute exists between the Governments of Argentina and the United Kingdom of Great Britain and Northern Ireland concerning sovereignty over the Falkland Islands (Malvinas).

MAP 17 Destinations of detected trafficking victims from East Asia and the Pacific, by subregion, 2012-2014

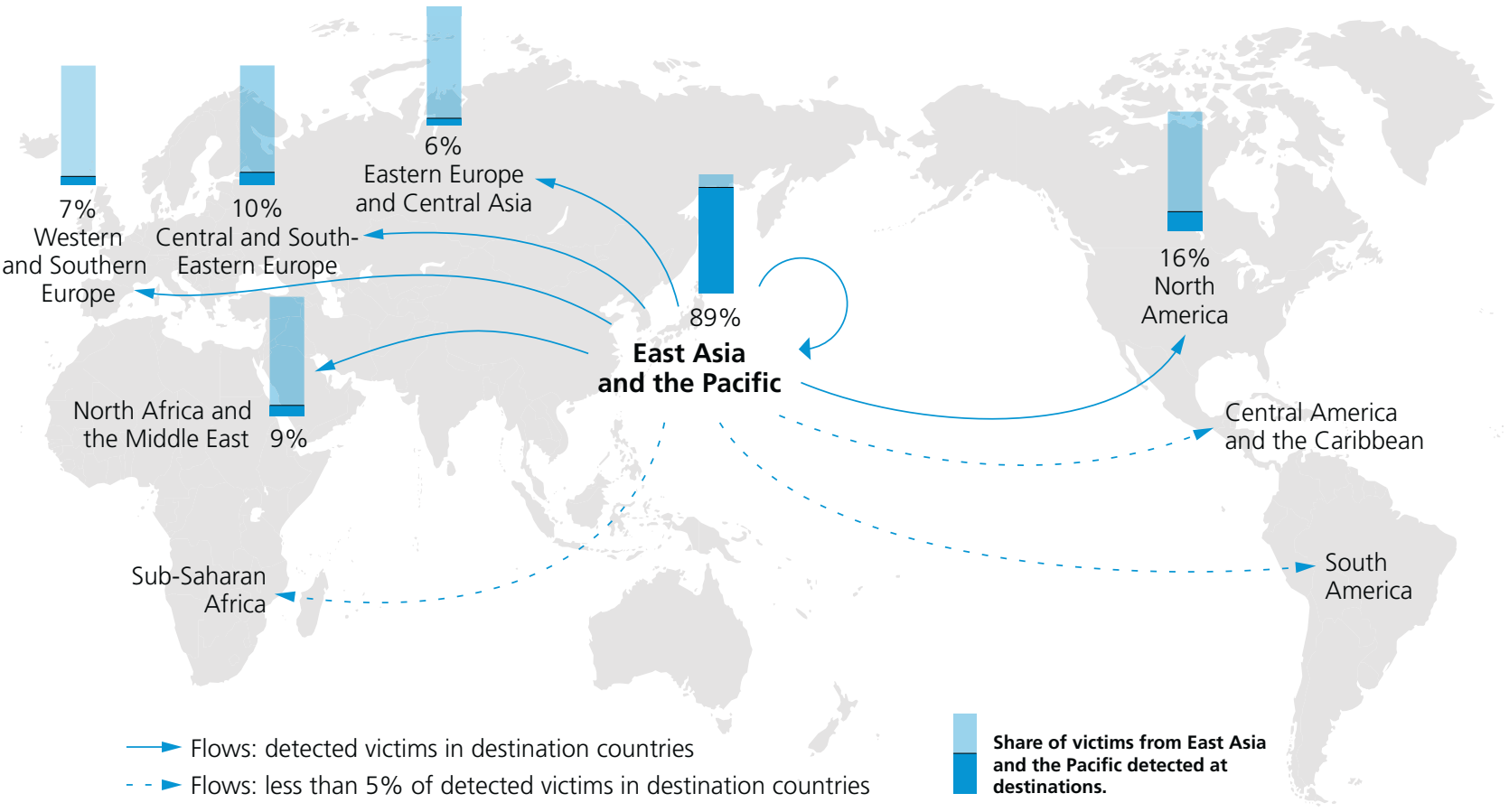

Source: UNODC elaboration of national data.

Note: The boundaries and names shown and the designations used on this map do not imply official endorsement or acceptance by the United Nations. 
FIG. 109 Share and number of countries in East Asia and the Pacific with a specific offence on trafficking in persons that criminalizes all forms listed in the UN Protocol, by period of introduction of the offence

Period 2

Full trafficking offence

introduced between January 2004 and November 2008

15

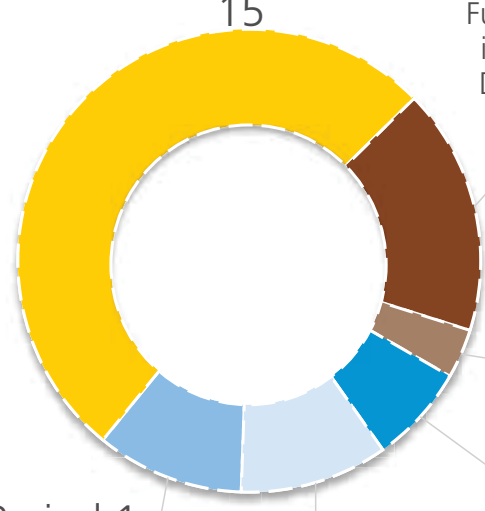

Period 1

Full trafficking offence introduced before December 2003 3

No or partial trafficking offence in September 2016 3

Period 3

Full trafficking offence introduced between December 2008 and August 2012 5

Period 4

Full trafficking offence between September 2012 and August 2014 1

\section{Period 5}

Full trafficking offence introduced between September 2014 and August 2016 2

Share of countries in East Asia and the Pacific, by number of trafficking convictions, 2012-2014 (one year within the period)

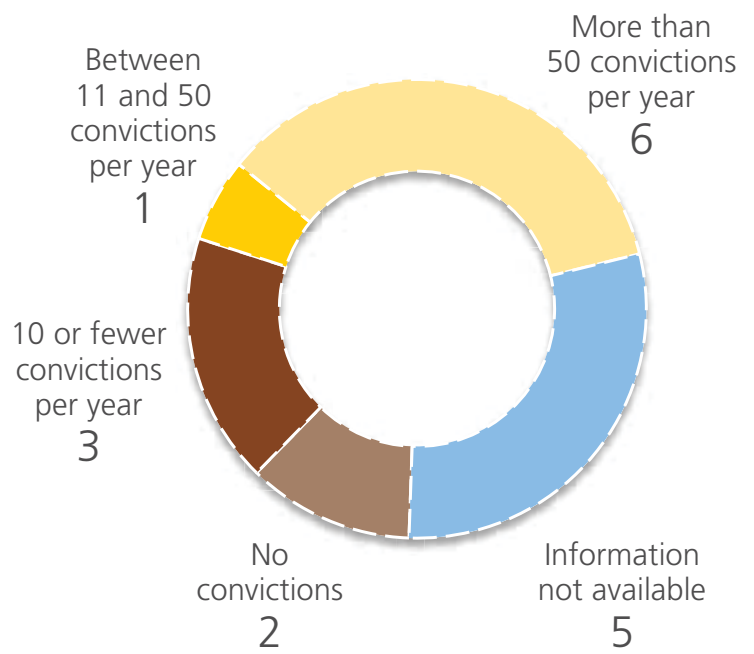

Source: UNODC elaboration of national data. Note: For the criminalization analysis, more countries are covered than for the section on patterns and flows.

\section{SOUTH ASIA}

\section{Key findings:}

Most frequently detected victim profile: Adults, $60 \%$

Most frequently detected form of exploitation: Forced labour, 85\%

Summary profile of trafficking flows: Destination for intraregional and origin for transregional trafficking.

\section{Emerging trend: Significant region of origin for} victims trafficked to the Middle East.

The available information concerning South Asia ${ }^{129}$ is very poor.

\section{Profile of the victims, forms of exploitation and offenders}

Detailed information concerning the profile of the detected victims of trafficking in persons was only available from Nepal, where most of the detected victims were adults. In Bangladesh, with regard to detections by the national police, the vast majority of victims detected in 2013 were reportedly assisted by their parents, indicating that these victims were children. In India, the large number of convictions under the Child Labour Prohibition Act, compared to the victims reported under trafficking in persons offences, suggests that child victims may outnumber adult victims also there. The lack of data means that no conclusive regional information for the 2012-2014 period can be presented. Information from 2010-2012 - published in the 2014 Global Report on Trafficking in Persons - showed that about 40 per cent of the victims detected at that time were children.

Child trafficking in the region has also been reported by international organizations operating in South Asia. According to these sources, children are being trafficked for the purpose of bonded labour, and girls, in particular, are being trafficked for domestic servitude and for child marriage. ${ }^{130}$

129 South Asia: Afghanistan, Bangladesh, India, Maldives, Nepal, Pakistan and Sri Lanka.

130 See: CCPR/C/MDV/CO/1, UN International Covenant on Civil and Political Rights, Consideration of reports submitted by States parties under article 40 of the Covenant: Concluding observations adopted by the Human Rights Committee at its 105th session, 9-27 July 2012, 31 August 2012, for Maldives; CEDAW/C/PAK/CO/4, UN Convention on the Elimination of All Forms of Discrimination against Women, Concluding observations on the fourth periodic report of Pakistan, adopted by the Committee at its fifty-fourth session (11 FebruaryMarch 2013), 27 March 2013; A/HRC/26/38/Add.1, UN General 
FIG. 110 Detected victims of trafficking in South Asia, by age, 2010-2012

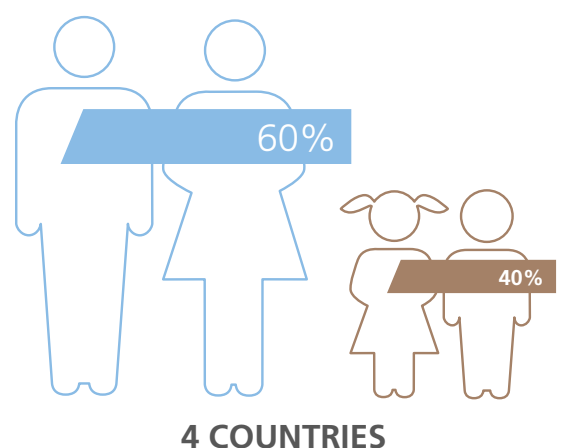

Source: UNODC elaboration of national data.

As there is no recent quantitative information available on the types of exploitation, it is not possible to report the prevalence of the different forms of trafficking in South Asia during the reporting period. Statistics from previous editions of the Global Report shows that trafficking for forced labour is predominant. Trafficking for sexual exploitation has been reported by national authorities, international organizations and non-governmental organizations throughout the region.

The lack of information also affects the analysis of the profile of the offenders. The only data available refers to the gender profiles of persons arrested in India under the previous legislation used to prosecute some forms of trafficking for sexual exploitation, the Immoral Traffic Prevention Act (ITPA). This data indicates that about 42 per cent of the offenders were females. However, the legislation underlying this data is partial in terms of the UN Trafficking in Persons Protocol standard, and the information cannot be considered as conclusive regarding the gender profiles of traffickers in the region. In the case of Pakistan, the persons convicted under the different articles of the criminal code used to convict traffickers, are mostly males.

\section{Trafficking flows affecting South Asia}

Information regarding the citizenships of victims detected in this region is scarce; however, it is sufficient to confirm that flows are primarily local (and regional) also here. About 88 per cent of the detected victims were trafficked domestically. This is not surprising as the region comprises vast countries with high levels of socio-economic inequalities, large populations and intense internal migratory flows.

Assembly, Human Rights Council, Report of the United Nations Special Rapporteur on violence against women, its causes and consequences, Rashida Manjoo, Addendum - Mission to India, 1 April 2014.
FIG. 111 Detected victims of trafficking in South Asia, by form of exploitation, 2010-2012

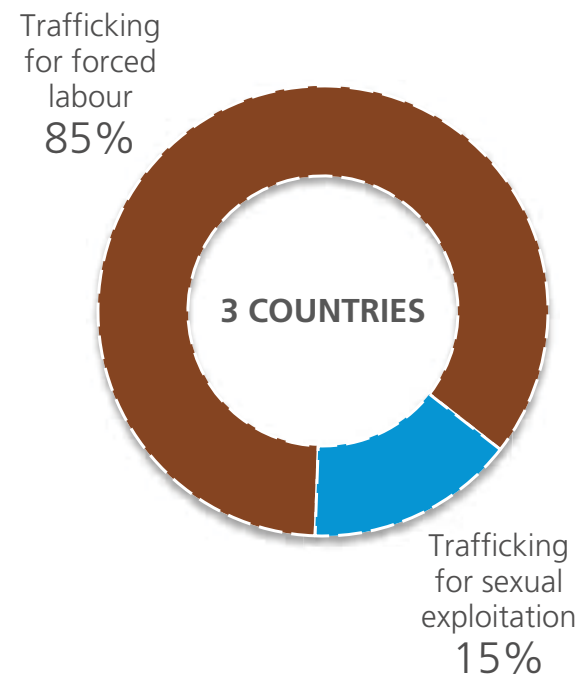

Source: UNODC elaboration of national data.

MAP 18 Origins of trafficking victims detected in South Asia, by subregion, 2014 (or most recent)

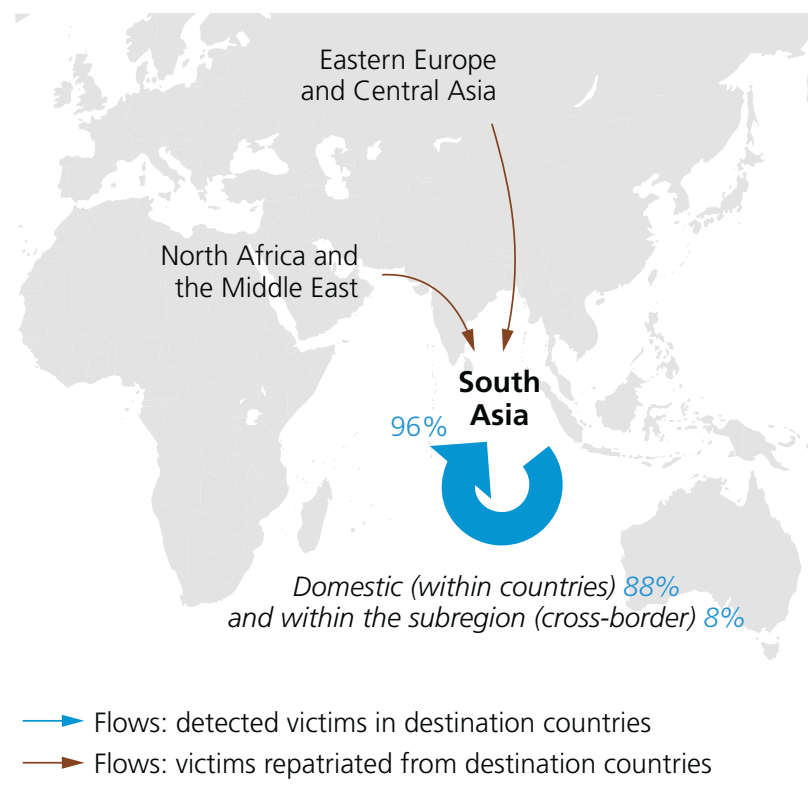

Source: UNODC elaboration of national data.

Note: The boundaries and names shown and the designations used on this map do not imply official endorsement or acceptance by the United Nations.

Looking at South Asia as a destination of cross-border trafficking, 8 per cent of the victims detected during the reporting period were trafficked between neighbouring countries, including victims trafficked from Bangladesh 
MAP 19 Destinations of detected trafficking victims from South Asia, by subregion, 2012-2014 (or most recent)

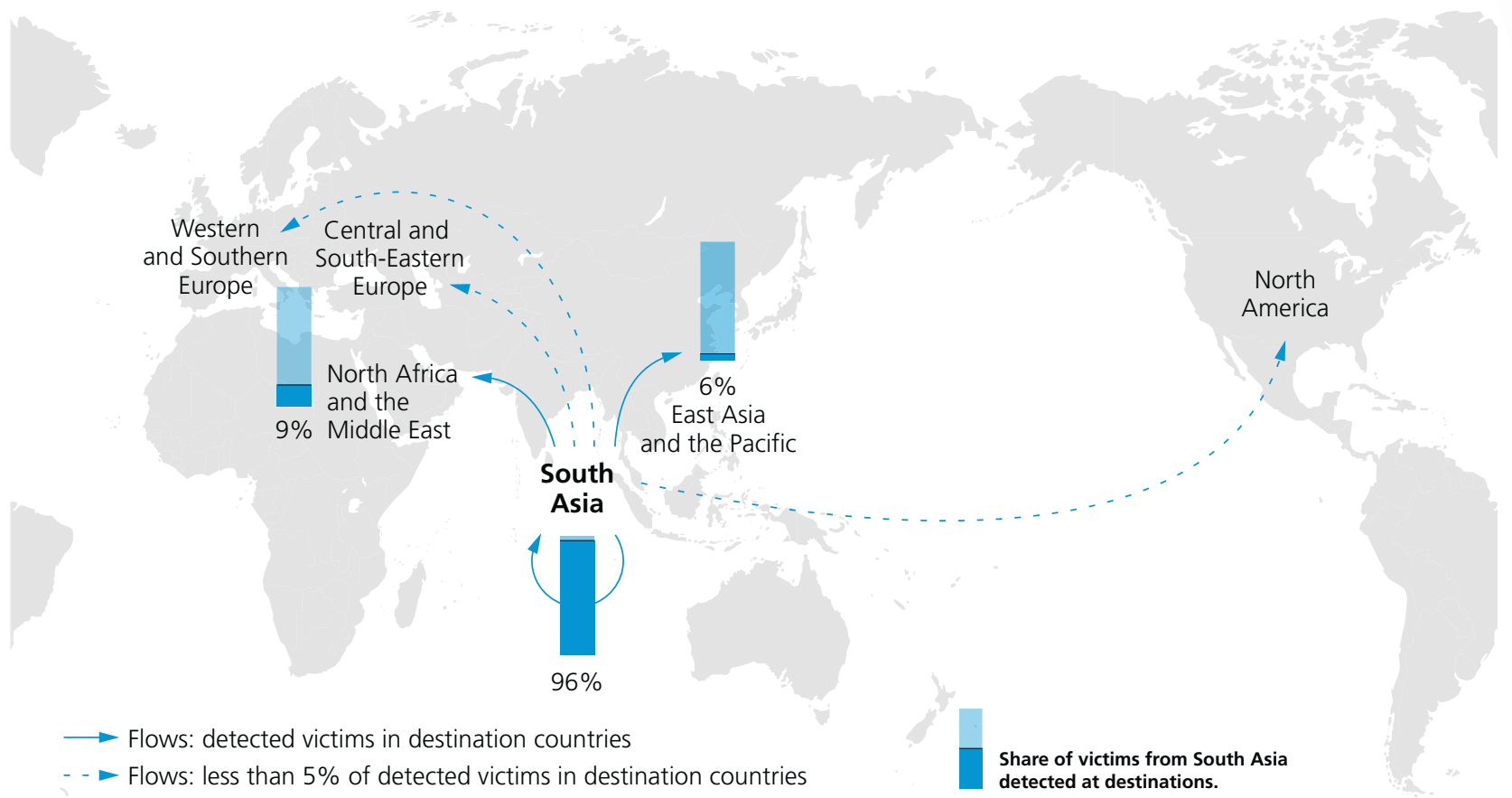

Source: UNODC elaboration of national data.

Note: The boundaries and names shown and the designations used on this map do not imply official endorsement or acceptance by the United Nations.

and Nepal to India. In addition, some victims from other regions, including Eastern Europe and Central Asia, and North Africa and the Middle East, were also detected.

These trafficking flows were confirmed by repatriation data from countries of origin. Uzbekistan reported that some Uzbek citizens had been trafficked to and repatriated from India and Pakistan during the reporting period, while victims from other countries in Eastern Europe and Central Asia were repatriated from India. The repatriation data also confirmed trafficking flows from Africa and the Middle East to South Asia. For instance, Uganda reported some own citizens trafficked to South Asia, and South Asian countries detected victims from the Middle East.

Looking at South Asia as an origin of cross-border trafficking in persons, victims from this region have been detected in many parts of the world. About 30 countries reported detections of South Asian trafficking victims between 2012 and 2014, including 12 countries in Western and Southern Europe (comprising 2 per cent of the victims detected there). Victims from Bangladesh and India were detected in four countries in South America; and the United States of America detected victims from all the South Asian countries considered. In addition, victims from South Asia were detected in or repatriated from East Asia and the Pacific, where South Asian victims (mainly from Bangladesh, and to a lesser extent from India) accounted for approximately 6 per cent of the victims in 2014 (or most recent).

The trafficking flow from South Asia to the Middle East is primarily directed towards the countries of the Gulf Cooperation Council. About 9 per cent of the victims detected in the Middle East in 2014 were citizens of South Asia, and nine countries in the Middle East have detected or repatriated victims from this region.

\section{Criminalization of trafficking in persons}

South Asian countries have more recent legislative frameworks than other regions. Half of the countries considered had an offence that criminalized all aspects listed in the UN Trafficking in Persons Protocol within five years after the entry into force of the Protocol in December 2003. Before this date, countries either had no specific trafficking legislation, or a situation where cases of trafficking in persons could be prosecuted under a combination of other offences.

In recent years, more countries have introduced specific offences of trafficking in persons with a definition of the crime in line with the UN Trafficking in Persons Protocol 
definition. In 2013, India passed the Criminal Law (Amendment) Ordinance, which includes a section (370A) that criminalizes trafficking in persons as defined by the Protocol. The previously used Immoral Traffic Prevention Act is still used to prosecute some forms of trafficking for sexual exploitation. Some countries, including Afghanistan and Maldives, criminalize all forms of exploitation included in the Protocol; however, the 'acts' and 'means' are different from those of the Protocol. In the case of Pakistan, a combination of different offences are used to prosecute different forms of exploitation.

There were no convictions for trafficking in persons in Maldives and Sri Lanka during the reporting period. Bangladesh reported between 10 and 15 convictions in the first instance per year between 2012 and 2014, while Nepal had between 50 and 80 . For the other countries in the region, information was either not available, or referred to a range of offences that could be used to prosecute different crimes, including trafficking in persons.

\section{SUB-SAHARAN AFRICA}

\section{Key findings:}

Most frequently detected victim profile: Boys, 39\%

\section{Most frequently detected form of} exploitation: Forced labour, 53\%

\section{Gender profile of convicted offenders: $60 \%$ males}

\section{Share of national citizens among offenders: $89 \%$}

\section{Summary profile of trafficking flows: Destination for intraregional and origin for transregional trafficking.}

\section{Emerging trend: Significant region of origin for transregional trafficking.}

The countries covered in this region can be grouped into West Africa, ${ }^{131}$ East Africa, ${ }^{132}$ and Southern Africa. ${ }^{133}$ Information on patterns and flows of trafficking in persons was only available from a limited number of coun-

\footnotetext{
131 West Africa: Benin, Cabo Verde, Cameroon, Central African Republic, Congo, Côte d'Ivoire, Ghana, Guinea, Guinea-Bissau, Liberia, Mauritania, Nigeria, Senegal, Sierra Leone and Togo.

132 East Africa: Burundi, Comoros, Kenya, Mauritius, Rwanda, Seychelles and Uganda.

133 Southern Africa: Democratic Republic of the Congo, Lesotho, Madagascar, Malawi, Mozambique, South Africa, Swaziland and Zambia.
}

tries. In addition, few countries have detected significant numbers of cases, and when cases were reported, the details were not always available. As a consequence, the basis for analysis in this region is limited.

\section{Profile of the victims}

The majority of the detected victims in Sub-Saharan Africa are children. Nearly two thirds of the approximately 5,500 victims detected in this region between 2012 and 2014 were underage. African countries report more boys than girls among the detected trafficking victims.

\section{FIG. 112 Detected victims of trafficking in Sub-Saharan Africa, by age and sex, 2014 (or most recent)}

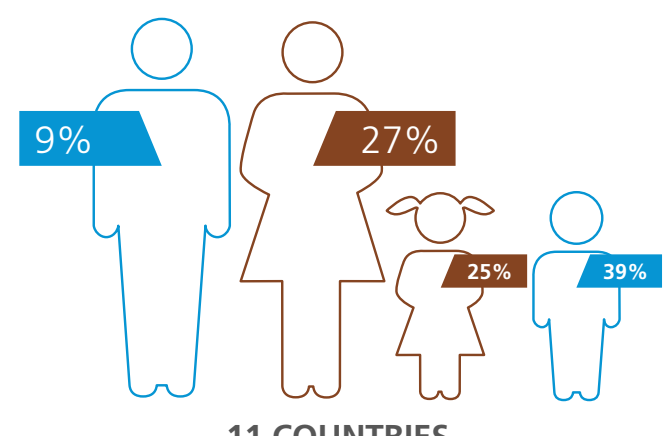

11 COUNTRIES

Source: UNODC elaboration of national data

The high prevalence of child trafficking can be observed in different parts of the region. It appears to be more pronounced in West Africa than in Southern Africa. The scarcity of data, however, does not permit conclusive analyses for sub-regional patterns.

Among the child victims, boys are more frequently detected than girls. This is connected with the prevalent forms of exploitation in this part of the world, which include trafficking for forced labour and child soldiers.

For adult victims, trafficking of women is more prevalent than trafficking of men. Women victims are mostly detected in Nigeria and Uganda, while at the regional level, they accounted for 27 per cent of victims in the year 2014 (or most recent). Trafficking of men is limited compared to trafficking in children and women.

\section{Forms of exploitation}

More than half of the 2,580 victims detected in SubSaharan Africa whose form of exploitation was reported were trafficked for forced labour. Among the types of forced labour, trafficking for domestic servitude was frequently reported. This form of trafficking affects children 


\section{FIG. 113 Detected victims of trafficking in persons, selected countries, by age, 2012-2014}

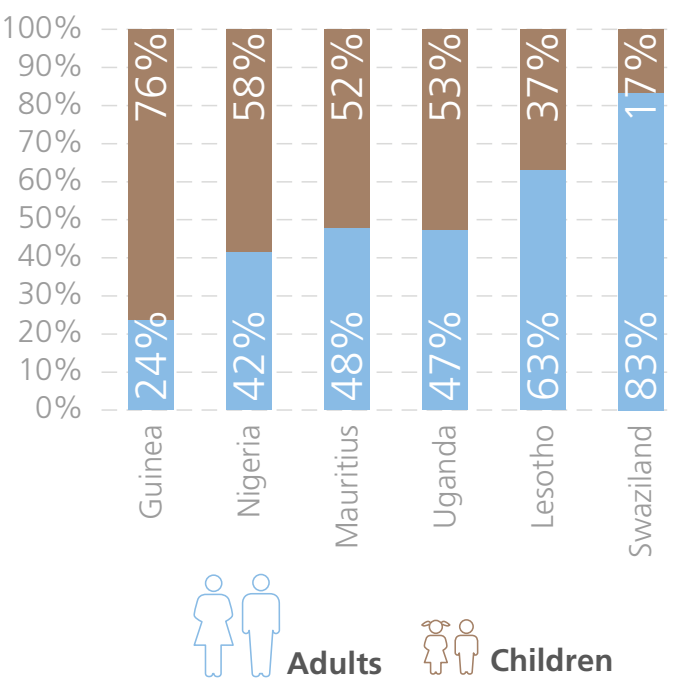

Source: UNODC elaboration of national data.

of both genders. For example, in Benin, it is reported the phenomenon of 'vidomégon' children. Traditionally, these children were placed in families who were responsible for their care and education, but many of them end up out of school and exploited at markets, in street trading and in domestic work. ${ }^{134}$ Similar situations are reported throughout West Africa, as well as in the Congo and the Great Lakes area.

Trafficking of children for exploitation in the fishing industry has been documented by different actors in many Sub-Saharan countries, from West Africa to the Great Lakes, and on the African islands. Trafficking for exploitation in agriculture has been reported by various national and international authorities, including exploitation in the cocoa and cotton plantations of West Africa. Trafficking in the mining sector and exploitation of children in quarries has also been widely reported. ${ }^{135}$ In several conflict

134 See, for example, A/HRC/25/48/Add.3, UN General Assembly, Human Rights Council, Report of the Special Rapporteur on the sale of children, child prostitution and child pornography, Najat Maalla M'jid, Addendum - Mission to Benin, 5 March 2014.

135 See, for example, Commission Nationale Independante des Droits de l'Homme (2014). Etude Sur l'exploitation et le traffic des enfants au Burundi; Cameroon National Commission on Human Rights and Freedom, Report on the State of Human Rights in Cameroon 2013; A HRC/25/73, UN General Assembly, Human Rights Council, Report of the Independent Expert on the situation of human rights in Côte d'Ivoire, Doudou Diéne, 13 January 2014; A/HRC/24/43/Add.2. UN General Assembly, Human Rights Council, Report of the Special Rapporteur on contemporary forms of slavery, including its causes and consequences, Gulnara Shahinian, Mission to Madagascar (10 to 19 December 2012).

\section{FIG. 114 Forms of exploitation among detected victims of trafficking in Sub-Saharan Africa, 2014 (or most recent)}

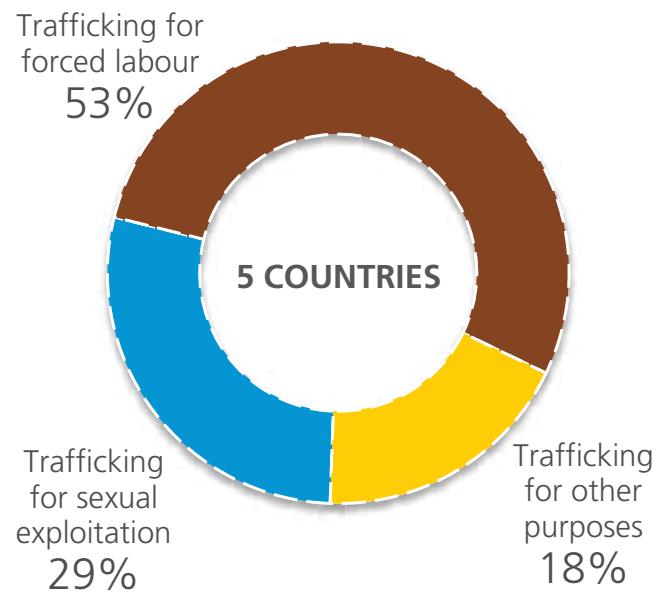

Source: UNODC elaboration of national data.

and post-conflict countries, ${ }^{136}$ United Nations peacekeeping operations, such as MONUSCO in the Democratic Republic of the Congo, have reported the exploitation of children for use as porters, cooks and sex slaves. ${ }^{137}$

The use of children as combatants takes place in some conflict and post-conflict countries of the region. The number of identified victims is significant. The 2014 edition of the Global Report discussed the trafficking of children in conflict areas such as the Central African Republic and the Democratic Republic of the Congo. ${ }^{138}$ Similar trafficking issues have been noted in post-conflict countries, such as Rwanda, where the Committee on the Rights of the Child reported that armed groups operating in the eastern part of the Democratic Republic of the Congo recruited Rwandan children, including refugee children, for use as child soldiers. ${ }^{139}$

For the purpose of the Global Report, trafficking in children as armed combatants is included as an 'other' form

136 See also Chapter 2: Human trafficking, migration and conflict.

137 See, for example, MONUSCO, Invisible survivors: girls in armed groups in the Democratic Republic of the Congo from 2009 to 2015, 25 November 2015.

138 See p. 42, UNODC, Global Report on Trafficking in Persons 2014 (United Nations publication, Sales No. E.14.V.10).

139 See CRC/C/OPAC/RWA/CO/1, UN Convention on the Rights of the Child, Committee on the Rights of the Child, Concluding observations on the initial report of Rwanda submitted under article 8 of the Optional Protocol to the Convention on the involvement of children in armed conflict, adopted by the Committee at its sixty-third session (27 May-14 June 2013), 8 July 2013. 
of trafficking. This broad category also includes forced marriage, which is relatively widely reported in the region, in both West and East Africa. Trafficking for rituals, for the commission of crime and mixed forms of exploitation were also reported in Sub-Saharan Africa during the reporting period.

Trafficking for the purpose of begging is also widely documented. Many cases occur either in the context of religious schools, like the phenomenon of the talibe, children who are forced to beg by their teachers or in the street. Overall, 18 per cent of victims in Sub-Saharan Africa were trafficked for 'other' purposes, which is a large share in a global perspective.

Trafficking for sexual exploitation is reported throughout the region, either with regard to sexual slavery in the context of conflict, or in trafficking for the prostitution of others, which mainly occurs in urban centres and in tourist areas. About 29 per cent of the victims detected in this region between 2012 and 2014 were trafficked for sexual exploitation.

\section{Profile of the offenders}

From the limited information available, the global pattern of a prominent female role in the trafficking process seems to apply also in this region. About half of the approximately 200 convicted traffickers whose gender was reported between 2012 and 2014 were females. Data from Nigeria was significant in this respect, given that this country convicted more traffickers than any other country in the region during the reporting period. The gender profiles of offenders in countries with fewer convictions, such as Guinea, Mauritius and South Africa, were similar.

This pattern is also reflected in the gender profiles of persons who were prosecuted for trafficking in persons. Out of the about 400 people who were prosecuted in SubSaharan Africa between 2012 and 2014 whose gender was known, more than 40 per cent were females. About 1,300 persons were investigated for trafficking in persons in the region during the reporting period, with females accounting for about half.

The vast majority of the traffickers in this region are citizens of the country where they were convicted. A limited number of traffickers were citizens of other countries in Sub-Saharan Africa; usually convicted of trafficking fellow citizens into other African countries. Similarly, the East Asians convicted in this region were often exploiting victims from their own countries in Southern Africa. With regard to Middle Eastern traffickers, the few detected cases involve victims trafficked from North Africa and the Middle East for exploitation in Sub-Saharan Africa.
FIG. 115 Persons investigated for trafficking in persons in Sub-Saharan Africa, by sex, 2014 (or most recent)

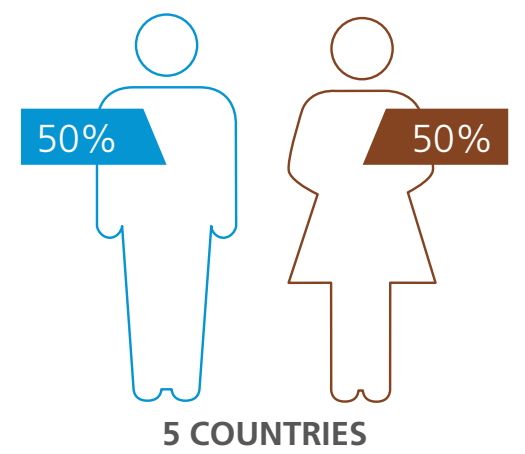

Persons prosecuted for trafficking in persons in Sub-Saharan Africa, by sex, 2014 (or most recent)

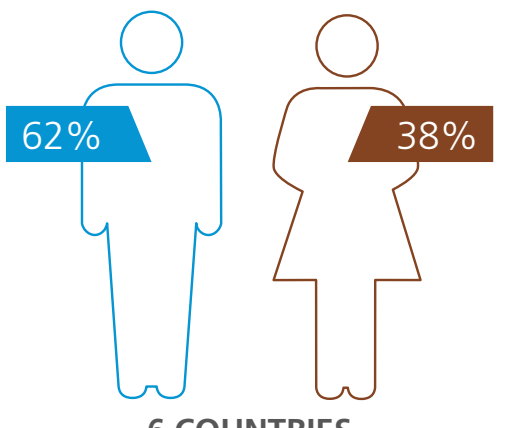

6 COUNTRIES

Persons convicted of trafficking in persons in Sub-Saharan Africa, by sex, 2014 (or most recent)

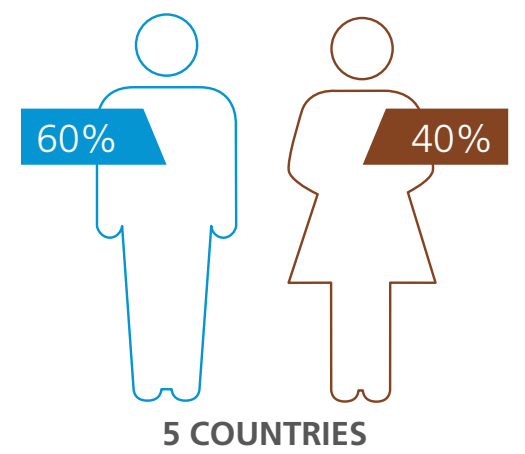

Source: UNODC elaboration of national data.

\section{Trafficking flows into Sub-Saharan Africa}

Trafficking flows into the countries of Sub-Saharan Africa are mainly domestic. Only a few countries report victims that have been trafficked from other countries, and even fewer detect victims from other regions. About 2,850 victims whose citizenship was reported were detected between 2012 and 2014, and about 83 per cent of them were traf- 
FIG. 116 Share of offenders convicted in Sub-Saharan Africa, by their area of citizenship, 2014 (or most recent)

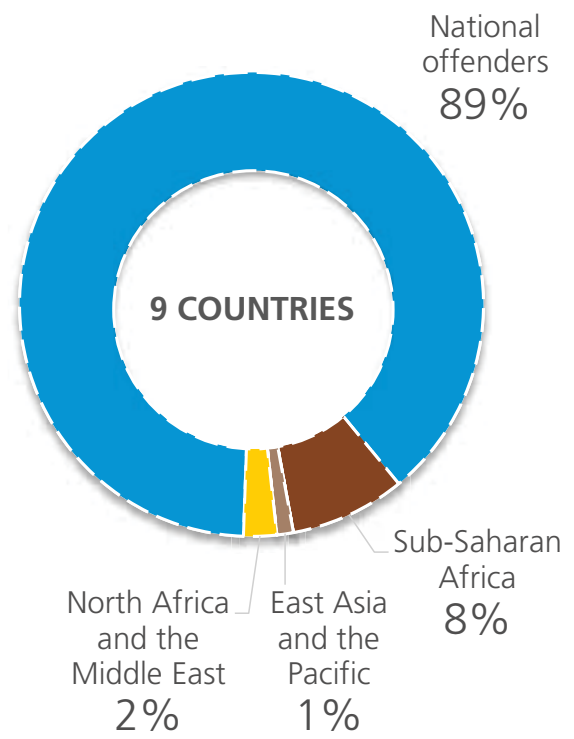

Source: UNODC elaboration of national data.

ficked domestically. Of the 32 different citizenships among trafficking victims, only 12 were from countries outside of Sub-Saharan Africa.

Victims are normally trafficked from rural to urban areas, as is the case of children trafficked for different forms of domestic servitude or for use as vendors at street markets. Children trafficked into the fishing, agricultural or mining sectors, or for sexual exploitation, largely come from poorer areas of the country. They are then exploited in locations with relevant economic activity, such as large quarries, coasts or lakes, tourist areas and similar settings.

Although domestic trafficking is most prevalent, there is significant trafficking between neighbouring countries, and also between countries in the region that do not share a border. In West Africa, for instance, victims from Benin, Burkina Faso, Cameroon, Mali and Niger were detected in neighbouring Nigeria, where victims from other West African countries, such as Côte d'Ivoire and Togo were also found. At the same time, Nigerian victims were detected or repatriated from the very same countries, revealing criss-crossing patterns of trafficking in persons across borders, probably related to ethno-linguistic and/ or tribal ties, and influenced by rural-urban and economic activity factors (as for domestic trafficking).

Similarly, in East Africa, Ugandan victims were repatriated from the neighbouring countries of the Democratic

\section{FIG. 117 Detected victims of trafficking in persons in Sub-Saharan Africa, by citizenship, 2014 (or most recent)}

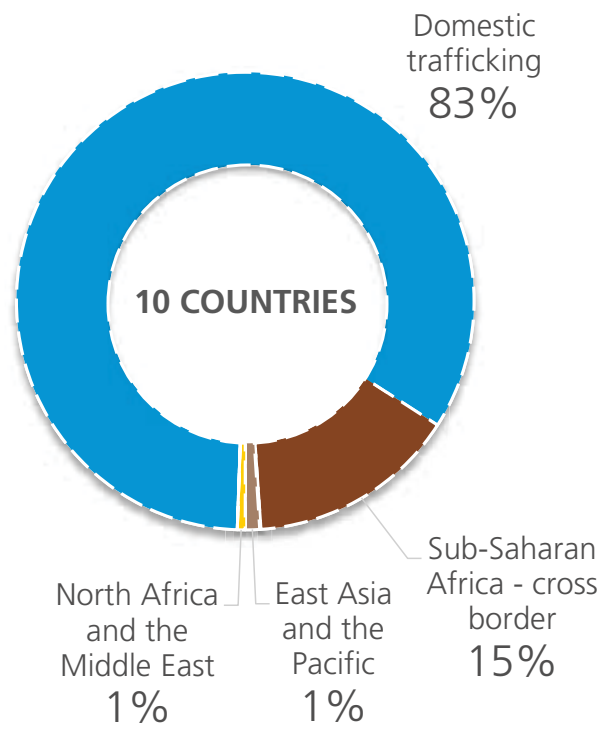

Source: UNODC elaboration of national data.

FIG. 118 Shares of detected trafficking flows in Sub-Saharan Africa, by geographical distance, * 2014 (or most recent)

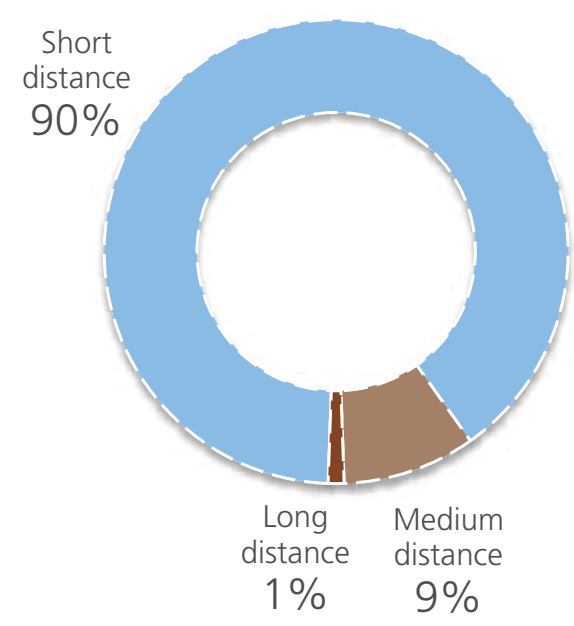

* Short-distance trafficking flows see victims trafficked within national borders or between neighbouring countries; medium-distance flows are between two countries that do not share a border and with the border of the origin country less than 3,500 kilometres away from the closest border of the destination country; and long-distance flows connect countries in which the border of the origin is farther than 3,500 kilometres away from the closest border of the destination.

Source: UNODC elaboration of national data.

Republic of the Congo, Kenya and South Sudan. Uganda detected victims from Burundi, Rwanda, Somalia and the United Republic of Tanzania. 
In Southern Africa, the trafficking flows appear somewhat more diverse and transnational. Victims detected in South Africa, for instance, are trafficked from different parts of Sub-Saharan Africa, including West and East Africa. South Africa and other Southern African countries also detect victims from other parts of the world, namely East Asia, South Asia and, to a lesser extent, Eastern Europe.

\section{Trafficking flows out of Sub-Saharan Africa}

In addition to the large number of domestic and intraregional flows, this region is an origin for transregional trafficking flows. Victims from Sub-Saharan Africa have been detected in or repatriated from about 55 countries outside the region, including some 20 countries in Western and Southern Europe. The majority of these victims were West Africans. About 3 per cent of the victims detected in Western and Southern Europe were citizens of East African countries, which may indicate an increasing trafficking flow from this part of world - especially from the Horn of Africa - towards Europe. A limited number of victims were trafficked from Southern Africa to Europe.

Another relatively prominent trafficking flow originating from Sub-Saharan Africa was bound for the Middle East.
About 13 per cent of the victims detected in North Africa and the Middle East between 2012 and 2014 were from Sub-Saharan Africa. The vast majority of these victims were from East Africa, mainly from the Horn of Africa. In addition, some 2 per cent of the victims detected in North America were citizens of countries in Sub-Saharan Africa; almost equally distributed between East and West Africans.

The repatriation data gives more details about the trafficking flows out of Sub-Saharan Africa. For one, East Africans were not the only victims from this region that were trafficked to the Middle East during the 2012-2014 period. Nigerian authorities reported that some 130 Nigerian citizens were trafficked to the countries of the Gulf Cooperation Council. Moreover, there is also a trafficking flow that runs from West Africa to North Africa; a flow that may be underreported, as North African countries do not report many cases of trafficking in persons. Finally, the repatriation data also shows a trafficking flow from Sub-Saharan Africa to South-East Asia. During the 20122014 period, about 60 victims from East and West Africa were repatriated from South-East Asian countries, and 40 from South Asian countries.

MAP 20 Destinations of detected trafficking victims from Sub-Saharan Africa, by subregion, 2012-2014

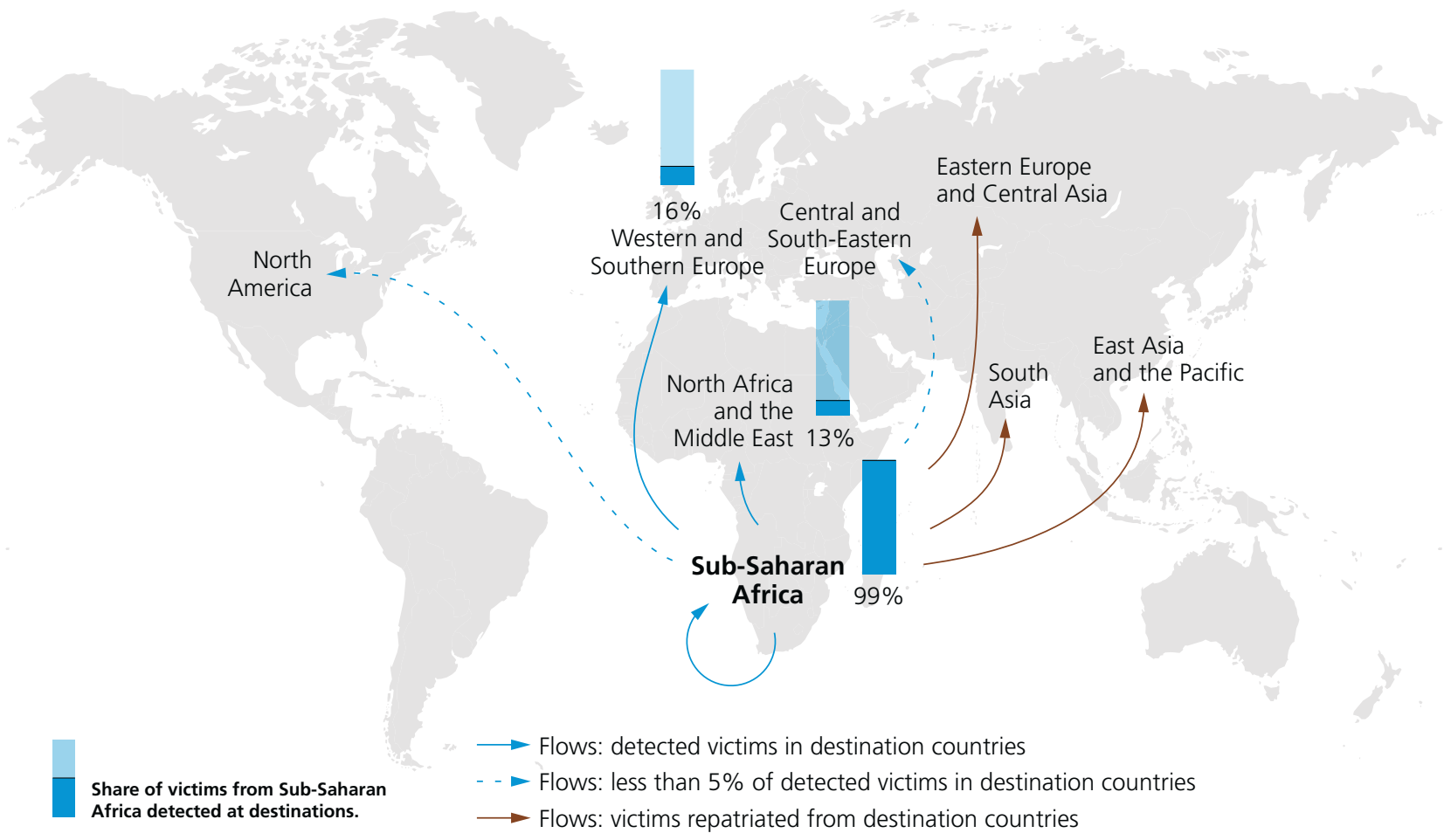


FIG. 119 Share and number of countries in Sub-Saharan Africa with a specific offence on trafficking in persons that criminalizes all forms listed in the UN Protocol, by period of introduction of the offence

Period 3

Full trafficking offence introduced between December 2008 and August 2012

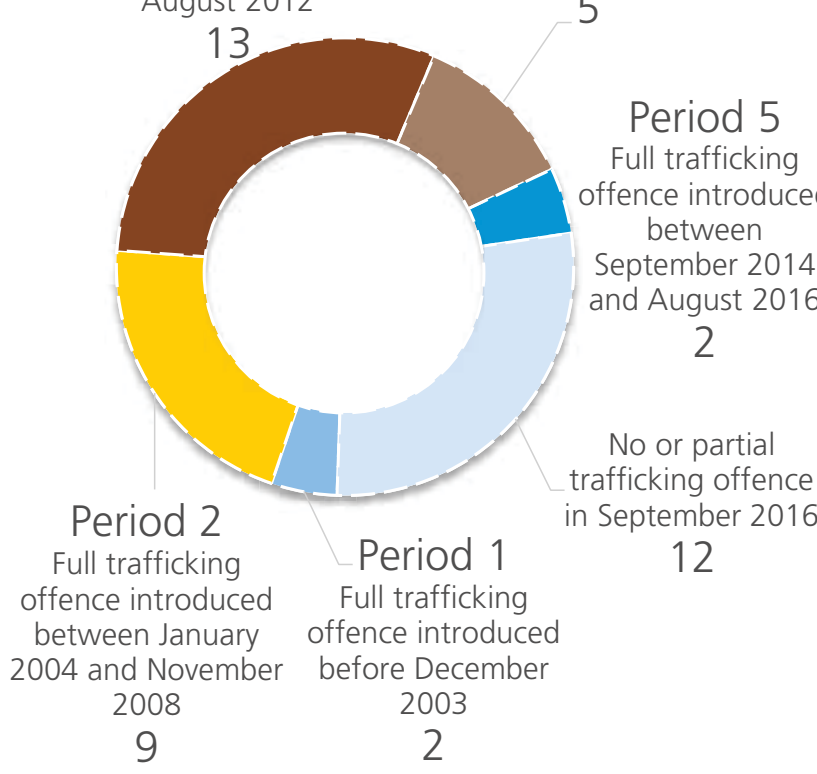

Share of countries in Sub-Saharan Africa, by number of trafficking convictions, 2012-2014 (one year within the period)

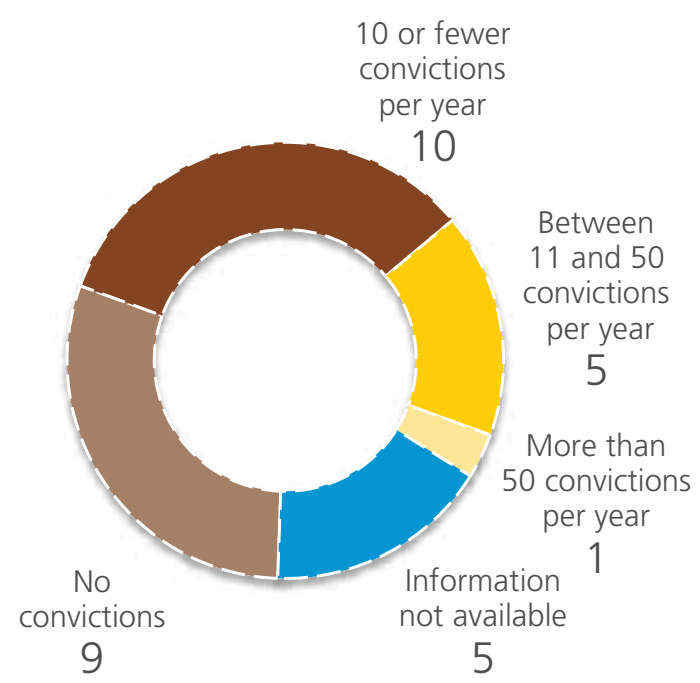

Source: UNODC elaboration of national data.

Note: For the criminalization analysis, more countries are covered than for the section on patterns and flows.

\section{Criminalization of trafficking in persons}

Countries in Sub-Saharan Africa generally have recent legislative frameworks for trafficking in persons. Among the countries covered, only two countries criminalized all or most aspects included in the UN Trafficking in Persons Protocol before the time of entry into force of the Protocol. At that time, many countries in this region either only criminalized child trafficking or prosecuted trafficking cases under other offences.

A first wave of legislative amendments were initiated by the Anglophone countries in West Africa in the five years after the entry into force of the Protocol in 2003. Some countries in West Africa still only criminalize trafficking in children or trafficking for sexual exploitation, however, and a few countries do not criminalize any aspects of trafficking in persons.

Mozambique and the United Republic of Tanzania also introduced the offence of trafficking in persons by the end of 2008. The other countries in Southern Africa enacted offences against trafficking in persons recently. With some exceptions, the countries have by now adopted legislation largely in line with the definition of trafficking contained in the UN Trafficking in Persons Protocol. Similar patterns were seen in East Africa, where by the end of 2012, many countries had introduced or amended their trafficking in persons legislation.

Considering that much of the trafficking legislation in the region is recent, it is not surprising that the number of convictions is very low. About 400 convictions were recorded in the region during the 2012-2014 period; mostly from countries in West Africa. A few countries had more than ten convictions per year; however, among these, only Nigeria criminalized trafficking in persons in line with the Protocol definition. The other countries reported more convictions for offences considering only certain aspects of trafficking.

Regarding the criminal justice process, on average, 36 per cent of the persons investigated in the region were prosecuted, and out of these, 33 per cent were convicted in the court of first instance. Overall, 10 per cent of the number of persons investigated were convicted. 


\section{NORTH AFRICA AND THE MIDDLE EAST}

\section{Key findings}

Most frequently detected victim profile:

Women, 38\%

Most frequently detected form of

exploitation: Forced labour, 44\%

Gender profile of convicted offenders:

$75 \%$ males

Share of national citizens among offenders:

$3 \%$

Summary profile of trafficking flows:

Destination for transregional trafficking (Middle

East). Origin for domestic and intraregional

trafficking (North Africa).

Emerging issue: Conflict and persecution-driven trafficking along some migration routes.

This region ${ }^{140}$ is extremely diverse from a socio-economic point of view. It includes some of the most affluent countries in the world - those of the Gulf Cooperation Council (GCC) - and the much poorer countries of North Africa. The region also includes countries currently involved in severe conflicts, which could be contributing to the general lack of data on trafficking in persons here.

\section{Profile of the victims}

There are different patterns within the region with regard to the profiles of detected victims, but the available information is too scarce to present the region's constituent areas separately. At the regional level, most victims are adults, with somewhat more women than men. But while the GCC countries detect very few child victims and a large share of men, in North Africa, children are more frequently detected than adults. Both areas detect significant shares of women.

\section{Forms of exploitation}

In North Africa and the Middle East, trafficking for forced labour is more frequently detected than trafficking for sexual exploitation. Nearly half of the victims in this region were trafficked for the purpose of forced labour. Victims were trafficked for forced labour in a range of

140 North Africa: Algeria, Egypt, Morocco, Sudan and Tunisia. Middle East: Israel, Jordan, Lebanon and Yemen. Countries of the Gulf Cooperation Council (GCC): Bahrain, Kuwait, Oman and the United Arab Emirates.
FIG. 120 Detected victims of trafficking in North Africa and the Middle East, by age and sex, 2014 (or most recent)

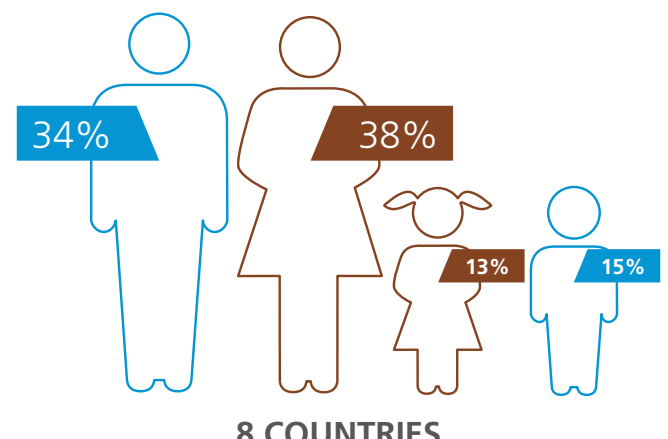

Source: UNODC elaboration of national data.

FIG. 121 Forms of exploitation among detected victims of trafficking in North Africa and the Middle East, 2014 (or most recent)

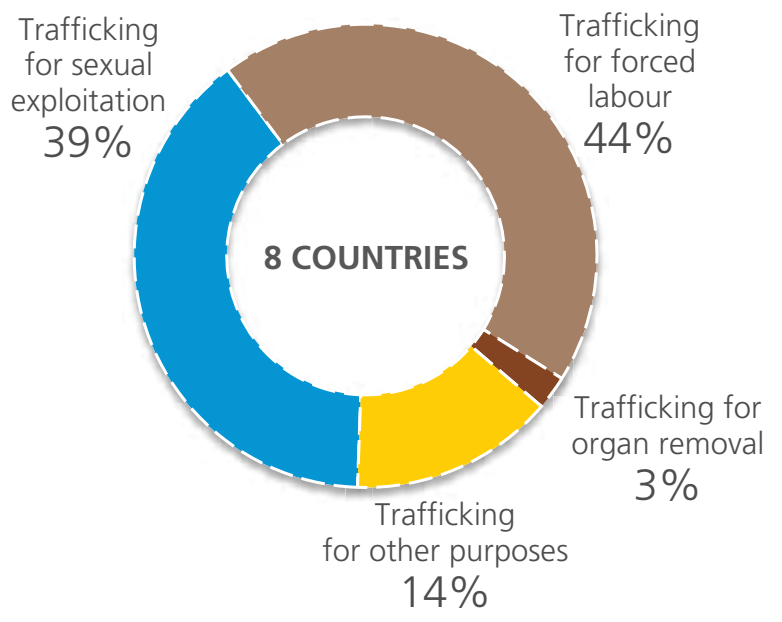

Source: UNODC elaboration of national data.

economic sectors, including in domestic servitude, which mainly affects women.

Trafficking for the purpose of sexual exploitation is widespread throughout the region, comprising around 39 per cent of the detected victims. Bahrain reported different court cases of Eastern European, North African and South-East Asian women who were promised employment in the GCC countries, usually by traffickers from their own country. Instead, they ended up being sexually exploited in Bahrain. ${ }^{141}$ Trafficking for other purposes,

141 Cases provided by Bahrain, which concluded with convictions by the First (two cases) or Third (one case) High Criminal Courts, with sentences of about 10 years of imprisonment plus permanent deportation for the foreign offenders. 
especially for begging, was also widely reported, mainly from North Africa.

\section{Profile of the offenders}

The prevalence of female offenders in trafficking activities in North Africa and the Middle East seems to be lower than in other regions. Only about 25 per cent of the 480 persons investigated in the region were female. Similar or somewhat smaller shares were reported for prosecutions and convictions.

The relatively low share of female participation in trafficking in persons in this region may be explained by the high prevalence of trafficking for forced labour, and especially by the predominance of trafficking of men. Female traffickers tend to be more involved in the recruitment of women and girls, especially for sexual exploitation.

The citizenships of convicted offenders were only reported by some Gulf Cooperation Council countries, namely Bahrain, Kuwait, Oman and the United Arab Emirates. Most of the persons investigated or convicted in these countries were foreigners; mainly from South and East Asia. A limited number of citizens of Eastern European and Central Asian countries were also convicted. The offenders' citizenships were connected with those of the victims. The available information is too limited to draw solid regional conclusions, however.

\section{Trafficking flows into North Africa and the Middle East}

Information was available for countries in the Middle East, as well as from North Africa. These two areas see different trafficking flows. The Middle East, especially the GCC countries, is a globally affluent area and, like Western and Southern Europe and North America, is a significant destination for transnational trafficking in persons. About 48 different citizenships were reported among victims of trafficking detected there; 35 from countries in regions outside North Africa and the Middle East.

Information concerning the citizenships of victims in North Africa is derived from detection and repatriation data. This region is also a destination of cross-border trafficking, but domestic trafficking is much more prevalent than in other parts of the broader region.

Most of the victims detected across the region were foreign citizens of other countries in North Africa and the Middle East, accounting for about 37 per cent of the victims detected in 2014 (or most recent).

Citizens from Sub-Saharan Africa were detected in sig-
FIG. 122 Persons investigated for trafficking in persons in North Africa and the Middle East, by sex, 2014 (or most recent)

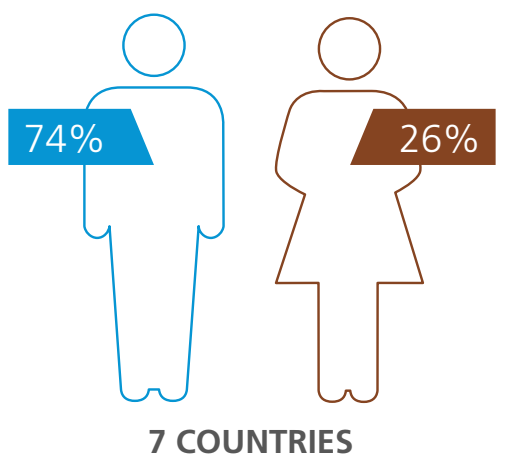

Persons prosecuted for trafficking in persons in North Africa and the Middle East, by sex, 2014 (or most recent)

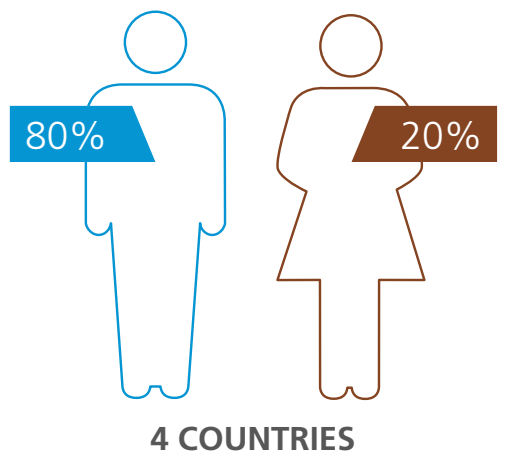

Persons convicted of trafficking in persons in North Africa and the Middle East, by sex, 2014 (or most recent)

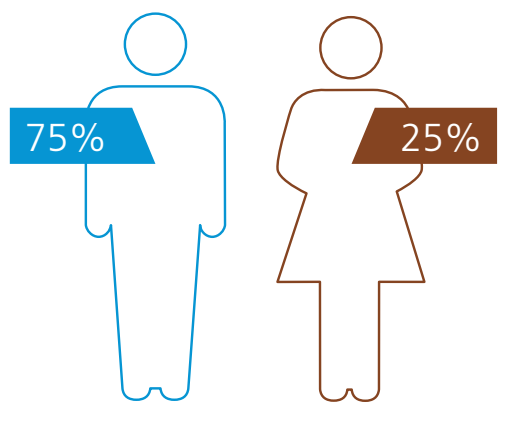

7 COUNTRIES

Source: UNODC elaboration of national data.

nificant numbers; particularly victims from the Horn of Africa. In addition, Nigeria reported that Nigerian victims had been repatriated from the Middle East, as well as from North Africa. During the same period, Uganda reported that some Ugandan citizens had been repatriated from the Middle East. 
FIG. 123 Share of offenders in selected Gulf Cooperation Council countries, by their area of citizenship, 2014 (or most recent)

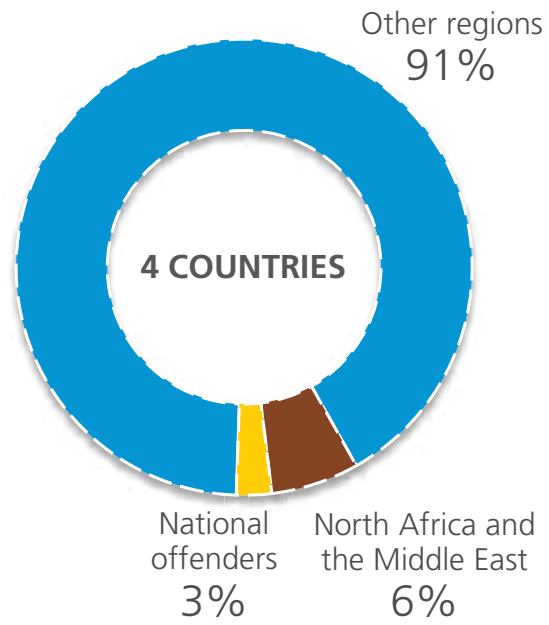

Source: UNODC elaboration of national data.

South Asians, mainly from Bangladesh, Nepal and Pakistan, accounted for about 9 per cent of the victims detected in the Middle East. Victims from East Asia were also detected, comprising a similar share of the total. Most of these victims were citizens of Indonesia, the Philippines and Thailand. Domestic trafficking is rarely detected in the Middle East, but more commonly detected in North Africa.

Most of the trafficking in this region occurs between countries that are more than 3,500 kilometres apart, which is relatively unusual. These flows include, for instance, victims trafficked from most North African countries to the GCC countries, and from East Asia to the Middle East. Most of the trafficking from South Asia and Sub-Saharan Africa, however, is included in the medium-distance trafficking flows.

\section{Trafficking flows out of North Africa and the Middle East}

This region is also an origin for cross-border trafficking. Some 30 countries have detected victims from North Africa and the Middle East; mainly flows within the region. However, Western and Southern Europe is also a destination, with victims from North Africa and the Middle East accounting for about 2 per cent of the victims detected there. Countries in the Americas and Asia also sporadically detect victims from North Africa and the Middle East. Among the most frequently detected victims in the destination areas indicated above are victims from the countries of the Maghreb, as well as from Iraq and the Syrian Arab Republic.

MAP 21 Origins of trafficking victims detected in North Africa and the Middle East, by subregion, 2014 (or most recent)

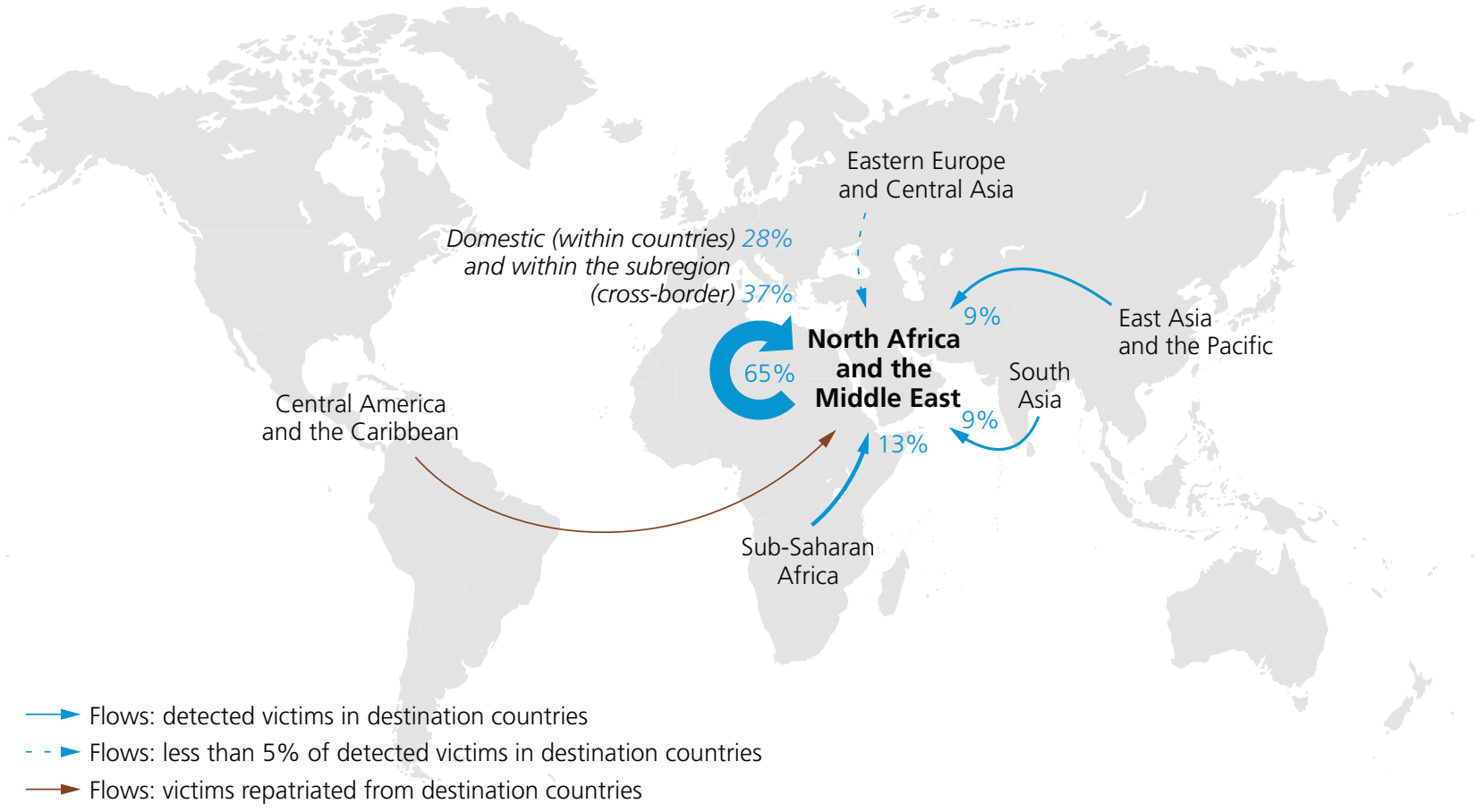


FIG. 124 Shares of detected trafficking flows in North Africa and the Middle East, by geographical distance, * 2014 (or most recent)

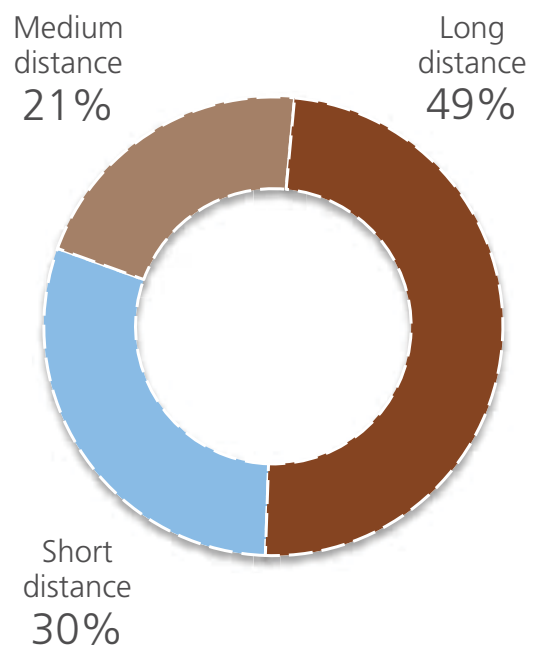

* Short-distance trafficking flows see victims trafficked within national borders or between neighbouring countries; medium-distance flows are between two countries that do not share a border and with the border of the origin country less than 3,500 kilometres away from the closest border of the destination country; and long-distance flows connect countries in which the border of the origin is farther than 3,500 kilometres away from the closest border of the destination.

Source: UNODC elaboration of national data.

\section{Criminalization of trafficking in persons}

All the countries in this region that have legislation on trafficking in persons introduced it after the entry into force of the UN Trafficking in Persons Protocol. More than half of the countries did so after 2008. With some exceptions, countries in the region did not previously consider trafficking in persons as an offence, and a few countries criminalized either only child trafficking or trafficking for sexual exploitation.

Among those with either partial or no legislation, Libya does not have a specific trafficking in persons offence, and the ongoing conflict there makes future improvements unlikely, at least in the short term. Similarly, in Yemen, a draft law was under preparation before the eruption of conflict. The current criminal code in Yemen does not include a trafficking in persons offence.

With regard to the criminal justice process, on average, about 34 per cent of the number of persons investigated in the region receive convictions in the first court instance. This is above the global average.
FIG. 125 Share and number of countries in North Africa and the Middle East with a specific offence on trafficking in persons that criminalizes all forms listed in the UN Protocol, by period of introduction of the offence

\section{Period 3}

Full trafficking offence introduced between December 2008 and August 2012

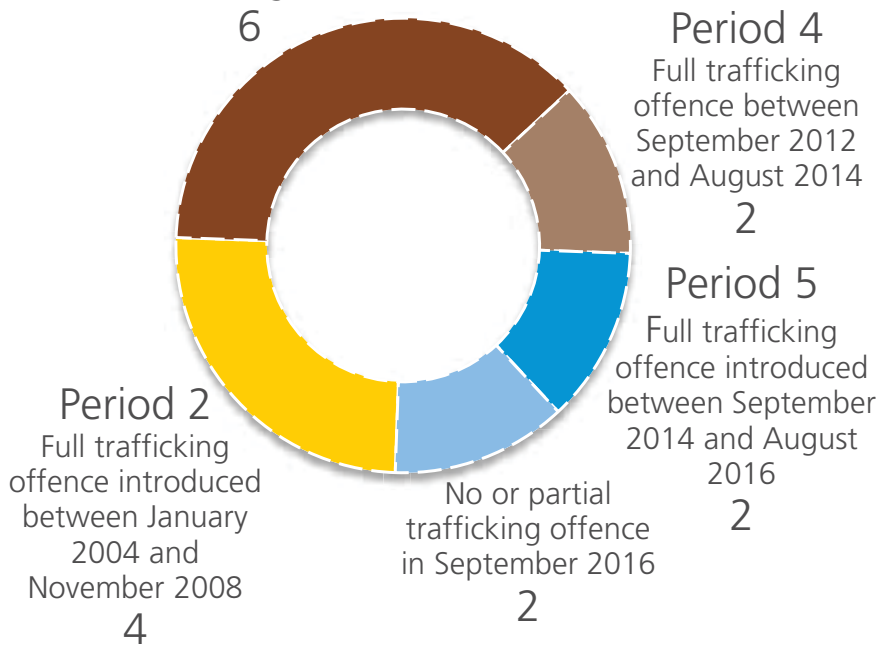

Share of countries in North Africa and the Middle East, by number of trafficking convictions, 2012-2014 (one year within the period)

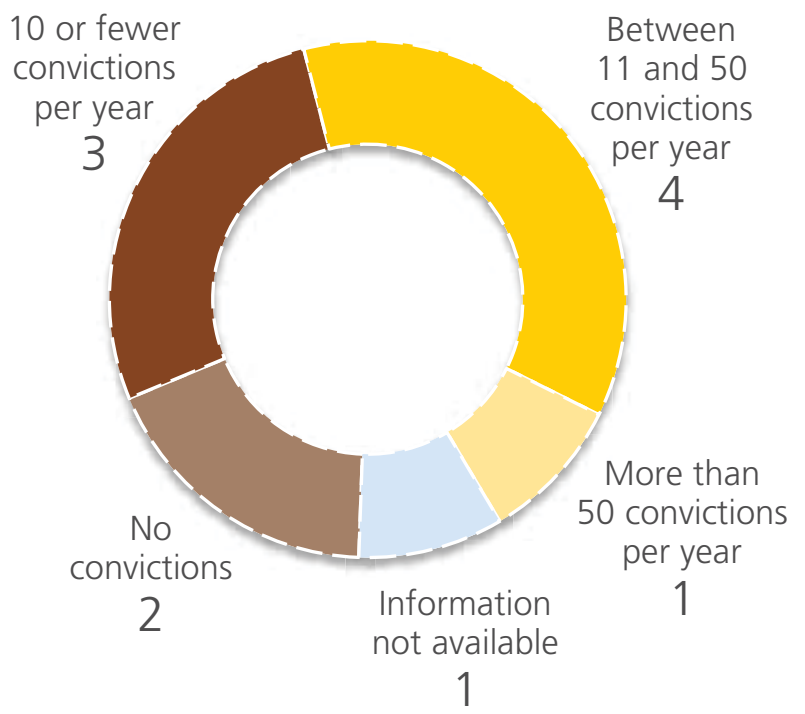

Source: UNODC elaboration of national data

Note: For the criminalization analysis, more countries are covered than for the section on patterns and flows. 
